\title{
TRILHA DE LONGA DISTÂNCIA NA SERRA DA MANTIQUEIRA : PLANEJAMENTO E DEFINIÇÃO DE ESTRATÉGIA PARA IMPLANTAÇÃO COM PARTICIPAÇÃO DE FORÇA VOLUNTÁRIA
}

\author{
WALDIR JOEL DE ANDRADE \\ Engenheiro Florestal
}

ORIENTADOR: PROF. DR. ÁLVARO FERNANDO DE ALMEIDA

Dissertação apresentada à Escola Superior de Agricultura "Luiz de Queiroz" da Universidade de São Paulo, para a obtenção do título de Mestre em Ciências. Área de Concentração: Ciências Florestais.

P I R A I C A B A

Estado de São Paulo - Brasil Agosto - 1998 


\section{Dados Internacionais de Catalogação na Publicação (CIP)}

DIVISÃO DE BIBLIOTECA E DOCUMENTAÇÃO - Campus "Luiz de Queiroz" / USP

Andrade, Waldir Joel de

Trilha de longa distância na Serra da Mantiqueira: Planejamento e definição de estratégia para implantação com participação de força voluntária. / Waldir Joel de Andrade. - Piracicaba, 1998.

133p.:il.

Dissertação (mestrado) -- Escola Superior de Agricultura Luiz de Queiroz, 1998.

Bibliografia

1. Ecologia florestal 2. Educação ambiental 3. Serra da Mantiqueira 4. Trilha florestal 5. Turismo ecológico I. TÍTULO

CDD 719.32 
TRILHA DE LONGA DISTÂNCIA NA SERRA DA MANTIQUEIRA : PLANEJAMENTO E DEFINIÇÃO DE ESTRATÉGIA PARA IMPLANTAÇÃO COM PARTICIPAÇÃO DE FORÇA VOLUNTÁRIA

\section{WALDIR JOEL DE ANDRADE}

Aprovado em:

Comissão julgadora:

Prof. Dr. Álvaro Fernando de Almeida

ESALQ / USP

Prof. Dr. Felisberto Cavalheiro

Profa. Dra. Maria Inez Pagani

FFLCH / USP

Dr. Eduardo Amaral Batista

Prof. Dr. Fábio Poggiani

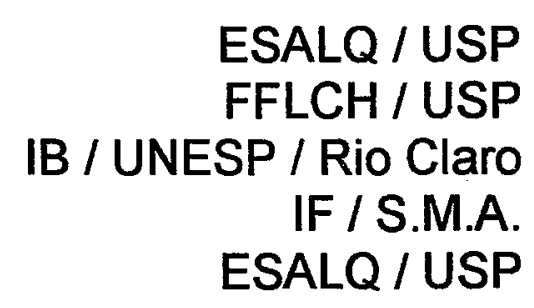

Prof. Dr. ÁLVARO FERNANDO DE ALMEIDA Orientador 
Dedico à

Neile, minha querida mãe e amiga, por despertar em mim o respeito e o amor pelas plantas, quem sabe o ponto de partida para 0 desenvolvimento de uma consciência conservacionista;

Stella e Adriana, minhas queridas filhas, fontes permanentes de inspiração e carinho, que já aprenderam amar a Mantiqueira, me acompanhando por algumas de suas trilhas, a pé e a cavalo;

Carlāo, grande companheiro também em diversas trilhas da Mantiqueira, sempre compartilhando sonhos e sentimentos; e

Anna Paula, com quem pretendo viver a Mantiqueira e na Mantiqueira. 


\section{AGRADECIMENTOS}

o autor agradece sinceramente a todos que direta ou indiretamente contribuíram para a realização deste trabalho e, em especial:

ao Instituto Florestal do Estado de São Paulo por entender a necessidade do nosso aprimoramento técnico científico, e autorizar a nossa participação no curso de pós - graduação a nível de Mestrado no Departamento de Ciências Florestais da ESALQ;

ao Prof. Dr. Álvaro Fernando de Almeida pelo incentivo à participação no curso de Mestrado e pela dedicação na orientação deste trabalho, bem como pela amizade que sempre nos dispensou;

ao colega e Pesquisador Científico do Instituto Florestal Francisco Correa Sério, catalisador dessa importante empreitada;

aos Pesquisadores Científicos Plínio de Souza Fernandez, Marco Antonio de Oliveira Garrido e Francisco José do Nascimento Kronka, enquanto Diretores da Divisão de Florestas e Estações Experimentais do Instituto Florestal de São Paulo, pelo apoio e incentivo nas diversas fases deste trabalho;

ao Dr. Eduardo Amaral Batista, Pesquisador Científico do Instituto Florestal, pelo apoio dispensado, principalmente na leitura e correção do texto original;

ao Eng. Agro. Odenir Buzatto pelo apoio e compreensão dispensados nas diversas fases deste trabalho;

ao Serviço de Comunicações Técnico-Científicas, do Instituto Florestal, seu Diretor Desenhista Antonio Sérgio Ferreira, a Chefe da Seção de Desenho Simone Filomena Torres Rodrigues e aos desenhistas Carlos Alberto de Freitas, Lúcia Rodrigues da Silva e Maria de Fátima Simões Anderson Marino, pelo apoio e assessoria na elaboração de diversas figuras; 
ao Físico Marco Aurélio Nalon, da Seção de Manejo e Inventário Florestal do Instituto Florestal, pela elaboração dos croquis;

à estagiária da Estação Experimental de Moji-Guaçu, graduanda do Curso de Geografia da Universidade de São Paulo, Anna Paula Costa Santos, pelo auxílio na elaboração dos croquis;

ao Geógrafo Dimas Antonio da Silva, Pesquisador Científico do Instituto Florestal, pelas diversas sugestões apresentadas e pela companhia em diversos trechos da trilha;

ao Eng. Agro. Ciro Koiti Matsukuma, da Seção de Manejo e Inventário Florestal do Instituto Florestal, pela assessoria no trato com os produtos provenientes de aerolevantamentos;

ao Eng. Agro. Fabio Raimo de Oliveira, pela revisão do summary e por diversas sugestões relativas a trilhas e trabalho voluntário;

à Leni Meire Pereira Ribeiro Lima, Técnico de Apoio à Pesquisa Científica e Tecnológica do Instituto Florestal, e a Carlos Marcelo Gurgel Villegas pela edição final do presente trabalho;

ao Pesquisador Científico João Evangelista de Melo Neto, responsável pela chefia do Parque Estadual de Campos do Jordão, pelo apoio dispensado; e

aos colegas do curso de pós-graduação do Departamento de Ciências Florestais da ESALQ, pelo respeito e convívio amistoso que nos proporcionaram. 


\section{SUMÁRIO}

LISTA DE FIGURAS

Página

LISTA DE TABELAS.

vii

RESUMO

ix

SUMMARY.

$x$

xiii

1 INTRODUÇÃO.

1

2 REVISÃO DE LITERATURA.

2.1 Trilhas.

5

2.2 Montanhismo/Mantiqueira

2.3 Unidades de Conservação na Mantiqueira................. 13

2.4 Trabalho Voluntário.

3 CARACTERIZAÇÃO DA ÁREA DE ESTUDO.

4 MATERIAL FOTOGRÁFICO E CARTOGRÁFICO

26

5 DESENVOLVIMENTO TÉCNICO

29

6 ESTRATÉGIA DE IMPLANTAÇÃO.

75

7 COMENTÁRIOS DOS RESULTADOS.

92

8 CONSIDERAÇÕES FINAIS

95

REFERÊNCIAS BIBLIOGRÁFICAS.

97

ANEXO 1: Hotéis, pousadas e áreas de camping nos

municípios atravessados pela trilha.

106

ANEXO 2: Listagem de organizações ambientalistas encontradas nos municípios e capitais envolvidos no estudo, com possibilidades de participarem do trabalho voluntário proposto 


\section{LISTA DE FIGURAS}

01. Anatomia da trilha.

Página

02. Serra da Mantiqueira (VÁRZEA, 1942).

03. Serra da Mantiqueira (IBGE, 1977)...

04. Localização da área de estudo.

05. Articulação das folhas topográficas na escala 1:10.000 que abrangem a área de estudo.

06. Articulação das folhas topográficas na escala 1:50.000 que abrangem a área de estudo.

07 . Unidades de Conservação na área de estudo.

08. Trilha da Mantiqueira sobre base cartográfica 1:250.000

09. Trecho 1 da trilha.

10. Pedra do Lopo.

11. Trecho 2 da trilha....................................................... 36

12. Salto dos Pretos........................................................... 37

13. Trecho 3 da trilha.................................................... 38

14. Pedra do Carmo .......................................................... 39

15. Pedra do Selado....................................................... 39

16. Chapéu do Bispo..................................................... 40

17. Pedra Redonda e Pedra Partida................................... $\quad 40$

18. Vista de Monte Verde desde a Pedra Redonda.............. 41

19. Trecho 4 da trilha................................................... 42

20. São Francisco Xavier (Praça da Matriz)......................... 43

21. Pedra Vermelha ....................................................... 43

22. Trecho 5 da trilha..................................................... 45

23. Bairro Santa Luzia (Igreja Matriz)................................ 46

24. Trecho 6 da trilha.................................................. 47

25. Pedra do Baú.............................................................. 48

26. Cachoeira do Toldi...................................................... 48

27. Trecho 7 da trilha..................................................... 49

28. Pesqueiro da Montanha............................................ 50

29. Bairro do Centro ....................................................... 50

30. Trecho 8 da trilha................................................... 52

31. Parque Estadual de Campos do Jordão......................... 53

32. São José dos Alpes.................................................. 53

33. Trecho 9 da trilha..................................................... 55 
34. Fazenda da Onça...................................................... 56

35. Pousada do Barão..................................................... 56

36. Morro do Ataque........................................................ 57

37. Trecho 10 da trilha................................................... 58

38. Pico dos Marins (vista paulista)................................. $\quad 59$

39. Pico dos Marins (vista mineira).................................... 59

40. Trecho 11 da trilha................................................... 60

41. Vargem Alegre......................................................... 61

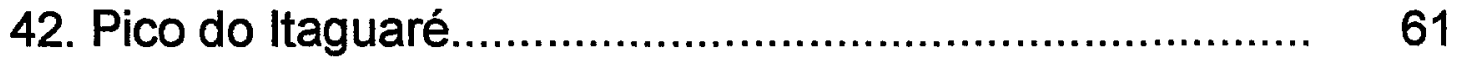

43. Trecho 12 da trilha.................................................... 63

44. Pico do Capim Amarelo................................................ 64

45. Serra Fina......................................................... 64

46. Trecho 13 da trilha................................................... 65

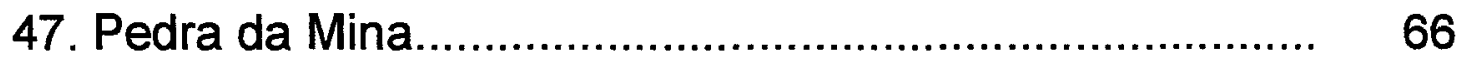

48. Pico dos Três Estados................................................... 66

49. Pedra do Picu................................................................ 67

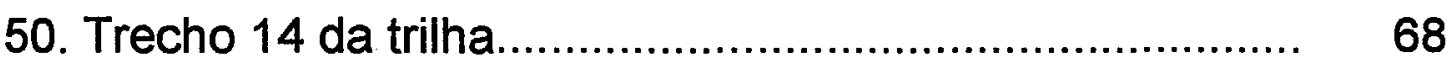

51. Pico das Agulhas Negras.......................................... 69

52. Pico das Prateleiras..................................................... 69

53. Pedra Cabeça de Leão................................................ 70

54. Abrigo Massena........................................................ 70

55. Cachoeira Véu da Noiva............................................... 71

56. Museu do P.N. do Itatiaia............................................... 71

57. Orientação da drenagem............................................ 80

58. Ponte pencil no P.E.C.J............................................ 81

59. Pinguela no P.E.C.J................................................... 81

60. Blocos de pedra e tablados ou estrados......................... 82

61. Tipos de degraus.................................................. 83

62. Paredes de contenção................................................. 83

63. Marcação a tinta em árvore........................................... 85

64. Marcação a tinta em pedra........................................... 85

65. Modelo de placa....................................................... 86

66. Placa confeccionada em pedra.................................... 87

67. Placa confeccionada em metal..................................... 87

68. Placa confeccionada em madeira................................. 88

69. Painel na trilha da Cachoeira (P.E.C.J.)........................ 89

70. Monte de pedra (totens)............................................. 90 


\section{LISTA DE TABELAS}

01. Relação das folhas topográficas que abrangem a área de estudo, na escala 1:50.000...................................... 14

02. Hospitais nos municípios atravessados pela trilha......... 56

03. Transporte para os municípios abrangidos pela trilha.... $\quad 57$

04. Clubes excursionistas situados em alguns municípios atravessados pela trilha e nas capitais dos estados envolvidos no presente estudo. 


\title{
TRILHA DE LONGA DISTÂNCIA NA SERRA DA MANTIQUEIRA: PLANEJAMENTO E DEFINIÇÃO DE ESTRATÉGIA PARA IMPLANTAÇÃO COM PARTICIPAÇÃO DE FORÇA VOLUNTÁRIA
}

\author{
Autor: WALDIR JOEL DE ANDRADE \\ Orientador: PROF. DR. ÁlVARO FERNANDO DE ALMEIDA
}

\section{RESUMO}

Este estudo propõe o planejamento de uma trilha de longa distância através do "trecho mais contínuo e expressivo" (IBGE, 1977) da serra da Mantiqueira. Seu traçado foi definido tendo como referência as maiores elevações, desta que é considerada a Cordilheira da Saúde, e é uma associação entre trechos de estradas de terra, trilhas propriamente ditas, e até pequenos trechos de asfalto, quando se faz necessário cruzar quatro rodovias federais pavimentadas.

Com extensão de aproximadamente $300 \mathrm{~km}$, calculada através de um sistema CAD (Computer Aided Design) AUTOCAD R12, a trilha tem seu início no morro ou pedra do Lopo (Estado de São Paulo - Brasil), marco histórico e referencial nas contendas pela definição de limites entre as então províncias de São Paulo e Minas Gerais; segue pela cumeada da grande serra, se alternando entre terras desses dois estados brasileiros e termina no interior do Parque Nacional de Itatiaia, em terras do Estado do Rio de Janeiro.

Evitou-se considerar e propor a abertura de novos caminhos pelo perigo que isto poderia representar para os recursos 
naturais e culturais da região abrangida pela trilha da Mantiqueira, uma vez que não há, ainda, uma cultura conservacionista desenvolvida entre usuários de trilhas, no Brasil, haja visto o estado de deterioração da maioria de suas trilhas de longa distância.

O traçado pode ser visualizado em 14 croquis, em escalas variáveis, que indicam, também, pontos de água, local para acampamento, mirantes naturais, cachoeiras e outros atrativos.

Propõe-se que a trilha seja implantada com a participação de força voluntária, arregimentada, em princípio, a partir das organizações ambientalistas e clubes excursionistas localizados nos municípios envolvidos e nas capitais dos três estados atravessados pela trilha.

Para tanto, torna-se necessário que os voluntários sejam apoiados e coordenados por instituições estaduais (paulistas, mineiras e fluminentes) e nacionais, que detenham conhecimentos em questões de conservação da natureza, que incluam 0 ecoturismo, a educação ambiental e manejo de trilhas. Importante, também, será a capacitação dos voluntários através de cursos que os habilitem para as tarefas necessárias à implantação, manutenção e operacionalização da trilha. Nesse sentido o presente estudo formata um curso básico que poderá ser aplicado não só a voluntários como também a técnicos das instituições selecionadas.

O trabalho sugere a elaboração de um regulamento para utilização da trilha e um plano de divulgação envolvendo entre outras atividades a confecção e distribuição de mapas, folhetos, etc. Apresenta também listagem de instituições ambientalistas, clubes excursionistas, hotéis, pousadas e camping, e horários de ônibus para as cidades envolvidas.

Oferece, também, orientação para eventuais intervenções como: abertura e/ou fechamento de trechos da trilha, clareamento da trilha, orientação da drenagem, contenção de encostas, construção de degraus, construção de estradas, tablados, 
construção de diversos tipos de pontes e pinguelas, implantação de áreas de acampamento e sinalização.

Concluindo, apesar de falta de certo conforto e segurança - que se pretende aportar com a implantação desse trabalho - hoje é possível caminhar da pedra do Lopo até o museu do Parque Nacional de Itatiaia, como possível será, ainda, ampliar e ramificar a trilha da Mantiqueira. 


\section{LONG DISTANCE TRAIL AT SERRA DA MANTIQUEIRA: PLANING AND STRATEGY FOR THE IMPLEMENTATION USING VOLUNTEER WORK}

\section{SUMMARY}

The objective of this study is to suggest a plan for a long distance trail through "the most expressive and continuos stretch" (IBGE, 1977) of Serra da Mantiqueira. The choice for the trail's path has been based on the range's higher elevations, of this so called "Health Mountain Range", and its path is a combination of trails, dirt roads, and even small stretches of paved road, at times when it is necessary to cross four federal highways.

Its length has been estimated in about $300 \mathrm{~km}$, using a CAD (Computer Aided Design) AUTOCAD R12.

The trail begins at Pedra do Lopo (São Paulo State, Brasil), an historic mark because of the troublesome period when boundaries between the provinces of São Paulo and Minas Gerais were being established; then it follows the main ridge, alternating parts within São Paulo and within Minas Gerais, and it ends at Itatiaia National Park, in Rio de Janeiro State.

The establishment of new pathways was avoided, as this could inflict impact both at natural and cultural resources of the areas that are crossed by the Mantiqueira Trail, specially when the fact that there is no conservationist culture developed among trail users in Brazil is considered, as it is pictured by the lack of care, and even deterioration, that can be observed at our long distance trails.

A sketch of the trail can be seen in 14 croquis, in different scales, and they also show water sources, campsites, viewpoints, waterfalls and other points of interest. 
It is suggested that this trail is implemented with the use of volunteer work, and the volunteers to be gathered from environmentalist organizations and hiking clubs of the municipalities and state capitals that are crossed by the trail.

Support and coordination from state (São Paulo, Minas Gerais e Rio de Janeiro) and federal agencies that have knowledge in nature conservation (including ecoturism, environmental education and trail management) are necessary for that volunteer task force. Volunteer training is also a very important part, so these can have skills to implement, maintain and manage the trail. Therefore, this study presents a model for a basic training phase, addressed not only for volunteers but also for employees of the above mentioned agencies.

Trail regulations and a communication plan including but not limited to making and distributing of maps and folders - are also suggested in this work. Other useful information, such as environmetalist organizations, hiking clubs, hotels, hostels, campgrounds and public transportation time tables for the trail's access points are also included in this work.

This work also bring guidelines for trail maintenance, including techniques on: how to open and/or to close parts of the trail, drainage, retaining wall, steps, roads, board walks, bridges and foot bridges, establishment of campsites and signs.

Concluding, despite the lack of comfort and safety - qualities that the implementation of this project pretends to improve - it is possible to hike from Pedra do Lopo to Itatiaia National Park's museum; as it will be possible to continually broaden and to branch out the Mantiqueira Trail. 


\title{
TRILHA DE LONGA DISTÂNCIA NA SERRA DA MANTIQUEIRA: PLANEJAMENTO E DEFINIÇÃO DE ESTRATÉGIA PARA IMPLANTAÇÃO COM PARTICIPAÇÃO DE FORÇA VOLUNTÁRIA
}

\section{WALDIR JOEL DE ANDRADE*}

\author{
"Serrania dominante! \\ És imponente como um altar imenso, \\ que recebe as preces e os votos numa \\ mesma língua e numa mesma crença! \\ Os teus altos píncaros não dividem povos! \\ A mesma gente sobe as tuas encostas, \\ transpõe as tuas cumiadas! \\ De um para outro lado há de sempre \\ existir acenos de irmãos, acolhida de \\ amigos e troca de benefícios! \\ Cordilheira da saúde como já te chamaram! \\ Tens a vida na tua superficie e as tuas entranhas \\ são prenhes de riquezas e de utilidades! \\ Na tua eternidade, que sejam também \\ eternos os laços que irmanam os que vivem \\ em teus flancos e em teus vales, \\ os que habitam a terra em que te altejas! \\ Que o esfórço da gente que vive em tua regiăo, \\ seja propicio para a multiplicação dos benefícios \\ que prometes e com que acenas, na plenitude \\ do teu potencial de utilidades e de belezas".

\section{Mario Leite, 1951 A Região da Mantiqueira}

\section{INTRODUÇÃO}

Na busca do chamado desenvolvimento econômico, o Homem, através dos tempos, modificou sensivelmente seus valores e sua relação com o meio.

\footnotetext{
" Pesquisador Científico do Instituto Florestal de São Paulo, Aluno do Curso de Pós Graduação em Ciências Florestais - Nivel de Mestrado - ESALQ-USP. Bolsista da CAPES.

Parque Estadual de Campos do Jordão. C.P. 264. Horto Florestal. CEP 12.460-000. Campos do Jordão. São Paulo. Fone (012) 263-1414.
} 
A partir do final do séc. XVII, o acelerado avanço da ciência e da tecnologia contribuiu muito para as transformações na relação Homem/Natureza. O conhecimento adquirido, ao contrário do que se poderia esperar, acabou por contribuir para a superficialidade desta relação. "Cada vez o Homem viu-se mais distante da Natureza $e$, graças à artificialidade de suas técnicas, julgou-se menos dependente dela " (SANTOS, 1998) ${ }^{1}$.

Nas últimas décadas deste século, vimos presenciando, como se refere SERRANO (1997), "um desejo contemporâneo do retorno à natureza", sendo o turismo, especialmente em sua variação "ecológica" ou "ambiental" uma possibilidade para se concretizar esse reencontro.

Segundo RUSCHMANN, 1997 a natureza e todos os seus componentes tornam-se pretextos para a descoberta, a iniciação, a educação e o espírito de aventura, dando origem a um turismo renovado, cuja clientela busca a calma, as aventuras e o conhecimento mais profundo das regiões visitadas.

Esse conjunto de atividades, já chamado excursionismo e redenominado ecoturismo, impõe uma filosofia que busca minorar os impactos da visitação pública, aliando a atividade propriamente dita à preservação da natureza.

Nesse sentido, as trilhas são um dos melhores meios de contato e interação com a Natureza. O exercício físico combinado com o descanso mental, proporcionado por uma caminhada, é bastante apreciado. Porém, nossas áreas naturais, onde um sistema de trilhas para uso público seria compatível, não possuem infra- estrutura adequada.

Para LINDBERG \& HAWKINS, 1995 "nos últimos anos, o número de turistas que visitam áreas naturais tem

\footnotetext{
${ }^{1}$ SANTOS, A. P. C. Proposta para a Educação Ambiental - Diretrizes de aplicação: exemplos para o segundo cíclo. São Paulo, 1998. 79p. no prelo. (Trabalho de Graduação Individual, a ser apresentado ao Departamento de Geografia - FFLCH - USP).
} 
aumentado de forma surpreendente. Infelizmente, essa tendência não tem sido acompanhada pelo planejamento e administração adequados dos locais visitados, principalmente em áreas ecológicas e culturalmente frágeis".

O Brasil é um exemplo desta realidade. As trilhas existentes, principalmente as de longa distância, não recebem qualquer tipo de manutenção, quase todas sofrem o problema de erosão e há pontos críticos com relação à segurança; surgem, não se sabe de onde, e freqüentemente desaparecem tomadas pela vegetação devido ao desuso. Algumas ainda apresentam bifurcações que não levam a lugar algum. Soma-se a isto, a constante ausência de mapas e sinalização.

O presente trabalho se apresenta relevante ao propor a utilização racional dos recursos, oferecendo a possibilidade de mudanças de comportamento frente ao ambiente. Para tanto, torna-se necessário o investimento em programas de educação formal e informal, ou seja, "(...) todas aquelas experiências do indivíduo através das quais o conhecimento é adquirido, o intelecto iluminado e a vontade fortalecida (REDDEN e RYAN, 1961)". Estes programas devem voltar-se para o questionamento dos valores do Homem em relação ao meio e a ele próprio. "Ações educativas ecologicamente responsáveis estão diretamente relacionadas a mudança de valores e devem passar, necessariamente, por uma reflexão a respeito da visão do ser humano sobre si mesmo e sobre a natureza, bem como por um cuidadoso exame das relações ( $e$ distanciamentos) entre 0 mundo humano e o mundo natural (SORRENTINO et al., 1995)".

Segundo SCHEINER (s/d), num país como o Brasil, ainda carente de recursos educativos, a Educação Ambiental surge como nova e atraente oportunidade de transmissão de experiências e conhecimentos. Ligada ao estudo da Natureza e defendendo a filosofia conservacionista, utiliza os métodos da educação formal e informal para orientar 0 indivíduo quanto às suas relações com 0 meio e com a sociedade. Através de experiências de sensibilização em relação a si mesmo e ao meio, complementadas com 
experiências práticas de observação e interpretação, quase sempre em sítios naturais - especialmente em áreas preservadas - a Educação Ambiental gera no indivíduo uma verdadeira consciência ecológica, com vistas ao uso equilibrado dos recursos do meio.

Outro recurso com o qual se pode contar é o treinamento de pessoal envolvido com atividades ligadas à natureza. Para CEBALLOS-LASCURAIN, 1995 "o treinamento é um componente vital. Cursos e seminários dirigidos a diferentes públicos (operadores turísticos, guias de campo, donos de hotéis, administradores de parques, grupos da comunidade local, funcionários do governo) são extremamente necessários. Programas de treinamento devem ter uma natureza prática, aliando as atividades de sala de aula ao trabalho de campo".

Face às carências institucionais o presente estudo tem como objetivos planejar o estabelecimento de uma trilha de longa distância através da serra da Mantiqueira, bem como definir estratégia de implantação com a participação de força voluntária, articulada e complementando a atividade institucional, pois como afirma BELART (1978) "trilhas são indiscutivelmente o meio mais econômico e mais educativo de se proporcionar recreação e alegria ao povo, o conhecimento da terra e o valor do que lhe pertence". 


\section{REVISÃO DE LITERATURA}

\subsection{Trilhas}

Segundo ANDRADE \& ROCHA (1990) "provavelmente as mais antigas trilhas surgiram como conseqüência direta dos movimentos migratórios dos grandes mamíferos, principalmente herbívoros, fugindo do inverno rigoroso. O ser humano começou a utilizar e/ ou estabelecer trilhas para vários fins, desde a simples procura de alimento (trilhas de caça) e água, até peregrinações religiosas, viagens comerciais e ações militares".

De acordo com MOREIRA (1975) "os cartagineses, ao que tudo indica, foram os primeiros a revestir seus caminhos com pedras rústicas nos locais pantanosos. No entanto alguns séculos antes da era cristã Apius Claudius, imperador romano, construiu notável estrada de quase duzentos quilômetros de extensão entre Roma e Cápua, no sul da península itálica. O seu leito era revestido por diversas camadas de lajes e lajotas de pedra, dando grande consistência aos trechos que cruzavam os banhados litorâneos. Tal estrada, obra de grande valor arquitetônico, passou para a história com o nome de "Via Ápia". No mesmo trabalho, o autor afirma que outros caminhos deixaram sinais evidentes de natureza lítica na era da pré-história árabe, babilônica, persa e grega, como também entre os povos asiáticos.

Segundo ANDRADE \& ROCHA (1990) "a principal função das trilhas sempre foi suprir a necessidade de deslocamento. No entanto, pode-se verificar que ao longo dos anos houve uma alteração de valores. De simples meio de deslocamento, as trilhas surgem como novo meio de contato com a Natureza. A caminhada incorpora um novo sentido; passa a ter um sentido em si própria e recebe um grande número de adeptos".

O Caminho de Santiago de Compostela é utilizado desde o século 11, por peregrinos que, partindo da França, na região dos Pirineus, atravessam o norte da Espanha - o País Basco, Cantábria e Astúrias - até alcançar o túmulo de Santiago, na Galícia. 
O Caminho é visitado, atualmente, por cerca de 150.000 turistas/ano, que ao longo de mais de $700 \mathrm{~km}$, passando por alguns vilarejos abandonados e em ruínas, descobrem velhas igrejas, castelos medievais, relíquias, obras de arte e arquitetura de diferentes estilos e épocas, um valioso patrimônio que torna o itinerário (que pode ser cumprido em aproximadamente 40 dias) uma aventura inesquecivel (VASCONCELOS, 1998).

Para GUILLAUMON (1977) as trilhas podem ser definidas como sendo percursos em sitio natural que conseguem promover um contato mais estreito entre o homem e a natureza. Consistem num instrumento pedagógico importante que possibilita $o$ conhecimento de fauna, flora, geologia, geografia, dos processos biológicos, das relações ecológicas, do meio ambiente e sua proteção.

BELART (1978), considera que andar, caminhar, passear, escalar, excursionar, longe do atropelo, da aglomeração, do ruído e do tráfego de veículos é um dos passatempos favoritos da maior parte das pessoas. É a forma de recreação mais econômica, mais sadia e que maiores oportunidades oferece de observação, pesquisa, tranqüilidade e devaneio". Propõe um Sistema Nacional de Trilhas e considera que "o importante é um planejamento de integração paisagística bem delineado com a seleção de trechos próprios a serem atravessados, de áreas de recreação em pontos de atração, de abrigos e outras facilidades indispensáveis em sítios sem recursos".

NEGREIROS et al. (1974), na elaboração do Plano de Manejo do Parque Estadual da llha do Cardoso, consideram que devem ser oferecidos meios para as pessoas que queiram excursionar para os lugares mais remotos de um Parque, e propõem um sistema de trilhas.

A respeito de um sistema de trilhas, GRIFFITH \& VALENTE (1979), GRIFFITH (1983) e IBDF \& FBCN (1981), propõem que seu planejamento deve considerar a seqüência paisagística de cada percurso procurando variá-lo entre diversas 
classes de paisagens, aproveitando as vistas das várias posições de observações e, por outro lado, evitando áreas de valor inferior. Podese enriquecer a experiência, perceptiva do visitante, conduzindo-o a áreast mais bonitas do Parque ou instalando as trilhas onde ele possa contemplar paisagens mais interessantes.

Segundo SCHELHAS (1986), as trilhas são normalmente uma das melhores opçōes para os visitantes aproveitarem áreas naturais como um parque de maneira tranqüila, o que permite maior familiaridade com o meio natural do mesmo; trilhas bem construídas e devidamente mantidas protegem o meio ambiente do impacto do uso e ainda asseguram aos visitantes maior conforto e segurança, além de desempenhar papel significativo na impressão que os visitantes terão sobre a área $e$ a instituição mantenedora.

A caminhada incorpora um novo sentido; passa a ter um sentido em si própria e vem recebendo um grande número de adeptos. Com a intensificação do uso de trilhas, alguns manuais de construção e manutenção vem sendo publicados por entidades públicas e privadas, norte americanas e européias, como por exemplo: "Appalachian Mountain Club" (PROUDMAN, 1977 e LEONARD, SPENCER \& PLUMLEY, s.d.); "British Trust for Conservation Volunteers"(AGATE, 1983); "Student Conservation Association" (BIRKBY, 1996) e "Forest Service" (HESSELBARTH \& VACHOWSKI, 1996).

Segundo GROVE (1987), nos Estados Unidos, a Trilha dos Appalaches foi proposta pelo conservacionista Benton Mackaye em 1921 e começou a ser implantada em 1922, com término em 1937 quando vários segmentos foram conectados totalizando $3.200 \mathrm{~km}$ aproximadamente. Centenas de aventureiros durante um ano, fazem o percurso inteiro da trilha que é visitada, no mesmo período, por quatro milhões de pessoas.

No Brasil, as primeiras publicações a respeito de trilhas tratam dos caminhos de penetração da Serra do Mar, no período de colonização. Em épocas pré-cabralinas o caminho mais 
importante foi o do Peabiru (ape + abiru = caminho batido, que teria sido um conjunto de trilhas vicinais, supostamente desde a costa de São Vicente até o Paraguai; ou uma longa estrada, tronco de um primitivo sistema de viação geral que, segundo PINTO (1903) permitia o contato das tribos da nação guarani, da bacia do Paraguai, com tribos do sul do Brasil, entre elas as que habitavam os campos de Piratininga. O Peabiru, que os jesuítas teriam denominado Caminho de São Tomé, constituiria o mais importante caminho précolombiano, excetuando-se o eixo viário incaico (PETRONE, 1965).

A primeira trilha a ser utilizada pelos colonizadores para, da costa vicentina, alcançar os Campos de Piratininga, foi a dos Tupiniquins. Depois passou-se a utilizar o Caminho do Padre José e sua variante do rio das Pedras (PINTO, 1903; WENDEL, 1952 e PETRONE, 1965).

Um avanço na construção de caminhos no Brasil, foi a Calçada do Lorena, por alguns chamada de Estrada da Independência, pois por ela subiu D.Pedro I, na memorável viagem de 7 de setembro de 1822. Concluída em 1792, seu traçado na serra era um ziguezague de 180 ângulos e com largura de aproximadamente 3 metros. Toda calçada com pedras de até 40 metros de largura não cruzava um vez sequer um curso d'água pois se desenvolvia principalmente no divisor de águas dos rios Perequê e das Pedras (TOLEDO, 1975).

No Brasil, várias são as trilhas de longa distância utilizadas pelos excursionistas, recentemente redenominados ecoturistas. As mais notáveis são: "Petrópolis - Teresópolis", com 35 km no Parque Nacional da Serra dos Órgãos (ANDRADE \& SILVA, 1987; BECK, 1977); "Rebouças-Sede", com 24 km ou "Itatiaia-Mauá" com $45 \mathrm{~km}$ no Parque Nacional de Itatiaia (ANDRADE \& SILVA, 1987; GASQUES, 1990 e BECK, 1997); "Trilha do Ouro", com 70 km no Parque Nacional da Serra da Bocaina (ANDRADE \& SILVA, 1987 e BECK, 1977); "Trilha do Pico da Bandeira" com 10 km no Parque Nacional de Caparaó (ANDRADE \& SILVA, 1987 e BECK (1997) e "Trilha da Serra Fina" com 60 km na Serra da Mantiqueira (ANDRADE et al., 1993 e BECK, 1997). 
Para ZIMMERLY (1978), os caminhos possuem grande importância na estruturação de áreas naturais, pois permitem o deslocamento dos visitantes ao mesmo tempo que os informam sobre os valores da área, seu manejo, regulamentos e objetivos de proteção.

De acordo com PROUDMAN (1977), a anatomia da trilha (FIGURA 1) é a seguinte:

a) superfície de pisoteio - é aquela na qual o andarilho toca o solo;

b) área marginal - é aquela ao redor da superfície de pisoteio e que apenas é clareada (limpa com roçadas) para passagem do excursionista;

c) zona tampão - é a área de cada lado da trilha que tem por objetivo proteger áreas frágeis. Junto com a área marginal e a superfície de pisoteio formam o corredor da trilha, ou zona de influência durante a caminhada.

\subsection{Montanhismo / Serra da Mantiqueira}

Sobre a atração exercida nos homens pelas montanhas, JOUTARD (1986), afirma que elas sempre estiveram presentes no horizonte mental europeu e na maioria das culturas, aparecendo como um espaço sagrado, interdito ao homem ordinário, residência da divindade boa ou má. No entanto sua descoberta pela cultura européia coloca dificuldades para uma datação uma vez que desde o Renascimento já existem signos de interesse por elas. Há as escaladas ao Ventoux por Petrarca em 1336 e do Dauphiné por de Ville em 1492, ao Mont Blanc (ponto culminante da Europa) em 1786, além de sua presença na pintura de Duhrer e Vinci. Nesse contexto, o Romantismo representaria apenas a popularização de tal interesse.

SERRANO (1993) assegura que "diante da teia formada pela sensibilidade estética, filosófica e conquistadora presente na atração pelas montanhas, por anseios econômicos e de denominação forjados no processo de colonização, associados 
também à curiosidade e interesse científico, torna-se complexo precisar o nascimento de um interesse "puro" pela montanha no Brasil. Muitos dos naturalistas e viajantes em trânsito por aqui empreenderam escaladas: Spix e Martius no Itambé (MG) em 1818, George Gardner na Pedra do Sino (RJ) em 1841, Liais no Itacolomi (MG) em 1862. A lista pode ser ampliada em muito, mas o caráter delas parece estar diretamente relacionado à pesquisa".

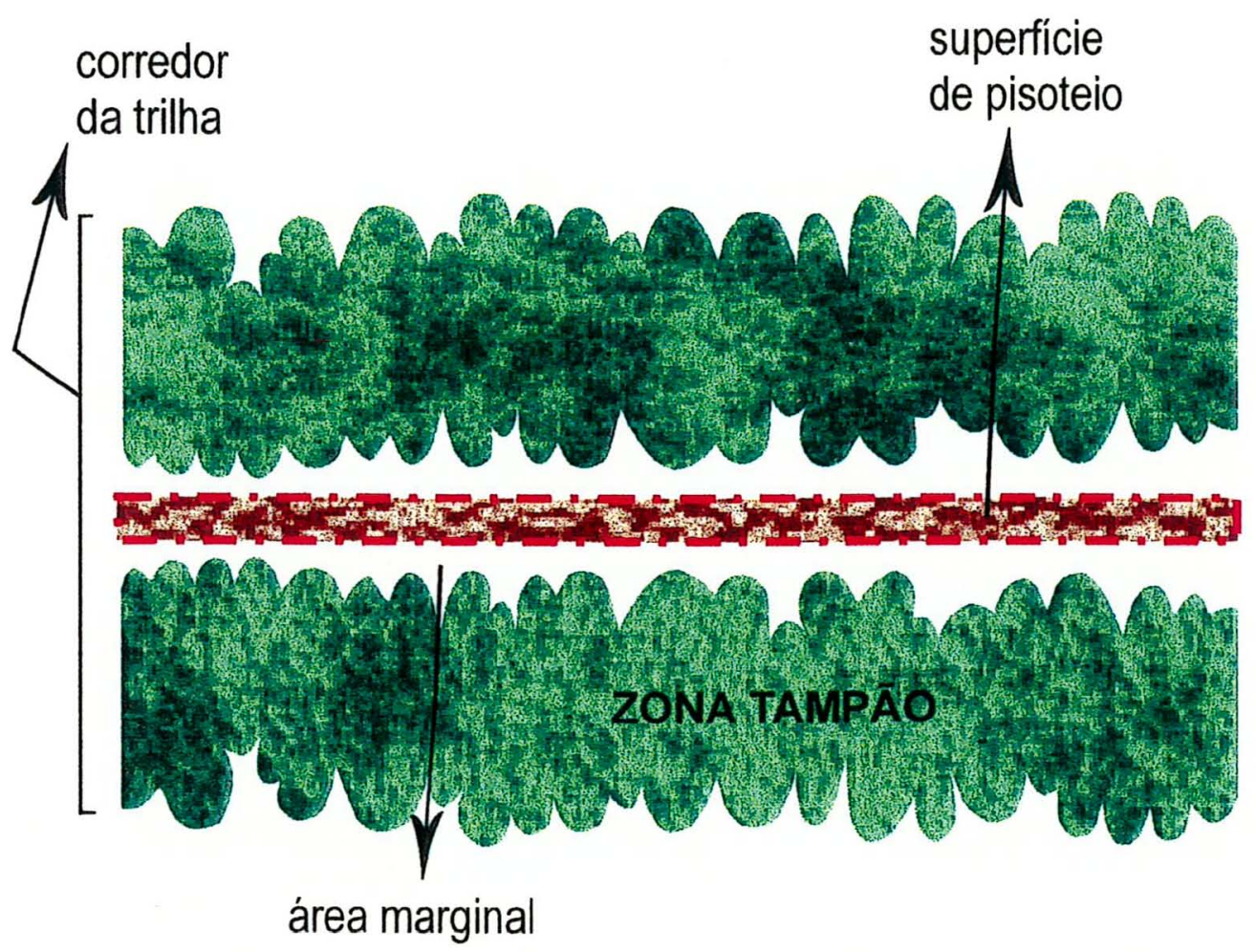

FIGURA 1 - ANATOMIA DA TRILHA.

De acordo com ANDRADE \& ROCHA (1990) paralelamente ao excursionismo científico introduziu-se 0 excursionismo de aventura no Brasil, supostamente através de 
imigrantes europeus. Segundo SIMAS (1983), o primeiro clube de montanhismo brasileiro foi fundado no Rio de Janeiro, em 1919.

De acordo com MENDES JR. et al. (1991), a serra da Mantiqueira é um conjunto orográfico com extensão e limites nem sempre bem definidos que se estende por três estados do sudeste brasileiro: Minas Gerais, São Paulo e Rio de Janeiro. O termo Mantiqueira teria como provável significado "local de precipitações abundantes" ou local em que se originam as águas".

Segundo VÁRZEA (1942), a Mantiqueira estende-se da margem norte do Tietê, onde se localiza o Pico do Jaraguá, até o sul da Baía, onde se encontra o "morro do descobrimento" (FIGURA 2).

Para MELLO (1909), o eixo principal da cordilheira da Mantiqueira parte do N.E. da cidade de São Paulo, e segue acompanhando, rio acima, a margem direita do Alto Tietê, e daí a margem esquerda do Paraíba, rio abaixo, sempre na direção de N.E. Nesta direção recebe os seguinte nomes locais: Serra da Cantareira; Serra dos Poncianos; Pico Agudo; Serra de São Bento; Serra de Campos do Jordão; Serra do Piquete; Serra do Passa Quatro; Serra do Jacú; Serra do Picú; Serra do Itatiaia, entre outros.

Para LEITE (1951) "no sistema orográfico do Brasil, a serra da Mantiqueira apresenta-se com destacado relevo e sobranceria. A sua extensão, os seus inúmeros e elevados picos, o lançamento dos seus contrafortes, a sua geologia, o seu clima excepcional, as suas múltiplas e variadas paisagens, dão-lhe real importância no conjunto de montanhas do país".

"Desde que viajo na Capitania de Minas, talvez nada visse de mais belo do que a região hoje atravessada. Seguimos um vale bastante largo, cercado de montanhas pitorescas e coberto de árvores no meio das quais se destaca sempre a majestosa araucária. Este vale é regado por um rio que dá mil voltas e pelo qual se passa quatro vezes para chegar aqui, donde lhe vem o nome Passa Quatro. Suas margens apresentam alternadamente, pastos, capões de mato 
pouco elevados, terrenos cultivados entre os quais se vê de distância em distância grupos de pinheiros. Pequenas casas acrescentam, ainda, nova variedade à paisagem. À nossa frente tínhamos a Serra da Mantiqueira, cujos cumes, bastante diferentes pelo formato, são cobertos de sombria floresta. Nada melhor lembra os vales da Suíça do que este de que acabo de fazer a descrição" (SAINTHILAIRE, 1822).

Para IBGE (1977) "em conjunto a Serra da Mantiqueira forma o segundo degrau do planalto brasileiro. Sua extensão tem sido dada ora como englobando a área que vai do planalto de Caldas até o Caparaó, ora como situada entre Bragança e Juiz de Fora ora localizada no norte da cidade de São Paulo até as proximidades de Barbacena. Caracteriza-se por uma imponente escarpa voltada para o Vale do Paraíba (FIGURA 3), cujos desníveis excedem a 2.000 metros. Seu trecho mais contínuo e expressivo é aquele que forma a escarpa situada ao longo do médio Paraíba".

MEIRELLES (1991) considera que a serra da Mantiqueira é uma das maiores cadeias de montanhas do leste sulamericano e conserva-se como um museu vivo, apesar de estar encravada no triângulo de maior concentração industrial e urbana do país.

GASQUES (1992) afirma que "outra característica da região é a infinidade de trilhas abertas ao longo de séculos por desbravadores que subiam do Vale do Paraíba em direção ao sertão mineiro: lavradores, tropeiros e outras pessoas que andavam não exatamente porque fosse bom, mas simplesmente porque, além do cavalo, não havia outra forma de viajar. Prossegue adiante o autor "....seus riachos cristalinos, pinheiros, animais e um estonteante céu estrelado, tudo, às vezes, temperado por um frio glacial, a Serra da Mantiqueira é um cenário perfeito para curtas e longas caminhadas". 


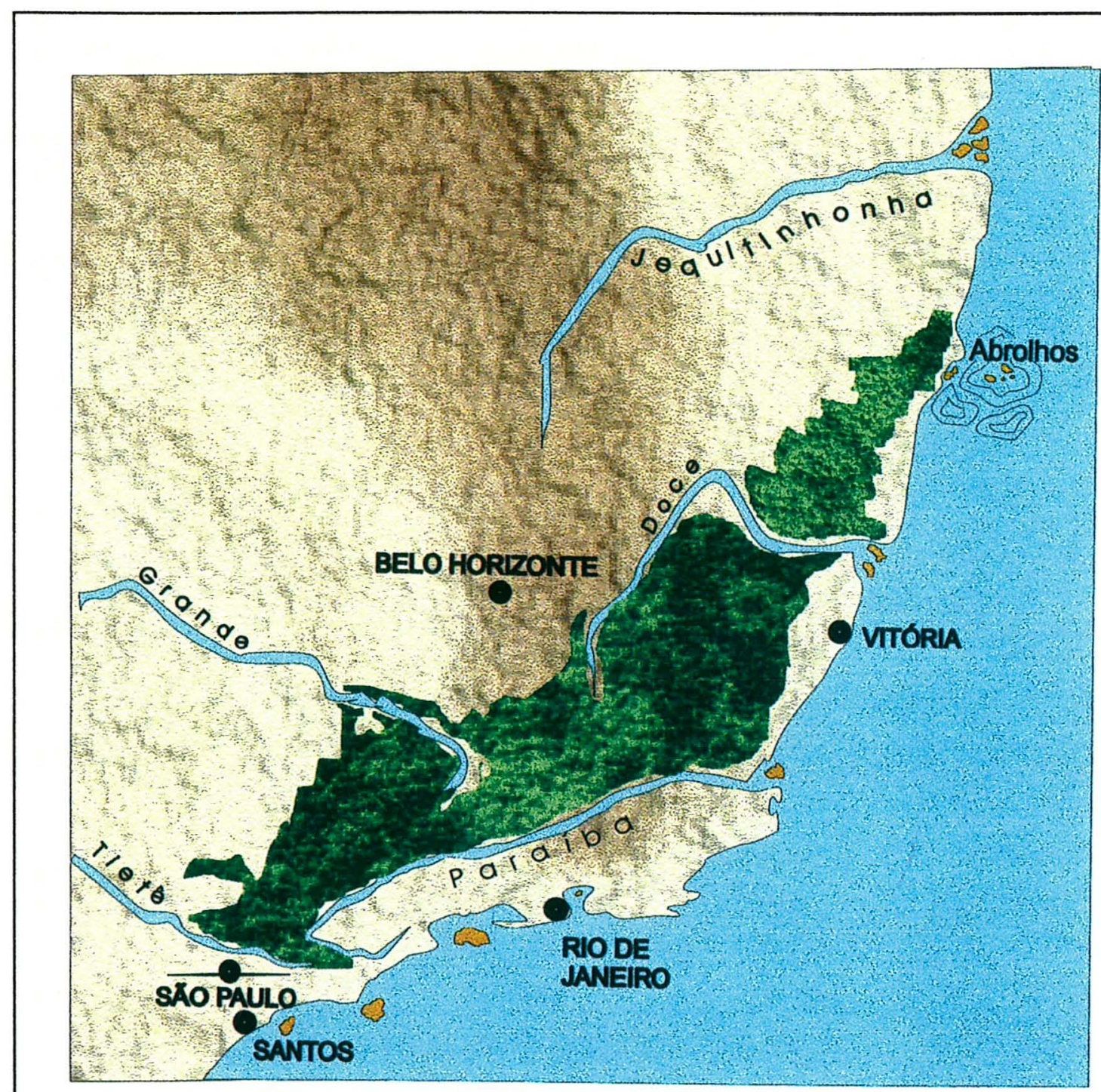

FIGURA 2 - SERRA DA MANTIQUEIRA

Fonte : VARZEA - 1942

\subsection{Unidades de Conservação na Mantiqueira}

Oito unidades de conservação se destacam na área de estudo. 


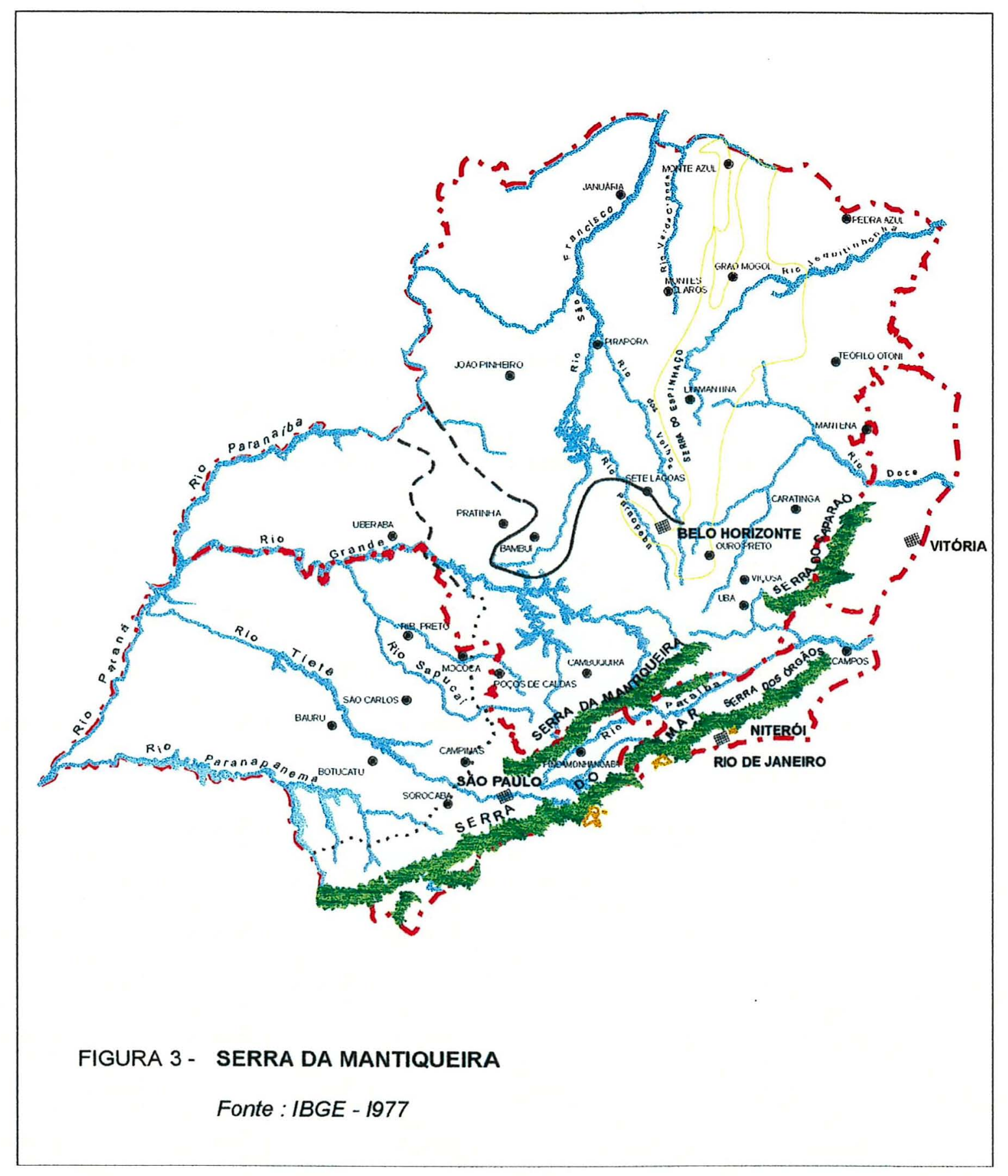

O Parque Nacional do Itatiaia - primeiro no Brasil - foi criado através do Decreto Federal n 1713, de 14 de junho de 1937 (MA/FBCN, 1982 ). 
- Parque Estadual de Campos do Jordão, localizado na serra da Mantiqueira, foi o primeiro a ser criado no Estado de São Paulo, em 1941 ( SEIBERT, 1975 ).

MENDES JR et al. (1991) informam que o Decreto $n^{\circ}$ 91.304 de 03 de junho de 1985 dispõe sobre a implantação da Área de Proteção Ambiental (APA) Federal da Serra da Mantiqueira, nos estados de Minas Gerais, Rio de Janeiro e São Paulo.Neste último ocupa parte dos municípios de Campos do Jordão, Cruzeiro, Lavrinhas, Pindamonhangaba, Piquete, Santo Antonio do Pinhal e Queluz.

Outras APAs existentes na área de estudo são: APA Federal Mananciais do Vale do Paraíba do Sul, criada através de Decreto Federal $n^{\circ} 87.561 / 82$; APA de Campos do Jordão, criada através da Lei Estadual n० 4.105/84 ; Área II da APA Estadual Piracicaba e Juqueri - Mirim, que engloba terras do município de Joanópolis (SÃO PAULO, 1992; e KURKDJIAN,et al., 1992) ; e a APA municipal da Pedra do Baú, que segundo LIMA SILVA (1985) foi criada em 31 de agosto de 1987, formando um círculo de quatro quilômetros ao redor daquele afloramento rochoso.

$\mathrm{Na}$ área se encontra ainda a Floresta Nacional de Passa Quatro, assim denominada a partir de 1967, com a criação do já extinto Instituto Brasileiro de Desenvolvimento Florestal (IBDF),tendo sido originalmente criada em 1946, como Parque Florestal (SILVA, 1988).

Além da unidades existentes na área de estudo e relatadas acima, outras duas foram propostas.

ANDRADE et al. (1992) propuseram a criação e manejo do Monumento Natural Estadual da Pedra do Baú, na serra da Mantiqueira. 
ANDRADE et al. (1993) propuseram a criação e manejo do Parque Estadual da Serra Fina, na serra da Mantiqueira, em terras dos municípios Cruzeiro, Lavrinhas e Queluz.

\subsection{Trabalho voluntário}

O trabalho voluntário direcionado para a conservação da natureza é uma realidade em diversos países do mundo.

Na Austrália, de acordo com ATCV Home Page, 1998, vários são os programas para voluntários em conservação da natureza: plantios de árvores, controle de erosão e salinidade, coleta de sementes de plantas nativas, restauração de construções históricas, restauração de habitats, erradicação de ervas daninhas e construção e manutenção de trilhas.

No Reino Unido, o British Trust for Conservation Volunteers (BTCV) é a maior organização promotora de atividades práticas voltadas para conservação da natureza através do trabalho voluntário, oferecendo milhares de oportunidades todo o ano através da Inglaterra, País de Gales e Irlanda do Norte (BTCV, Home Page, 1998).

$\mathrm{Na}$ Costa Rica, a Associação de Voluntários em Investigação e Desenvolvimento Ambiental (VIDA), realiza desde sua criação em 1998, um programa de atividades e serviços voluntários, tanto a nível nacional como internacional. Os voluntários de VIDA participam em campanhas de reflorestamento, tomam parte em oficinas de educação ambiental, auxiliam na manutenção de trilhas em Refúgios e Parques Nacionais, entre outros (VIDA, Home Page, 1998).

Nos Estados Unidos, de acordo com a FUNDAÇÃO SOS MATA ATLÂNTICA, 1989, 89 milhões de pessoas praticam 0 voluntariado. Uma recente pesquisa descobriu que um terço do público americano já foi ou é voluntário e mais da metade dos atuais 
voluntários envolvidos, também trabalham em empregos de tempo integral ou parcial. (KANIAK, 1990).

De acordo com o NPS, 1988, o Serviço de Parques Nacionais (NPS) coordena o Programa Voluntários em Parques (VIP), autorizado pela Lei Federal $n^{\circ} 91357$ e tem como propósito principal aceitar e utilizar a força voluntária em benefício dela própria, do Serviço de Parques Nacionais (NPS) e da conservação da natureza. Praticamente qualquer pessoa pode ser um voluntário e há um programa para cada Parque, que desenvolve uma operação local para recrutamento, seleção, treinamento e demais atividades que envolvam voluntários.

O Serviço Florestal, órgão do Departamento de Agricultura dos Estados Unidos, dentro do Programa de Recursos Humanos, aceita voluntários desde que foi legalmente formalizado o Ato de Voluntários em Florestas Nacionais, em 1972. Tanto indivíduos como grupos de diversas idades, estilo de vila e profissões, podem contribuir com a missão do Serviço Florestal. 0 Programa inclui, aposentados, profissionais, visitantes internacionais, colegiais, adolescentes e crianças que se envolvem em diversas atividades como: construção e manutenção de trilhas, divulgação de programas e atividades do Serviço Florestal, reflorestamento, educação ambiental, manutenção e gerenciamento de áreas de camping, entre outras (FOREST SERVICE, 1995).

\section{O Corpo de Engenheiros do Exército Americano} também mantém um programa de voluntários no qual se prove uma orientação geral, bem como um treinamento específico, se necessário, nas seguintes áreas: recreação ao ar livre, manejo da terra, manejo da pesca e vida silvestre, recursos culturais e administração e relações púbicas (U.S. ARMY, 1994).

No Brasil, podemos destacar algumas atividades envolvendo voluntários em trabalhos de conservação da natureza. Segundo SAVI, 1997, no Parque Estadual do Marumbi, no Estado do Paraná, dentre as ações utilizadas para o manejo dos visitantes se encontra o incentivo à participação voluntária, baseado no princípio 
da etologia do estímulo ao comportamento positivo, principalmente para a retirada do lixo, plantio de mudas do palmito, contenção de erosão e a utilização correta de regras de baixo impacto em áreas de acampamento selvagem.

No Estado de São Paulo, o Grupo de Ação Voluntária - GAV, da Fundação SOS Mata Atlântica, desde 1988 vem organizando grupos de profissionais e estudantes das mais variadas idades, que aproveitando o tempo livre se dedicam à defesa da natureza. Um dos projetos do GAV é TRILHAS E TRILHOS, que abrange três áreas que se interligam: a vila de Paranapiacaba, em Santo André; as trilhas do Parque Estadual da Serra do Mar, e o vale do rio Quilombo, já em Santos. Para orientação de visitantes, nas trilhas, o GAV oferece um treinamento de formação de monitores (FUNDAÇÃO SOS MATA ATLÂNTICA 1989).

O Instituto Florestal de São Paulo vem desenvolvendo desde 1991, em convênio com o Fundo Mundial para a Natureza - WWF, o Projeto Atuar - Treinamento de Voluntários em Unidades de Conservação, cujo objetivo geral é treinar os técnicos de unidades de conservação, universitários, para que quando capacitados possam treinar estudantes universitários em suas respectivas unidades, orientando-os no trabalho voluntário, desta forma eles, técnicos e estudantes, poderão implementar programas de educação ambiental, interpretação, manutenção e proteção (CATALDI, 1993).

Também no Instituto Florestal de São Paulo, há várias modalidades de estágio voluntário, sendo que uma das áreas abrangidas é o Manejo de Áreas Silvestres, na qual o aluno de curso superior se envolve com várias operações em unidades de conservação, tais como: manejo de trilhas, programas de uso público, prevenção e combate a incêndios florestais, patrulhagem, etc. (ANDRADE, 1993). 
Segundo Naylor ${ }^{2}$ citado por KANIAK (1990) "voluntários são motivados por satisfação e benefícios que não envolvem dinheiro. É um modo de oferecer um serviço público à sociedade. É oportunidade para se descobrir vocações, dar vazão à criatividade, oportunidade para as pessoas fazerem coisas que elas desejam e podem fazer bem". Ainda segundo o mesmo autor, com relação à disponibilidade para a realização de dez tipos de tarefas voluntárias, destacam-se o trabalho de fiscalização com $70 \%$ e recuperação de trilhas com $54 \%$.

De acordo com CORULLÓN, 1998, o voluntário tem o dom de se doar; dispõe-se a fazer um trabalho sem interesse de retorno material, apenas espiritual, ou em troca de algo intangível; através da atuação junto à sociedade sente-se útil; doa sua força de trabalho para alguma causa humana, social ou ambiental; tem um conceito mais estruturado do papel do indivíduo na sociedade... pensa e age de maneiras coletivas; coloca-se à disposição, contribui, se oferece sem pensar em retribuição, de livre e espontânea vontade; e valoriza a satisfação pessoal de ter colaborado para tornar os outros mais felizes.

Segundo definição das Nações Unidas (CORULLON,1998), "o voluntário é o jovem ou adulto que, devido a seu interesse pessoal e ao seu espírito cívico, dedica parte de seu tempo, sem remuneração alguma, a diversas formas de atividades, organizadas ou não, de bem estar social, ou outros campos". O mesmo autor ainda informa que em recente estudo realizado na Fundação Abrinq pelos Direitos da Criança, definiu-se o voluntário como ator social e agente de transformação, que presta serviços não remunerados em benefício da comunidade, doando seu tempo e conhecimentos, realiza um trabalho gerado pela energia de seu impulso solidário, atendendo às necessidades do próximo e os imperativos de uma determinada causa.

\footnotetext{
${ }^{2}$ Naylor,H.H. Volunteers today: finding, training and working with them. DI S:A. Drayden Assoc., 1973. p.9.
} 


\section{CARACTERIZAÇÃO DA ÁREA DE ESTUDO}

A área de estudo se localiza na Região Sudeste do Brasil, entre as coordenadas geográficas $22^{\circ} 20^{\prime}$ a $23^{\circ} 00^{\prime}$ latitude Sul e $44^{\circ} 30^{\prime}$ a $46^{\circ} 20^{\prime}$ longitude W., abrangendo terras dos estados de São Paulo, Minas Gerais e Rio de Janeiro. Foi definida tomando por base as visitas e pesquisas de campo na região, bem como as considerações de LEITE, 1951 "... por ramificações da Mantiqueira até frontear o Morro do Lopo, grimpando no maciço principal da Serra, e seguindo pela cumiada até o Ribeirão do Salto, nas vizinhanças do imponente Itatiaia-Açu" (FIGURA 4).

Climaticamente a área de estudo, segundo Köppen, corresponde ao tipo $\mathrm{Cfb}$, ou seja, subtropical de altitude, mesotérmico e úmido, sem estiagem, com temperatura média do mês mais quente inferior a $22^{\circ} \mathrm{C}$. Segundo SEIBERT(1975), entre 1965 e 1974,0 mês mais quente predominante foi fevereiro, com média de $17,7^{\circ} \mathrm{C}$ e o mais frio foi julho com $9,5^{\circ} \mathrm{C}$ em média, com mínima absoluta de $-4,4{ }^{\circ} \mathrm{C}$.

Segundo MONTEIRO (1973), na face da serra da Mantiqueira voltada para o mar predomina a atuação de correntes de ar leste, vindas do oceano, que têm sua umidade diminuída pela precipitação ocorrida na subida da serra do Mar. Também pela latitude, está mais sujeita às ondas de frio polares.

Nos seus contrafortes ocidentais, nos limites do estado de Minas Gerais, apresenta índices pluviométricos elevados (1400 a $1700 \mathrm{~mm}$ anuais), mas com inverno mais seco (200 a 400 $\mathrm{mm}) .0$ bloco elevado destaca-se pela diminuição da temperatura $e$ aumento da pluviosidade. No período de 1965 a 1974, SEIBERT (1975), observou que o mês mais chuvoso no Parque Estadual de Campos do Jordão foi janeiro, com índice pluviométrico acima de $300 \mathrm{~mm}$, e o mais seco é julho, com índice ao redor de $30 \mathrm{~mm}$, num total anual de $1911 \mathrm{~mm}$. 


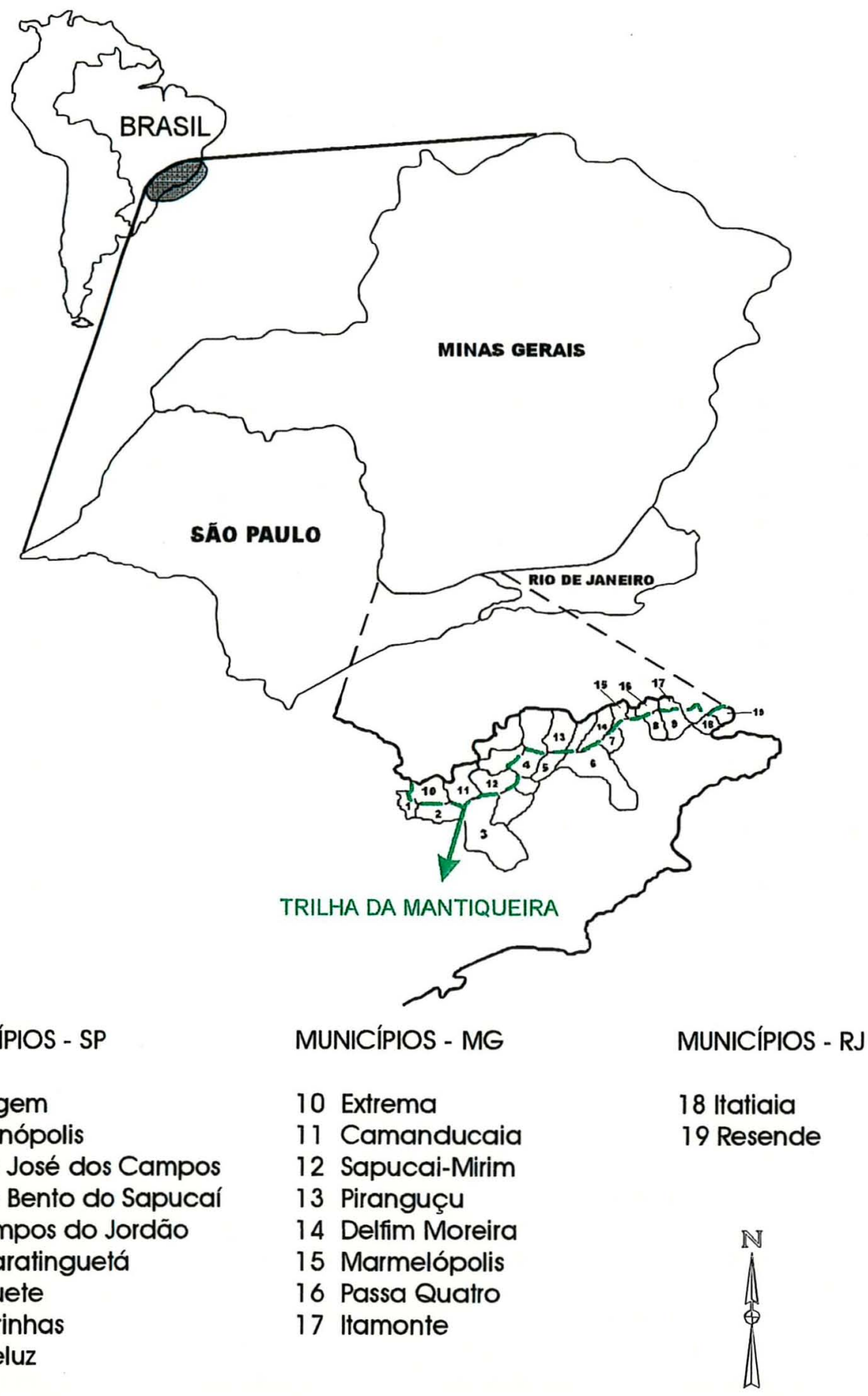

FIGURA 4 - LOCALIZAÇÃO DA ÁREA DE ESTUDO. 
$\mathrm{Na}$ constituição geológica da Mantiqueira predominam as rochas do complexo cristalino tais como gnaisses, xistos cristalinos, quartzitos, ocorrendo também intrusões de rochas eruptivas alcalinas( MENDES JR. et al., 1991).

O conjunto tectônico serra do Mar / vale médio do rio Paraíba do Sul / serra da Mantiqueira é um caso singular entre os grandes sistemas montanhosos do globo, pois sua gênese está ligada ao soerguimento não por orogênese (forças ascensoriais) e sim por tectonismo de abertura do continente (COSTA, 1987). Quanto a morfologia, a área pertence, segundo ALMEIDA (1974), à província geomorfológica do Planalto Atlântico, zona da serra da Mantiqueira e subzona oriental. A zona da serra da Mantiqueira corresponde ao conjunto de elevadas escarpas, e morros mais ou menos isolados em que o planalto sul-mineiro termina diante do vale do rio Paraíba. Entre a crista da serra da Mantiqueira e as planícies do vale do rio Paraíba, encontram-se desniveis de 1500 a 2000 metros, tornando esse relevo um dos mais abruptos do país. Suas maiores elevações, segundo IBGE (1977), são: Morro do Selado (2.014 m), Pedra do Baú $(1980 \mathrm{~m})$, Pico dos Marins $(2.421 \mathrm{~m})$, Pico do Itaguaré $(2328 \mathrm{~m})$, Pedra da Mina $(2770 \mathrm{~m}$ ) e Pico das Agulhas Negras - Itatiaiuçu (2787 m).

Segundo IPT (1981) a serra da Mantiqueira Oriental é essencialmente composta pelas Escarpas Festonadas, que são relevos de transição muito abruptos entre o Planalto de Campos do Jordão e sua continuação ao Itatiaia, e a região do médio vale do rio Paraíba.

O mesmo autor afirma que a área de estudo apresenta um relevo de escarpas festonadas desfeitas em anfiteatros separados por espigões. Os topos são angulosos e as vertentes apresentam perfís retilíneos. A drenagem é de alta densidade e o padrão é subparalelo e dendrítico, com vales fechados. Predominam declividades altas, acima de $30 \%$, e amplitudes maiores que 100 metros. 
Os levantamentos de solos desta região, foram efetuados em escalas pequenas e nos demonstram segundo BRASIL (1960) a ocorrência de Litossolos fase granito-gnaisse e Latossolos Vermelho-Amarelo fase rasa. Os primeiros constituindo solos pouco desenvolvidos, com espessura em torno de $0,40 \mathrm{~m}$, em relevo tipo montanhoso com declives em torno de $60 \%$. O segundo, já é um solo bem drenado, pouco mais profundo com espessura média, em torno de $1,20 \mathrm{~m}$, e encontra-se em relevo forte ondulado a montanhoso.

Para RADAMBRASIL (1983), a área apresenta a ocorrência de associações de solos, tais como: Cambissolo húmico com solos Litólicos húmicos e Afloramentos rochosos; Cambissolo álico com Latossolo Vermelho-Amarelo e Afloramentos rochosos. Todas estas associações ocorrem em relevo montanhoso ou escarpado. Em geral, tais solos não são usados para agricultura, apresentando como fatores limitantes a declividade excessiva e o alto teor de alumínio no solo. A presença do caráter húmico, indica a baixa mineralização da matéria orgânica, principalmente à altitudes elevadas e à ocorrência de temperaturas mais baixas.

A cobertura vegetal da área, segundo RADAMBRASIL (1983) caracteriza-se como Floresta Ombrófila Densa-Formação Floresta Montana, que ocupam faixas de altitude de 500 a $1.500 \mathrm{~m}$, apresentando um extrato dominante com altura até mais ou menos, 25 metros; acima do nível de $1.500 \mathrm{~m}$ ocorre a Floresta Alto-Montana, que apresenta uma estrutura nano microfanerófita, cuja altura pode variar em torno de 5 a10 m em função da altitude local.

Verifica-se também a ocorrência de Campo Altimontano, que segundo RIZZINI (1979) se distende sobre os planaltos das montanhas cristalinas, acima do limite arbóreo, de uns 1800 a $2000 \mathrm{~m}$ para o alto, em tais áreas o solo é humoso e negro, o vento dessecante é comum e a insolação poderosa; HUECK (1978) chama estes campos de subalpinos, compostos por gramíneas e ciperáceas que formam em conjunto uma densa cobertura, somente interrompida onde afloram as rochas. 
Com relação a fauna, MENDES JR. et al. (1991), consideram a presença de determinadas espécies por nível de altitude: nos campos de cultivo (altitudes inferiores a 600 metros, no vale do Paraíba) é encontrada uma fauna adaptada, que inclui aves como: gavião (várias espécies); pardal (Passer domesticus); tico-tico (Zonotrichia capensis); anu preto (Crotophaga ani); anu branco (Guira guira); e andorinha (Progue sp), pequenos roedores: serelepe (Querlinguetus ingrami); preá (Cavea aperea); paca (Caniculus paca) e lebre (Sylvilagus brasiliensis), pequenos carnivoros: cachorro-domato (Cerdocyon thons) e irara (Eira barbara), tatu (Dasypus novencinctus) e gambá (Didelphis $s p$ ).

Entre 600 e 1900 metros, na zona florestal de altitude, ocorrem aves de pequeno porte, inhambu (Crypturellus patalta), porco-do-mato (Tayassu tajacu), macacos: bugio (Alouata fusca clamitans); sauá (Cebus nigrifrons); mono (Aotus sp) e micopreto (Cebus apella), tamanduá-colete (Tamandua tetradactyla), preguiça (Bradypus variegatus), ouriço-cacheiro (Sphigurus villosus), serelepe (Querlinguetus ingrami), furão (Galictis vittata), irara (Eira barbara), gambá (Didelphis sp), guaiquica (Marmosops incanus) e felinos: onça parda ou suçuarana (Puma concolor); onça pintada (Pantera onca); gato-do-mato (Leopardus tigrinus) e jaguatirica (Leopardus pardalis).

Nas altitudes superiores a 1900 metros, nos campos de altitude e pequenos bosques, destacam-se as aves, entre elas duas espécies de abutres (Coragyps atratus brasiliensis e Cathartes aura ruficollis), a coruja-do-mato (Pulsatrix koeniswaldiana), o corujão-da-mata (Strix hylophila), a siriema (Cariana cristata) e aquelas de pequeno porte, exclusivas das grandes altitudes: Poospiza thoracica, Oreophylos moreirae e Hemitricus obsoletus. De mamíferos ocorrem o cachorro-do-mato (Cerdocyon thous), quati (Nasua nasua), lobo-guará (Chrysocyon brachyurus) e paca (Caniculus paca).

BARBOSA, 1988, estudando a avifauna do Parque Estadual de Campos do Jordão, registrou a ocorrência de 178 
espécies de aves, distribuídas em 41 famílias, das quais, 146 são residentes permanentes e 32 são migratórias.

HÖFLING, CAMARGO \& IMPERATRIZ-FONSECA consideram que "poucos levantamentos têm sido feitos e os dados disponíveiis fornecem uma estimativa de cerca de 300 espécies de aves. A sua distribuição vai variair com o tipo de vegetação e o clima de cada região da serra, incluindo sua partes baixas. 


\section{Material fotográfico e cartográfico}

Como apoio aos levantamentos de campo foram utilizadas fotografias aéreas pancromáticas, nas escalas aproximadas 1:25.000 e 1:45.000 provenientes de aerolevantamentos realizados respectivamente nos anos de 1971 a 1973 (Secretaria da Agricultura do Estado de São Paulo / Instituto Brasileiro do Café. TERRAFOTO) e 1977 (Secretaria de Economia e Planejamento do Estado de São Paulo / TERRAFOTO - Plano Cartográfico do Estado de São Paulo).

Utilizou-se como apoio de campo, folhas topográficas na escala 1:10.000 (FIGURA 5) e como base para mapeamento das trilhas, folhas topográficas na escala 1:50.000 (FIGURA 6 e TABELA 1) editadas pelo Instituto Brasileiro de Geografia e Estatística - IBGE).

TABELA 1: Relação das folhas topográficas que abrangem a área de estudo, na escala 1:50.000.

\begin{tabular}{llc}
\hline Nome & Nomenclatura & Ano de edição \\
\hline Extrema & SF.23-Y-B-IV-3 & 1972 \\
Camanducaia & SF.23-Y-B-IV-4 & 1972 \\
Monteiro Lobato & SF.23-Y-B-V-3 & 1973 \\
Campos do Jordão & SF.23-Y-B-V-2 & 1971 \\
Delfim Moreira & SF.23-Y-B-VI-1 & 1971 \\
Lorena & SF.23-Y-B-VI-2 & 1971 \\
Virgínia & SF.23-Y-B-III-4 & 1972 \\
Passa Quatro & SF.23-Z-A-I-3 & 1972 \\
Agulhas Negras & SF.23-Z-A-I-4 & 1972 \\
\hline
\end{tabular}

Fonte: IBGE (1971, 1972 e 1973)

Quando necessárias, foram utilizadas bússola e trena para se proceder ao levantamento de trechos de trilhas existentes. 

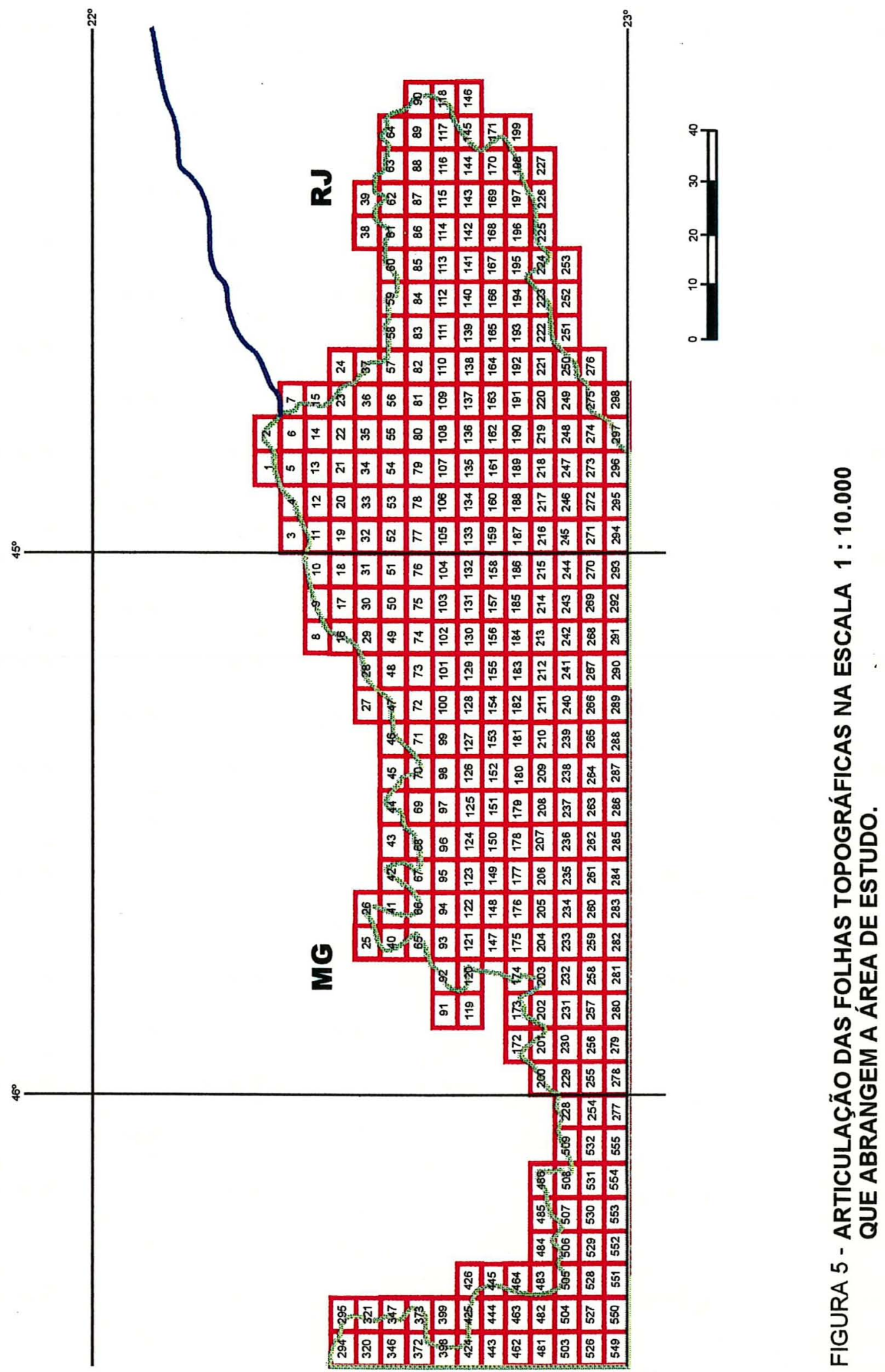

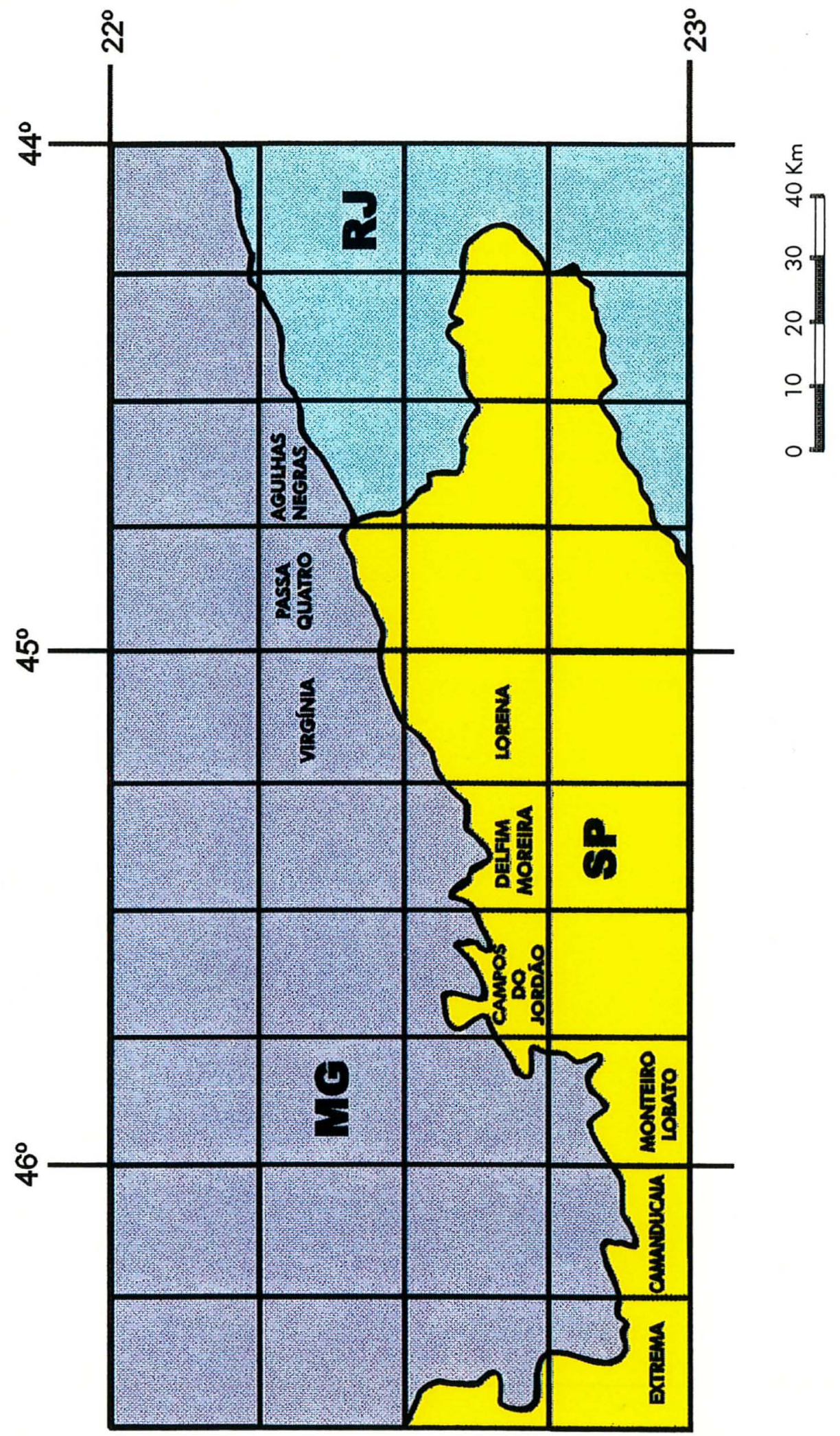

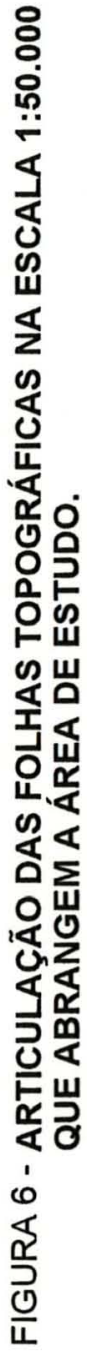




\section{DESENVOLVIMENTO TÉCNICO}

\subsection{Levantamento e mapeamento das trilhas}

Com auxílio do material descrito no capítulo $4 \mathrm{e}$ através de diversas visitas ao campo foi possível levantar e mapear os caminhos encontrados paralelos, próximos ou transversais à linha de cumeada.

O autor vem explorando e mapeando as trilhas da região deste 1985 , principalmente nas sete grandes elevações que se destacam: Morro do Lopo; Morro do Selado; Pedra do Baú; Parque Estadual de Campos do Jordão; Pico dos Marins e Itaguaré; Serra Fina e Parque Nacional de Itatiaia.

A partir do início do presente trabalho, além de ratificar tais mapeamentos, passou a explorar e mapear novos caminhos com objetivo de unir aquelas sete grandes elevações de destaque, através da grande Trilha.

5.2 Levantamento e mapeamento das unidades de conservação

Identificou-se e mapeou-se nos municípios atravessados pela Trilha da Mantiqueira as unidades de conservação existentes (FIGURA 7).

5.3 Levantamento e mapeamento de pontos de interesse turístico

Procedeu-se in loco o levantamento e mapeamento de cachoeiras, mirantes, pontos de água e áreas com potencial para acampamento (FIGURAS 9, 11, 13, 19, 22, 24, 27, 30, 33, 40, 43, 46, 50). 


\section{MINAS GERAIS}

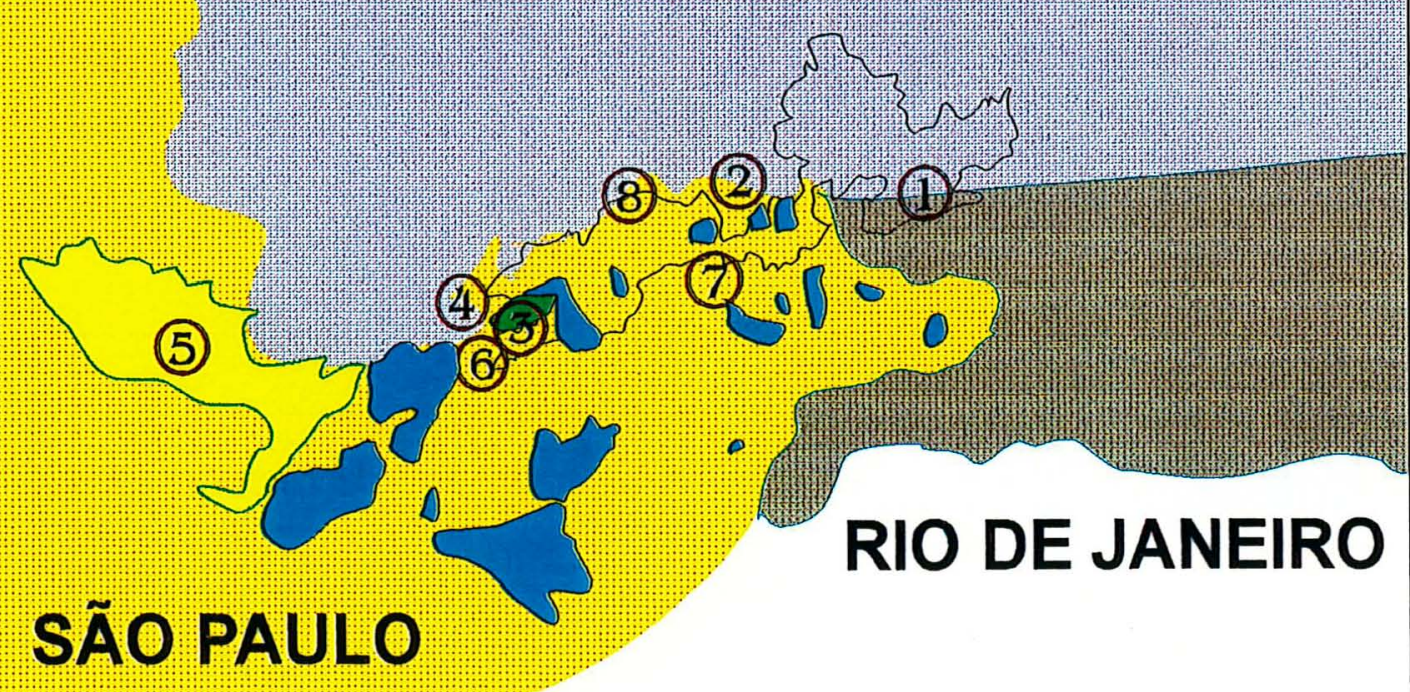

(1) PARQUE NACIONAL DE ITATIAIA

(2) FLORESTA NACIONAL DE PASSA QUATRO

(3) PARQUE ESTADUAL DE CAMPOS DO JORDÃO

(4) APA MUNICIPAL DA PEDRA DO BAÚ

५ (5) ÁREA II DA APA ESTADUAL PIRACICABA E JUQUERI-MIRIM

- (6) APA ESTADUAL DE CAMPOS DO JORDÃO

- (7) APA FEDERAL - MANANCIAIS DO VALE DO PARAÍBA DO SUL

s (8) APA FEDERAL DA SERRA DA MANTIQUEIRA

FIGURA 7 - UNIDADES DE CONSERVAÇÃO NA ÁREA DE ESTUDO. 


\subsection{Definição e descrição do traçado}

Na definição do traçado da trilha latu sensu levou-se em consideração as trilhas strictu sensu e estradas de terra, além de pequenos trechos onde se cruzam as rodovias pavimentadas. Para tanto adotou-se a seguinte convenção:

\section{ESTRADA}

Caminho de terra, onde trafegam, além do pedestre, veículos motorizados, para transporte de passageiros e/ou carga. Apresenta trânsito permanente ou temporário.

\section{TRILHA STRICTU SENSU}

Caminho de terra onde trafegam pedestres e não há condições para o tráfego de veículos motorizados, exceto motos, o que não seria aconselhável. Em alguns desses caminhos, no máximo seria desejável também o tráfego de muares e cavalos.

\section{TRILHA LATU SENSU}

É o percurso que se buscou definir na conjunção de diversas estradas e trilhas strictu sensu, cruzando-se por vezes estradas asfaltadas e até cidades como Joanópolis e Sapucai Mirim. Denominada de Trilha da Mantiqueira.

A extensão da Trilha da Mantiqueira foi calculada em aproximadamente 300 quilômetros, através de um sistema CAD (Computer Aided Design) AUTOCAD R12.

O traçado se mantém sempre próximo à Divisa São Paulo / Minas, no chamado maciço principal da serra como define LEITE, 1951 e foi definido e mapeado em croquis na escala aproximada 1:80.000 (FIGURAS 9, 11, 13, 19, 22, 24, 27, 30, 33, 40, $43,46,50)$, tomando-se por base folhas topográficas na escala 1:50.000, cuja articulação pode-se visualizar através da FIGURA 6, e 
plotado também sobre base topográfica na escala 1:1.000.000 (FIGURA'8).

\section{Trecho 1}

Locáliza-se entre as coordenadas UTM 358 e 372 da folha topográfica EXTREMA (FIGURA 9). Pode-se considerar como início da Trilha da Mantiqueira, a Pedra do Lopo ou da Extrema $(1.568 \mathrm{~m})$ (FIGURA 10), no município de Vargem (SP). Destaca-se também, nesse trecho, a Pedra da Guaraiúva $(1.669 \mathrm{~m})$ e a Pedra das Flores $(1.792 \mathrm{~m})$.Todos três integram a Serra do Lopo, também conhecida nas contendas pela definição da Divisa São Paulo e Minas Gerais, como Morro do Lopo, que segundo MORAES FILHO \& CARDOSO (1920), entrava em cena como localização principal da fronteira. $O$ croqui relativo a esse trecho engloba as áreas urbanas de Extrema (MG) e Joanópolis (SP).

O acesso ao início da Trilha da Mantiqueira pode-se dar através da Rodovia Fernão Dias - BR 381, de duas maneiras: a) Um kilometro antes da Divisa SP/MG, sentido São Paulo - Belo Horizonte. entra-se em estrada de terra na direção de Joanópolis, percorrendo-se $12 \mathrm{~km}$ até o bairro do Lopo, quando então, também por terra, após $2 \mathrm{~km}$ se alcança a Pedra do Lopo; e b) a partir da cidade mineira de Extrema, busca-se 0 alto da serra até as proximidades da Pedra das Flores.

No alto caminha-se ora por trilhas, ora por estradas e a descida da serra até Joanópolis se dá por estrada de terra, cidade a qual se cruza em direção a São Francisco Xavier. Nesse trecho a Trilha da Mantiqueira se estende por 18,2 km. 


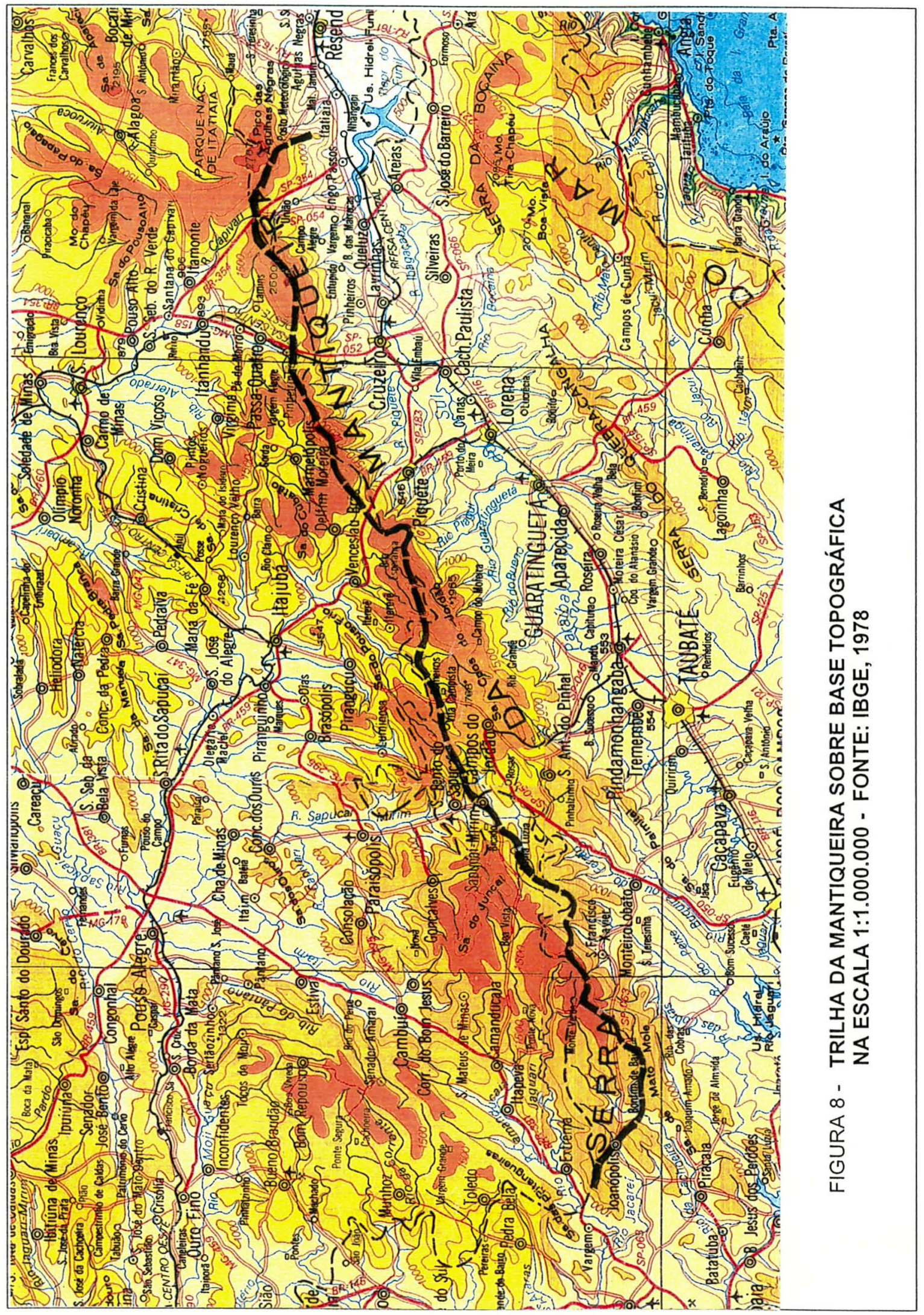




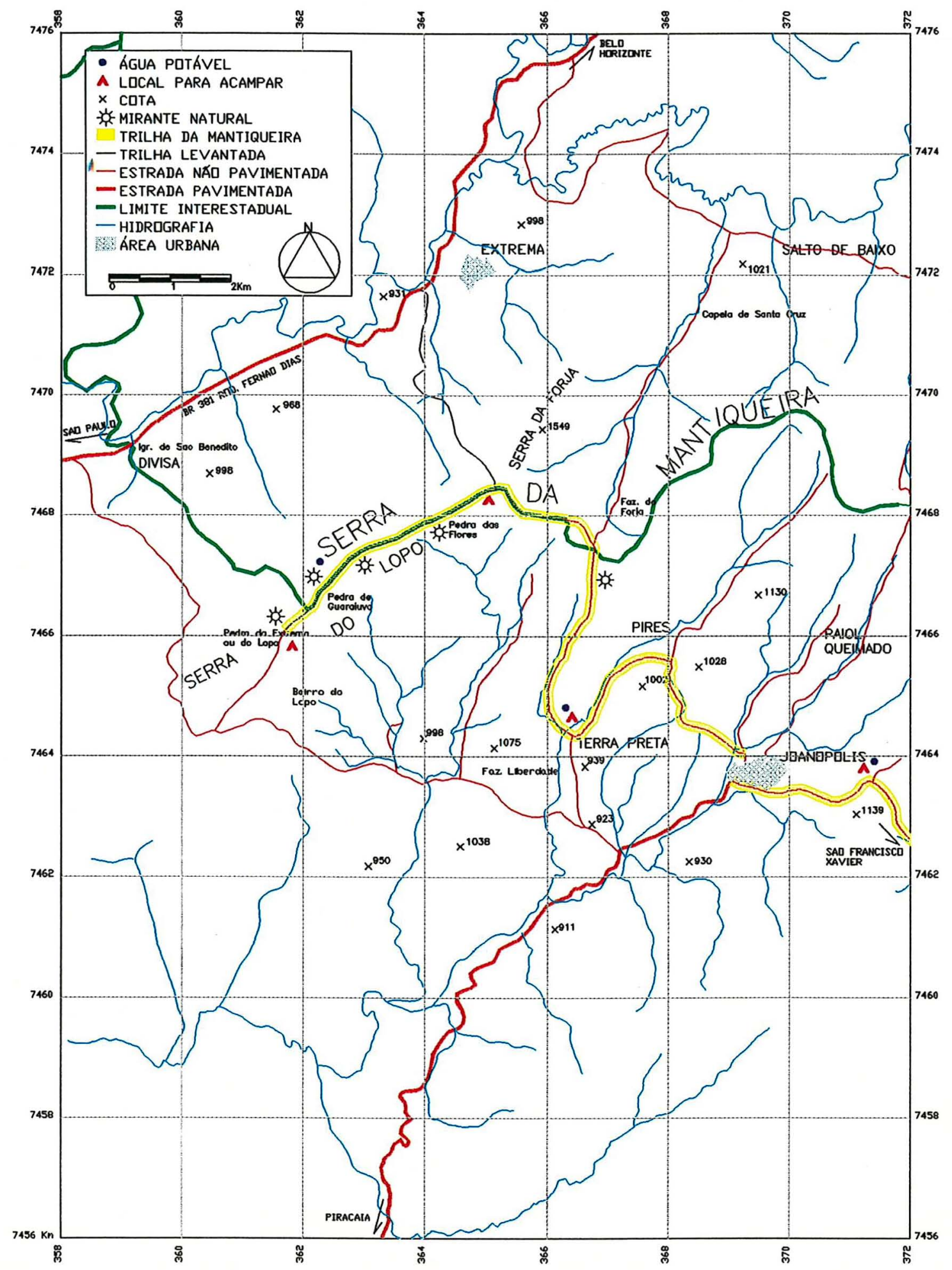

FIGURA 9 : Trecho 1 da Trilha da Mantiqueira. 


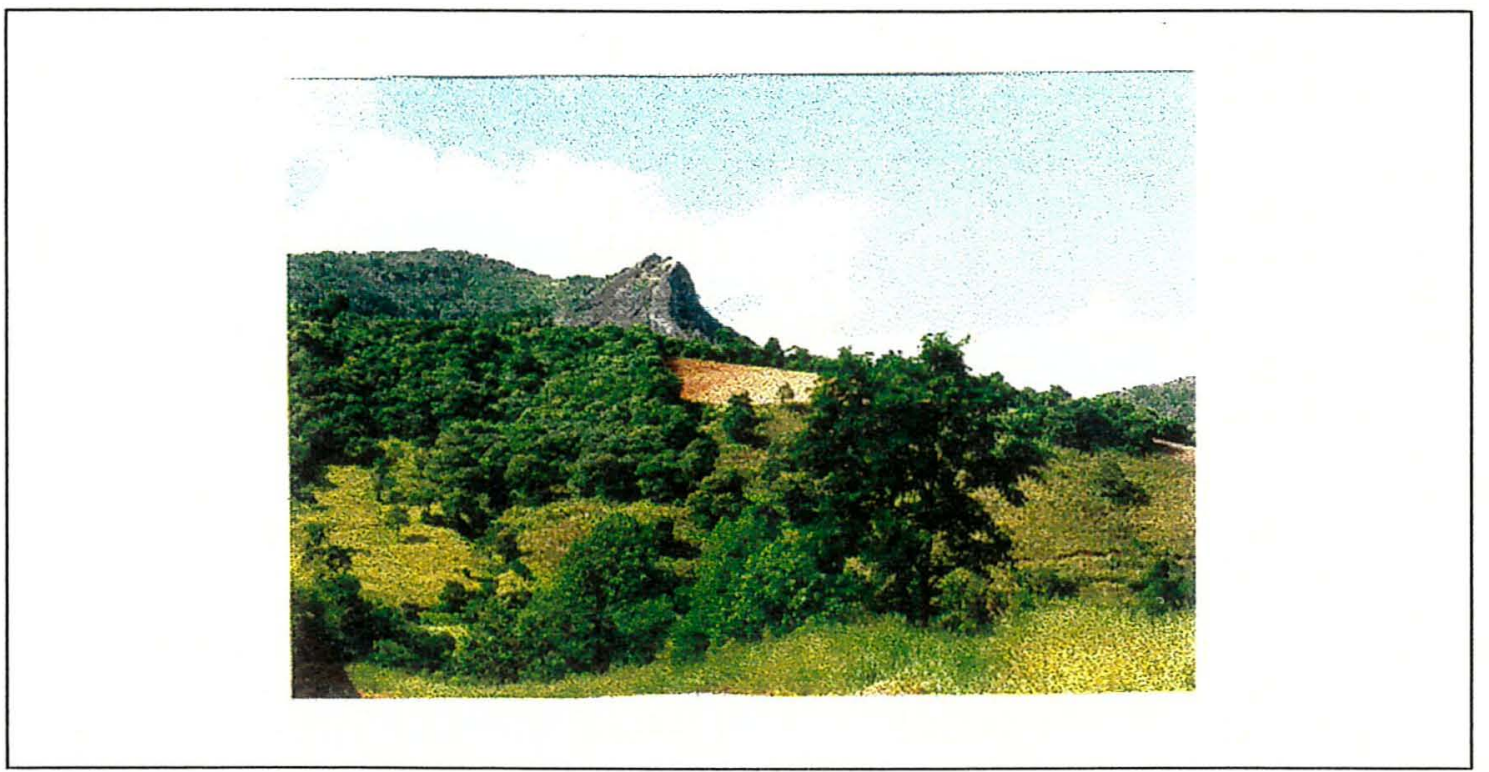

Figura 10 - Pedra do Lopo

\section{Trecho 2}

Localiza-se entre as coordenadas 372 e 386 da folha topográfica CAMANDUCAIA (FIGURA 11). Como pontos de interesse turístico pode-se destacar o Salto dos Pretos (queda d'água de aproximadamente 30 metros de altura) (FIGURA 12) e o próprio rio dos Pretos ou da Cachoeira. O acesso a esse trecho, de 20,2 km, se dá a partir das cidades paulistas Joanópolis ou São Francisco Xavier

\section{Trecho 3}

Localiza-se entre as coordenadas 384 e 398 da folha topográfica CAMANDUCAIA (FIGURA 13). Destaca-se, nesse trecho, a Pedra do Carmo (1.482 m) (FIGURA 14), a Serra dos Poncianos com as elevações Pedra do Selado (2.082 m) (FIGURA 15), Chapéu do Bispo (1.900 m) (FIGURA 16), Pedra Redonda $(2.000 \mathrm{~m})$ e Pedra Partida (2.080 m) (FIGURA 17). No croqui desse trecho está inserida a cidade de Monte Verde (FIGURA 18). O acesso a esse trecho, de $20,7 \mathrm{~km}$, pode se dar por Joanópolis, S. F. Xavier ou Monte Verde (MG). 


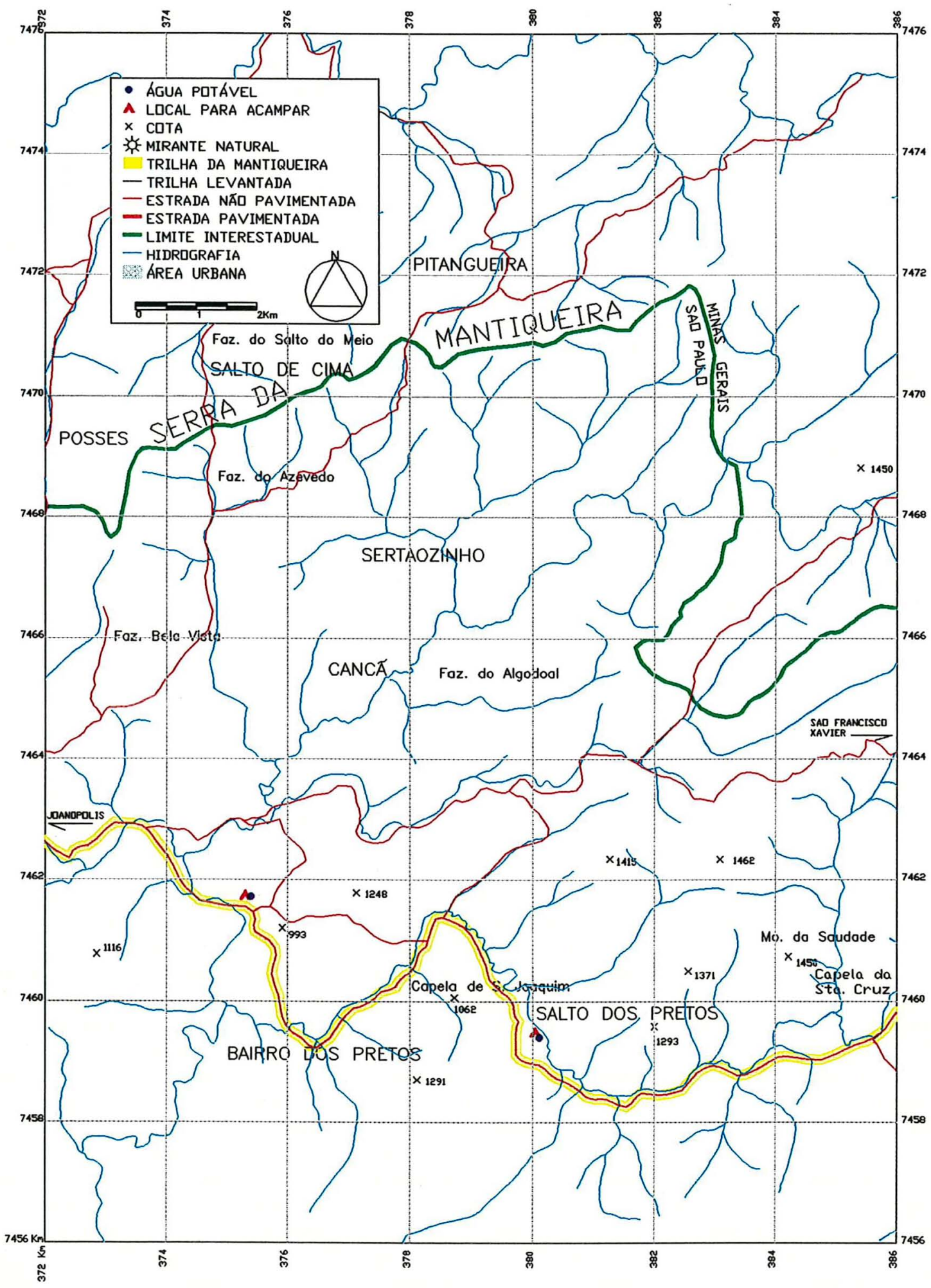

FIGURA 11: Trecho 2 da Trilha da Mantiqueira. 


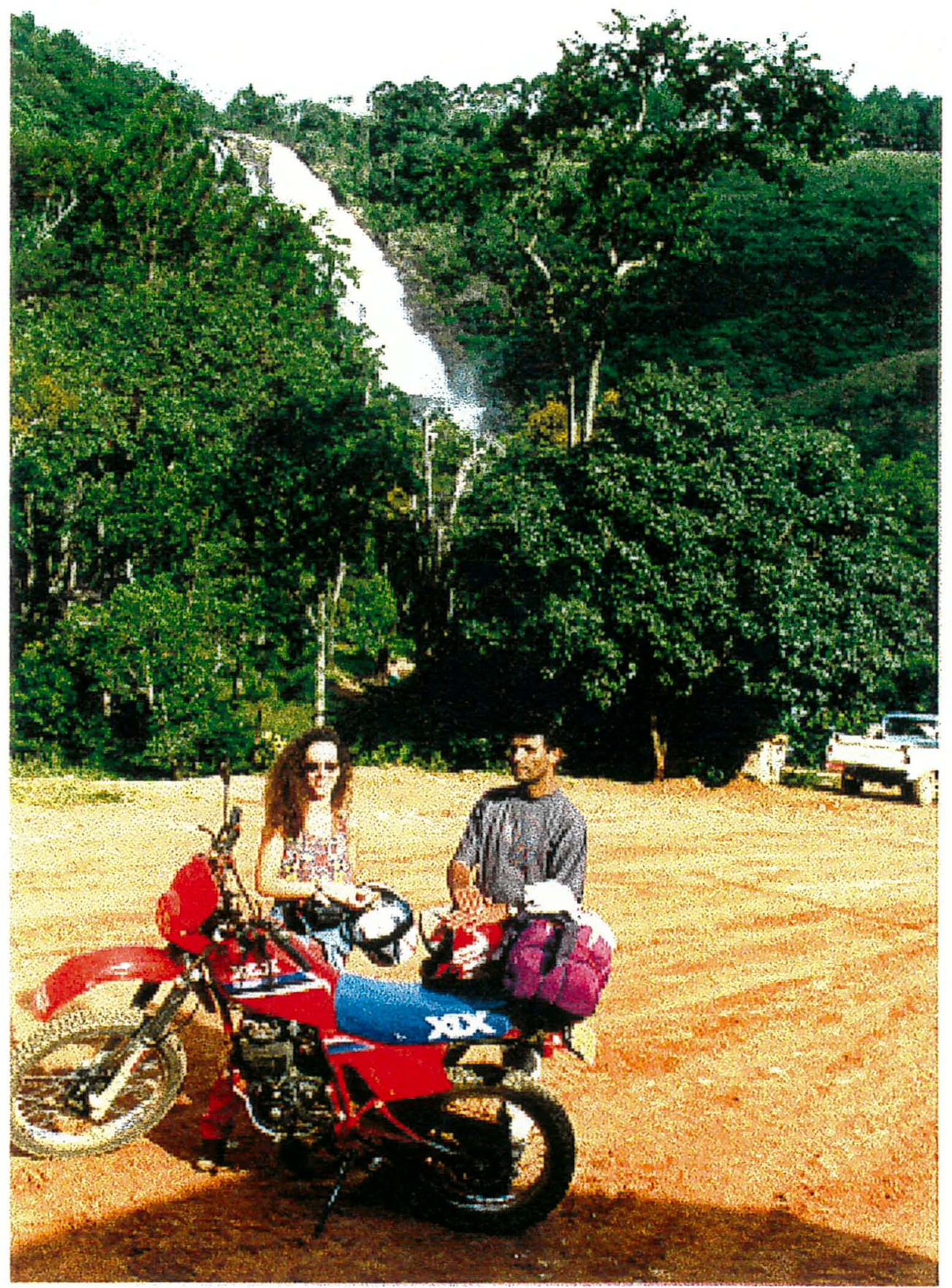

Figura 12 - Salto dos Pretos 


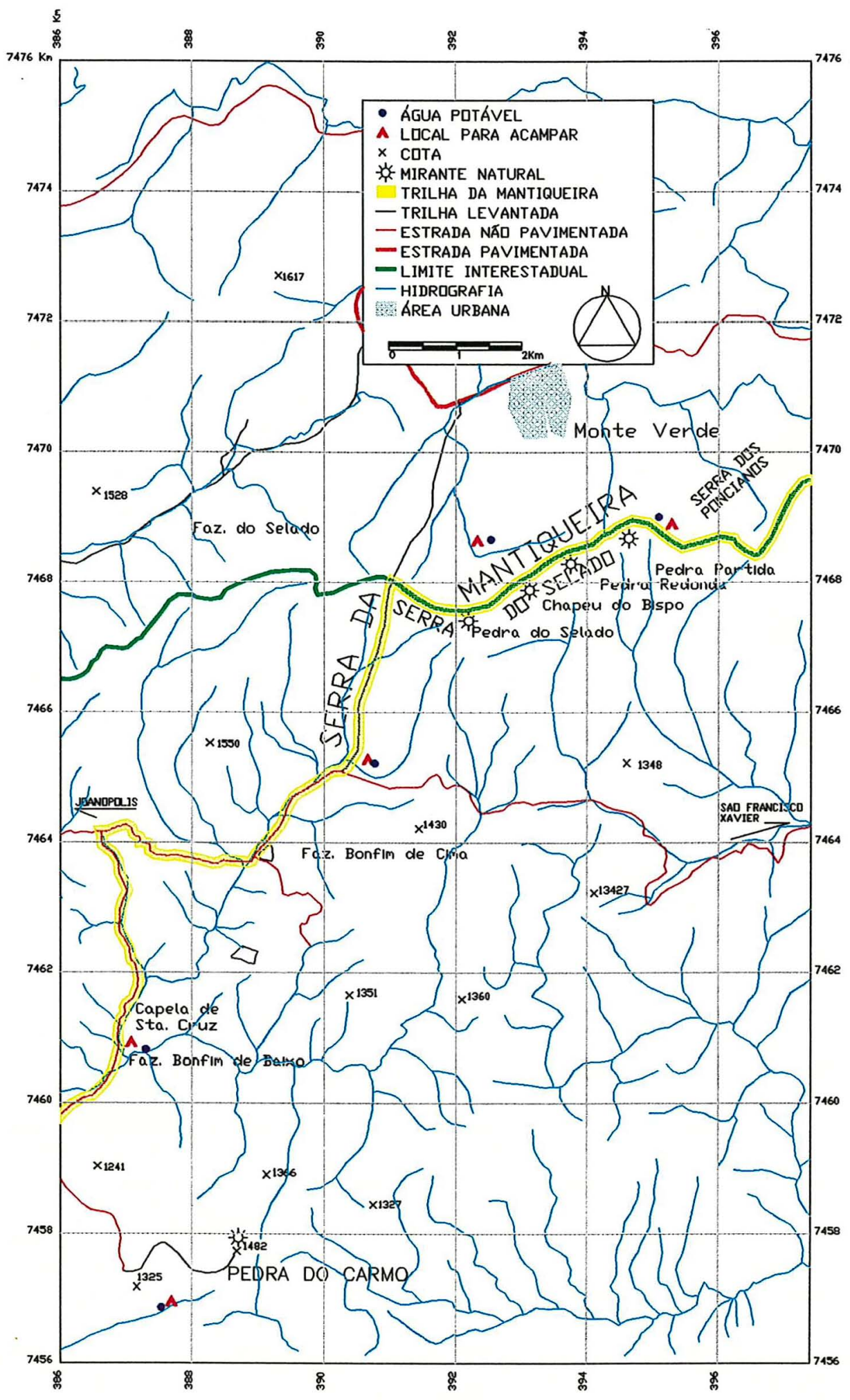

FIGURA 13: Trecho 3 da Trilha da Mantiqueira. 


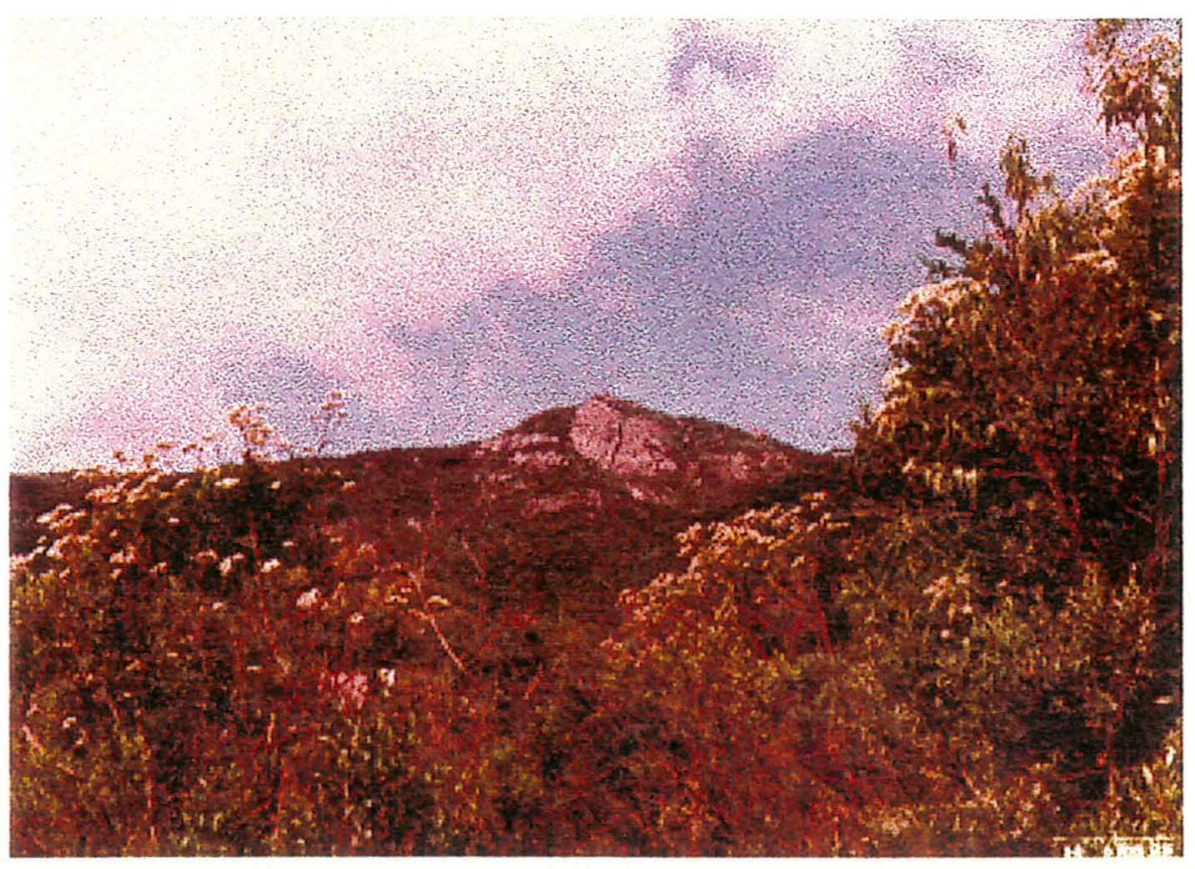

Figura 14 - Pedra do Carmo

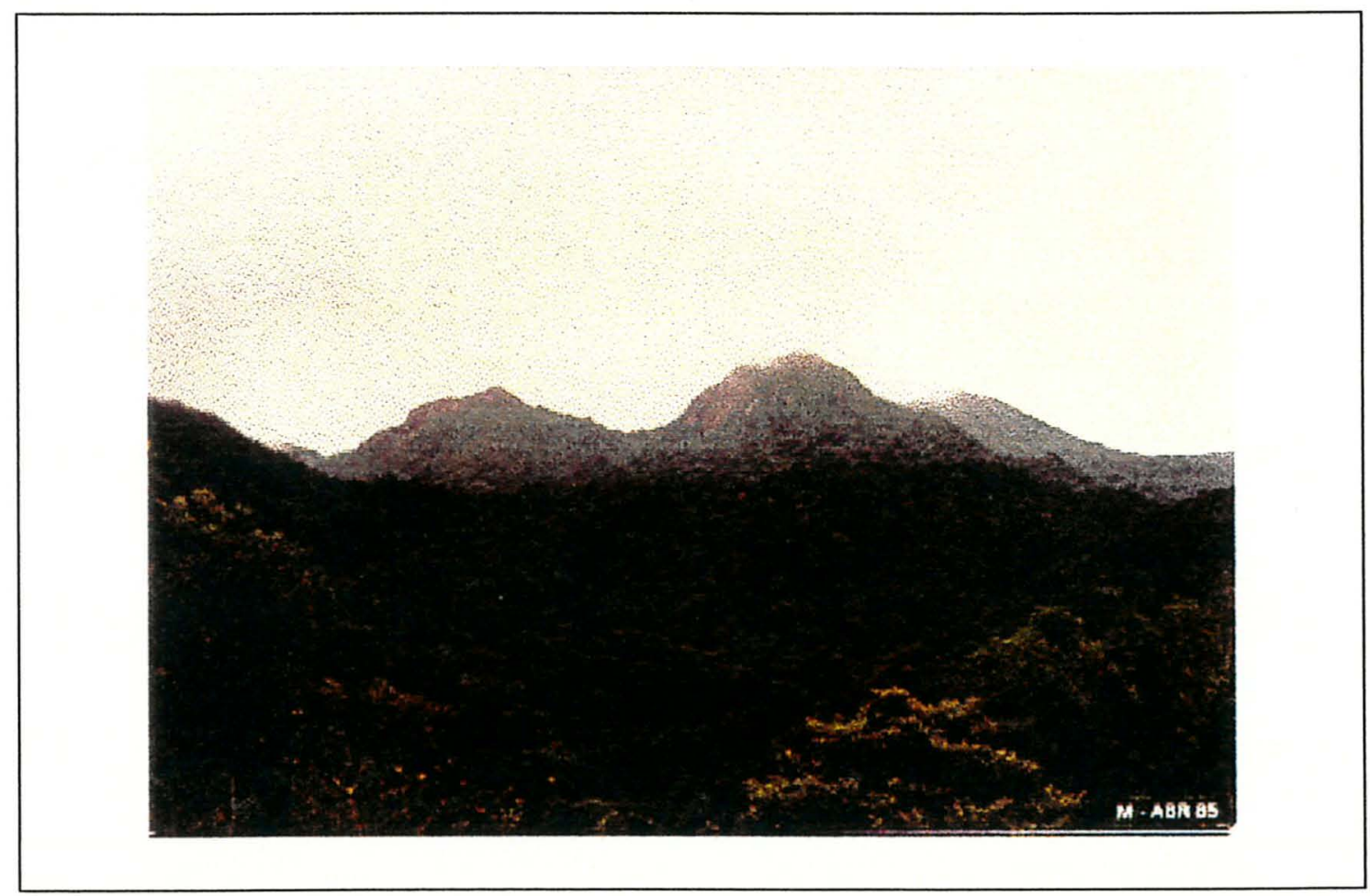

Figura 15 - Pedra do Selado 


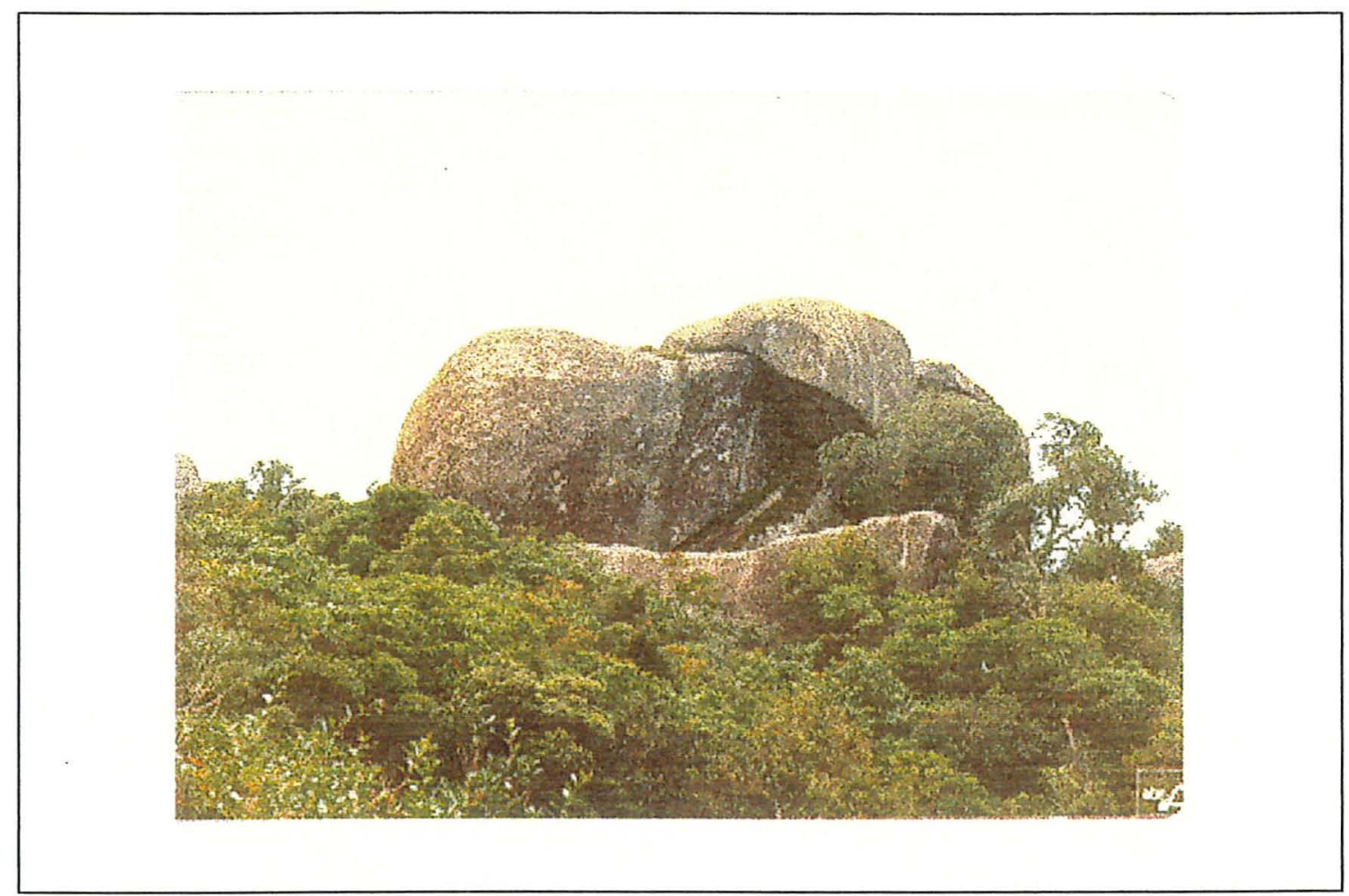

Figura 16 - Chapéu do Bispo

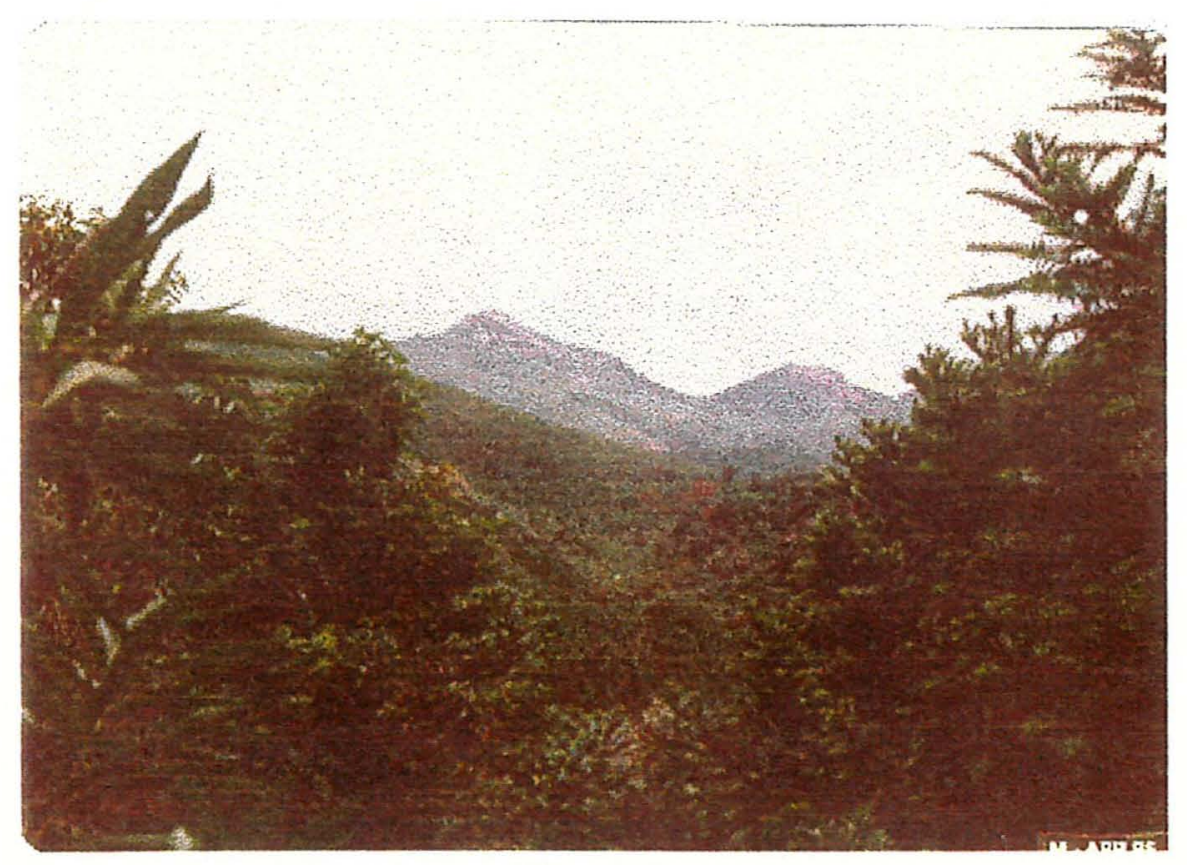

Figura 17 - Pedra Redonda e Pedra Partida 


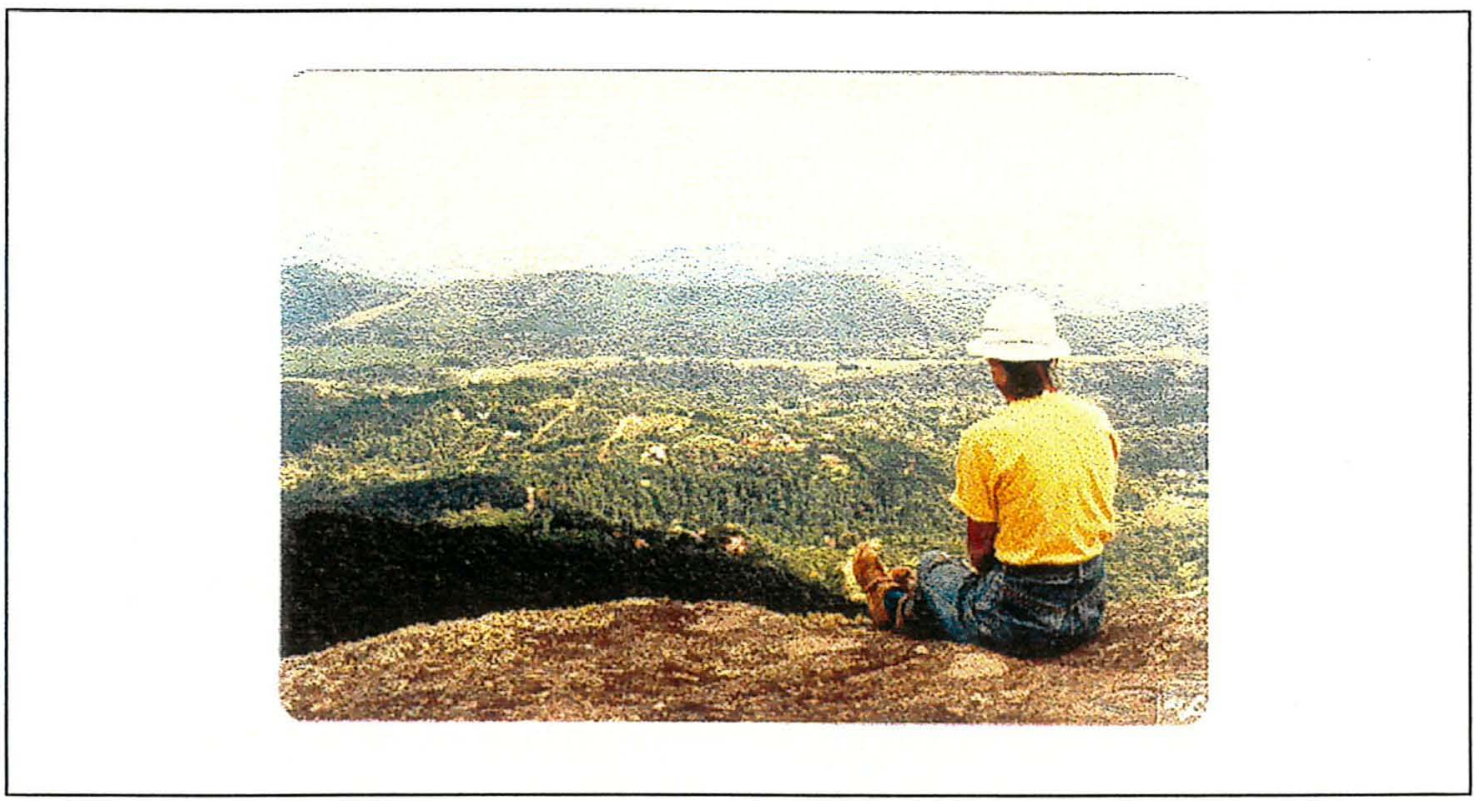

Figura 18 - Vista de Monte Verde desde a Pedra Redonda

\section{Trecho 4}

Localiza-se entre as coordenadas 398 e 410 da folha topográfica MONTEIRO LOBATO (FIGURA 19). Destaca-se nesse trecho, além da cidade de São Francisco Xavier (FIGURA 20), a Serra da Pedra Vermelha (1.876 m) (FIGURA 21).

O acesso a esse trecho, de 18,9 km, pode se dar por Monte Verde (MG) ou São Francisco Xavier (SP). Daí pela rua que leva ao serviço de abastecimento de água da cidade seguir sempre no sentido noroeste até o alto da serra, passando pelo antigo Rancho dos Boiadeiros. Para quem estiver em Monte Verde deve seguir pelo caminho das montanhas até encontrar a Pedra do Selado, Chapéu do Bispo, Pedra Redonda ou Pedra Partida (localizados no trecho 3) e seguir para leste até adentrar o trecho 4.

No alto da serra segue-se por trilha propriamente dita até a descida da Pedra Vermelha, quando por estrada de terra segue-se no sentido do alto da serra (Divisa São Paulo / Minas Gerais - São José dos Campos / Sapucaí Mirim). Deve-se descer por essa estrada de terra e adentrar o trecho 5. 


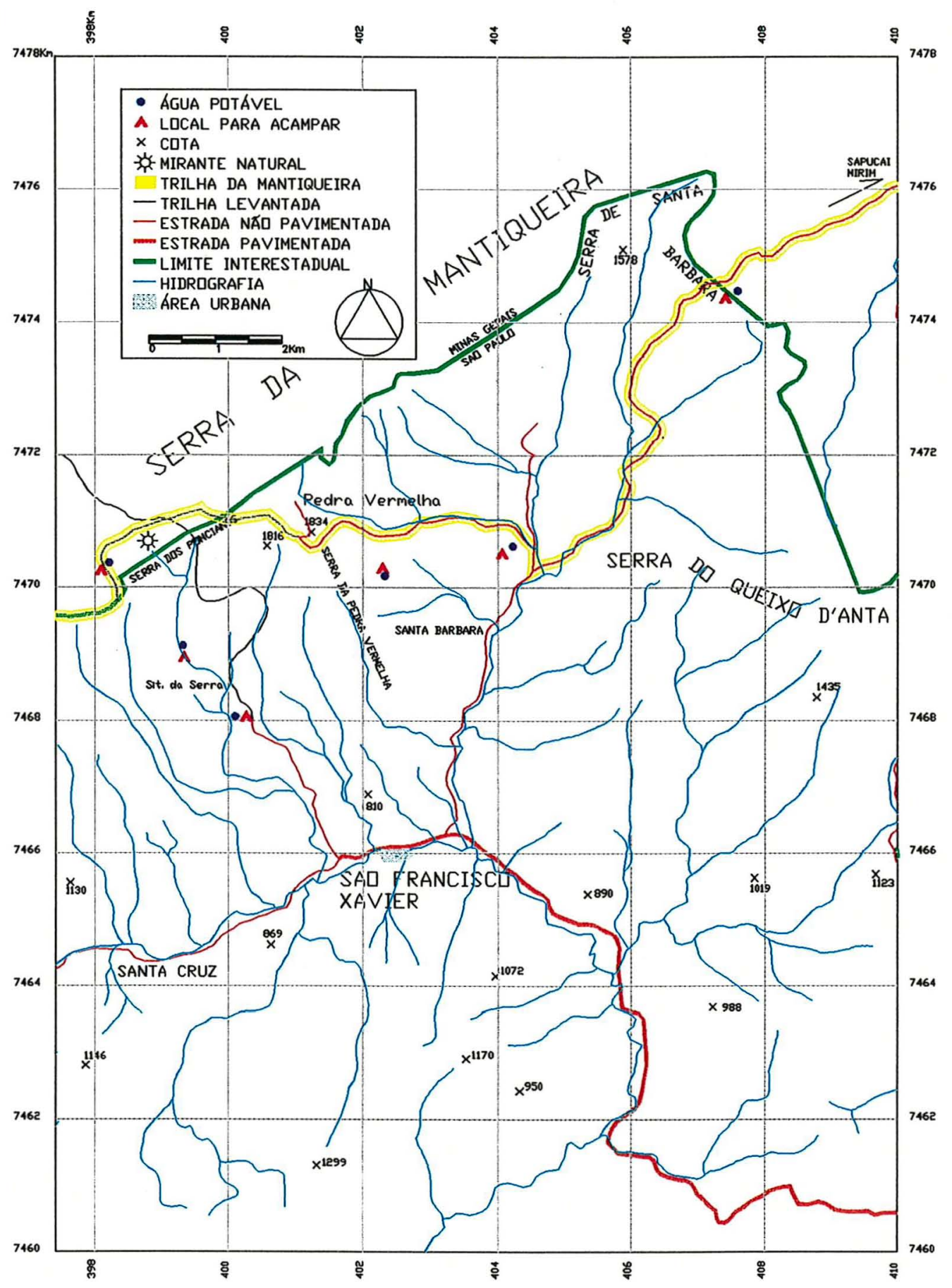

FIGURA 19: Trecho 4 da Trilha da Mantiqueira. 


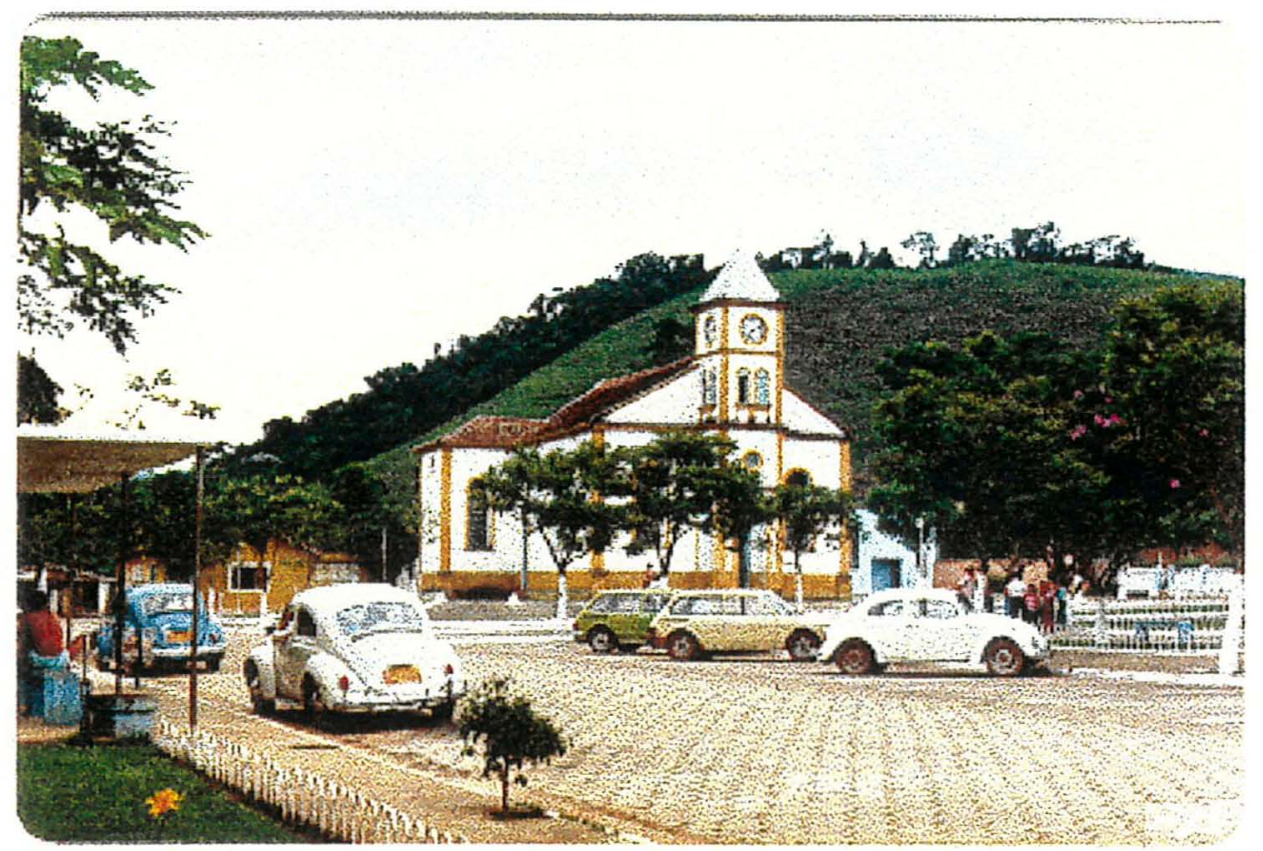

Figura 20 - São Francisco Xavier (Praça da Matriz)

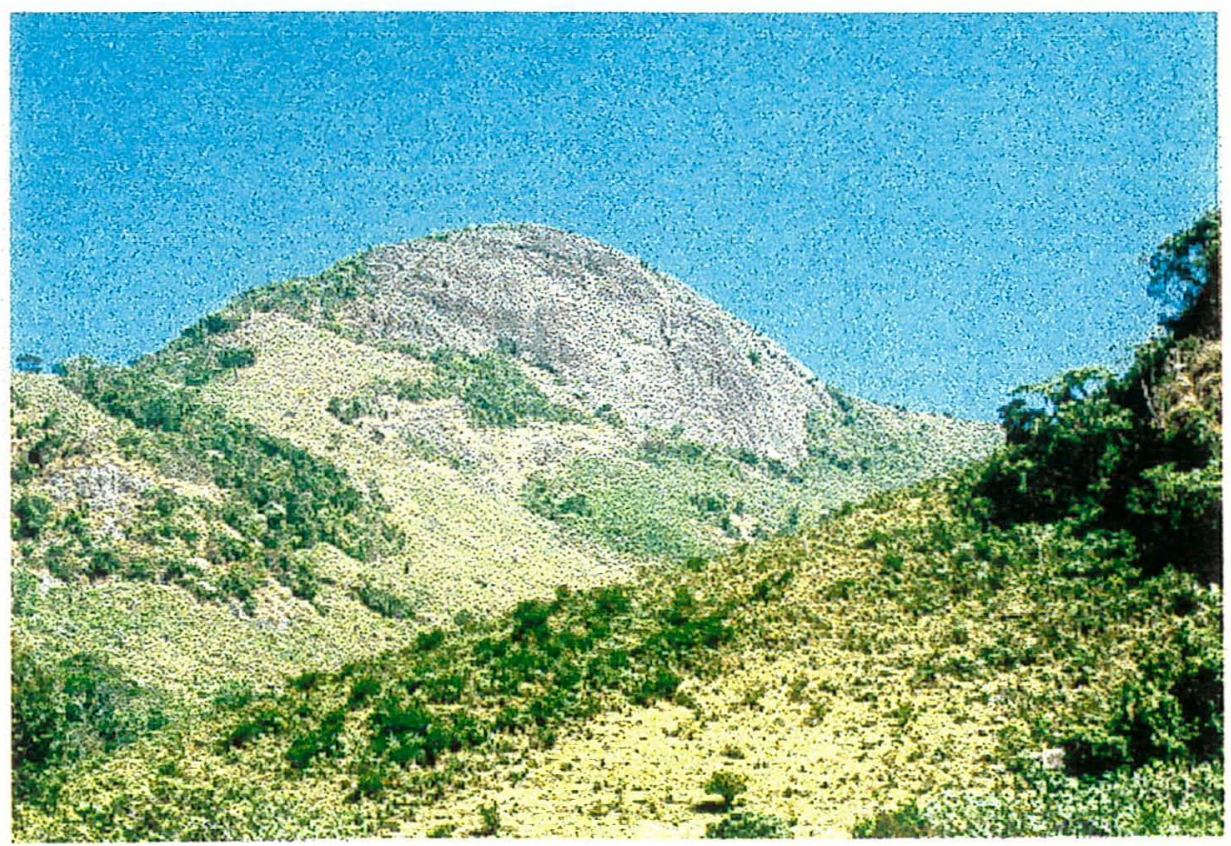

Figura 21 - Pedra Vermelha 


\section{Trecho 5}

Localiza-se entre as coordenadas 410 e 424 da folha topográfica MONTEIRO LOBATO (FIGURA 22). Destaca-se o bairro de Santa Luzia (FIGURA 23), município de Sapucaí-Mirim (MG), nas proximidades da Serra das Posses.

O acesso pode se dar de duas maneiras a saber: a) por São Francisco Xavier (SP), quando após $2 \mathrm{~km}$ pela estrada asfaltada de Monteiro Lobato, entra-se a esquerda, por terra, até o alto da serra, no sentido do Bairro Santa Luzia, já no município de Sapucaí Mirim (MG); ou b) por Sapucaí Mirim (MG), às margens da rodovia que liga São José dos Campos (SP) ao sul de Minas,SP 050, seguindo no sentido de Santa Luzia.

$19,5 \mathrm{~km}$.

Nesse trecho a Trilha da Mantiqueira se estende por

\section{Trecho 6}

Localiza-se entre as coordenadas 422 e 436 da folha topográfica CAMPOS DO JORDÃO (FIGURA 24), engloba as cidades de Sapucaí-Mirim (MG) e São Bento do Sapucaí (SP). O grande destaque desse trecho, onde a Trilha se estende por 19,5 $\mathrm{km}$, é a Pedra do Baú $(1.800 \mathrm{~m}$ ) (FIGURA 25) e seus vizinhos próximos Bauzinho e Ana Chata, além do acampamento Paiol Grande e a Cachoeira do Toldi (FIGURA 26).

O acesso a esse trecho se dá por Sapucaí Mirim (MG) ou São Bento do Sapucaí (MG), quando nas proximidades do córrego do Monjolinho deve-se seguir por estrada de terra até a Fazenda Monjolinho. Depois, por trilha alcança-se a crista da serra nas proximidades da Pedra Ana Chata.

Nesse trecho há vários locais possíveis para acampamento rústico com água boa e farta todo o ano. 


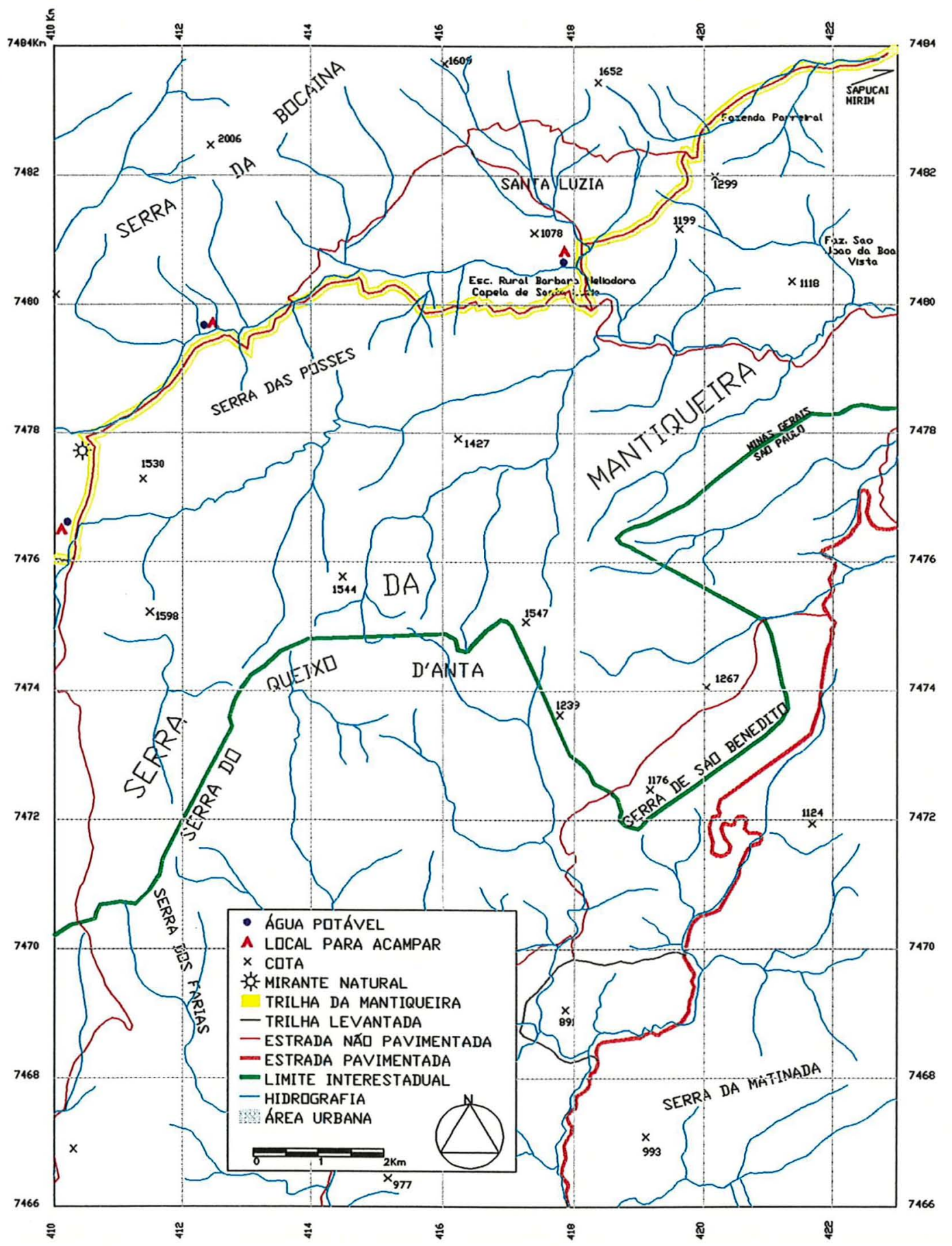

FIGURA 22: Trecho 5 da Trilha da Mantiqueira. 


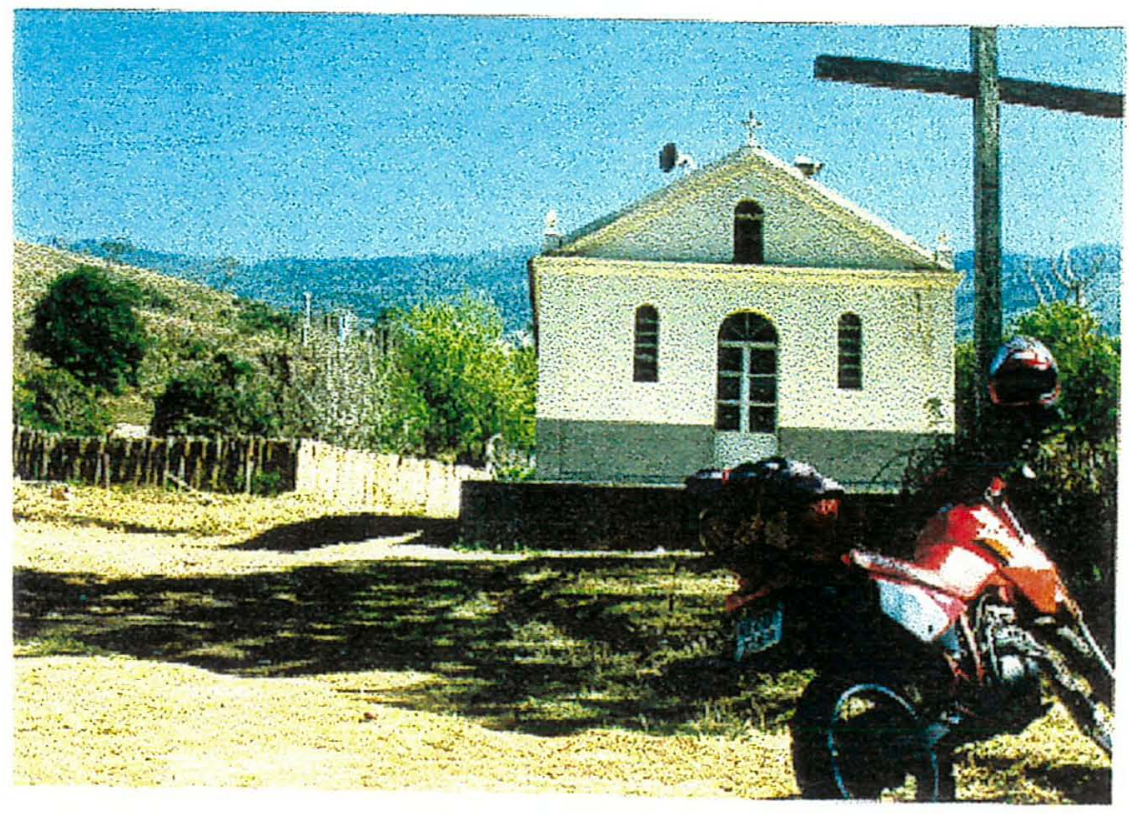

Figura 23 - Bairro de Santa Luzia

\section{Trecho 7}

Localiza-se entre as coordenadas 436 e 450 da folha topográfica CAMPOS DO JORDÃO (FIGURA 27), englobando a cidade de Campos do Jordão (SP). A Trilha da Mantiqueira passa ao norte da cidade e nesse trecho, no qual ela se estende por $21,2 \mathrm{~km}$, se destacam o Pesqueiro da Montanha (FIGURA 28), a serra da Água Santa e o Bairro do Centro (FIGURA 29). No extremo leste desse trecho a trilha adentra o Parque Estadual de Campos do Jordão (P.E.C.J.).

O acesso a esse trecho pode-se dar por duas maneiras a saber: a) por São Bento do Sapucaí (SP), onde se pode alcançar a Pedra do Baú e caminhar pela Trilha da Mantiqueira por aproximadamente quatro quilômetros, adentrando-se assim, a porção oeste do setor; ou b) por Campos do Jordão pela estrada para a Pedra do Baú, via Fazenda Campista, encontrando-se a Trilha da Mantiqueira nas proximidades da coordenada 438. Nesse ponto a 


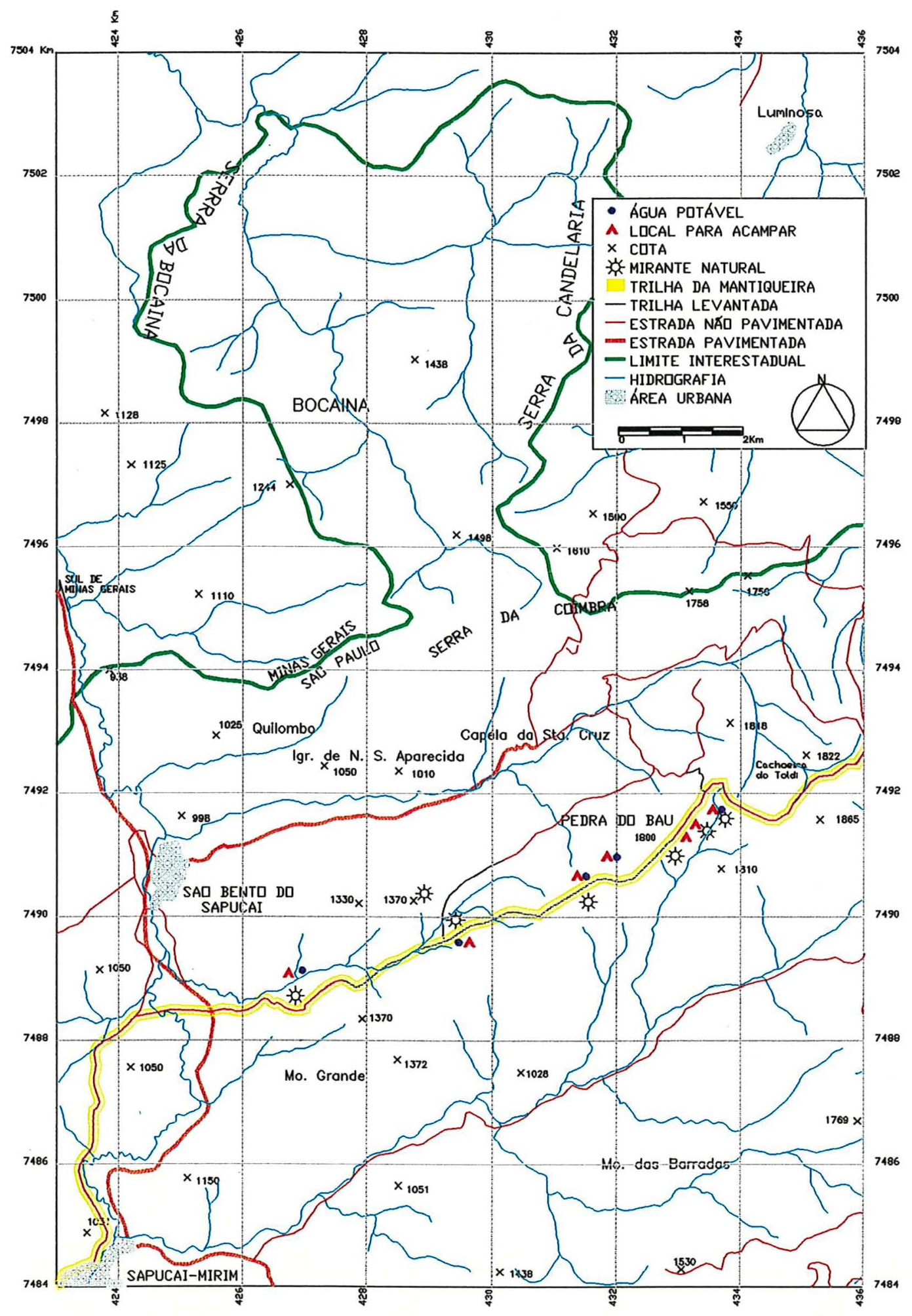

FIGURA 24: Trecho 6 da Trilha da Mantiqueira. 


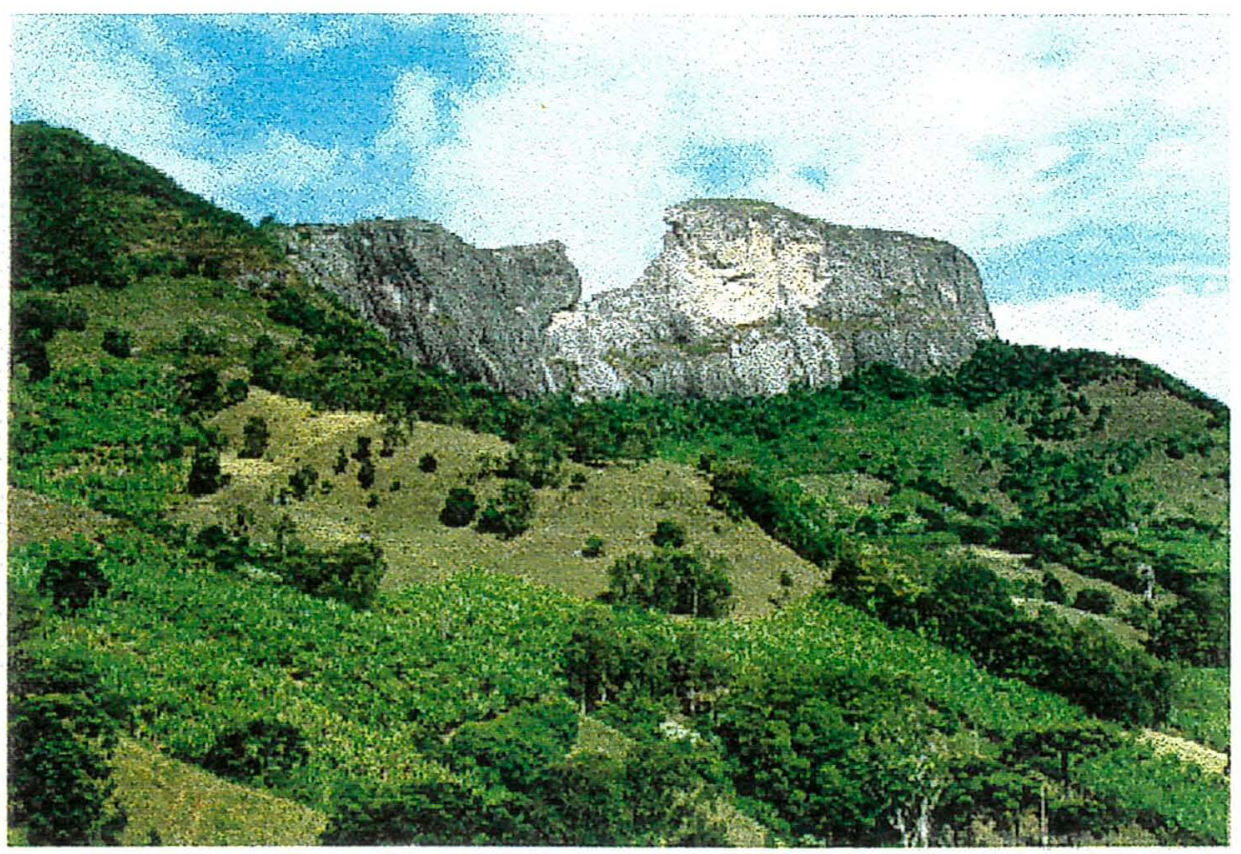

Figura 25 - Pedra do Baú

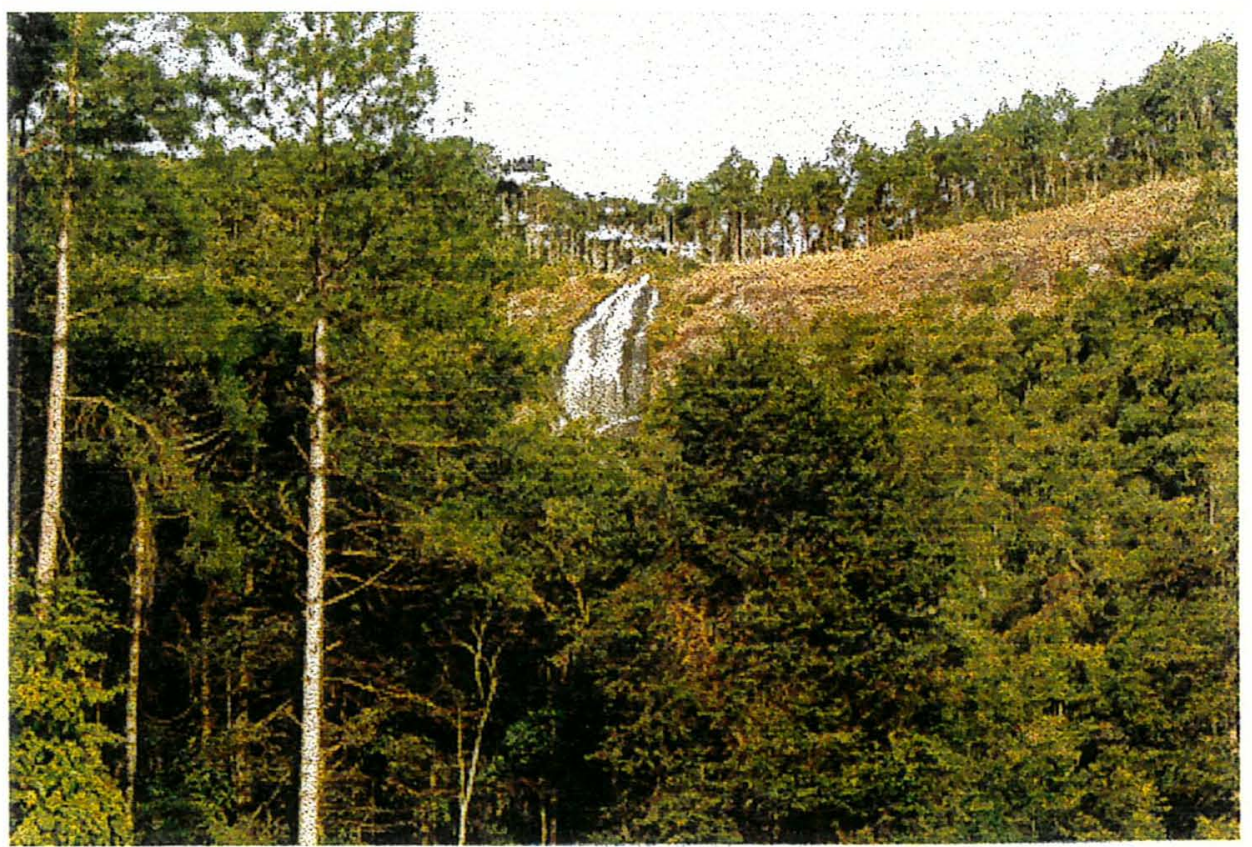

Figura 26 - Cachoeira do Toldi 


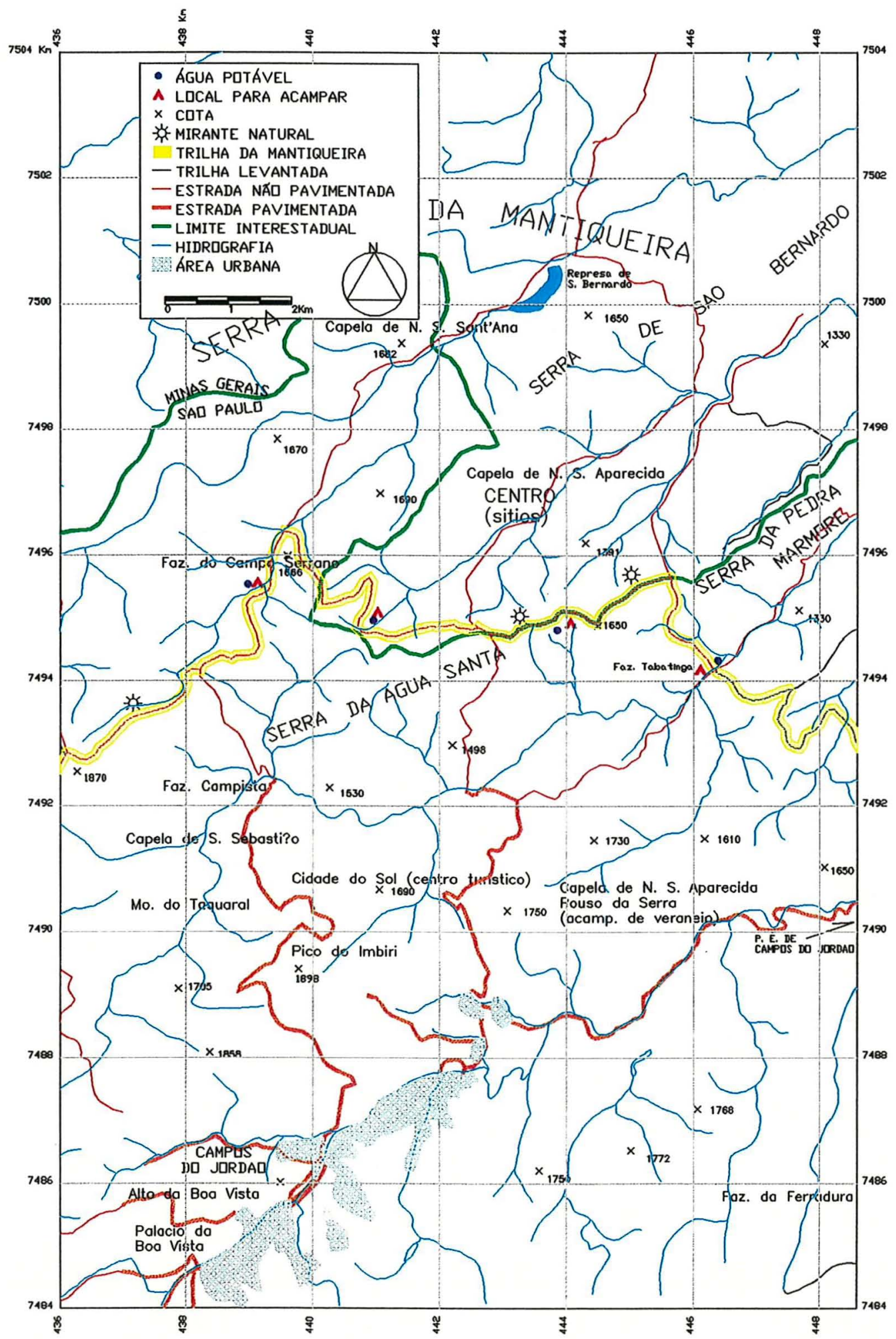

FIGURA 27: Trecho 7 da Trilha da Mantiqueira. 


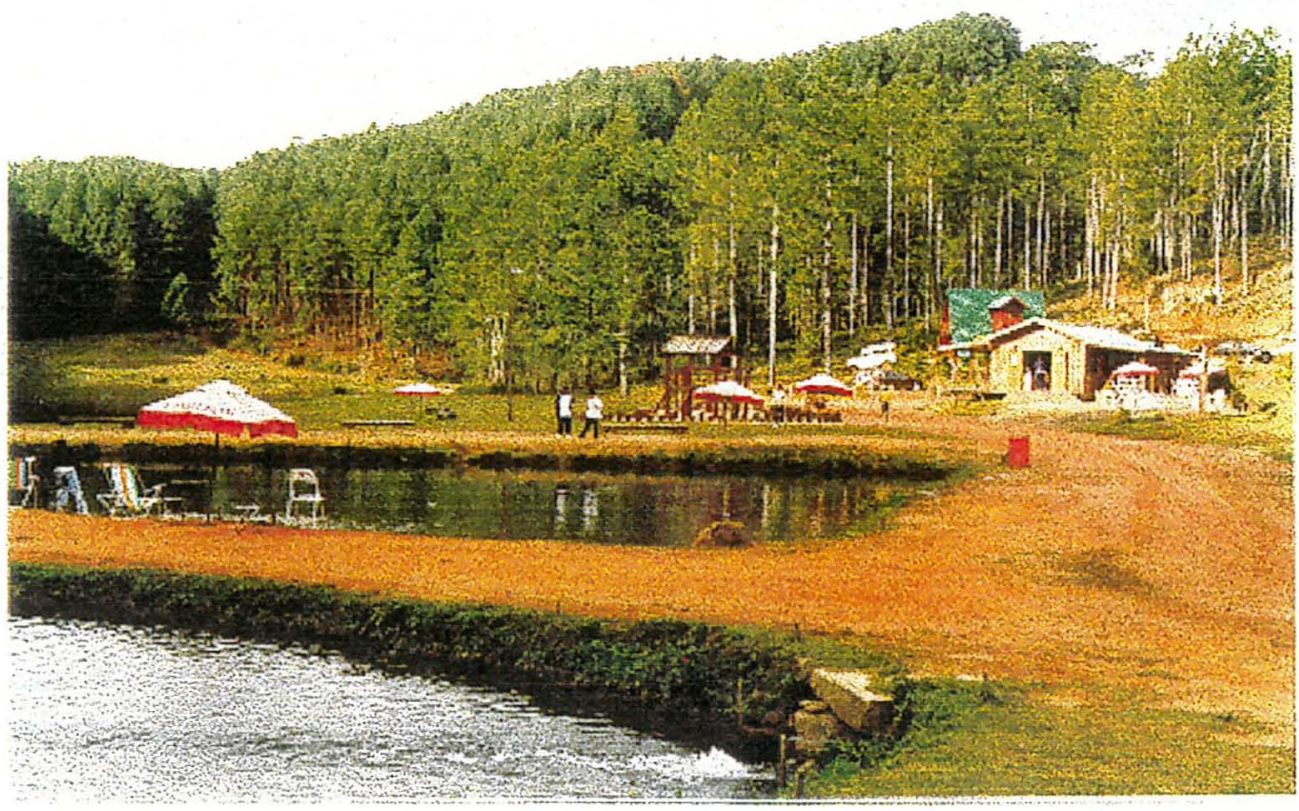

Figura 28 - Pesqueiro da Montanha

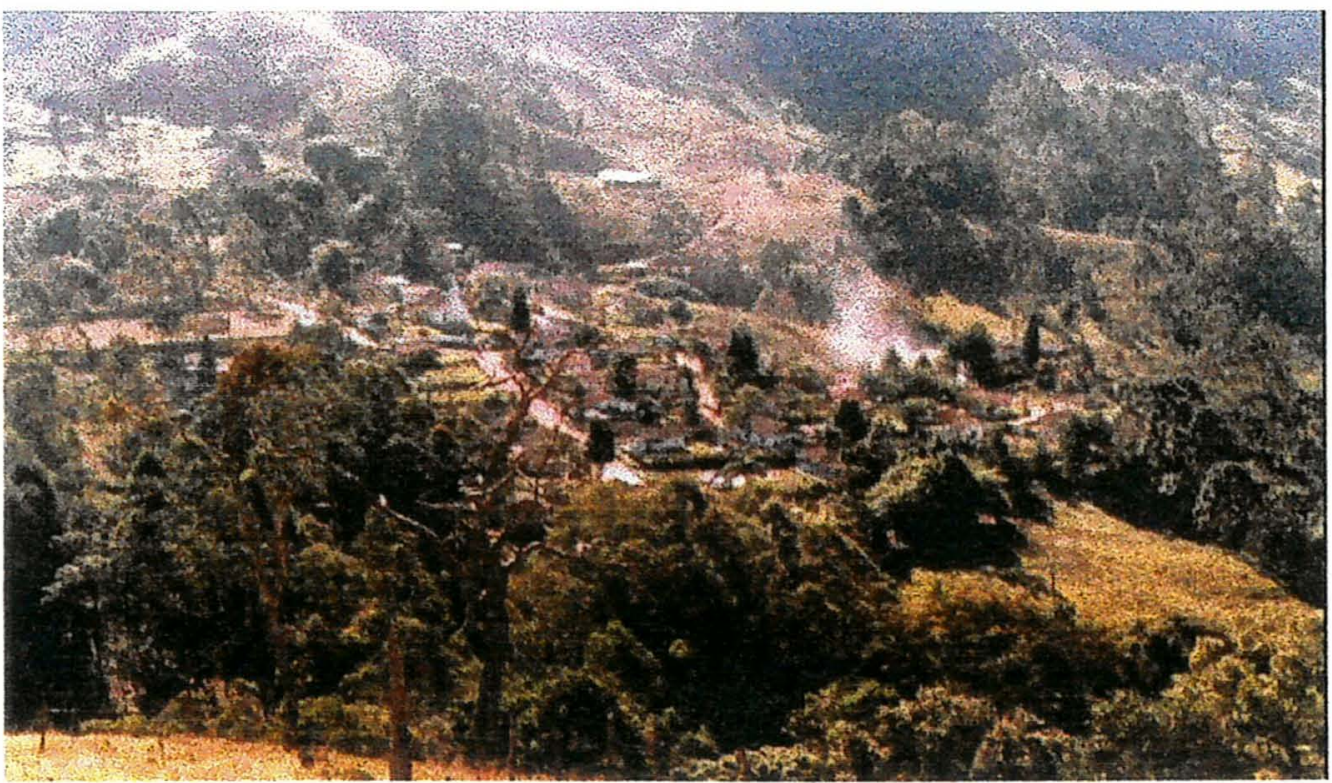

Figura 29 - Bairro do Centro 
Trilha da Mantiqueira segue por estrada de terra no sentido nordeste por aproximadamente 3 quilômetros até encontrar a Fazenda Campo Serrano. Logo após à direita deve-se entrar pela Fazenda do Jacú e seguir pela linha de Divisa SP/MG, passando-se pelo Morro da Pedra do Centro, quando após pouco mais de 1 quilometro a grande trilhà desce no sentido da Fazenda Tabatinga. Daí a Trilha da Mantiqueira volta a subir na direção sudeste adentrando o Parque Estadual, como dito anteriormente, em direção ao trecho 8.

\section{Trecho 8}

Localiza-se entre as coordenadas 448 e 462 da folha topográfica DELFIM MOREIRA (FIGURA 30). A trilha adentra esse trecho pelo P.E.C.J. (FIGURA 31) - seu grande destaque atravessando-o para alcançar a Fazenda da Lavrinha, nas proximidades da localidade conhecida como São José dos Alpes (FIGURA 32), de onde se descortinam vistas belíssimas do vale do rio Paraíba.

A Trilha da Mantiqueira adentra o Parque Estadual por antigo caminho que ligava uma região dessa Unidade de Conservação, conhecida por Paiol, à Fazenda Tabatinga - região hoje coberta por reflorestamento de coníferas exóticas, manejado de forma a propiciar o retorno da vegetação nativa. A Trilha da Mantiqueira segue na direção da sede do Parque para depois se sobrepor à Trilha da Cachoeira até o Recanto das Mimosas, a partir de onde se confunde com a Trilha da Pedra Moura até a Fazenda Lavrinhas, além dos limites do Parque. Nesse trecho, o mais longo de todos, a Trilha da Mantiqueira se estende por $29,8 \mathrm{~km}$, e o acesso é pela cidade paulista de Campos do Jordão. 


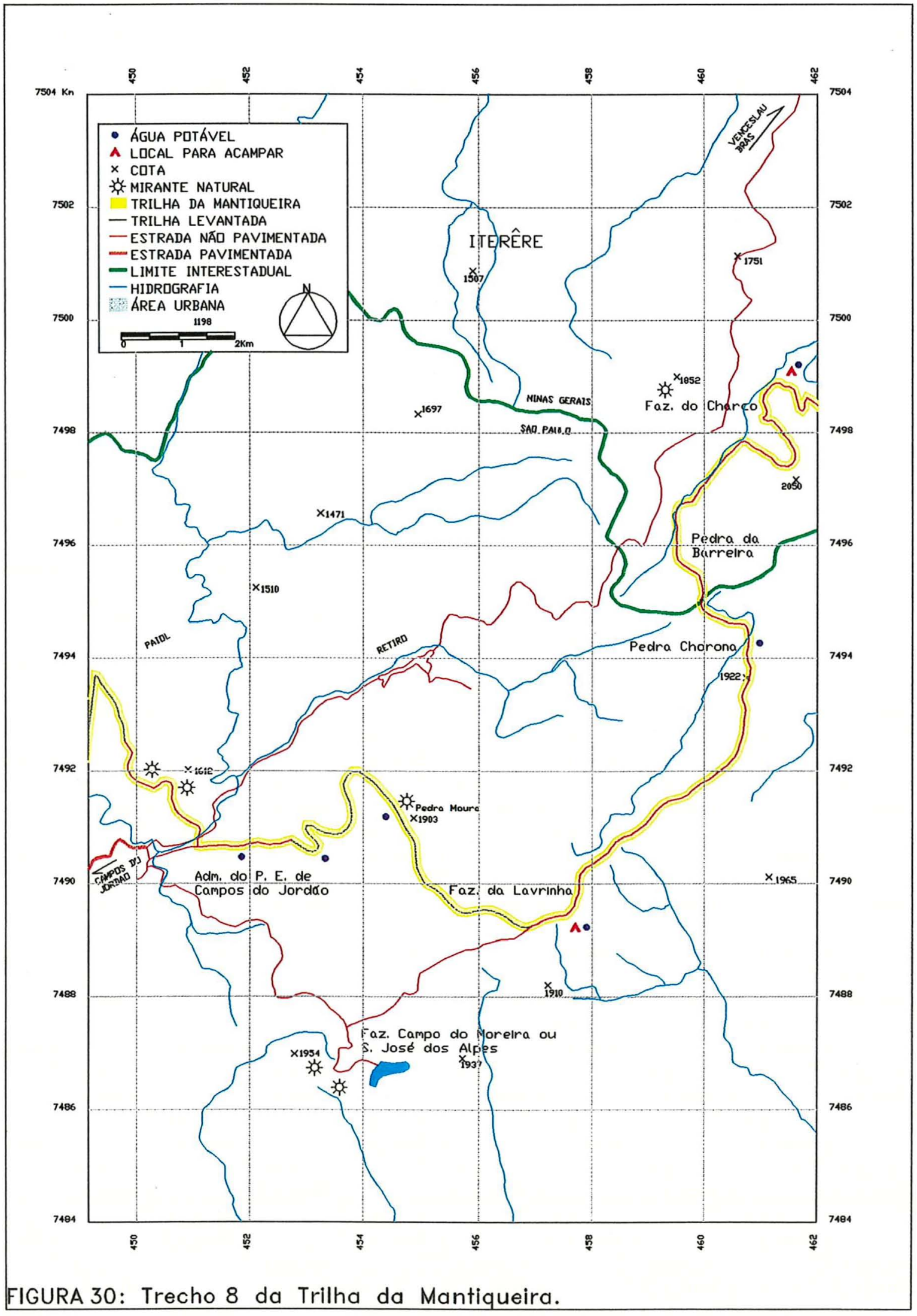




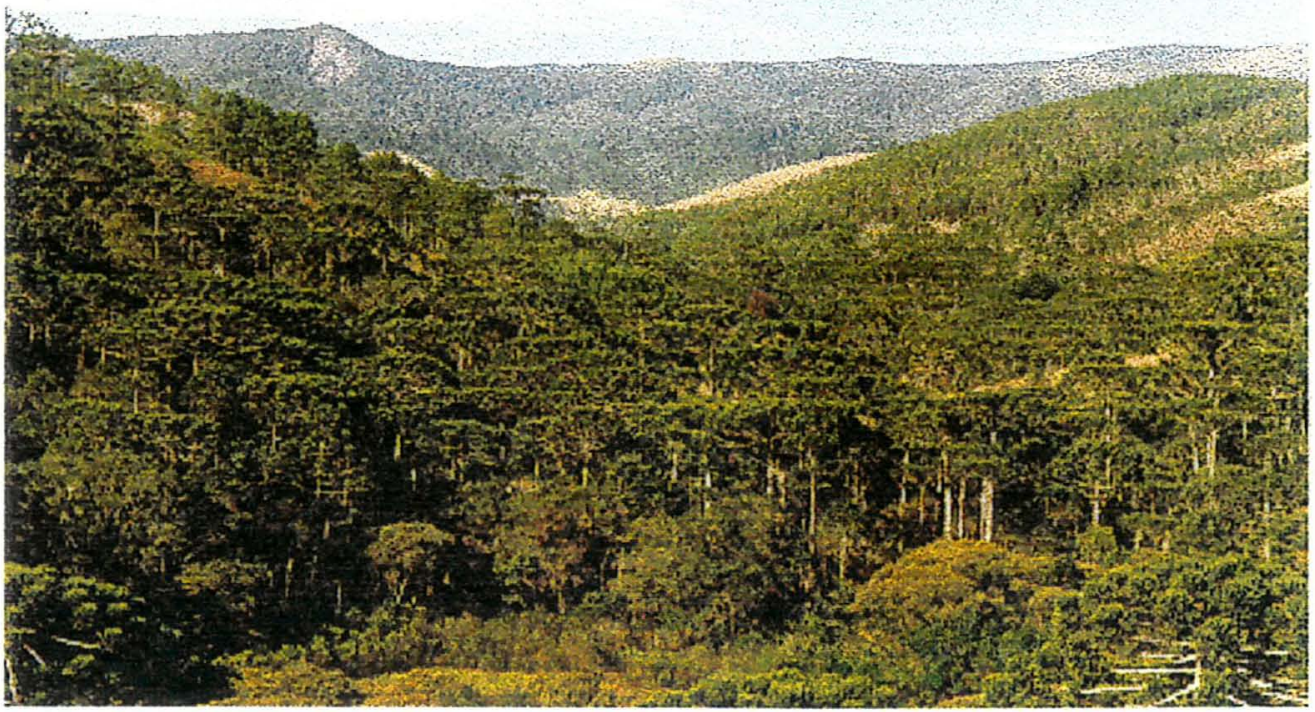

Figura 31 - Parque Estadual de Campos do Jordão

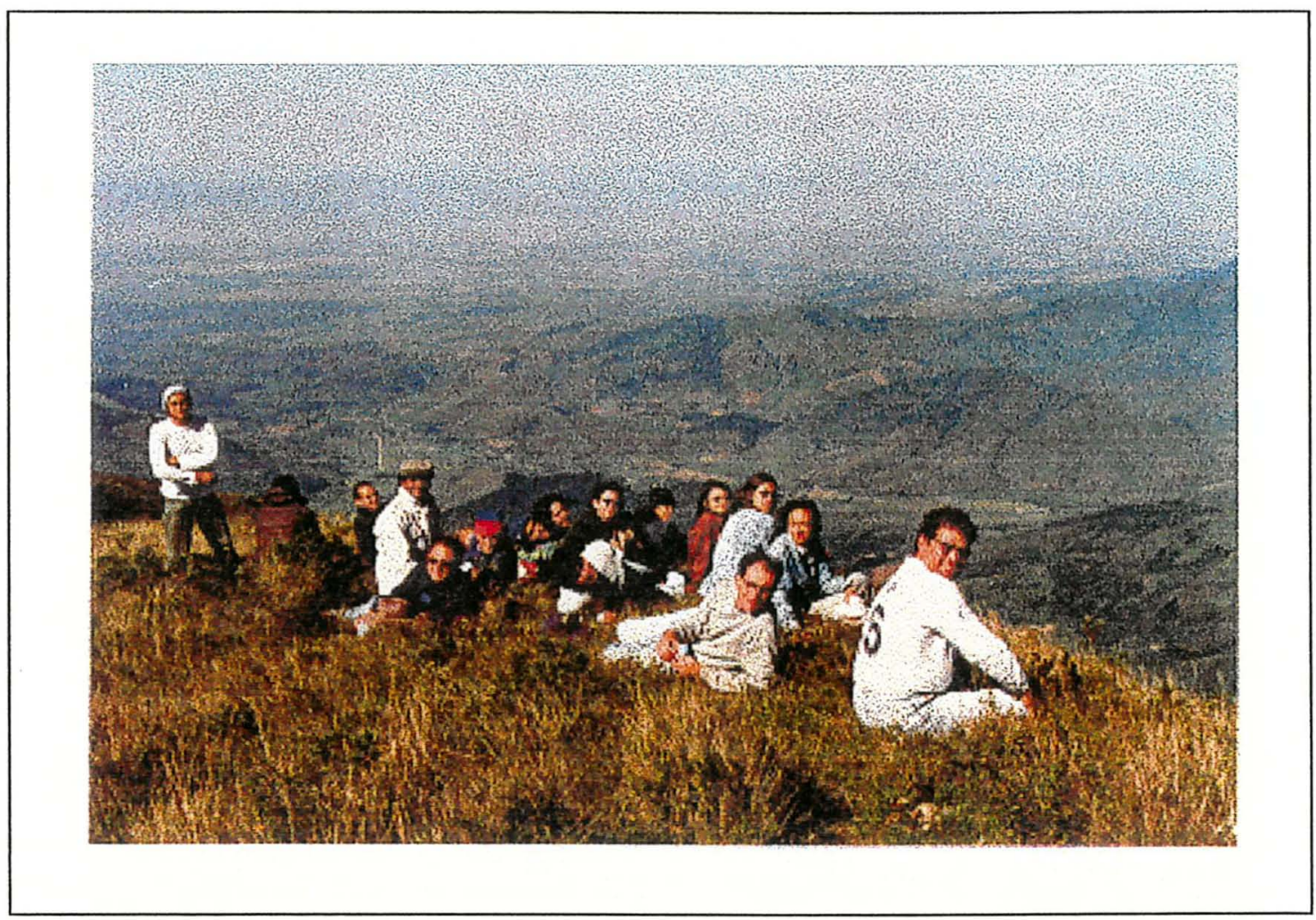

Figura 32 - São José dos Alpes 


\section{Trecho 9}

Localiza-se entre as coordenadas 462 e 476 da folha topográfica DELFIM MOREIRA (FIGURA 33). Destaca-se nesse trecho, que é o mais curto de todos, com $16,7 \mathrm{~km}$, a Fazenda da Onça (FIGURA 34) - de propriedade do Exército Brasileiro - nas proximidades do Pico do Carrasco $(2.013 \mathrm{~m})$. A localidade São Francisco dos Campos - onde se encontra a Pousada do Barão (FIGURA 35), o Pico do Cabrito $(1.817 \mathrm{~m})$ e o Morro do Ataque $(2.010 \mathrm{~m})$ (FIGURA 36). O acesso a esse trecho se dá pela cidade paulista de Piquete ou pelo Parque Estadual de Campos do Jordão.

\section{Trecho 10}

Localiza-se entre as coordenadas 474 e 488 da folha topográfica LORENA (FIGURA 37). Engloba a cidade paulista de Piquete e o grande destaque desse trecho é o Pico dos Marins (2.421 m) (FIGURA 38 e 39).

Após passar pelo Morro do Ataque, no trecho 9, a Trilha da Mantiqueira adentra o trecho 10 em descida até encontrar a Rodovia Lorena-Itajubá, 1,5 quilômetros após a Divisa SP/MG. A Trilha da Mantiqueira se confunde com a BR 459 por 2,5 quilômetros até a entrada para Fazenda Saiqui, no sentido leste, que se alcança após percorrer 16 quilômetros em estrada de terra. Dois quilômetros depois sobe-se à direita no sentido do alto da serra em busca do Pico dos Marins (2421m).

Nesse trecho, a Trilha da Mantiqueira se estende por $20,8 \mathrm{~km}$, e o melhor acesso se dá por Piquete, cruzando-se o alto da serra pela BR 459.

\section{Trecho 11}

Localiza-se entre as coordenadas 486 e 500 da folha topográfica VIRGíNIA (FIGURA 40). Não engloba a área urbana de 


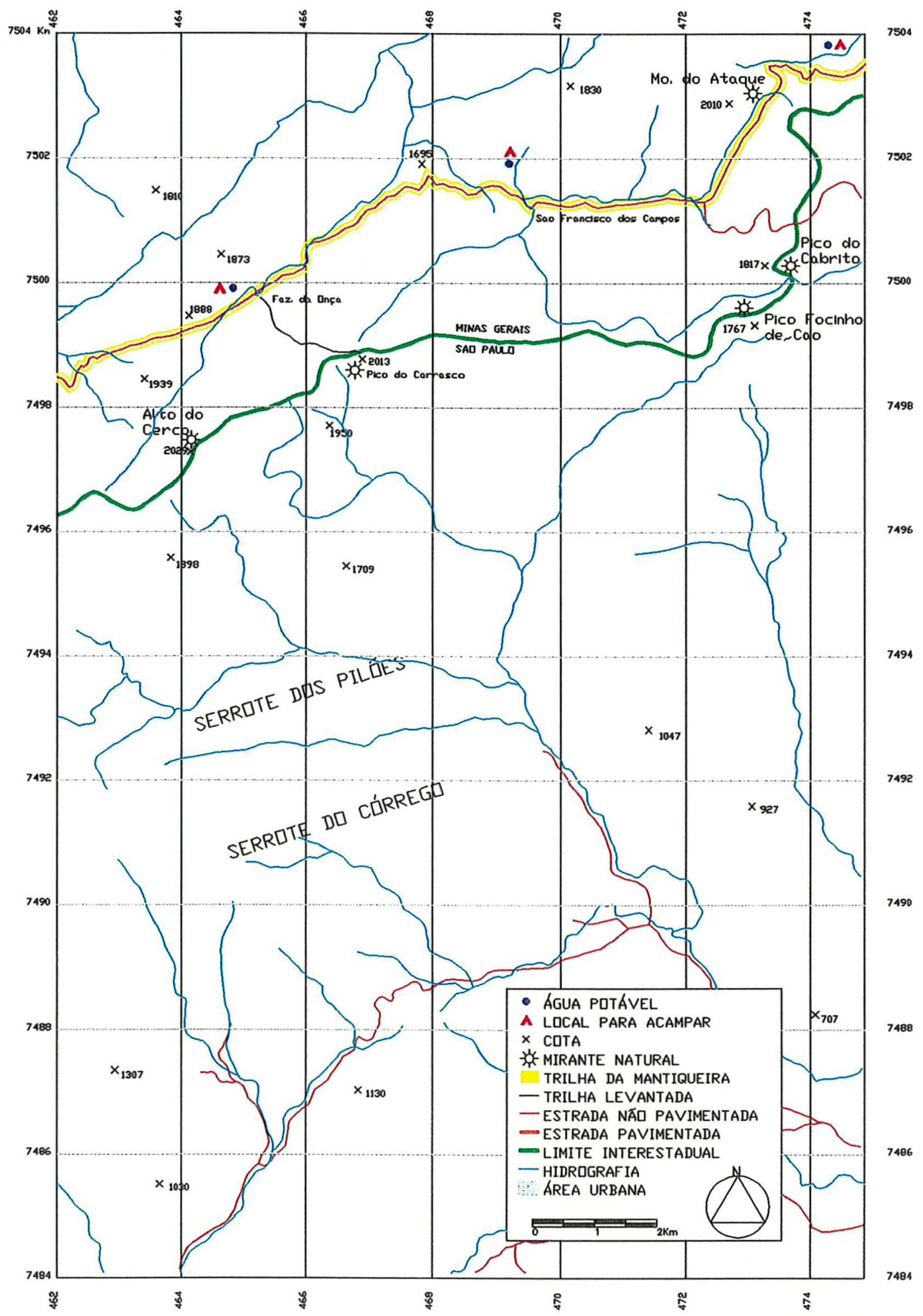

FIGURA 33: Trecho 9 da Trilha da Mantiqueira. 


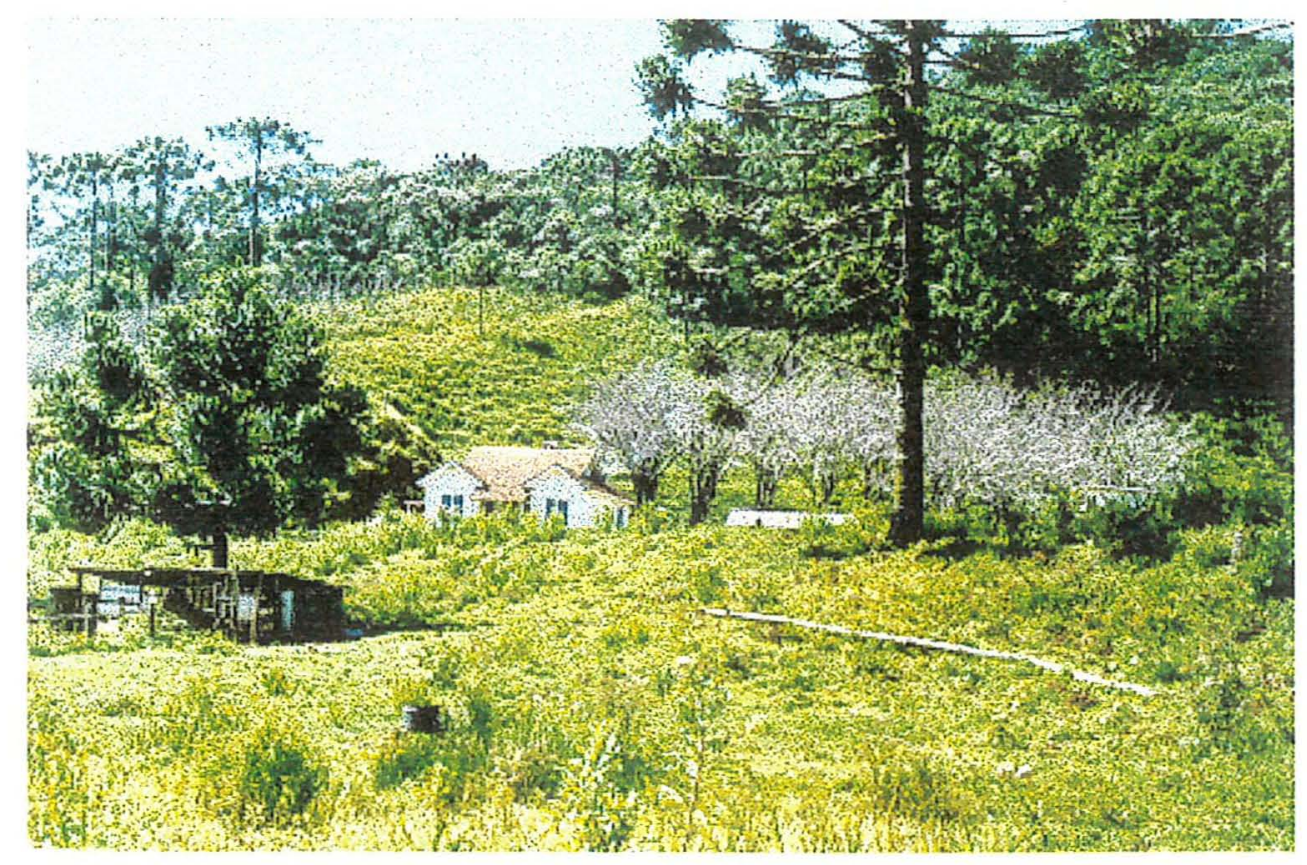

\section{Figura 34 - Fazenda da Onça}

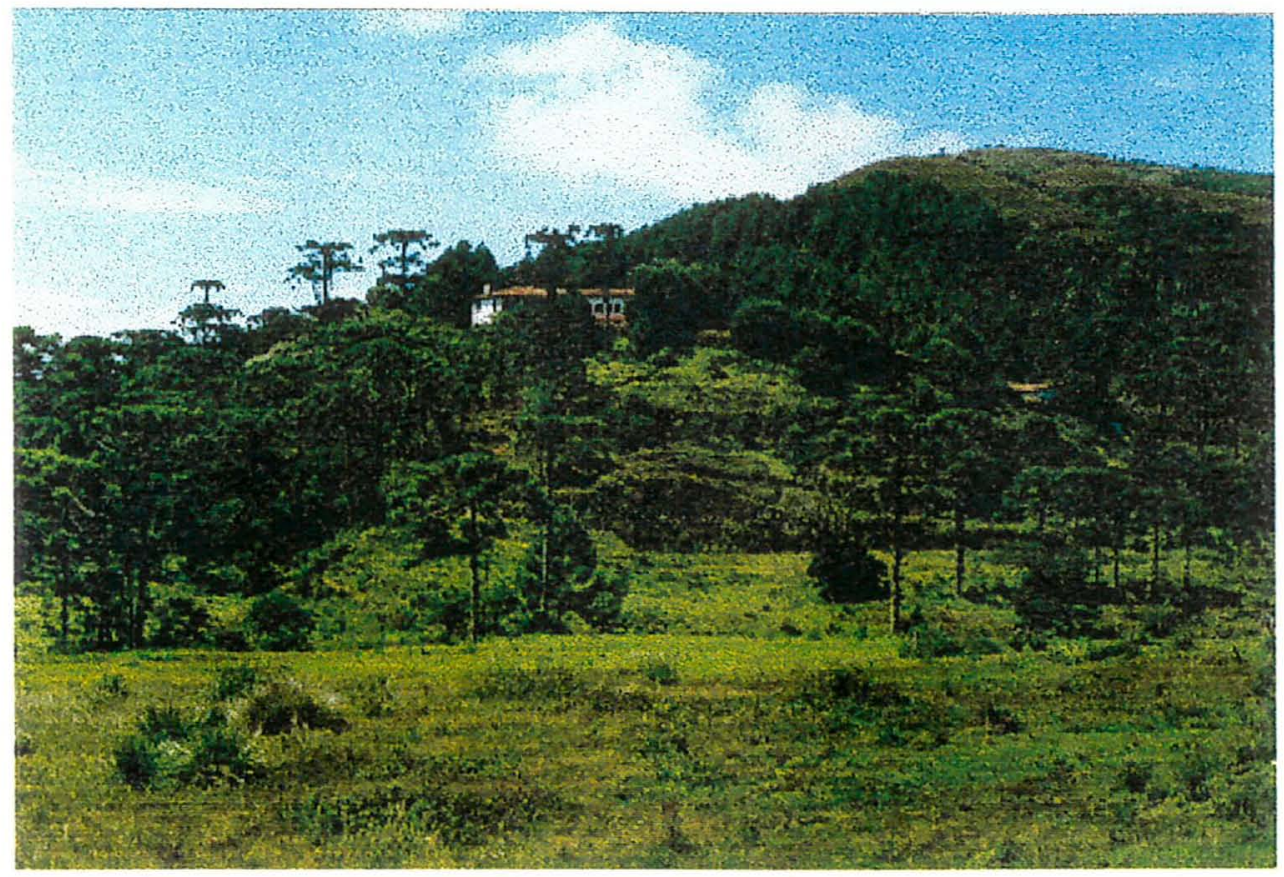

Figura 35 - Pousada do Barão 


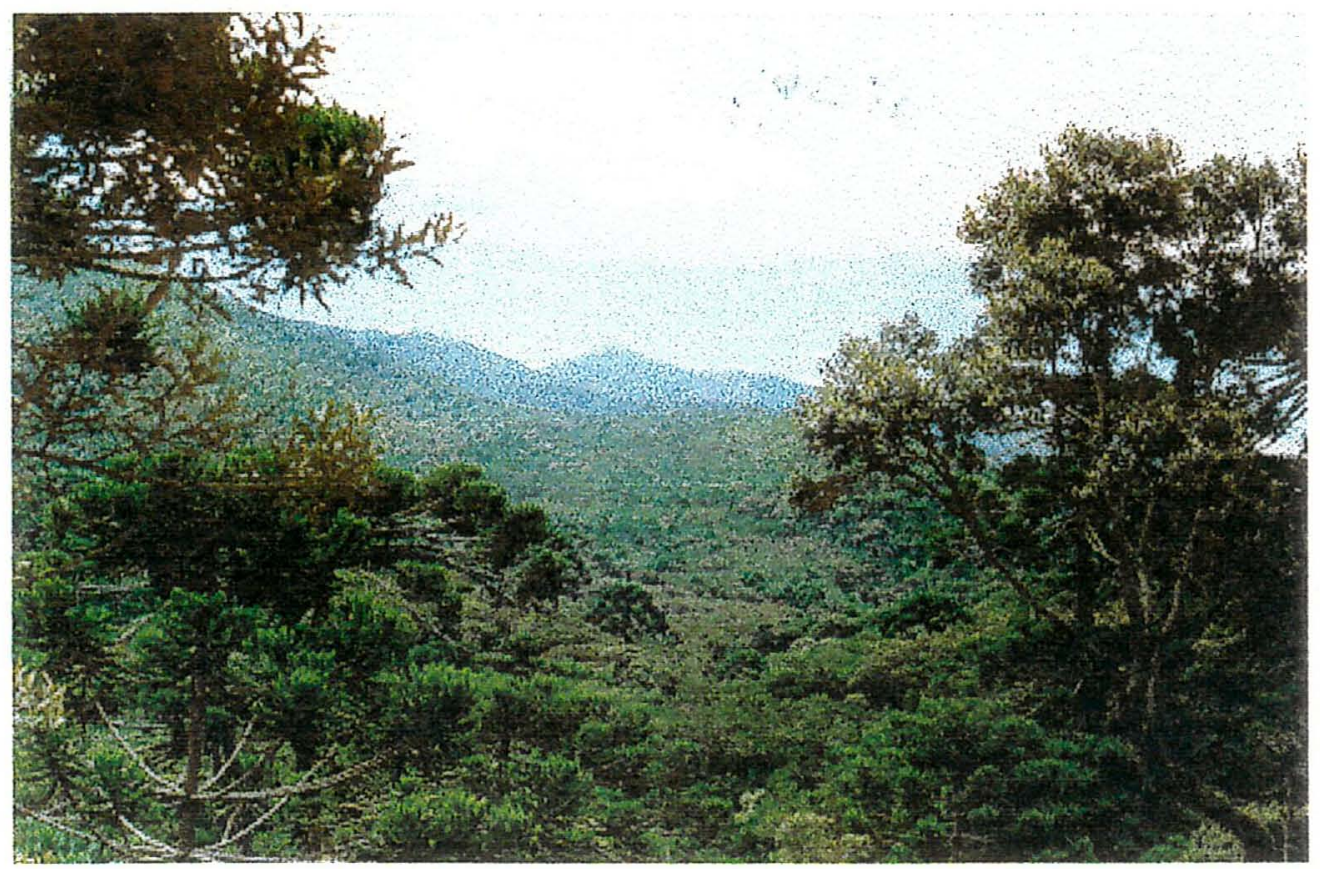

Figura 36 - Morro do Ataque

nenhum município. Destaca-se o lugarejo Vargem Alegre (FIGURA 41) e o Pico do Itaguaré (2.308 m) (FIGURA 42).

A Trilha da Mantiqueira adentrando esse trecho, nele se estendendo por $21,7 \mathrm{~km}$, é a própria travessia Marins-Itaguaré, onde pontos de água existem mas são de difícil localização, aconselhando-se portanto a qualquer montanhista carregar bastante água.

A descida do ltaguaré é feita também por trilha até estrada sobre o rio Lourenço Velho. Aí segue-se sentido leste passando-se pela Fazenda Três Barras e pelo lugarejo conhecido por Caxambu. O acesso a esse trecho pode-se dar por: a) Piquete (SP), ou Itajubá (MG) através da BR-459; ou b) Cruzeiro (SP), ou Passa Quatro (MG), tendo por referência a Rodovia Cruzeiro-Passa Quatro, MG 152, até encontrar Caxambú, nas proximidades de Pinheirinho (MG). 


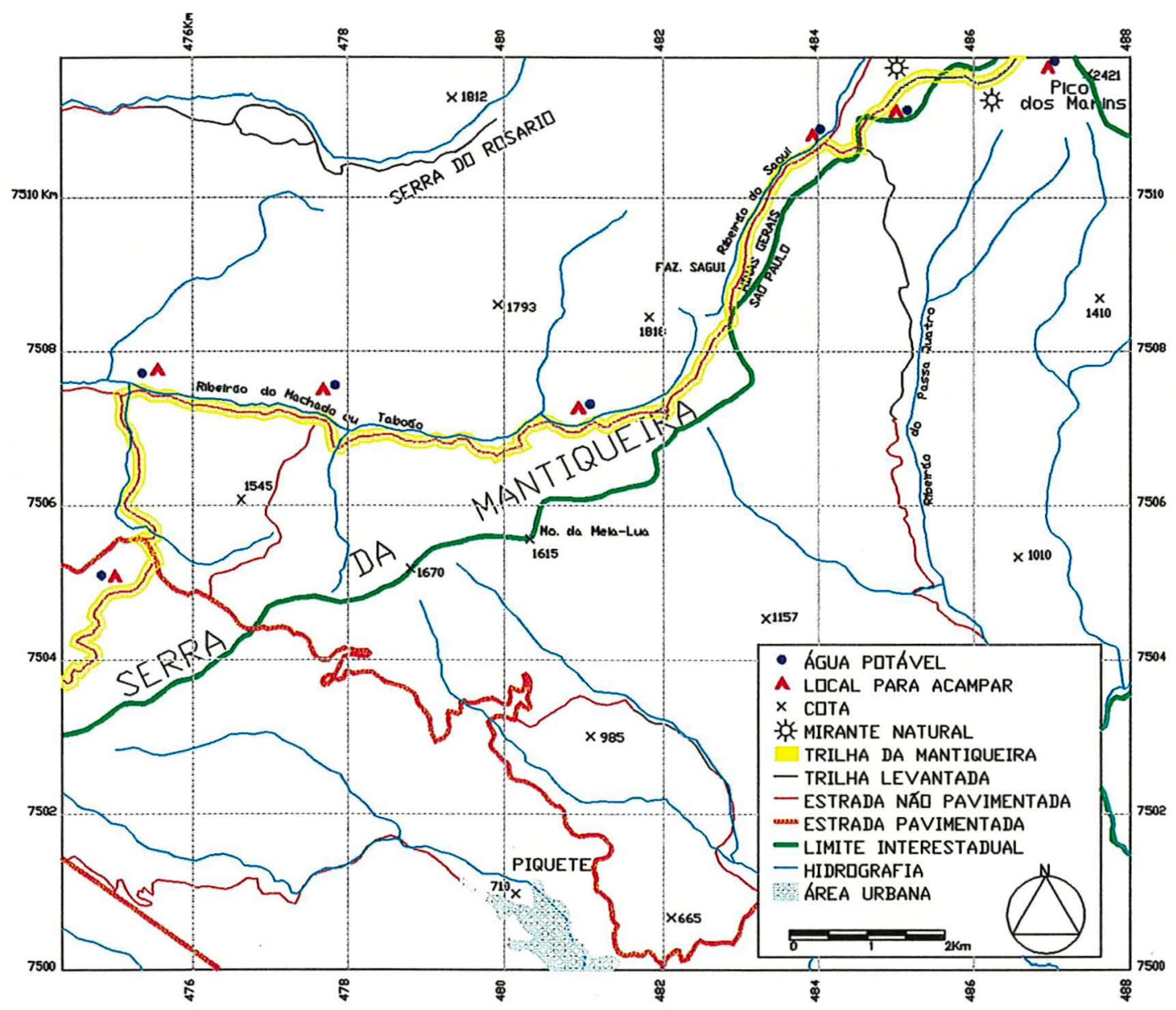

FIGURA 37: Trecho 10 da Trilha da Mantiqueira. 


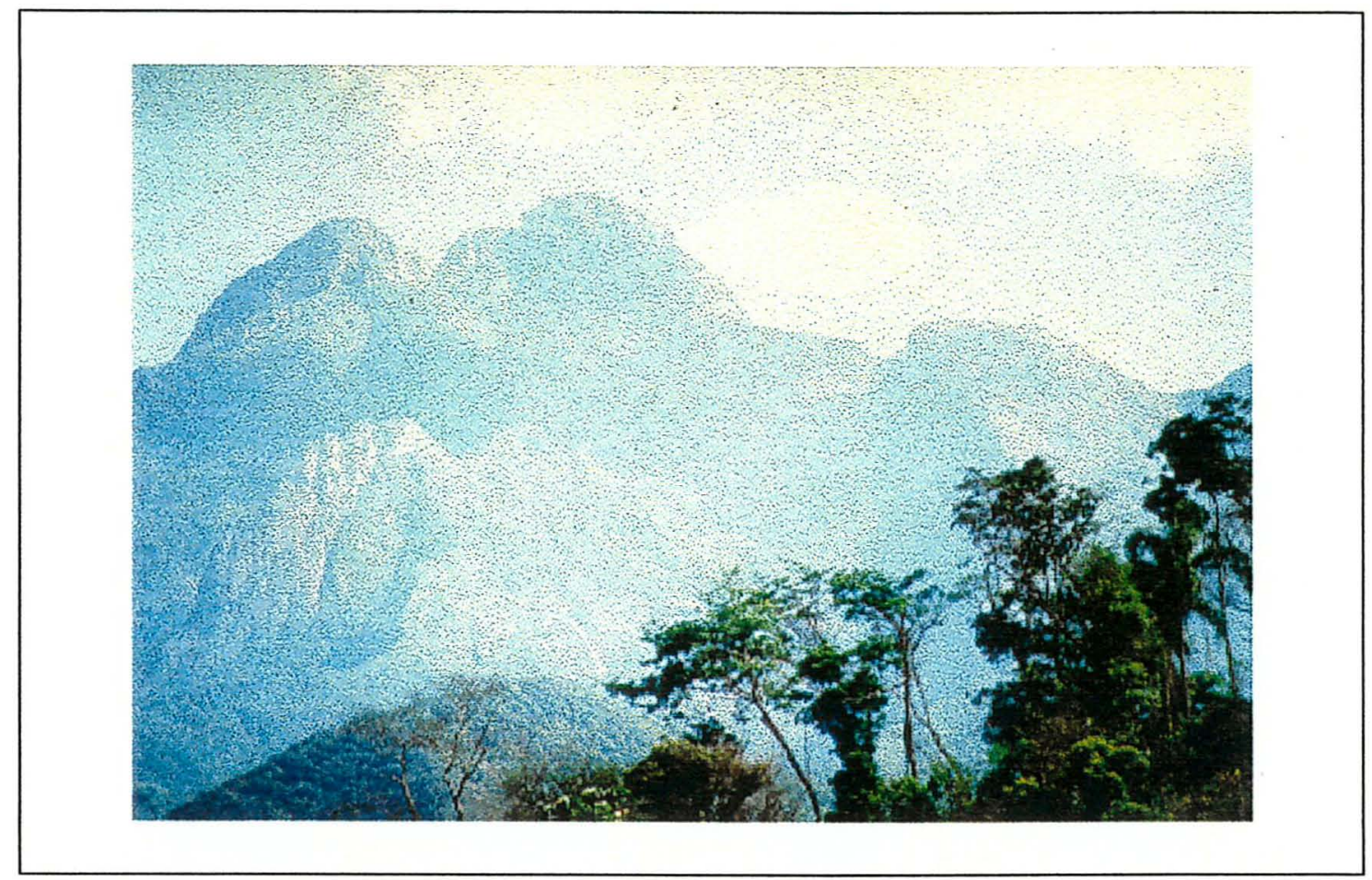

Figura 38 - Pico dos Marins (vista paulista)

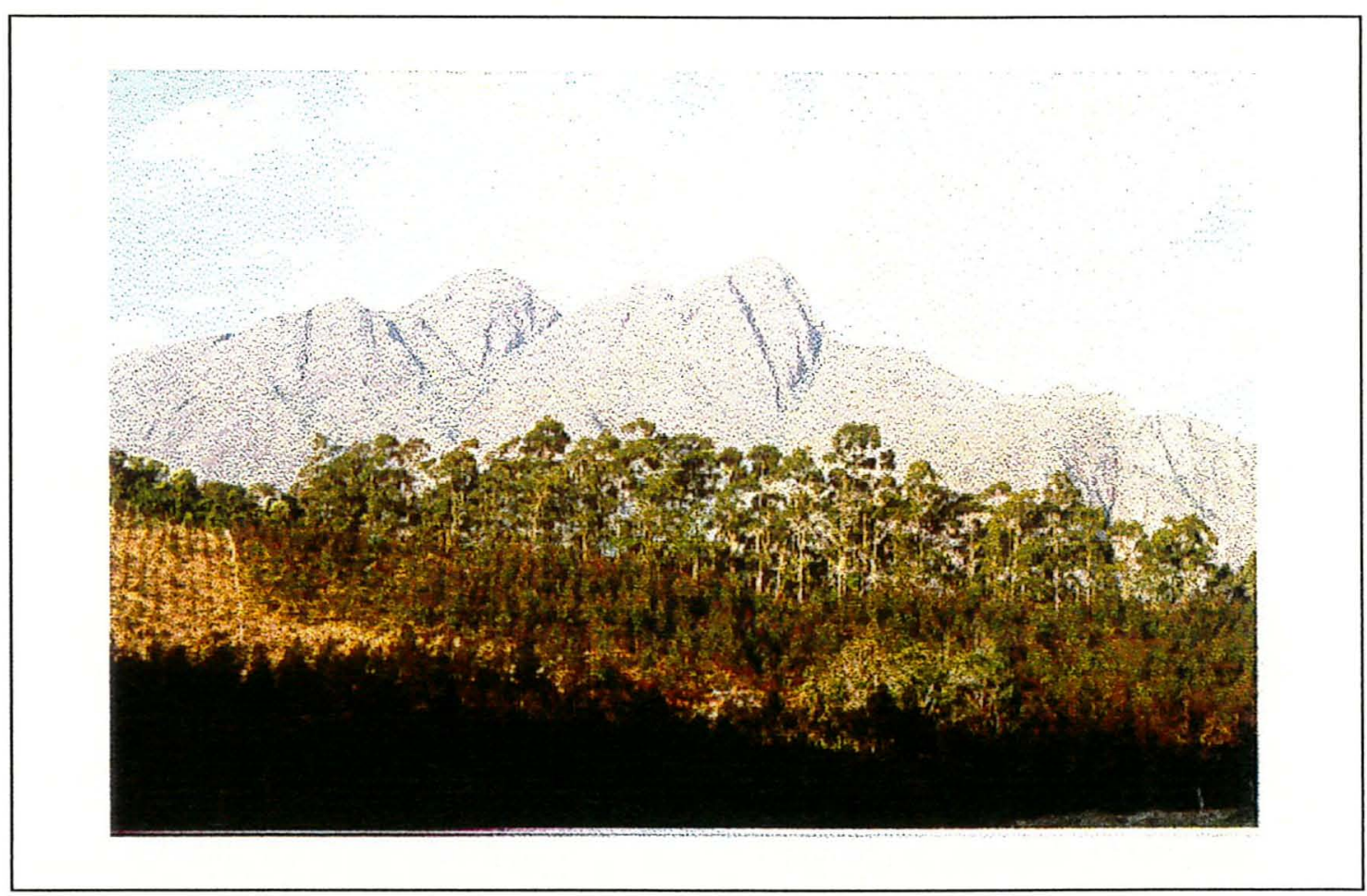

Figura 39 - Pico dos Marins (vista mineira) 


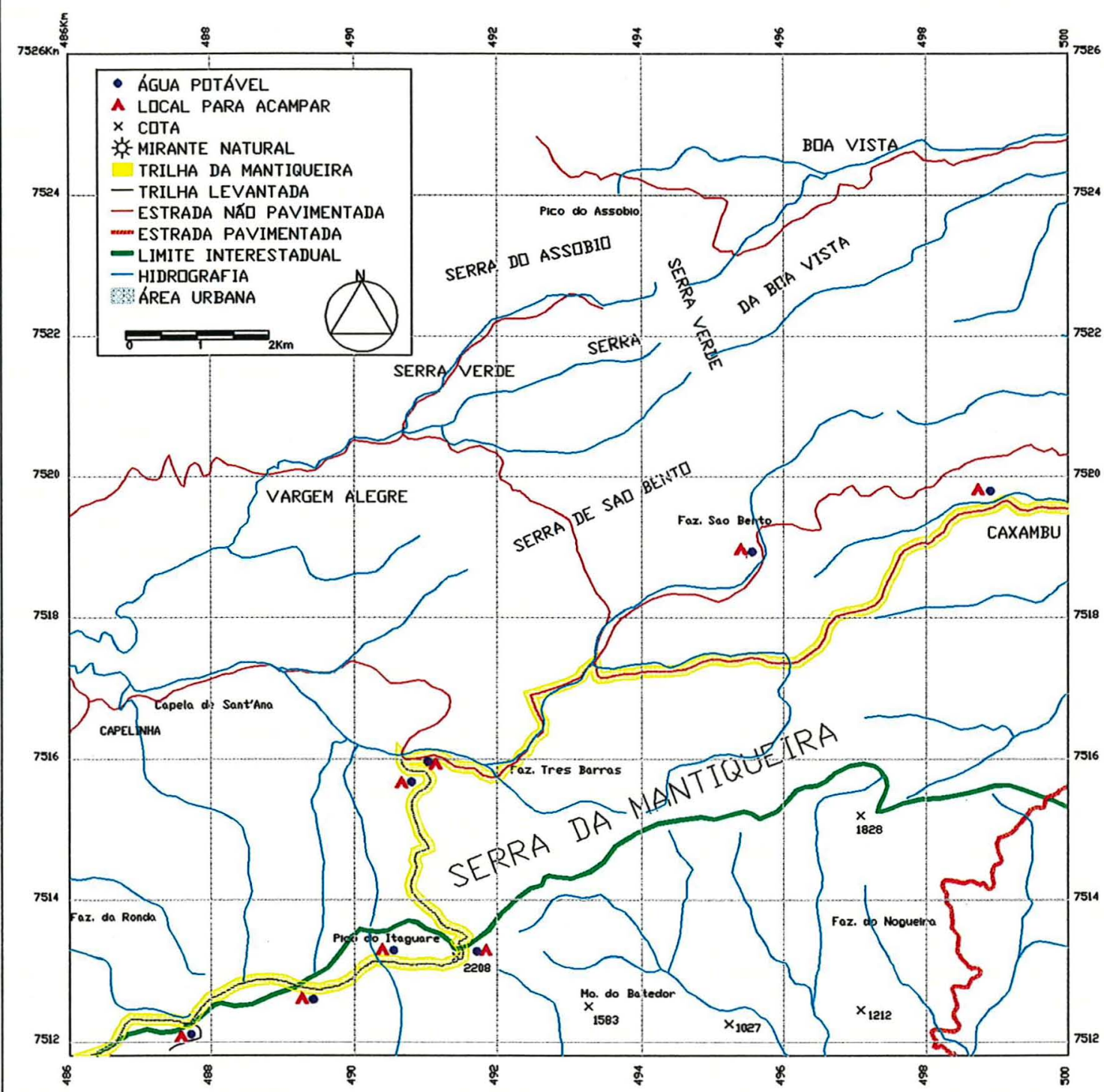

FIGURA 40: Trecho 11da Trilha da Mantiqueira. 


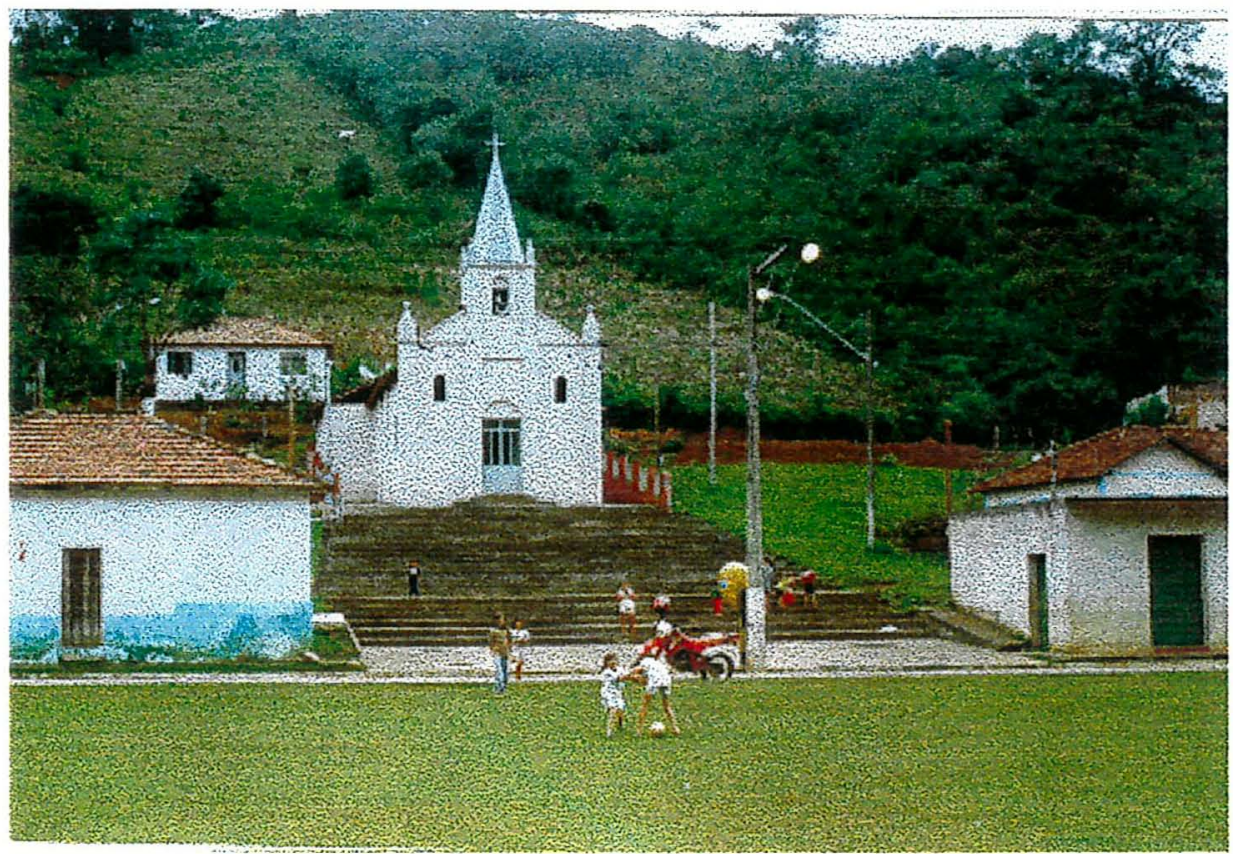

Figura 41 - Vargem Alegre

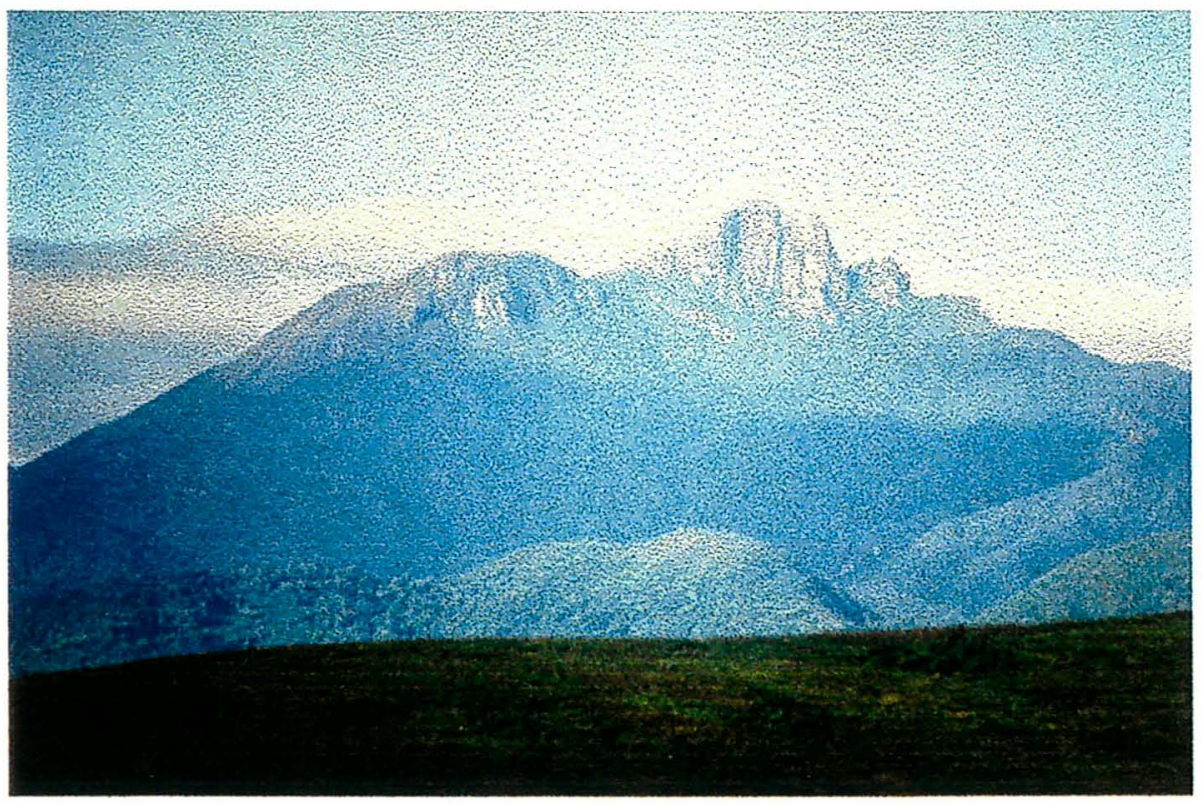

Figura 42 - Pico do Itaguaré 
Trecho 12

Localiza-se entre as coordenadas 500 e 512 da folha topográfica PASSA QUATRO (FIGURA 43). Engloba a cidade de mesmo nome e destaca-se nesse trecho, a Toca do Lobo e o Pico do Capim Amarelo (2.392 m) (FIGURA 44), já na serra Fina (Figura 45). Quando a trilha adentra esse trecho, ela segue por cerca de 1,5 km sobre a rodovia que liga Cruzeiro (SP) a Passa Quatro (MG).

A Trilha da Mantiqueira adentra esse trecho, se estendendo por $18,1 \mathrm{~km}$, passando por Caxambú e Pinheirinho, seguindo por estrada de terra, no sentido sudeste até a Toca do Lobo, passando, a partir daí, para uma trilha propriamente dita, que vai subindo a serra.

No alto da serra encontra o ramal que vem da Fazenda Mato Quieto, Município de Cruzeiro. Aproximadamente um quilometro a frente, antes da grande subida para o Capim Amarelo, é o último ponto de água da subida, e deve-se abastecer o cantil, pois no topo do Capim Amarelo, ótimo lugar para pernoitar, não há água. O acesso a esse trecho pode-se dar por Passa Quatro, entrando-se pela Toca do Lobo, ou por Cruzeiro, através da Fazenda Mato Quieto.

\section{Trecho 13}

Localiza-se entre as coordenadas 512 e 526 da folha topográfica PASSA QUATRO (FIGURA 46). Nesse trecho, quase todo na serra Fina a trilha segue pela crista da grande serra onde se destaca a Pedra da Mina (2.770 m) (FIGURA 47), Cupim do Boi $(2.600 \mathrm{~m})$ e Pico dos Três Estados (2.685 m) (FIGURA 48). Na descida do Pico dos Três Estados destaca-se a nordeste, no horizonte, a Pedra do Picu (2.151 m) (FIGURA 49). No final desse trecho a Trilha segue por aproximadamente 5 quilometros sobre a rodovia que une Engenheiro Passos (RJ) e Itamonte (MG), até a Divisa MG/RJ na Garganta do Registro onde, por estrada de terra, na direção leste, adentra o trecho 14. 


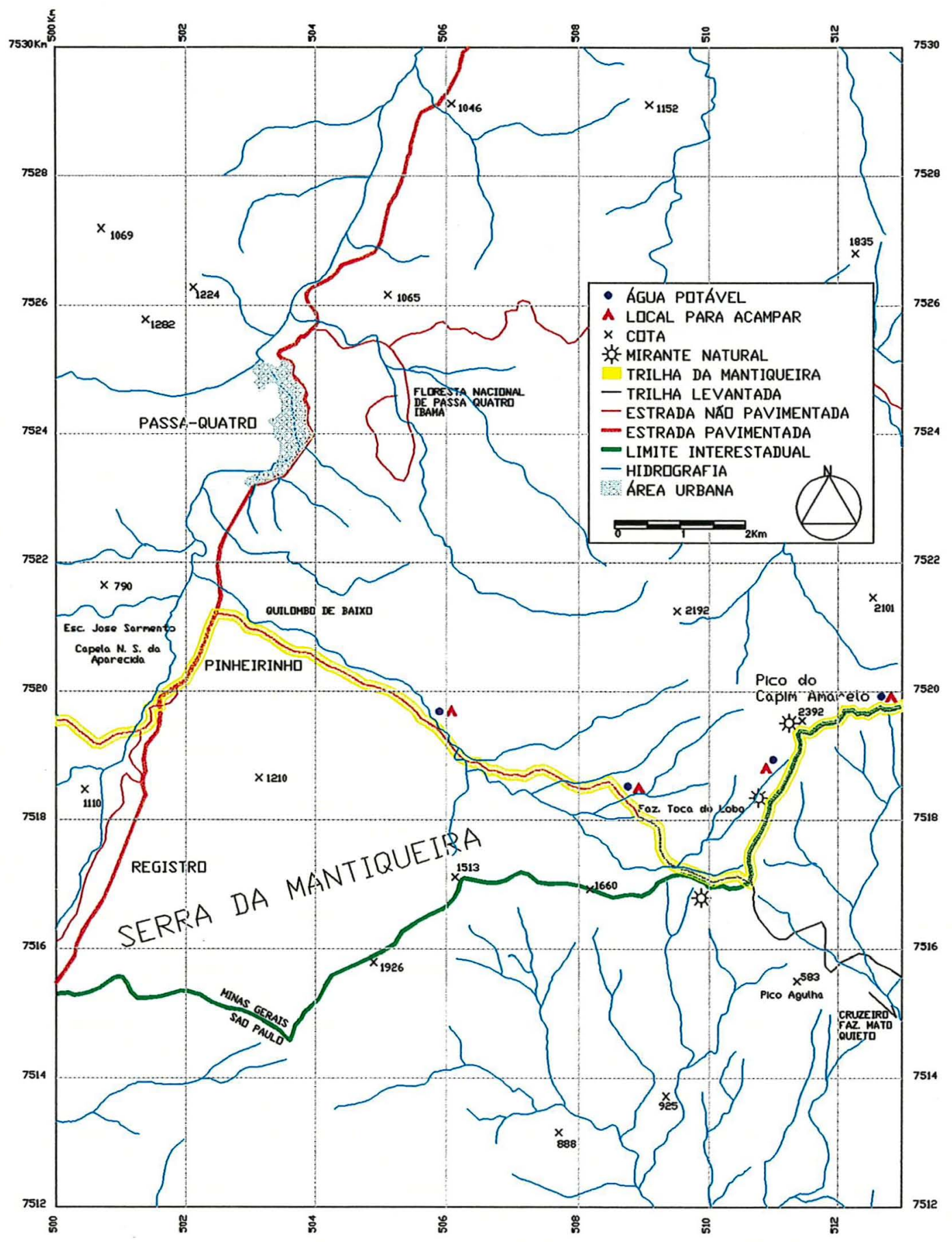

FIGURA 43: Trecho 12 da Trilha da Mantiqueira. 


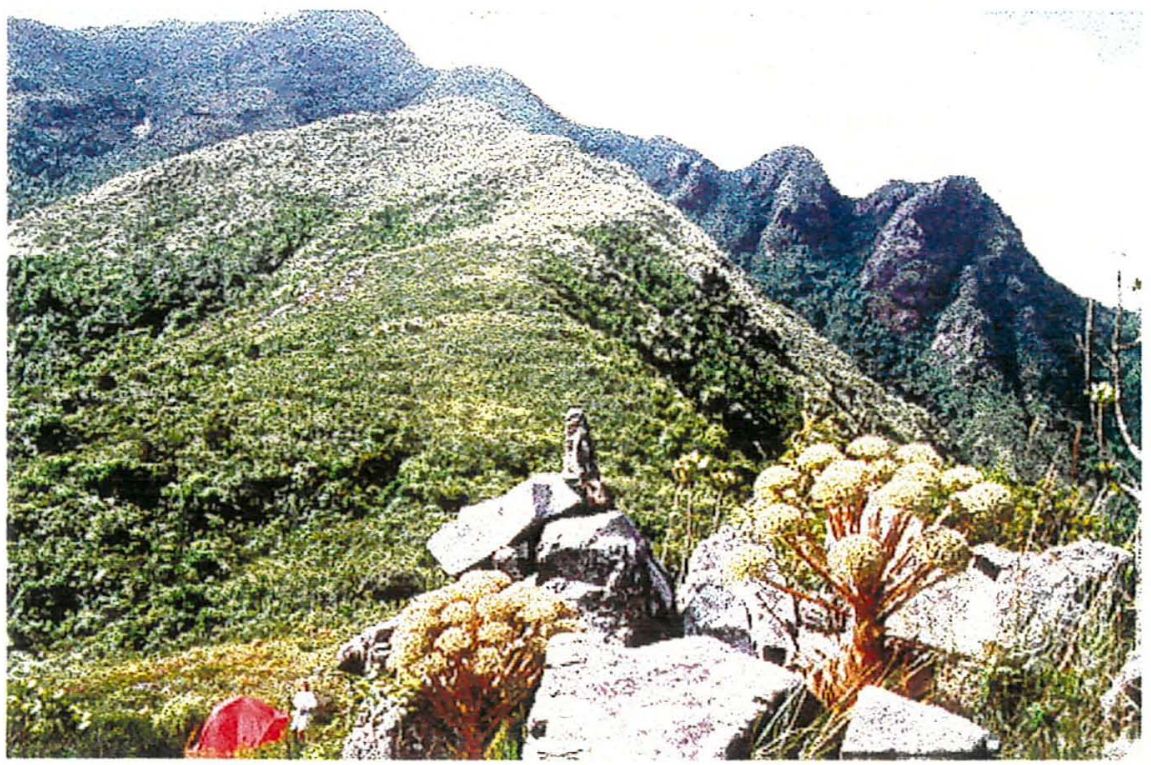

Figura 44 - Pico do Capim Amarelo

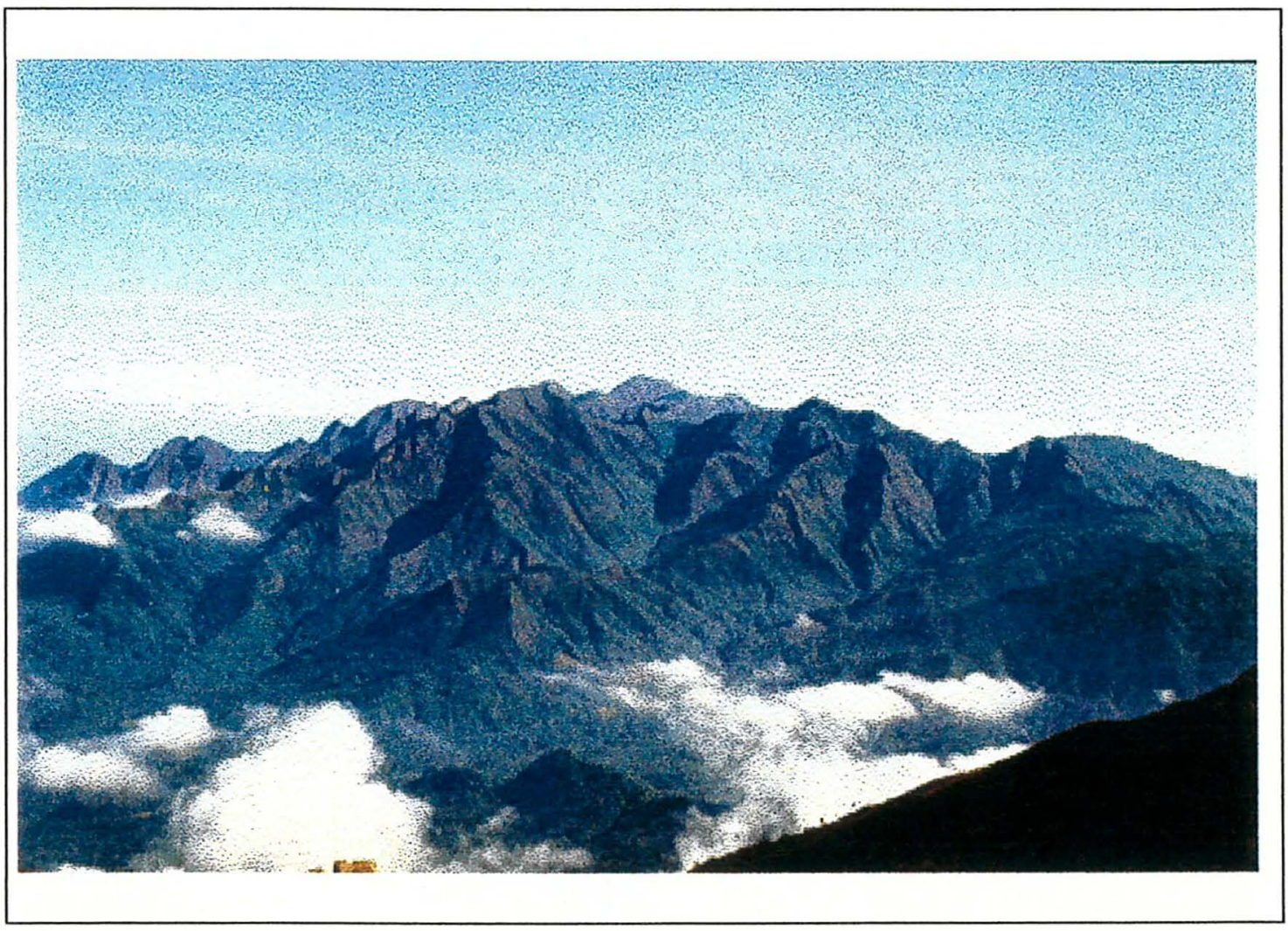

Figura 45 - Serra Fina 


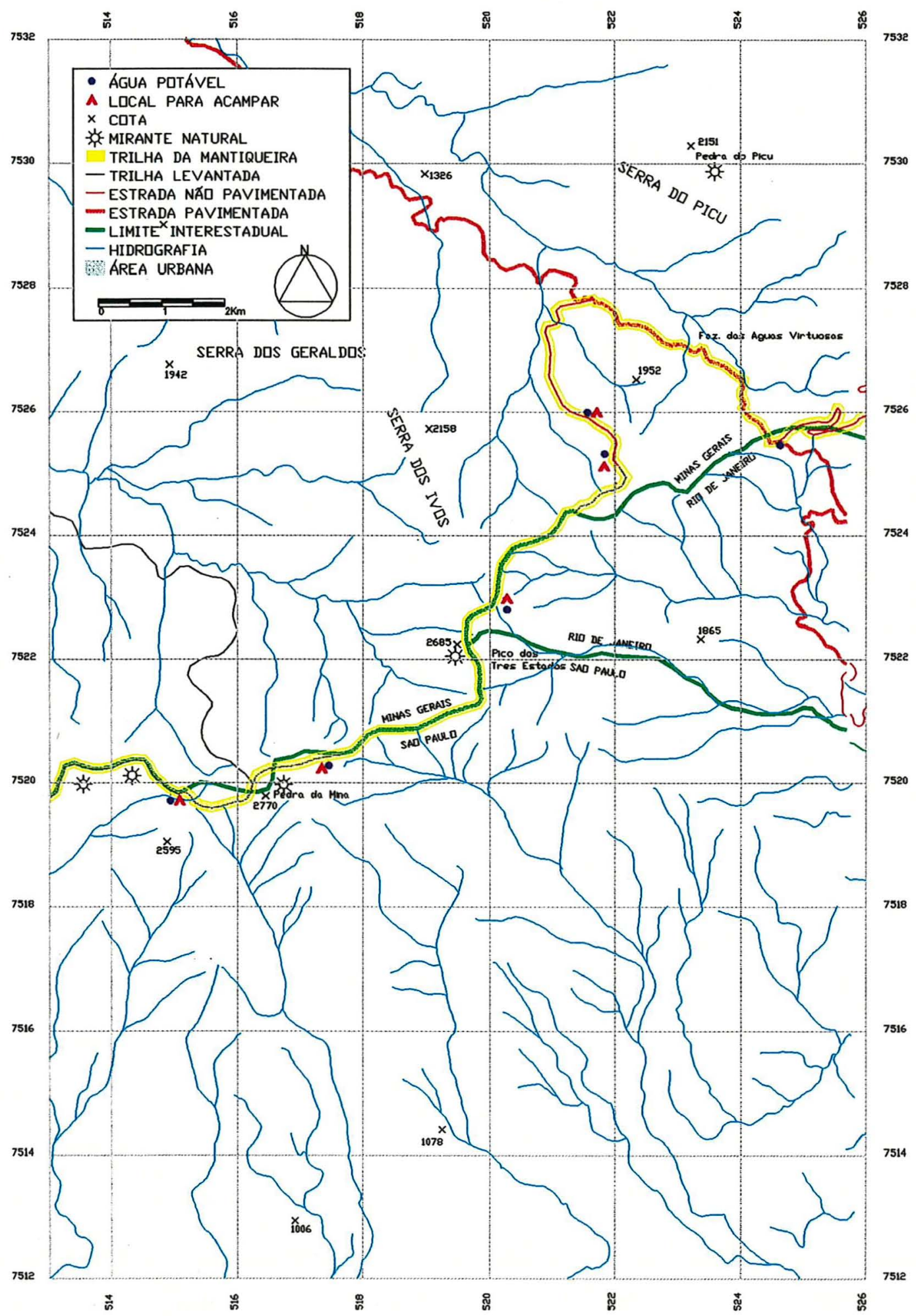

FIGURA 46: Trecho 13 da Trilha da Mantiqueira. 


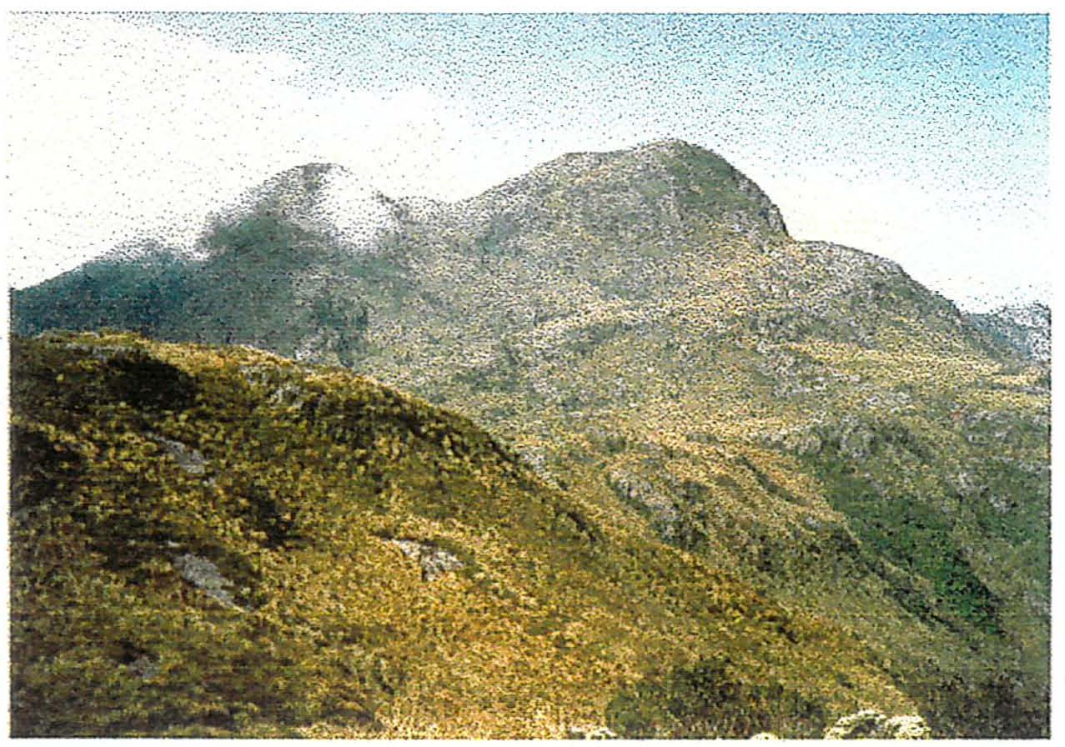

Figura 47 - Pedra da Mina

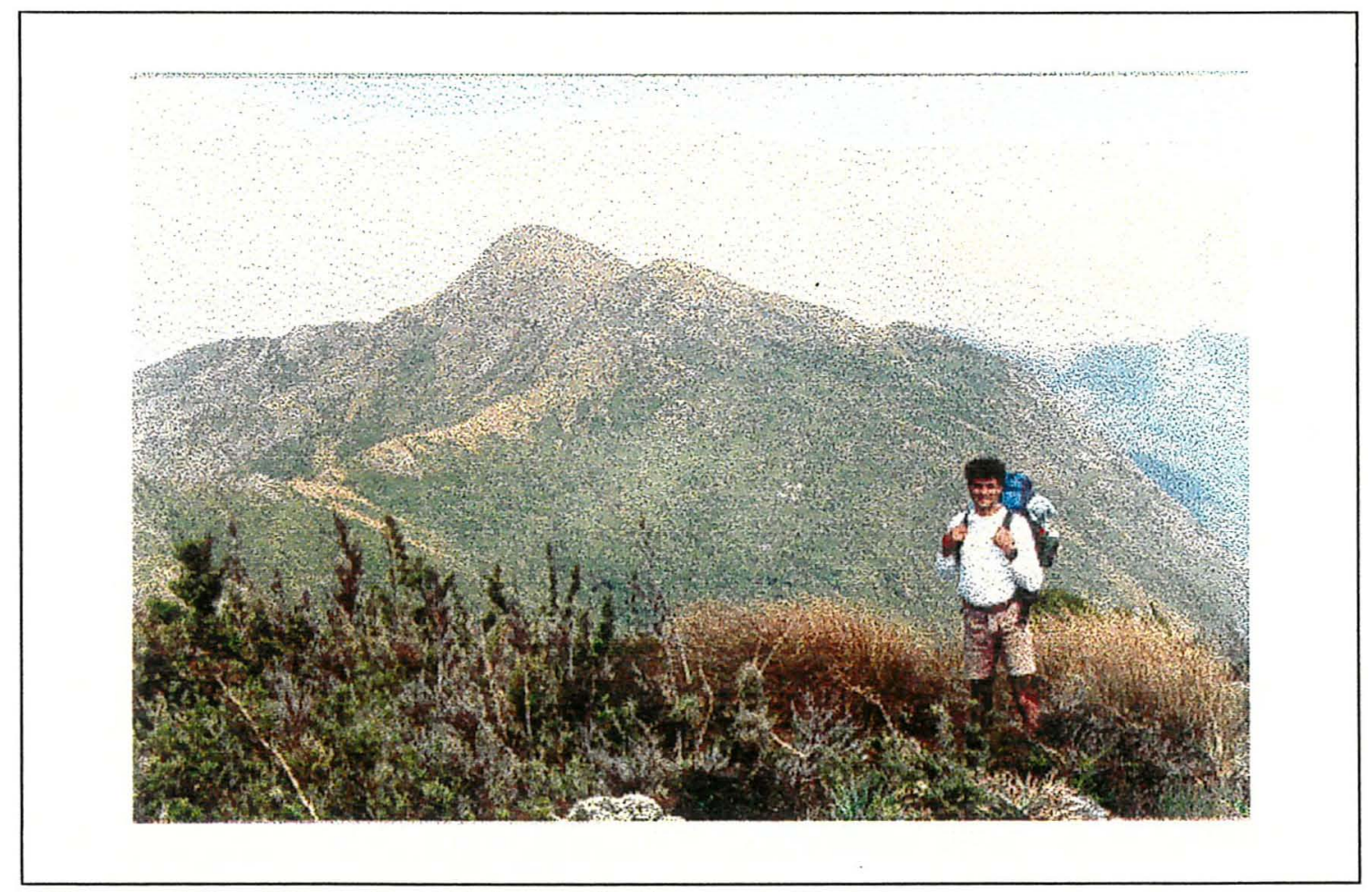

Figura 48 - Pico dos Três Estados 
O acesso a esse trecho se dá por: a) Passa Quatro (MG), seguindo em estrada de terra até o Paiolinho e não Paiolzinho como se encontra em folha original. Daí por trilha propriamente dita chega-se à Pedra da Mina; ou b) Itamonte (MG) ou Engenheiro Passos (RJ), tendo por referência a BR-354 e o Hotel Casa Alpina.

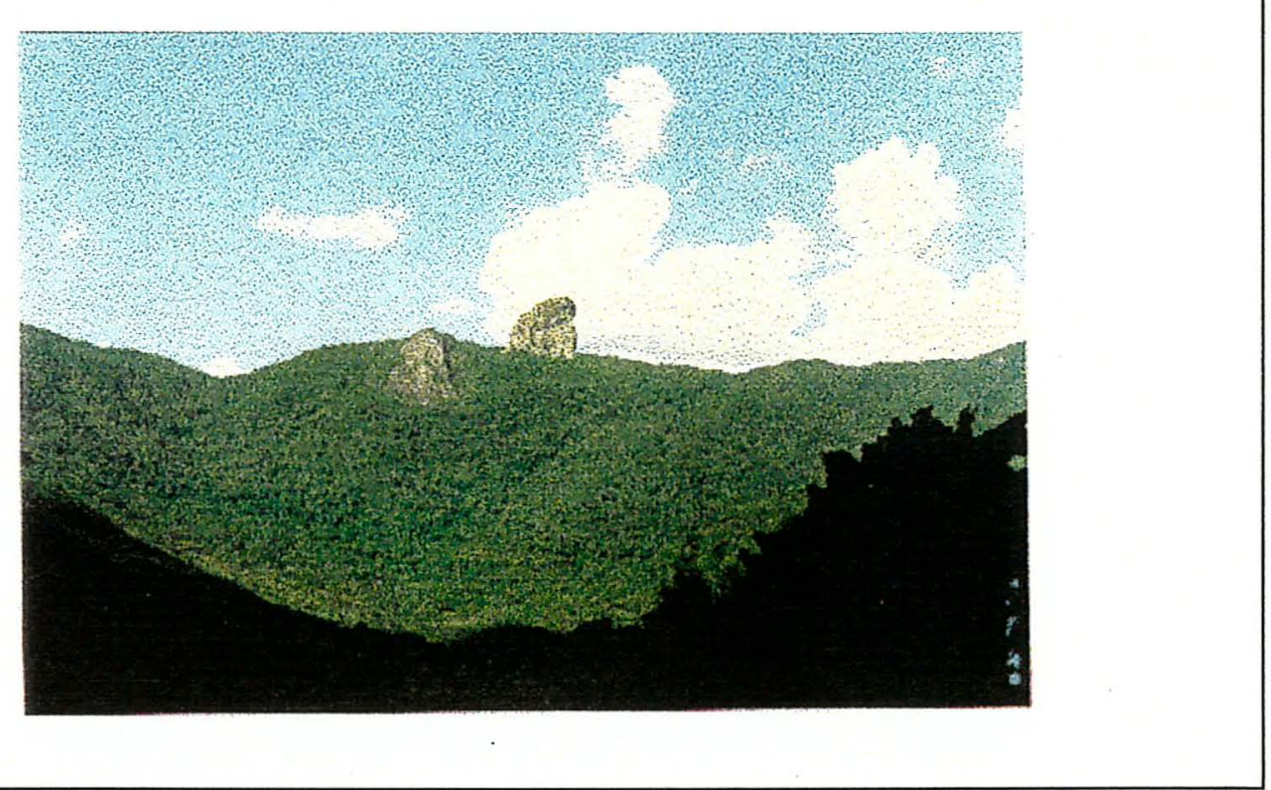

Figura 49 - Pedra do Picu

\section{Trecho 14}

Localiza-se entre as coordenadas 524 e 542 da folha topográfica AGULHAS NEGRAS (FIGURA 50). Esse trecho tem início bem próximo ao Parque Nacional de Itatiaia. Aí vários são os destaques: Casa de Pedra, Abrigo Rebouças, Pico das Agulhas Negras (2.787 m) (FIGURA 51) - ponto culminante da região Sudeste - Pico das Prateleiras (2.570 m) (FIGURA 52), Pedra Cabeça de Leão (2.483 m) (FIGURA 53), Abrigo Massena (FIGURA 54), cachoeira Véu da Noiva (FIGURA 55), entre outros atrativos. A Trilha da Mantiqueira segue por estrada de terra até o Abrigo Rebouças. Daí, desce em direção à sede desta Unidade de Conservação, por trilha e por estrada de terra, até o Museu do Parque Nacional, final da Grande Trilha (FIGURA 56). 


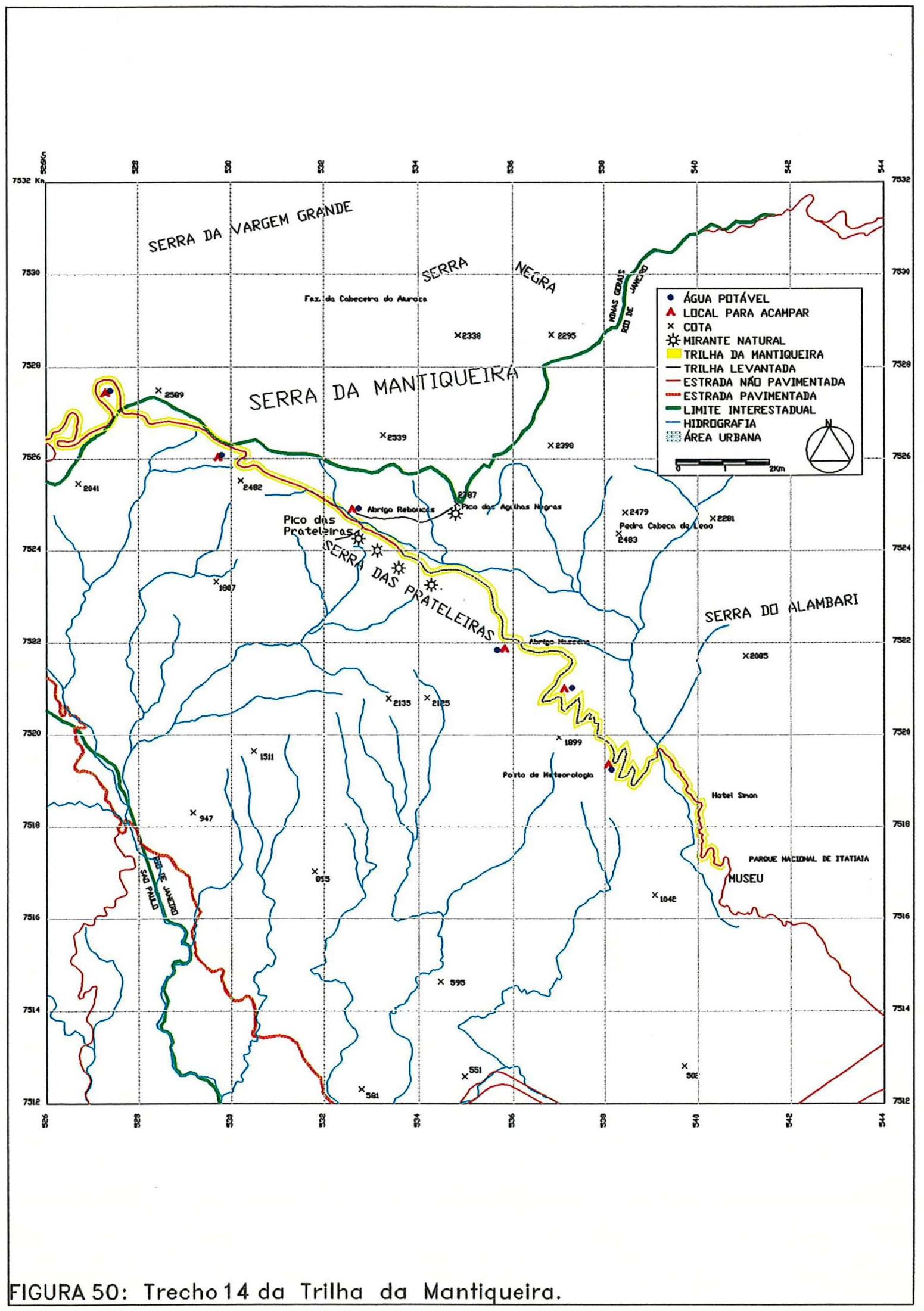




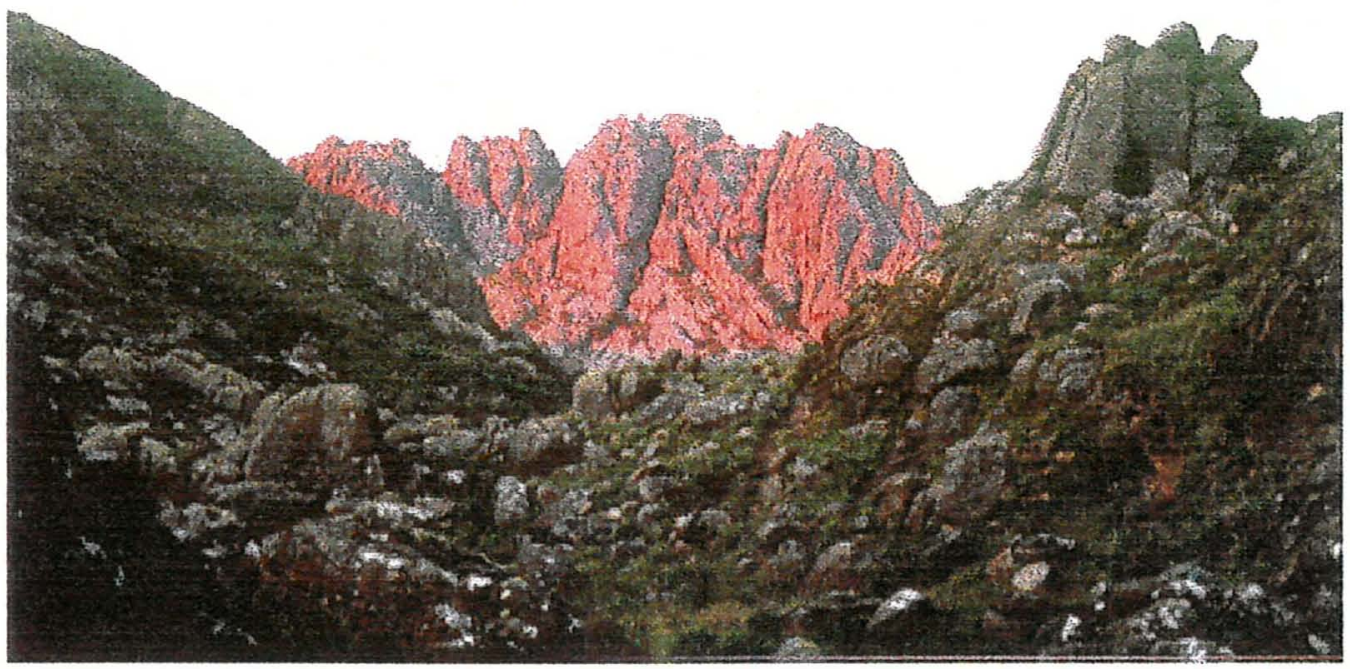

Figura 51 - Pico das Agulhas Negras

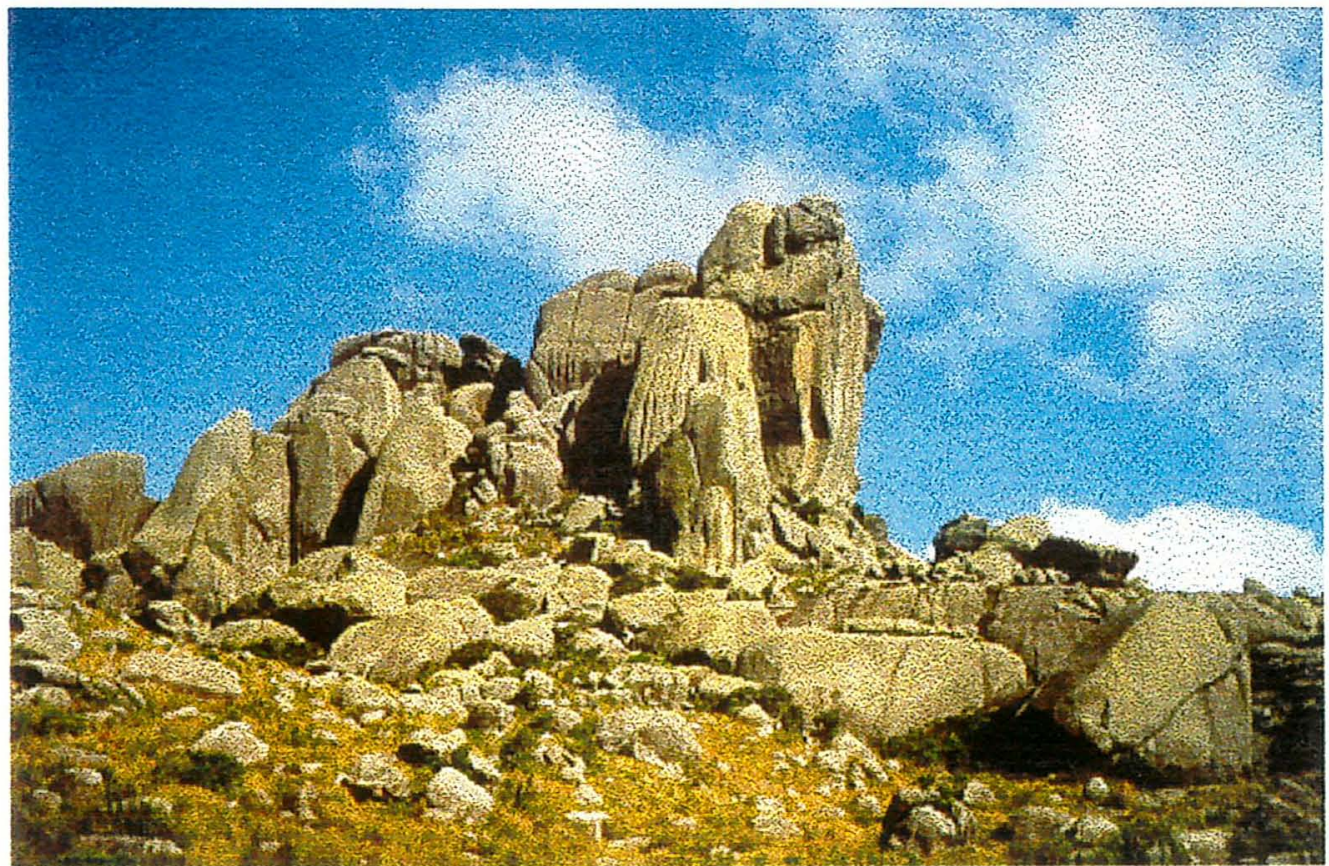

Figura 52 - Pico das Prateleiras 


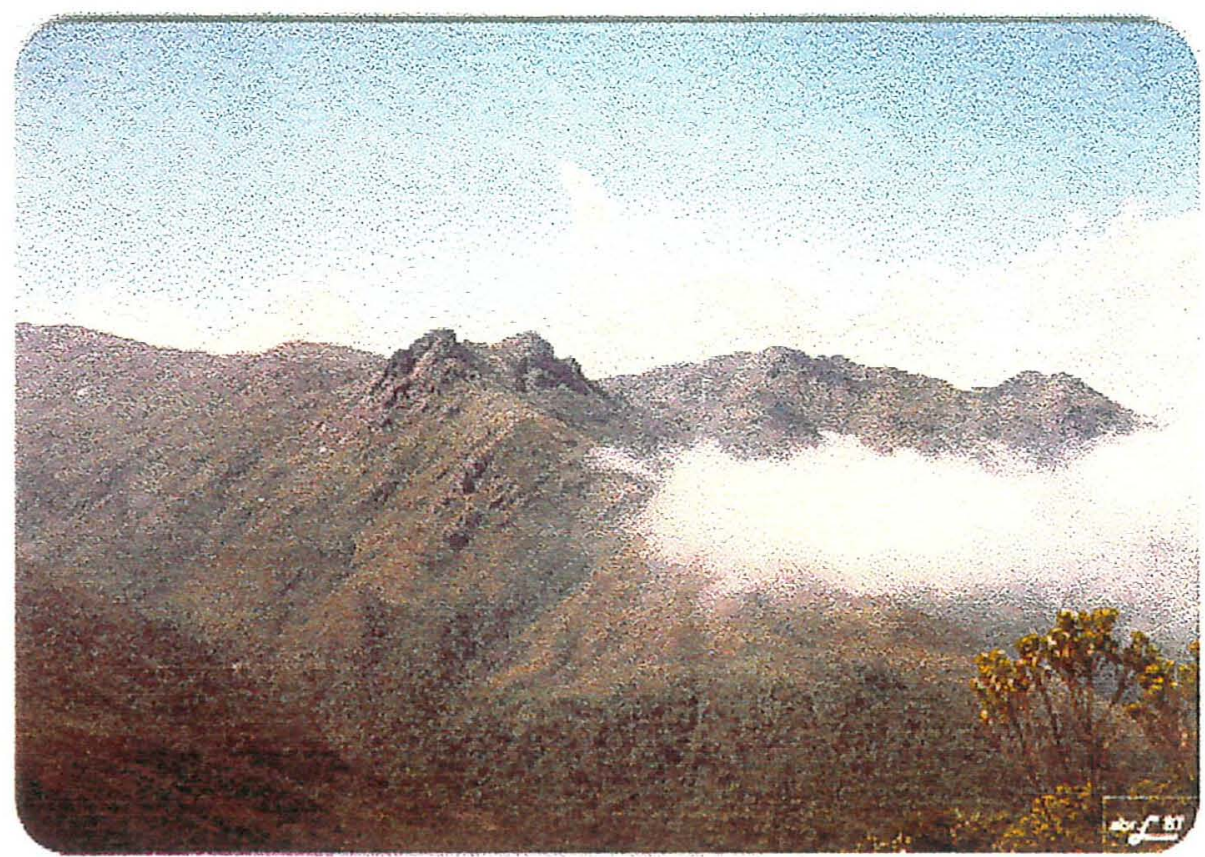

Figura 53 - Pedra da Cabeça de Leão

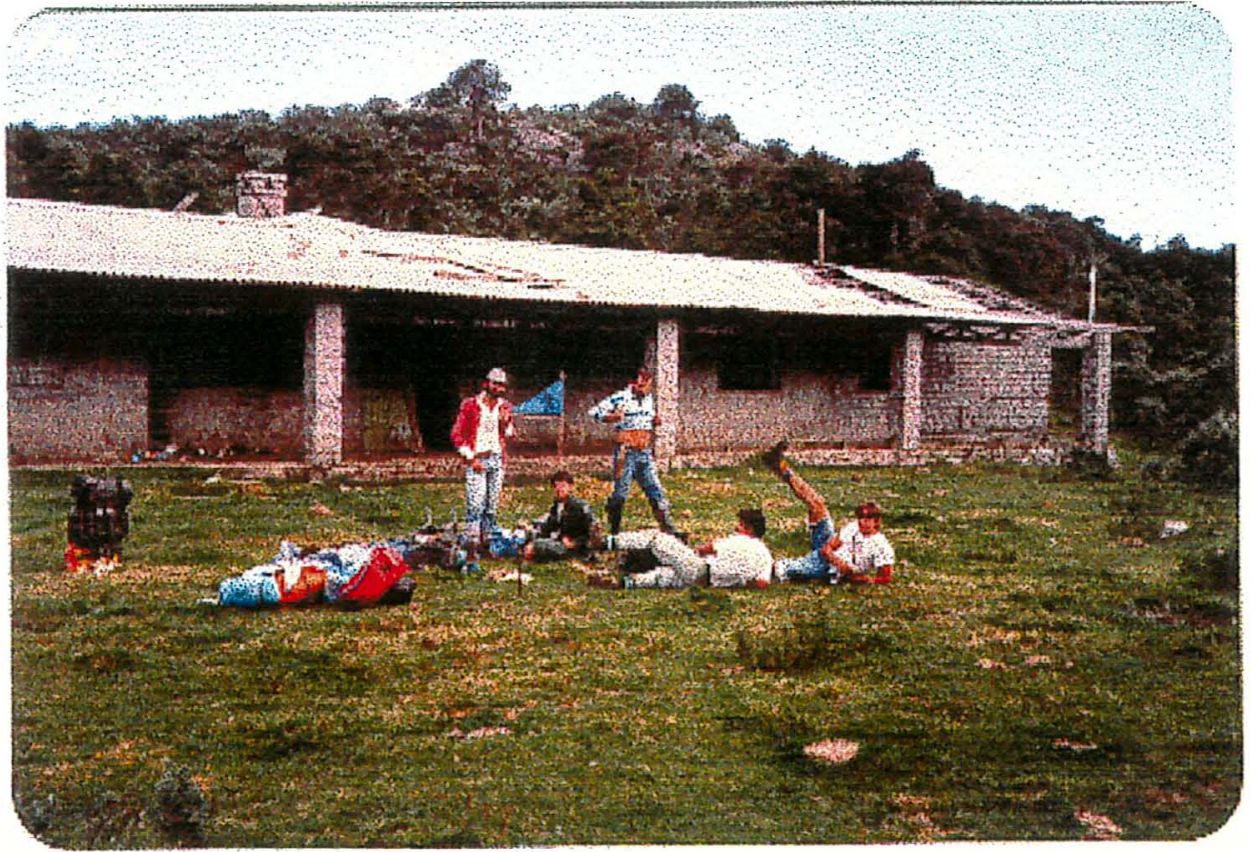

Figura 54 - Abrigo Massenas 


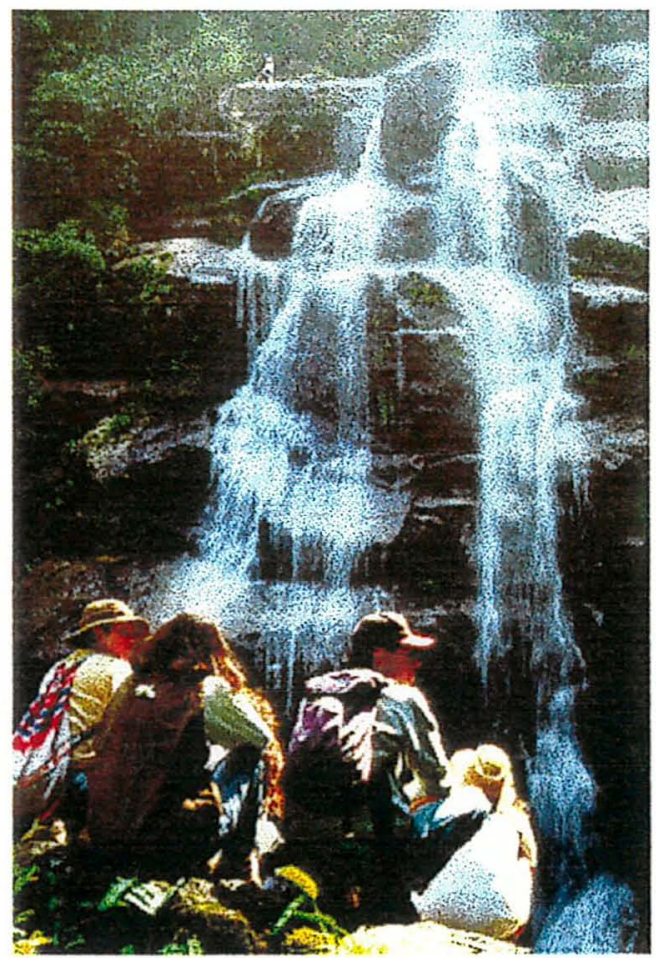

Figura 55 - Cachoeira Véu da Noiva

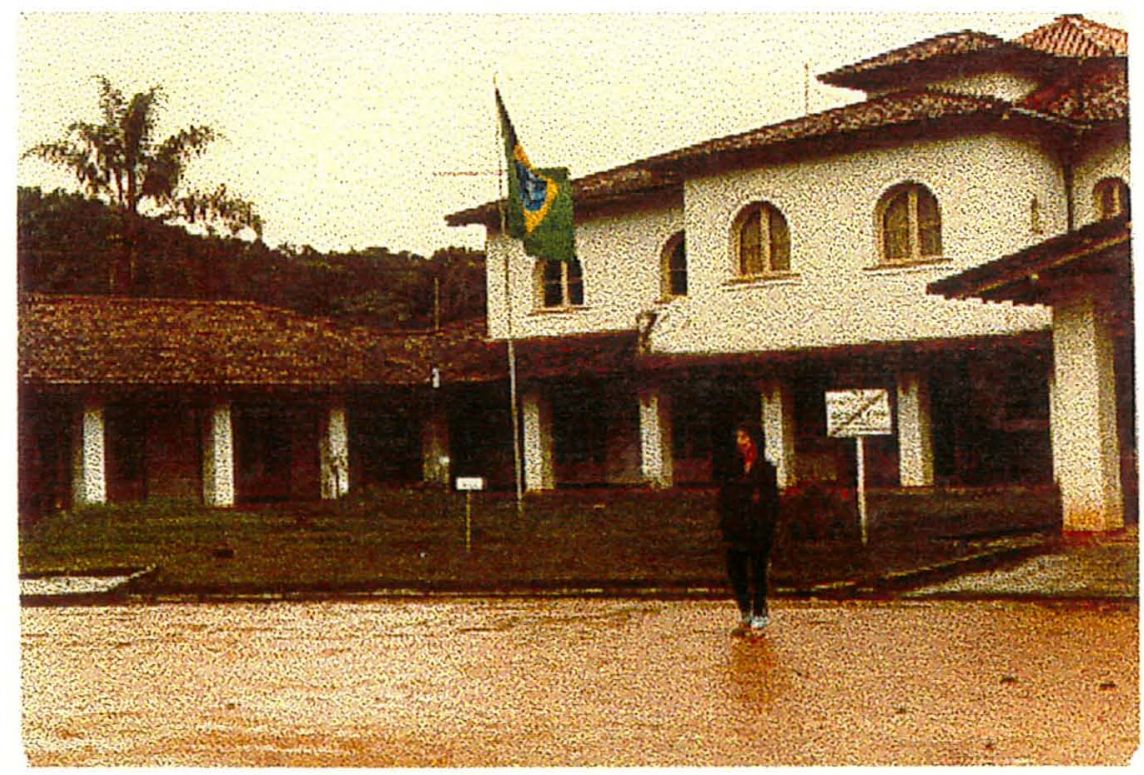

Figura 56 - Museu do P.N. de Itatiaia 


\subsection{Caracterização da infra-estrutura de apoio}

Realizou-se o levantamento de hotéis / pousadas / pensões, áreas de camping (ANEXO 1), hospitais e transportes dos municípios que integram a área de estudo (TABELAS 2 e 3).

TABELA 2: Hospitais nos municípios atravessados pela Trilha.

\begin{tabular}{|c|c|c|}
\hline MUNICÍPIO & HOSPITAL & ENDEREÇO \\
\hline CAMANDUCAIA & $\begin{array}{l}\text { Irmandade Santa Casa de } \\
\text { Misericórdia }\end{array}$ & Av.Dr. Bueno de Paiva $s / n^{\circ}$ \\
\hline CAMPOS DO JORDÃO & Santa Casa & $\begin{array}{l}\text { R. Inácio Caetano } \\
\text { Fone: } 262-1196\end{array}$ \\
\hline DELFIM MOREIRA & $\begin{array}{l}\text { Pronto Atendimento } \\
\text { Municipal }\end{array}$ & Av. J.K. de Oliveira $s / n^{\circ}$ \\
\hline EXTREMA & São Lucas & $\begin{array}{l}\text { Jd. S. Cristóvão } \\
\text { Fone: 435-1333 }\end{array}$ \\
\hline GUARATINGUETÁ & Santa Casa & $\begin{array}{l}\text { Pça. } 15 \text { de Novembro, } 243 \\
\text { Fone: } 532-4555\end{array}$ \\
\hline ITAMONTE & Casa de Caridade & $\begin{array}{l}\text { R. Antônio Ribeiro Couto, } 103 \\
\text { Fone: } 363-1500\end{array}$ \\
\hline ITATIAIA & Posto de saúde & $\begin{array}{l}\text { Av. dos Expedicionários } \\
\text { Fone: } 52-1260, r .316\end{array}$ \\
\hline JOANÓPOLIS & Santa Casa & $\begin{array}{l}\text { R. Francisco Wohlens, } 57 \\
\text { Fone: } 7869-9333\end{array}$ \\
\hline $\begin{array}{l}\text { LAVRINHAS } \\
\text { MARMELÓPOLIS }\end{array}$ & $\begin{array}{l}\text { Centro de Saúde } \\
\text { Posto de Saúde }\end{array}$ & $\begin{array}{l}\text { R. Gabriela Faria s/n }{ }^{\circ} \\
\text { R. Manoel Frederico Ribeiro,197 } \\
\text { Fone } 625-1257\end{array}$ \\
\hline PASSA QUATRO & Santa Casa & $\begin{array}{l}\text { Av. Cel. Ribeiro Pereira, } 632 \\
\text { Fone: } 371-1036\end{array}$ \\
\hline PIQUETE & Unidade Mista de Saúde & $\begin{array}{l}\text { Pça Prof. Olga Maria Ecklund } \\
\text { Armando, } 5 / n^{\circ} \\
\text { Fone } 556-1100 / 1108\end{array}$ \\
\hline PIRANGUÇU & Posto de Saúde & $\begin{array}{l}\text { Pça João Pereira Pinto } s / n^{\circ} \\
\text { Fone } 643-1144\end{array}$ \\
\hline QUELUZ & Santa Casa & $\begin{array}{l}\text { Ld. N.S. de Fátima, } 11 \\
\text { Fone: } 547-1236\end{array}$ \\
\hline RESENDE & Santa Casa & $\begin{array}{l}\text { Pça. Clemente Ferreira, } 39 \\
\text { Fone: } 54-0159\end{array}$ \\
\hline SÃO BENTO DO SAPUCAÍ & Santa Casa & $\begin{array}{l}\text { Pça. Gen. Marcondes Salgado, } 34 \\
\text { Fone: } 371-1122\end{array}$ \\
\hline SÃO JOSÉ DOS CAMPOS & Santa Casa & $\begin{array}{l}\text { R. Dolzani Ricardo, } 620 \\
\text { Fone: } 321-1999\end{array}$ \\
\hline $\begin{array}{l}\text { SAPUCAÍ MIRIM } \\
\text { VARGEM }\end{array}$ & $\begin{array}{l}\text { Centro de Saúde } \\
\text { Centro de Saúde }\end{array}$ & $\begin{array}{l}\text { Av. Pres. Tancredo Neves, } s / n^{\circ} \\
\text { R. Euclides Fredegh } s / n^{\circ}\end{array}$ \\
\hline
\end{tabular}


TABELA 3: Transporte para os municípios abrangidos pela Trilha, ou próximos.

\begin{tabular}{|c|c|c|c|}
\hline ORIGEM & DESTINO & HORÁRIO & EMPRESA \\
\hline São Paulo & Camanducaia & $\begin{array}{l}8: 30 / 9: 45 / 12: 00 / 13: 30 / \\
15: 00 / 16: 45 / 18: 00 / 19: 30 \\
/ 20: 30\end{array}$ & Viação Cambuí \\
\hline Camanducaia & São Paulo & $\begin{array}{l}4: 50 / 6: 05 / 7: 20 / 9: 20 / \\
12: 20 / 14: 50 / 16: 50\end{array}$ & Viação Cambuí \\
\hline São Paulo & $\begin{array}{l}\text { Extrema ( apoio } \\
\text { também para } \\
\text { Vargem) }\end{array}$ & $\begin{array}{l}\text { 8:30/ } / 9: 45 / 12: 00 / 13: 30 / \\
15: 00 / 16: 45 / 18: 00 / 19: 30 \\
/ 20: 30\end{array}$ & Viação Cambuí \\
\hline Extrema & São Paulo & $\begin{array}{l}5: 20 / 6: 35 / 7: 50 / 9: 50 / \\
12: 50 / 15: 20 / 17: 20\end{array}$ & Viação Cambuí \\
\hline São Paulo & $\begin{array}{l}\text { Itajubá (apoio para } \\
\text { Delfim Moreira, } \\
\text { Marmelópolis, } \\
\text { Piranguçu) }\end{array}$ & $8: 15 / 13: 15 / 16: 15 / 18: 45$ & Viação Cambuí \\
\hline $\begin{array}{l}\text { Itajubá } \\
\text { São Paulo }\end{array}$ & $\begin{array}{l}\text { São Paulo } \\
\text { Passa Quatro }\end{array}$ & $\begin{array}{l}\text { 4:30/8:00/12:00 / 16:00 } \\
\text { 7:45/ 12:15 / 15:30/ 18:45 / } \\
23: 15\end{array}$ & $\begin{array}{l}\text { Pássaro Marrom } \\
\text { Pássaro Marrom }\end{array}$ \\
\hline Passa Quatro & São Paulo & $\begin{array}{l}2: 15 / 9: 30 / 13: 15 / 16: 00 / \\
18: 00\end{array}$ & Viação Resendense \\
\hline São Paulo & $\begin{array}{l}\text { São Lourenço } \\
\text { (apoio para } \\
\text { Itamonte) }\end{array}$ & $\begin{array}{l}\text { 8:00/ 12:15/ 15:30/18:45/ } \\
20: 15\end{array}$ & \\
\hline São Lourenço & São Paulo & $\begin{array}{l}1: 00 / 8: 30 / 11: 45 / 14: 30 / \\
16: 30\end{array}$ & \\
\hline São Paulo & Sapucai-Mirim & $6: 30 / 18: 30$ & $\begin{array}{l}\text { Expresso da } \\
\text { Mantiqueira }\end{array}$ \\
\hline Sapucaí-Mirim & São Paulo & $\begin{array}{l}\text { 6:30 / 18:30 (saida de } \\
\text { Brasópolis) }\end{array}$ & $\begin{array}{l}\text { Expresso da } \\
\text { Mantiqueira }\end{array}$ \\
\hline São Paulo & Campos do Jordão & $\begin{array}{l}\text { 6:00 / 8:00 / 10:00 / 12:00 / } \\
15: 00 / 17: 00 / 19: 00\end{array}$ & $\begin{array}{l}\text { Expresso da } \\
\text { Mantiqueira }\end{array}$ \\
\hline Campos do Jordäo & São Paulo & $\begin{array}{l}6: 00 / 8: 00^{*} / 10: 00 / 12: 00 / \\
15: 00 / 17: 00 / 19: 00 \\
{ }^{*} \text { menos aos domingos }\end{array}$ & $\begin{array}{l}\text { Expresso da } \\
\text { Mantiqueira }\end{array}$ \\
\hline São Paulo & Guaratinguetá & $\begin{array}{l}\text { 6:20 / 7:05 / 8:05 / 8:45* } / \\
\text { 9:35 / 10:45 / 12:05 / 15:35 / } \\
\text { 19:10 } \\
\text { * menos aos sábados }\end{array}$ & Viação Cometa \\
\hline Guaratinguetá & São Paulo & $\begin{array}{l}\text { 6:55 / 8:55 / 10:25 / 12:05/ } \\
13: 55 / 15: 55 / 17: 05 / 18: 55\end{array}$ & Viação Cometa \\
\hline São Paulo & Joanópolis & $9: 00 / 19: 00$ & $\begin{array}{l}\text { Viação Atibaia - } \\
\text { São Paulo }\end{array}$ \\
\hline Joanópolis & São Paulo & $6: 00 / 13: 00$ & $\begin{array}{l}\text { Viação Atibaia - } \\
\text { São Paulo }\end{array}$ \\
\hline $\begin{array}{l}\text { São Paulo } \\
\text { Piquete }\end{array}$ & $\begin{array}{l}\text { Piquete } \\
\text { São Paulo }\end{array}$ & $17: 20$ & $\begin{array}{l}\text { Pássaro Marrom } \\
\text { Pássaro Marrom }\end{array}$ \\
\hline São Paulo & $\begin{array}{l}\text { Queluz (apoio } \\
\text { também para } \\
\text { Lavrinhas) }\end{array}$ & $16: 30$ & Pássaro Marrom \\
\hline
\end{tabular}




\begin{tabular}{|c|c|c|c|}
\hline $\begin{array}{l}\text { Queluz } \\
\text { São Paulo }\end{array}$ & $\begin{array}{l}\text { São Paulo } \\
\text { São Bento do } \\
\text { Sapucaí }\end{array}$ & $\begin{array}{l}6: 00 \\
6: 30 / 18: 30\end{array}$ & $\begin{array}{l}\text { Pássaro Marrom } \\
\text { Expresso da } \\
\text { Mantiqueira }\end{array}$ \\
\hline São Bento do Sapucaí & São Paulo & $\begin{array}{l}\text { 6:30 / 18:30 (saída de } \\
\text { Brasópolis) }\end{array}$ & $\begin{array}{l}\text { Expresso da } \\
\text { Mantiqueira }\end{array}$ \\
\hline São Paulo & $\begin{array}{l}\text { São José dos } \\
\text { Campos }\end{array}$ & $\begin{array}{l}\text { De } 20 \text { em } 20 \text { minutos, das } \\
6: 00 \text { as } 20: 00 \text { hs e de } 30 \text { em } \\
30 \text { minutos das } 20: 00 \text { as } \\
24: 00 \text { horas }\end{array}$ & Pássaro Marrom \\
\hline São José dos Campos & São Paulo & $\begin{array}{l}0: 00 / 9: 15 / 9: 30 / 9: 45 / \\
10: 00 / 10: 15 / 10: 30 / 10: 45 \\
/ 11: 00 / 11: 15 / 11: 45 / \\
12: 00 / 12: 15 / 12: 45 / \text { das } \\
13: 00 \text { as 16:00 horas de } 20 \\
\text { em } 20 \text { minutos, das 16:00 } \\
\text { as 18:00 de } 15 \text { em 15 } \\
\text { minutos / 19:00/19:20/ } \\
\text { 20:00 / 21:00/21:30/22:00 } \\
/ 23: 40\end{array}$ & Pássaro Marrom \\
\hline São Paulo & Itatiaia & $\begin{array}{l}7: 00 / 10: 00 / 12: 00 / 15: 00 / \\
16: 30 / 18: 00 / 24: 00\end{array}$ & Viação Resendense \\
\hline Itatiaia & São Paulo & $\begin{array}{l}\text { 1:00 / 1:15 / 3:00 / 7:00 / } \\
\text { 19:00 }\end{array}$ & Viação Resendense \\
\hline São Paulo & Resende & $\begin{array}{l}\text { 7:00 / 10:00 / 12:00 / 15:00 / } \\
16: 30 / 18: 00 / 24: 00\end{array}$ & Viação Resendense \\
\hline Resende & São Paulo & $\begin{array}{l}7: 00 / 10: 00 / 12: 00 / 15: 00 / \\
16: 30 / 18: 00 / 24: 00\end{array}$ & Viação Resendense \\
\hline Rio de Janeiro & Itatiaia & $9: 15 / 13: 30$ & $\begin{array}{l}\text { Viação Cidade do } \\
\text { Aço }\end{array}$ \\
\hline Itatiaia & Rio de Janeiro & $12: 00 / 17: 00$ & $\begin{array}{l}\text { Viação Cidade do } \\
\text { Aço }\end{array}$ \\
\hline Rio de Janeiro & Resende & $\begin{array}{l}\text { 7:00 / 9:15/11:00 / 12:30/ } \\
\text { 13:30 / 15:00 / 16:00 / 17:00 } \\
/ 18: 30 / 20: 00\end{array}$ & $\begin{array}{l}\text { Viação Cidade do } \\
\text { Aço }\end{array}$ \\
\hline Resende & Rio de Janeiro & $\begin{array}{l}5: 45 / 7: 00 / 8: 30 / 10: 00 / \\
13: 00 / 14: 30 / 16: 30 / 17: 30 \\
/ 18: 00 / 19: 00\end{array}$ & $\begin{array}{l}\text { Viação Cidade do } \\
\text { Aço }\end{array}$ \\
\hline Rio de Janeiro & Itamonte & $8: 30 / 16: 00$ & Viação Beltur \\
\hline $\begin{array}{l}\text { Itamonte } \\
\text { Rio de Janeiro }\end{array}$ & $\begin{array}{l}\text { Rio de Janeiro } \\
\text { Campos do Jordão }\end{array}$ & $\begin{array}{l}8: 30 / 16: 00 \\
8: 00 / 16: 00\end{array}$ & $\begin{array}{l}\text { Viação Beltur } \\
\text { Expresso da } \\
\text { Mantiqueira }\end{array}$ \\
\hline Campos do Jordão & Rio de Janeiro & $06: 20 / 16: 00$ & $\begin{array}{l}\text { Expresso da } \\
\text { Mantiqueira }\end{array}$ \\
\hline Belo Horizonte & $\begin{array}{l}\text { Passa Quatro } \\
\text { (apoio também } \\
\text { para ltamonte) }\end{array}$ & 7:00 & Viação Gardênia \\
\hline $\begin{array}{l}\text { Passa Quatro } \\
\text { Belo Horizonte }\end{array}$ & $\begin{array}{l}\text { Belo Horizonte } \\
\text { Camanducaia } \\
\text { (apoio também } \\
\text { para Extrema) }\end{array}$ & $\begin{array}{l}7: 30 \\
8: 15 / 9: 30 / 12: 00 / 18: 15 / \\
20: 15 / 20: 30\end{array}$ & $\begin{array}{l}\text { Viação Gardênia } \\
\text { Viação Gontijo }\end{array}$ \\
\hline Camanducaia & Belo Horizonte & $10: 00 / 11: 30 / 18: 15$ & Viação Gontijo \\
\hline
\end{tabular}




\section{ESTRATÉGIA DE IMPLANTAÇÃO}

\subsection{Definição das instituições coordenadoras}

De acordo com as Diretrizes para uma Política Estadual de Ecoturismo (SÀO PAULO, 1997), uma das estratégias consideradas findamentais para 0 desenvolvimento e/ou realinhamento das atividades do ecoturismo no Estado de São Paulo é o fortalecimento e interação institucional, cujo objetivo primordial é promover a articulação e o intercâmbio de informações e de experiências entre órgãos governamentais, entidades da sociedade civil e setor privado.

Dentre as várias instituições analisadas selecionouse com base em critérios como atuação na área, pessoal técnico capacitado e com potencial para capacitação, e serviços prestados, as seguintes instituições:

a) âmbito estadual

$>$ Estado de Minas Gerais: Instituto Estadual de Florestas-IEF-MG e Fundação Estadual do Meio Ambiente - FEAM

$>$ Estado do Rio de Janeiro: Instituto Estadual de Florestas - IEF-RJ

$>$ Estado de São Paulo: Instituto Florestal -IF e Coordenadoria de Educação Ambiental - CEAM

b) âmbito federal

$>$ Instituto Brasileiro de Meio Ambiente e dos Recursos Naturais - IBAMA

Selecionou-se também o Serviço Nacional de Aprendizagem Comercial - SENAC, por sua reconhecida competência e idoneidade, representando as instituições voltadas para o aprendizado e que mantém cursos regulares e em vários níveis, na área de meio ambiente e turismo 


\subsection{Levantamento e cadastramento de voluntários potenciais}

Com base no Cadastro Nacional de Instituições Ambientalistas (MATER NATURA, 1996), selecionou-se as organizações ambientalistas localizadas no Vale do Paraíba, Micro Região Sul (202) e as capitais Belo Horizonte, Rio de Janeiro e São Paulo (ANEXO 2). A essas agrupou-se seus clubes excursionistas (TABELA 4).

TABELA 4: Clubes excursionistas situados em alguns municípios atravessados pela trilha e nas capitais dos estados envolvidos no presente trabalho

\begin{tabular}{|c|c|}
\hline Nome & Endereço \\
\hline CENTRO EXCURSIONISTA BRASILEIRO & $\begin{array}{l}\text { Av. Almirante Barroso, } 2 \text { - 80. andar - Centro } \\
\text { Rio de Janeiro - RJ CEP 20031-000 }\end{array}$ \\
\hline CENTRO EXCURSIONISTA GUANABARA & $\begin{array}{l}\text { Rua Washington Luiz, } 9 \text { - cobertura - Centro } \\
\text { Rio de Janeiro - RJ CEP 20230-020 }\end{array}$ \\
\hline CENTRO EXCURSIONISTA LIGHT & $\begin{array}{l}\text { Av. Marechal Floriano, } 199 / 501 \text { - Centro Rio de } \\
\text { Janeiro - RJ CEP 20080-005 }\end{array}$ \\
\hline $\begin{array}{l}\text { CENTRO EXCURSIONISTA RIO DE } \\
\text { JANEIRO }\end{array}$ & $\begin{array}{l}\text { Av. Rio Branco, 277/805 - Centro Rio de } \\
\text { Janeiro - RJ CEP 20040-009 }\end{array}$ \\
\hline CENTRO EXCURSIONISTA UNIVERSITÁRIO & $\begin{array}{l}\text { Prédio da Antiga Reitoria, sala } 208 \text { - Cidade } \\
\text { Universitária - USP - São Paulo - SP CEP } \\
05508-900\end{array}$ \\
\hline CLUBE ALPINO PAULISTA & $\begin{array}{l}\text { Rua Dr. Amâncio de Carvalho, } 86 \text { - Vila } \\
\text { Mariana - São Paulo - SP CEP 04012-080 }\end{array}$ \\
\hline CLUBE DA MONTANHA & $\begin{array}{l}\text { Caixa Postal } 81788 \text { - Resende - RJ CEP } \\
22040-020\end{array}$ \\
\hline CLUBE MINEIRO DE MONTANHISMO & $\begin{array}{l}\text { Rua Padre Odorico, } 231 \text { - São Pedro - Belo } \\
\text { Horizonte - MG CEP } 30330-040\end{array}$ \\
\hline $\begin{array}{l}\text { GRUPO EXCURSIONISTA AGULHAS } \\
\text { NEGRAS }\end{array}$ & $\begin{array}{l}\text { Caixa Postal } 81788 \text { - Resende - RJ CEP } \\
27501-970\end{array}$ \\
\hline
\end{tabular}

6.3 Caracterização e quantificação de lideranças institucionais e voluntárias

Dever-se-á levantar junto às organizações ambientalistas e clubes excursionistas os voluntários interessados, bem como pessoal habilitado à coordenar o programa delineado a seguir, e participar da fase de implantação. 


\subsection{Programa de treinamento e capacitação de voluntários e técnicos institucionais}

Com base em metodologia desenvolvida pelo autor em diversos cursos no Instituto Florestal de São Paulo, como o de Manejo de Áreas Silvestres ( ANDRADE, 1993 ), e estágios voluntários coordenados também pelo autor, formatou-se o programa abaixo:

a) Histórico e objetivos da Conservação da Natureza

e histórico e manejo de unidades de conservação

$8 \mathrm{~h}$

b) Filosofia e diretrizes do trabalho voluntário

$8 \mathrm{~h}$

c) Manejo de trilhas

$8 \mathrm{~h}$

> elaboração e adequação de traçado

$>$ orientação da drenagem

$>$ contenção de encostas

$>$ recuperação de áreas degradadas

$>$ travessia de corpos d'água

$>$ sinalização

$>$ ferramentas e seu manuseio

d) Técnicas de construções rústicas

$8 h$

$>$ abrigos de montanha

$>$ camping rústico

$>$ sanitários

$>$ pontes, etc.

e) Emprego de eco-técnicas

$8 \mathrm{~h}$

> captação, tratamento, armazenamento e distribuição d'água

$>$ geração e aproveitamento de energia

$>$ tratamento de efluentes

$>$ tratamento de resídos sólidos

$>$ telecomunicações

PRÁTICA $=0$ voluntário estará capacitado após desenvolver 40 horas práticas, em campo. 


\subsection{Plano de implantação}

a) Gestão no sentido de se constituir comissão organizadora e coordenadora da implantação da Trilha da Mantiqueira que poderá ser assim composta:

1 membro do IBAMA preferivelmente integrante do quadro funcional da APA federal da Mantiqueira

$>1$ integrante do IF - SP

$>1$ integrante da CEAM

1 integrante do IEF-MG

$>1$ integrante da FEAM

$>1$ integrante do IEF-RJ

$>1$ integrante do SENAC, envolvido diretamente com os cursos na área de meio ambiente e turismo

$>06$ integrantes do movimento ambientalista e/ou clubes excursionistas

b) Realização de um seminário com a participação dos membros elencados acima mais um moderador, com a finalidade de estruturar ou reestruturar o processo com base nos itens seguintes deste plano

c) Dimensionar os treinamentos específicos necessários

Complementando os trabalhos de campo, deverá se realizar cursos periódicos e abrangentes.

d) Definir os trechos prioritários da Trilha

Dever-se-á priorizar alguns trechos da trilha, para início dos trabalhos, de acordo com a necessidade de cada um e o interesse dos grupos voluntários.

e) Reavaliar o traçado proposto neste trabalho, para cada trecho da trilha 
Dever-se-á realizar uma análise detalhada de cada trecho antes de sua efetiva implantação, divulgação e liberação ao público excursionista.

f) Caracterizar e dimensionar eventuais intervenções

$>$ fechamento da trilha

$>$ abertura da trilha

$>$ clareamento da trilha

$>$ orientação da drenagem

$>$ contenção de encostas

$>$ degraus

$>$ estrados e pula-pedras

$>$ pontes

$>$ sinalização

$>$ áreas de acampamento (sanitários, pontos de água e lava-pratos)

g) Regulamento de utilização

O regulamento de utilização deverá orientar o visitante a utilizar a trilha, atentando para aspectos e normas relativos à sua conservação, bem como a de seu entorno.

h) Plano de divulgação

O plano de divulgação poderá envolver entre outras atividades a confecção e distribuição de mapas, folhetos, regulamentos para visitação, etc.

i) Orientação para obras a serem realizadas

A necessidade de pequenas obras está presente tanto na fase de implantação quanto de manutenção de trilhas. Há quatro fatores mais comuns que exigem a realização de obras em trilhas: drenagem, ultrapassagem de corpos d'água, contenção de erosão e sinalização. 


\section{$>$ Drenagem:}

Como a presença de uma trilha altera o padrão de circulação de água na área, algumas obras de "reorganização" de drenagem são necessárias.

Pode-se construir canais laterais de escoamento (para que a água corra paralelamente à trilha), canais que cruzam perpendicularmente a trilha (tanto em nível quanto por baixo da mesma) e valas ou barreiras oblíquas à superfície da trilha (para facilitar o escoamento da água que está eventualmente sobre a mesma) (FIGURA 57).

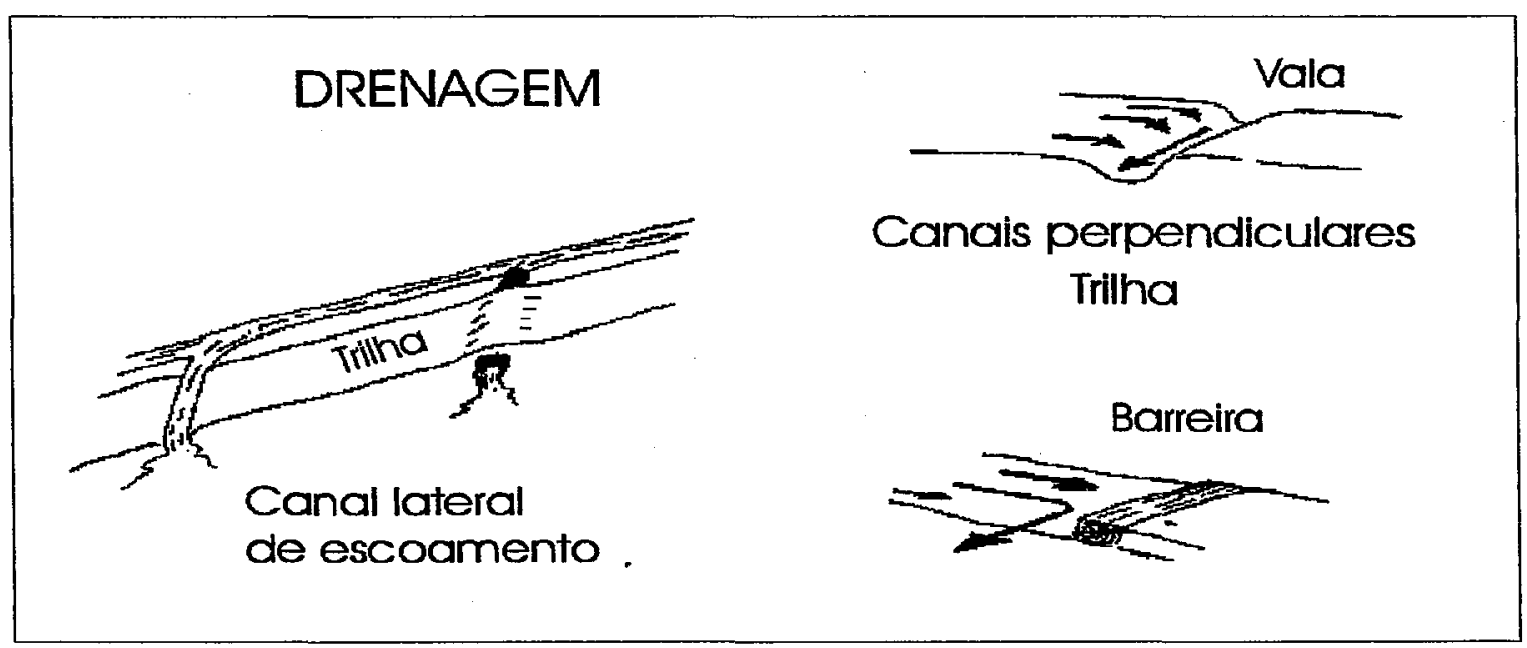

FIGURA 57 - Orientação da drenagem

$>$ Ultrapassagem de corpos d'água:

Neste tema estão incluídos não só a ultrapassagem de rios e riachos como também a ultrapassagem de locais alagados. No primeiro caso as obras são basicamente de construção de pontes (FIGURA 58) ou pinguelas (FIGURA 59). Segundo AGATE (1983), na construção de qualquer ponte maior que nove metros, não devese prescindir de um engenheiro. 


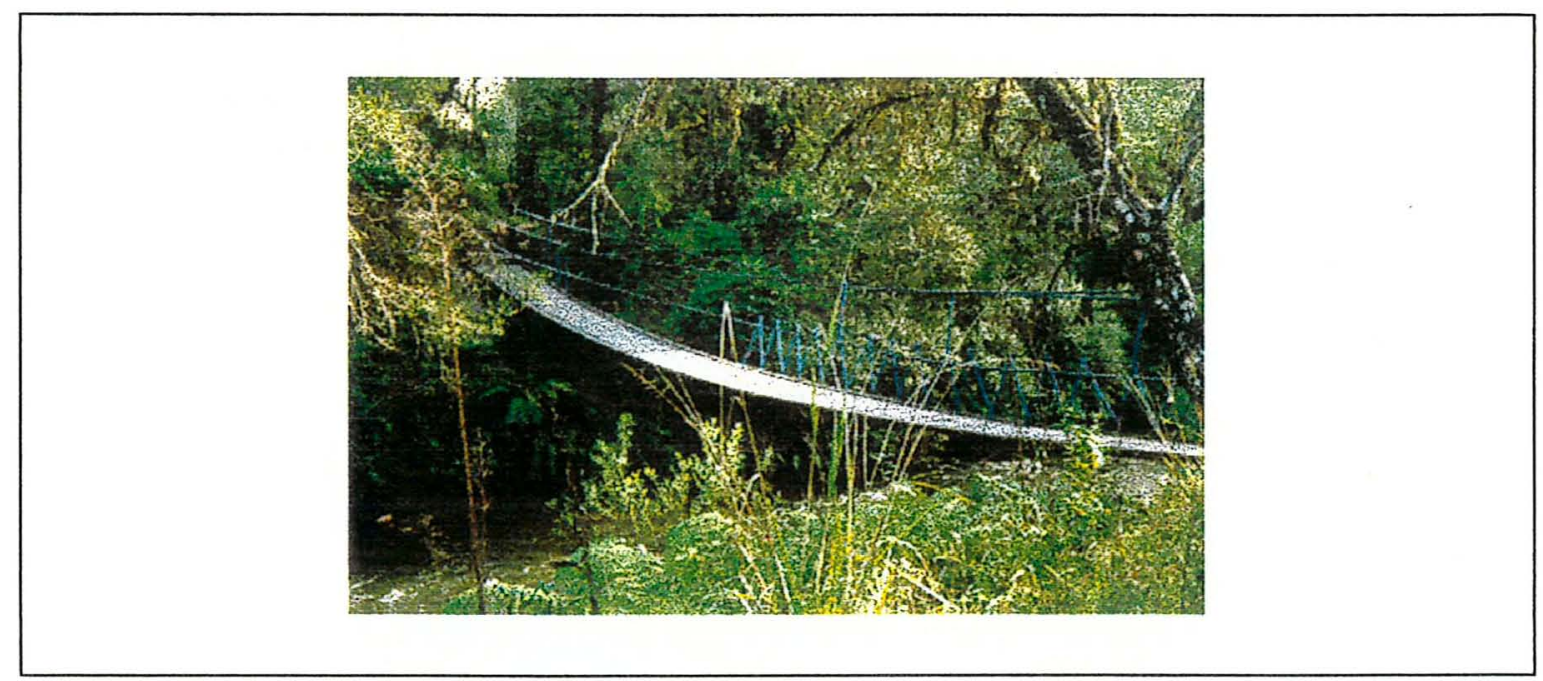

FIGURA 58 - Ponte pencil no P.E.C.J.

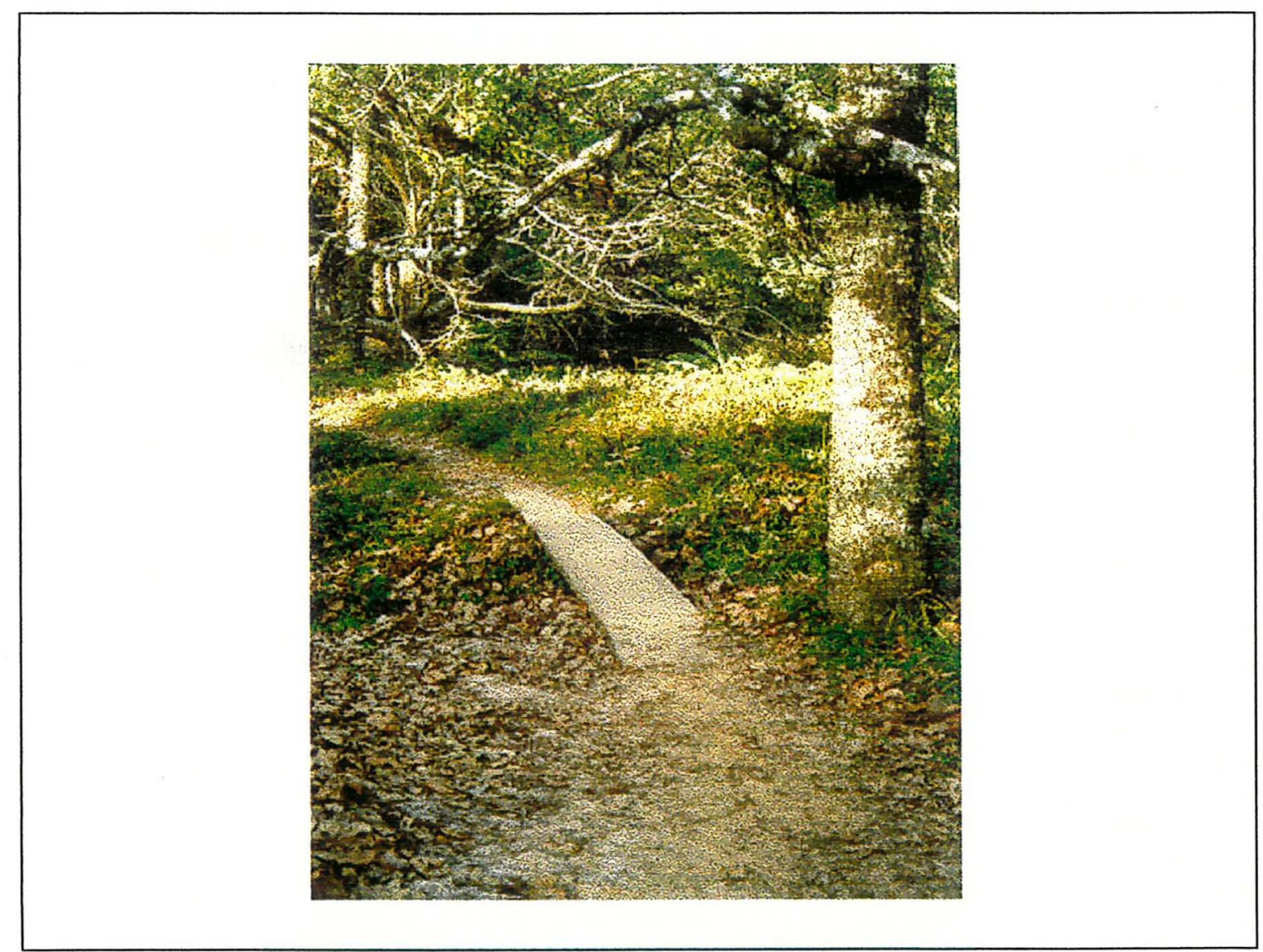

FIGURA 59 - Pinguela no P.E.C.J.

Com relação à ultrapassagem de alagados pode-se solucionar o problema com blocos de pedra e/ou secções 
transversais de troncos dispostos estratégica e seqüencialmente (FIGURA 60). Outra maneira (porém mais dispendiosa) são os tablados ou estrados, que permitem uma caminhada fácil e segura, transferindo a superfície de uso direto do solo para a madeira.

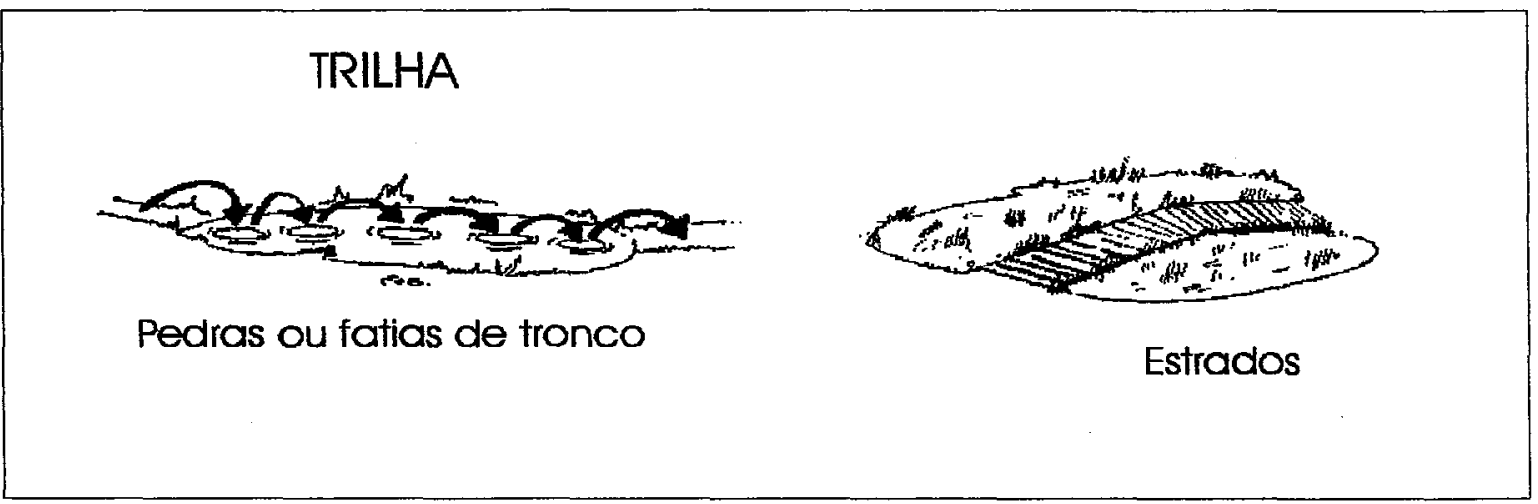

FIGURA 60 - Blocos de pedra e tablados/estrados

> Contenção de erosão:

Dois tipos de obras podem ser feitas na contenção de erosão: degraus e "paredes".

A construção de degraus é uma das mais difíceis obras em trilhas e devem ser construídos somente se não houver outra maneira. Deve-se evitar longos trechos de degraus em linhas retas, construção em terrenos ao lado de quedas abruptas (terrenos normalmente instáveis) e deve-se ainda analisar o local da obra tanto com uma visão de quem desce quanto de quem sobe, a fim de tornar o traçado o mais atrativo possível (AGATE, 1983).

Os degraus podem ser feitos de várias maneiras: com pedras, troncos e pranchas de madeira (FIGURA 61).

A construção de "paredes" de contenção em declives (FIGURA 62) tanto previne a erosão da trilha, no caso de encosta abaixo da mesma, quanto previne a deposição de material advindo da encosta acima. Aqui também pode ser feita de pedras, troncos ou com os dois (AGATE, 1983; PROUDMAN, 1977). 


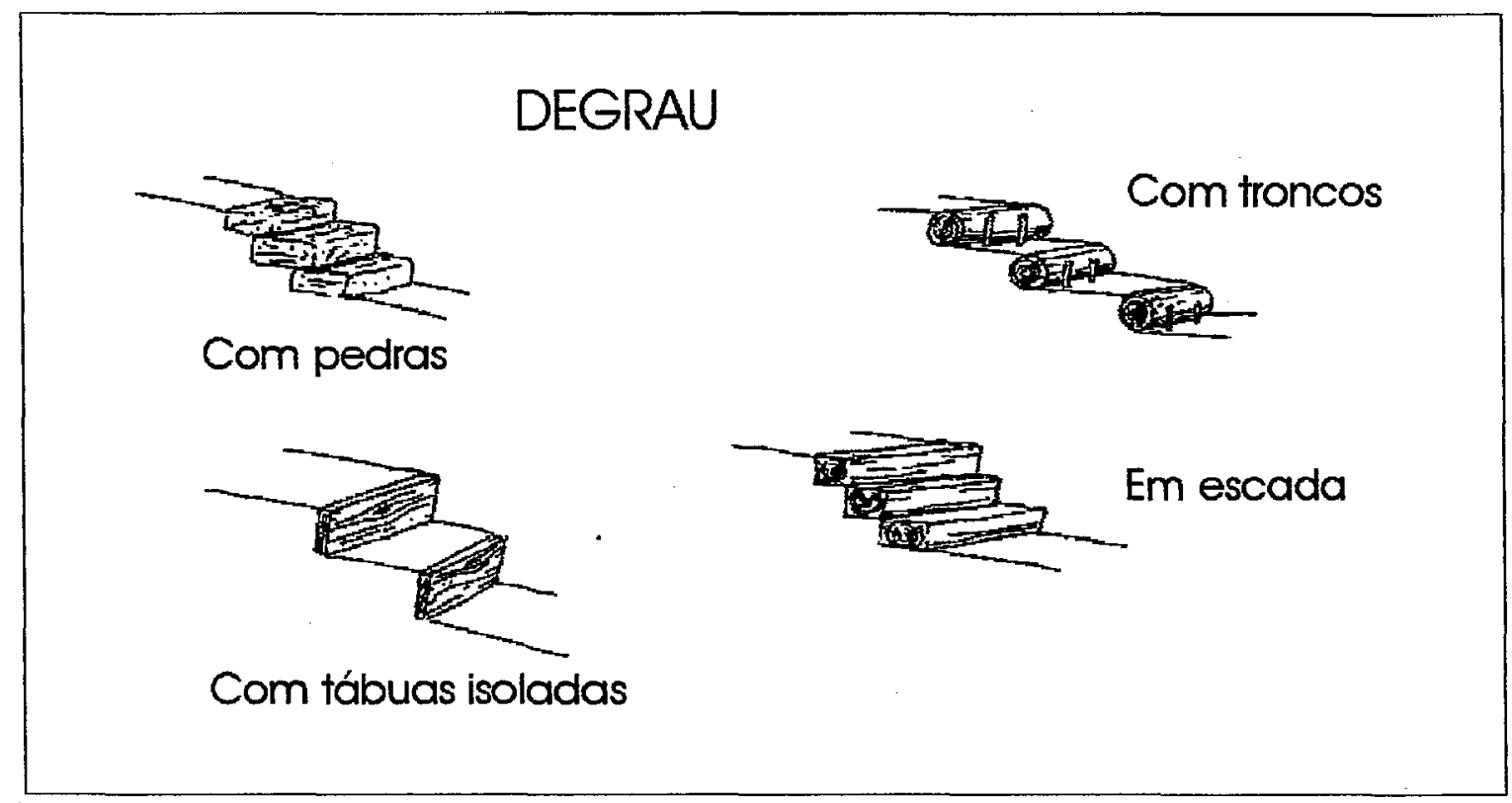

FIGURA 61 - Tipos de degraus utilizados em trilhas

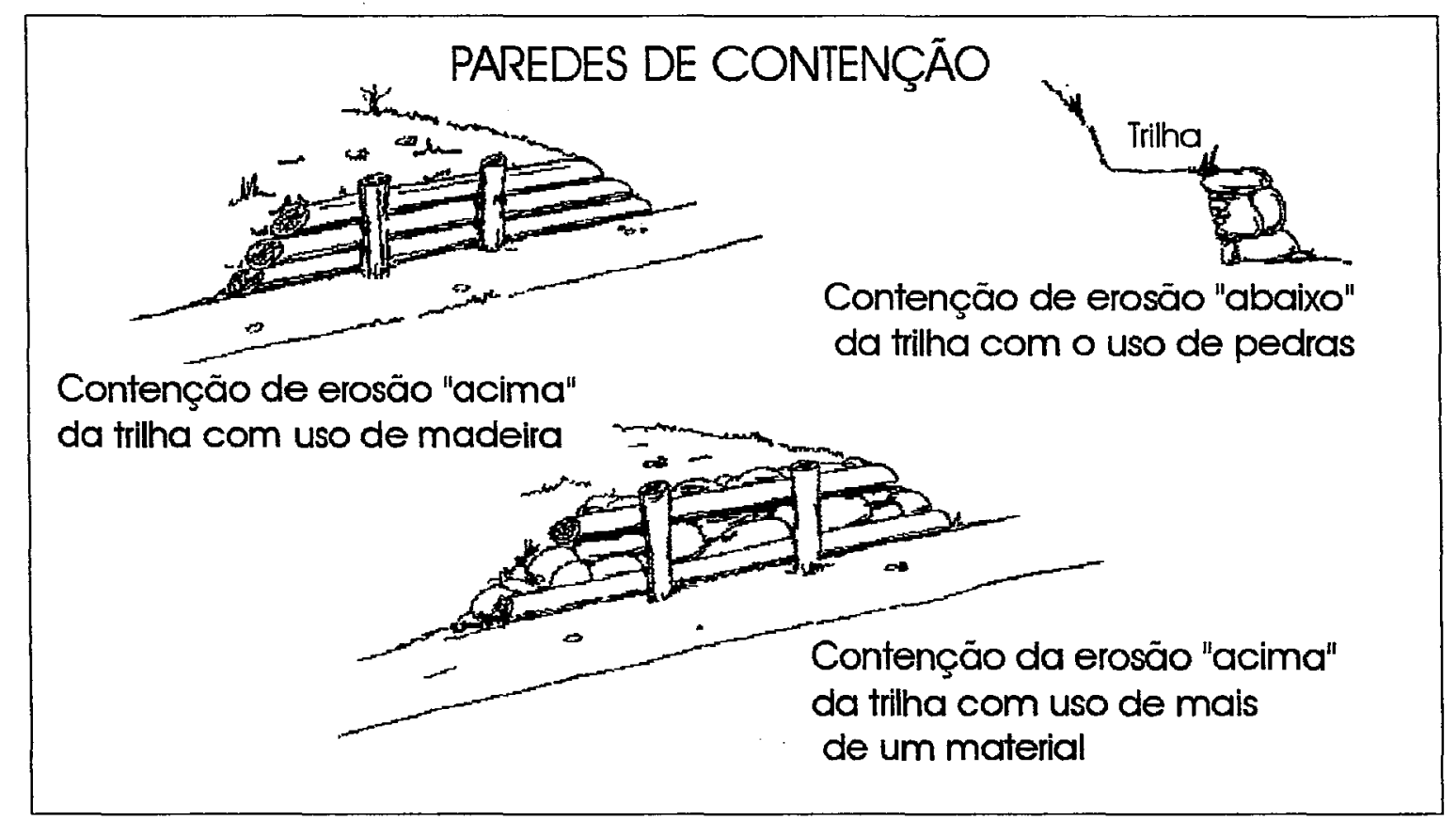

FIGURA 62 - Paredes de contenção

\section{$>$ Sinalização}

Há necessidade de se proceder a sinalização de triihas visando a segurança do excursionista e dos recursos da área 
atravessada pelas trilhas. A sinalização deve ser sistemática, compreensível e dificultar o vandalismo (PROUDMAN, 1977).

Segundo AGATE (1983), as vantagens de sinalização em trilhas são as seguintes:

- Permitir aos excursionistas (não familiarizados com a área a ser explorada) evitar despender verbas para aquisição de mapas;

- Possibilitar que se encontre o caminho em áreas florestais onde até mesmo os mapas de maiores escalas não apresentam detalhes suficientes;

- Reduzir invasões acidentais; e

- Encorajar o uso de trilhas pouco conhecidas, reduzindo a freqüência de limpeza (clareamento) da trilha.

- Os tipos de sinalizações considerados neste capítulo são: marcação à tinta, placas, painéis, montes de pedra (totem) e fitas.

* Marcação à tinta:

Marca padronizada colocada estrategicamente numa árvore (FIGURA 63) ou pedra (FIGURA 64). A marca na "Appalachian Trail", segundo PROUDMAN (1977), é uma mancha branca de $2 \times 6$ polegadas (aproximadamente $5 \times 15 \mathrm{~cm}$ ). Deve-se definir uma forma e cor padrão para a trilha. As melhores cores para uso nestes casos são azul, vermelho, amarelo, branco e laranja. Num sistema de trilhas o interessante é usar cor primária para a trilha principal e uma cor secundária para as trilhas secundárias. Látex ou lucite são suficientes.

Após selecionar-se os pontos a serem marcados, deve-se preparálos apropriadamente para receber a tinta. Com um raspador ou escova de aço deixa-se a superfície do tronco uniforme para ser pintada. Para se preparar a superfície de pedra, a escova de aço é suficiente. Em caso de se alterar o traçado da trilha, marcações abandonadas devem ser obstruídas para não causarem confusão aos excursionistas. 


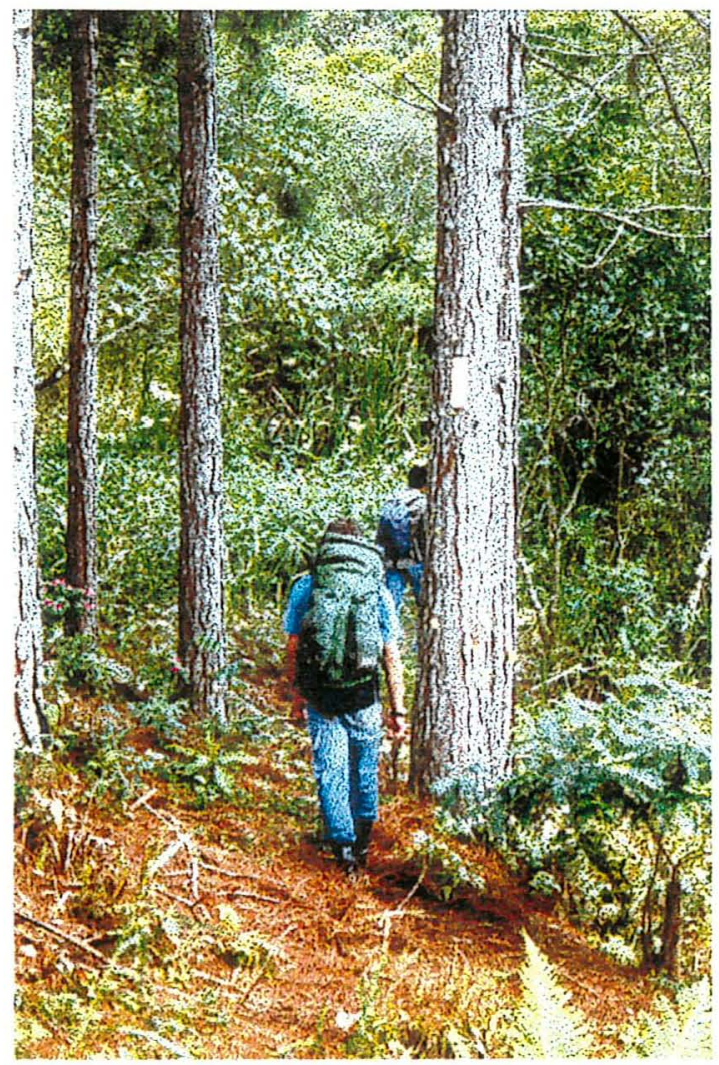

Figura 63 - Marcação a tinta em árvore

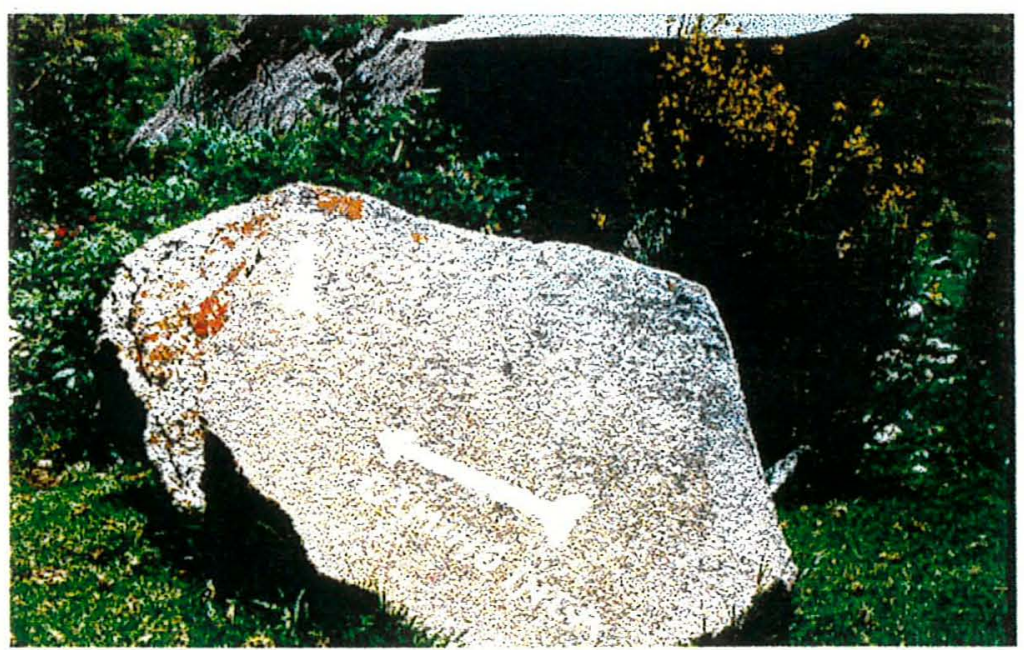

Figura 64 - Marcação a tinta em pedra. 


\section{- Placas / Painéis}

As placas são de importante utilização ao longo da trilha pois informam quanto ao nome, direção, pontos importantes, distância e destino (FIGURA 65).

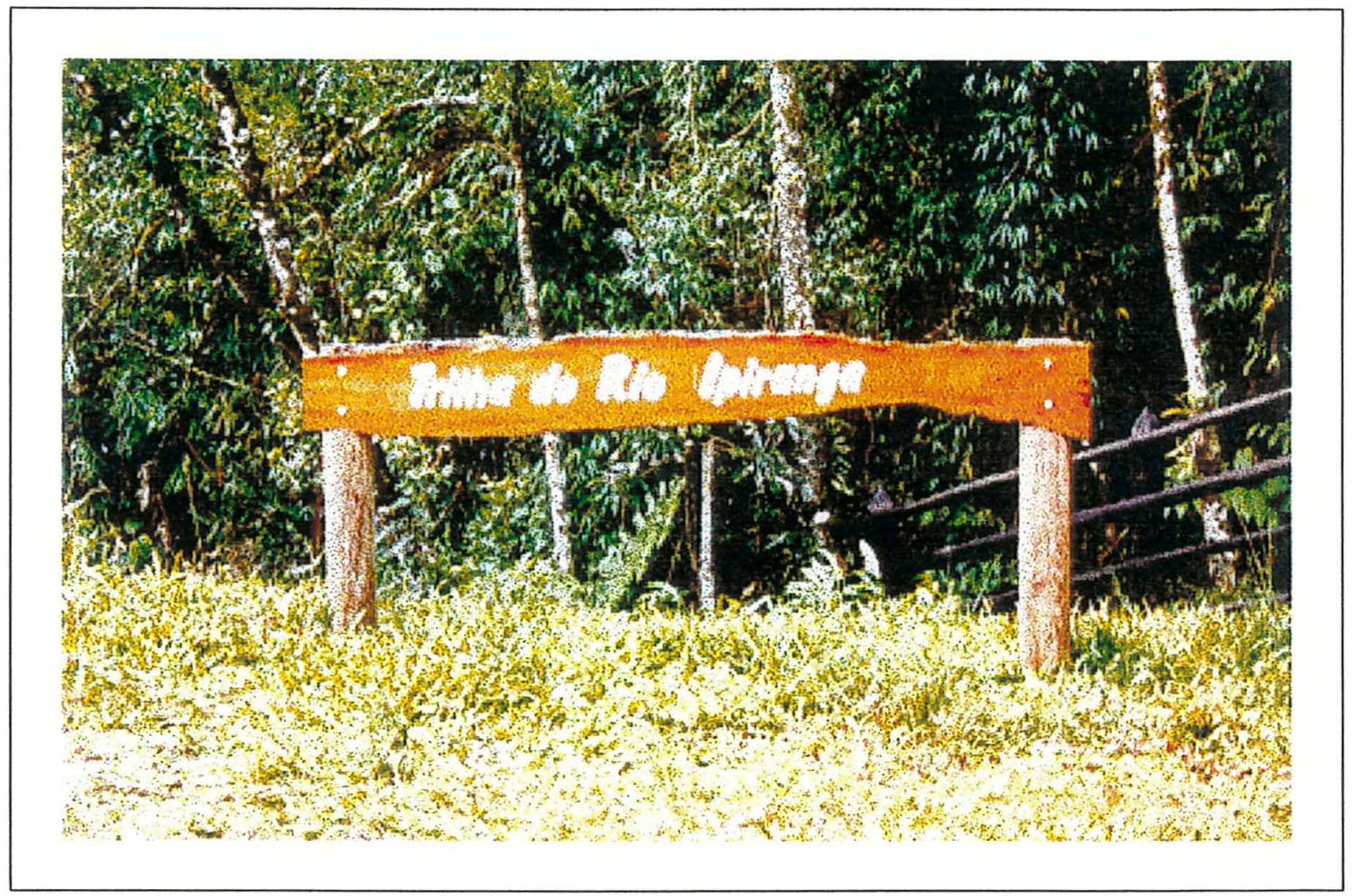

FIGURA 65 -Modelo de placa

Elas podem ser confeccionadas em pedra (FIGURA 66), metal (FIGURA 67) ou madeira (FIGURA 68). Esta última é a mais popular e atrativa e, se devidamente afixada, dificilmente será retirada como "souvenir" pelos visitantes. Para se confeccionar tais placas não se necessita técnica sofisticada.

$\mathrm{Na}$ escolha da madeira deve-se levar em conta os seguintes fatores: durabilidade, resistência de ser trabalhada, disponibilidade e custo. Uma placa de boa qualidade é aquela que não entorta e não possui nós. 


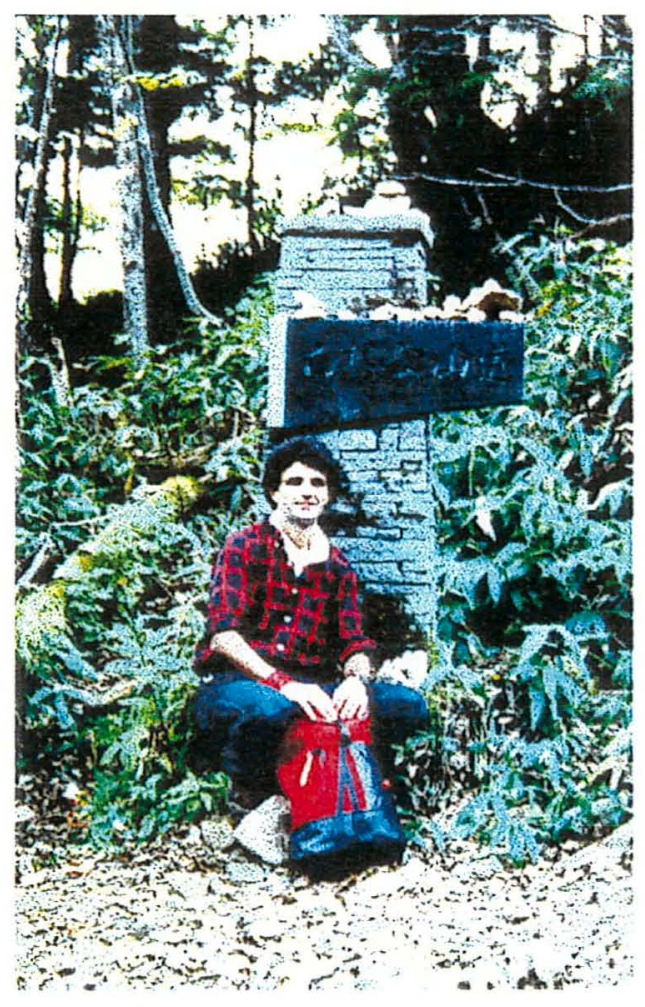

Figura 66 - Placa confeccionada em pedra.

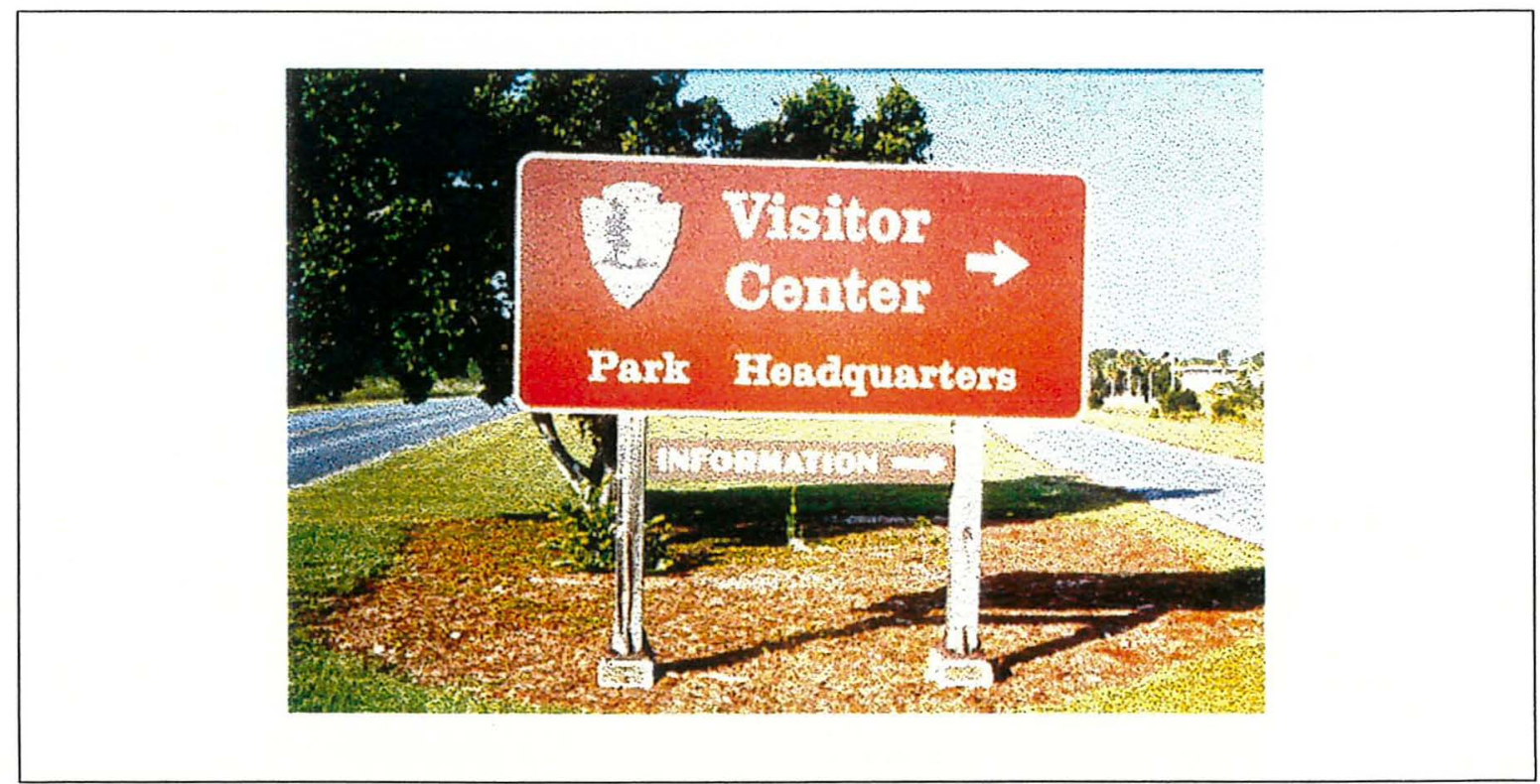

Figura 67 - Placa confeccionada em metal, no Parque Nacional dos Everglades - EUA 


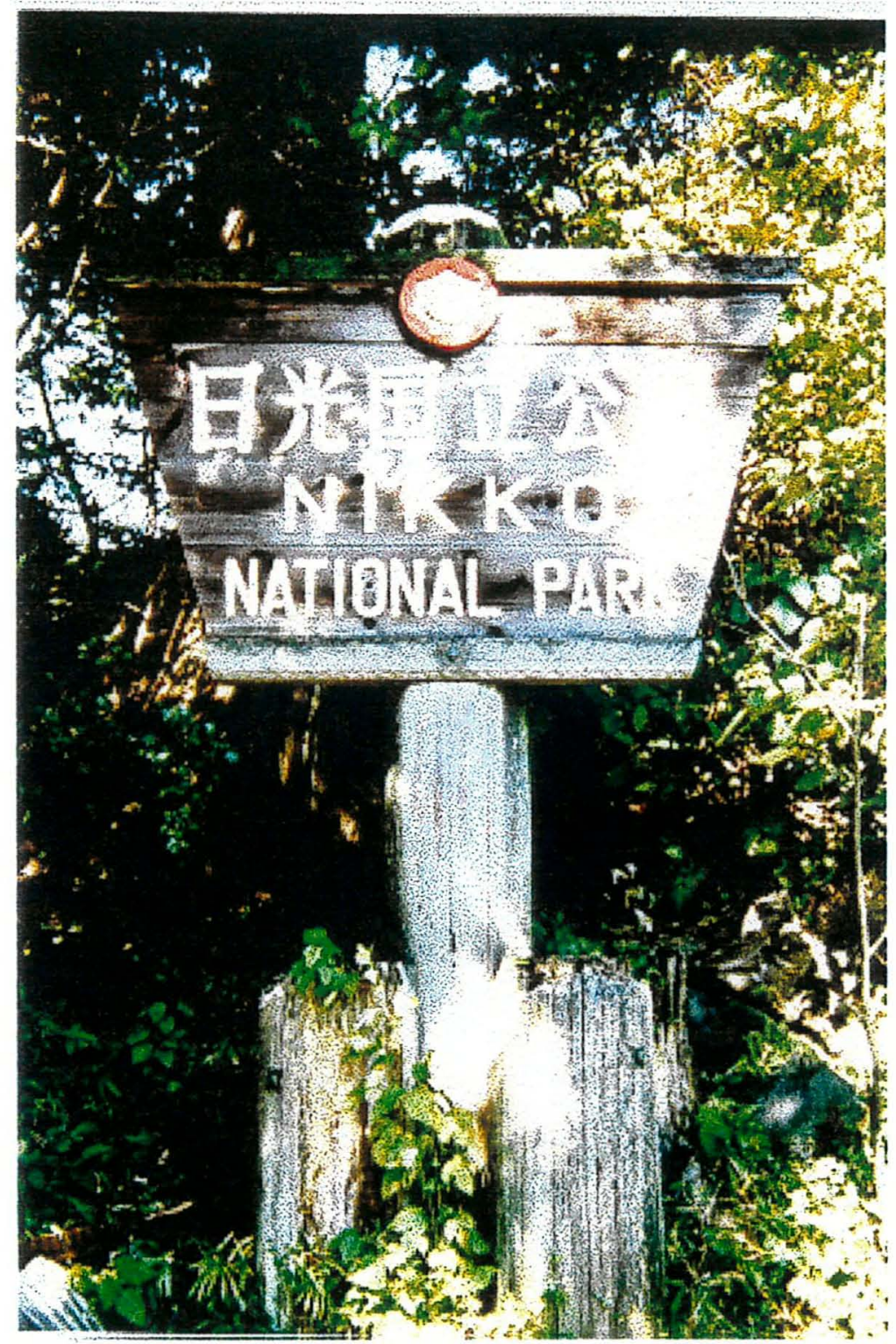

FIGURA 68 - Placa confeccionada em madeira, no Parque Nacional Nikko - Japão.

As dimensões das placas são variáveis de acordo com o comprimento da mensagem. Placas de início de trilha, por conterem um número grande de informações, devem ter aproximadamente $3,5 \mathrm{~cm}$ de espessura e as demais de 1 a $2 \mathrm{~cm}$. Estas devem ser geralmente pequenas. Forma, cor 'e letreiro devem ser padronizados. 
A maioria das placas, em geral, não necessitará de letras com altura superior a $5 \mathrm{~cm}$. Para pintá-las pode-se usar 2 cores de fundo e outra para as letras ou ainda apenas uma cor para a letra sobre fundo natural. Neste último caso, deve-se aplicar verniz náutico para proteger a placa das intempéries ou carbolineum.

Para instalação das placas pode-se utilizar um poste de madeira, tratada de preferência, ou apoiá-la sobre pilhas de tótem). Pode-se ainda pendurá-las nas árvores ou arbustos, utilizando arame ou fio de nylon. Fixar placas em árvores utilizandose pregos não é indicado, do ponto de vista ético.

A mensagem ou informação pode estar contida também em painéis (FIGURA 69), principalmente no início da trilha, podendo incluir nome, distância, grau de dificuldade e até croqui com os pontos de destaque.

- Montes de pedras (Totem):

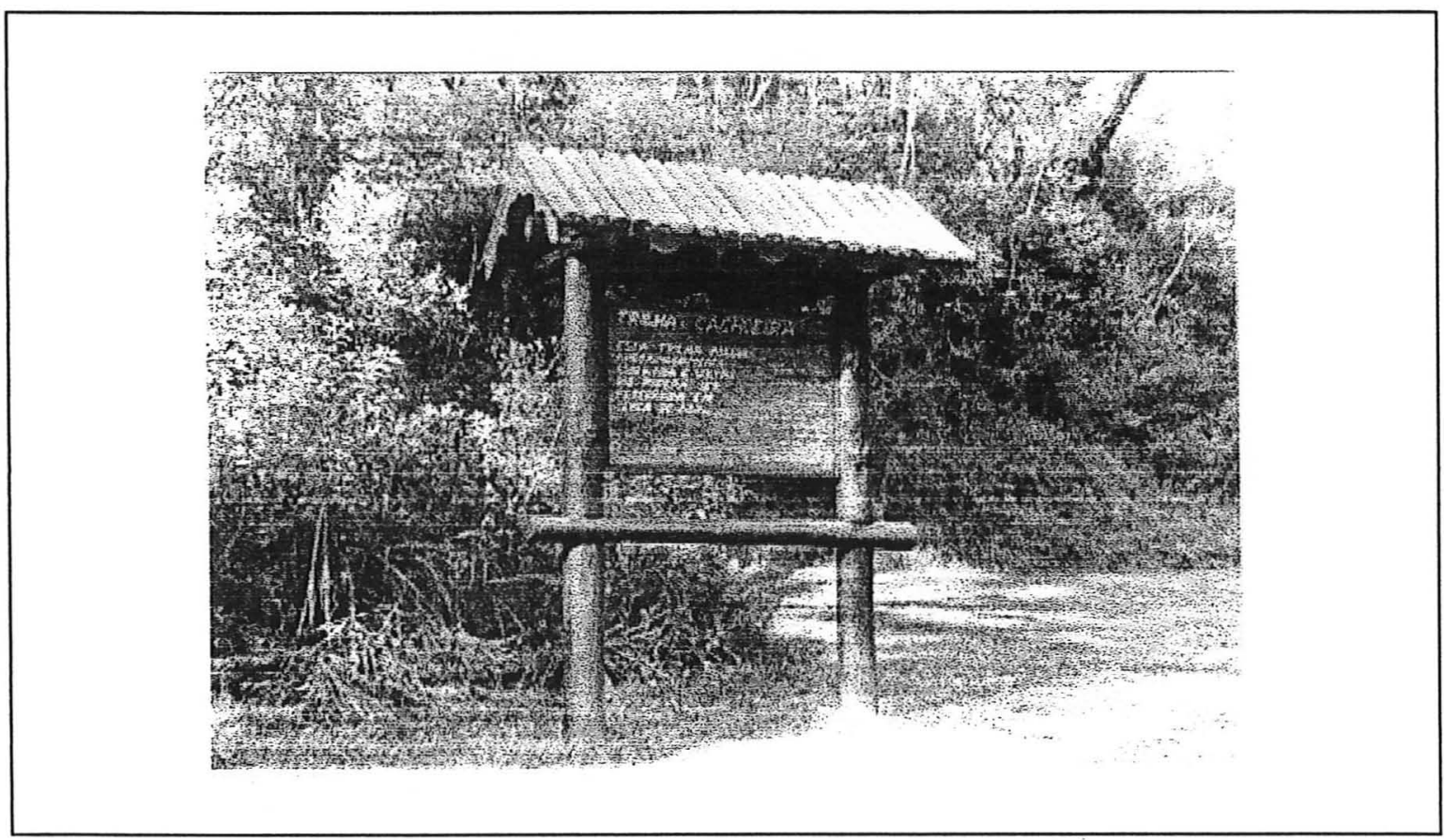

FIGURA 69 - Painel na trilha da Cachoeira (P.E.C.J.) 
Para se marcar trilhas em áreas desprovidas de árvores, necessita-se construir pilhas de pedras, de fácil visualização, também conhecidas pelo nome de totens (FIGURA 70).

A distância entre elas deve ser de 30 a $50 \mathrm{~cm}$. O importante é que o excursionista ao lado de um totem, possa visualizar outros dois - da frente e de trás. Desta maneira cada um deve estar estrategicamente posicionado. Ocasionalmente pode-se pintar as pedras do topo do totem para facilitar a visualização.

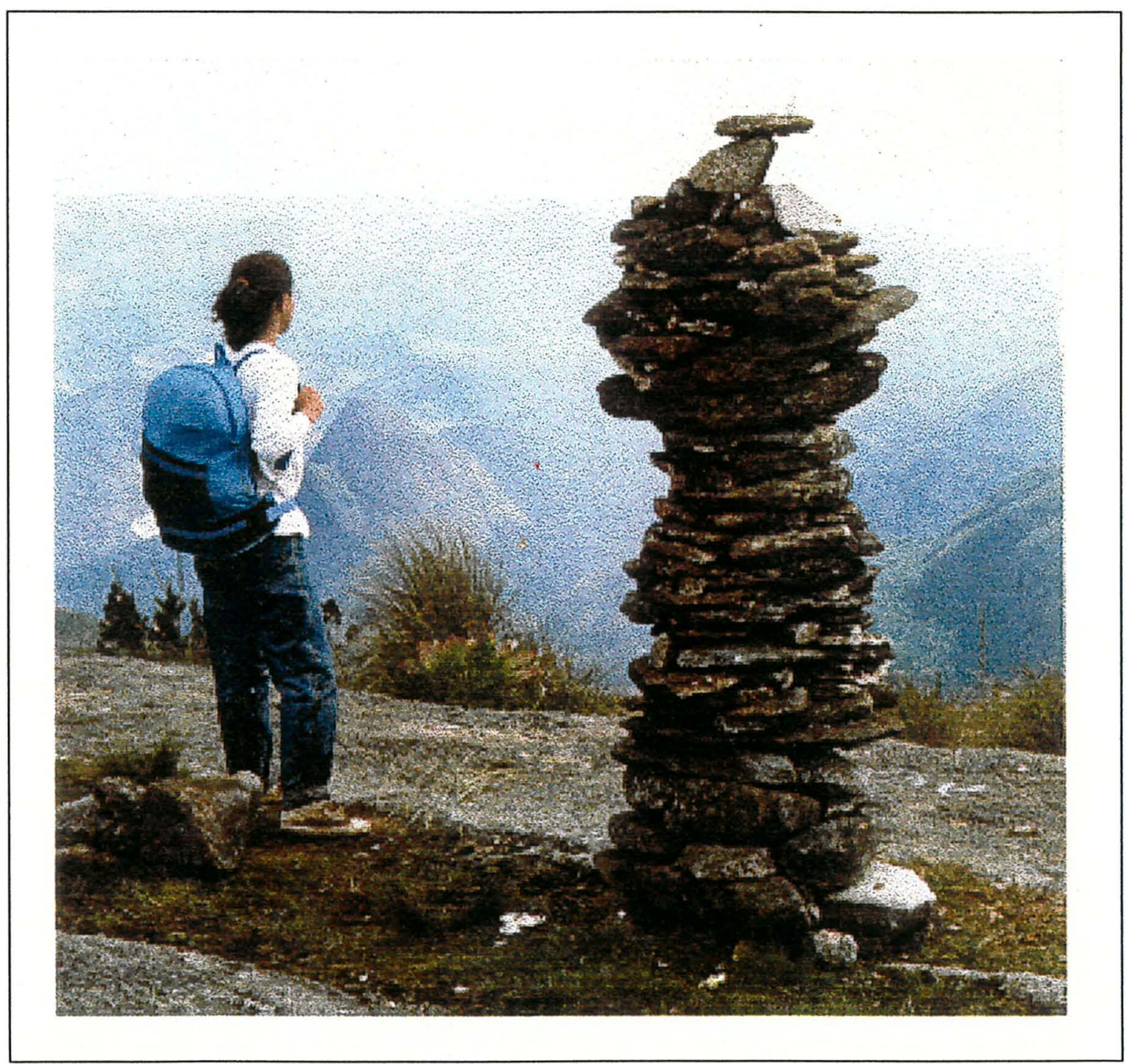

FIGURA 70 - Monte de pedra (Totem), na Trilha Petrópolis Teresópolis - P. N. da Šerra dos Órgãos. 
* Fitas:

Outra forma de se marcar o caminho é através da utilização de fitas coloridas (as de plástico são duráveis e não perdem a cor facilmente) amarradas nos galhos, em troncos de árvores ou arbustos ou, quando em regiões desprovidas daqueles, no alto de uma estaca de madeira ou ferro.

Para o desenvolvimento das obras elencadas, uma lista de ferramentas é sugerida a seguir:

- Machados: são muito utilizados para cortar árvores e grandes galhos caídos e para preparar mourões usados em degraus ou na contenção de paredes. Existem os machados de duas faces afiadas, mas os de face única são mais seguros e populares. 0 tamanho e o peso dependerão da pessoa que irá usar e do tipo de trabalho a ser feito.

- Pé-de-cabra: essencial no deslocamento de grandes pedras ou troncos

- Serras: são utilizadas para cortar galhos e árvores. O tipo e o tamanho dependerão do trabalho e do espaço disponível. O uso da moto-serra deve ser planejado devido a possivel dificuldade de acesso a transporte de combustível aos locais de trabalho.

- Picareta.

- Pá.

- Baldes: podem ser utilizados para eventuais transportes da terra, areia, água, etc.

- Ferramentas de carpintaria: utilizadas na construção de pontes, degraus, etc.

- Kit com martelo, pregos, arames, barbantes, panos (para secar os cabos das ferramentas em tempos úmidos e para limpar placas de sinalização), etc.

Deve-se salientar a necessidade de equipamentos de segurança como óculos para a proteção dos olhos (utilizados durante o trabalho de cortar ou serrar madeira), luvas, capacetes e roupas adequadas). 


\section{COMENTÁRIOS DOS RESULTADOS}

1. Desde a edição das folhas topográficas que serviram de base para a elaboração dos diversos croquis, aqui apresentados, muito tempo se passou e várias estradas e trilhas surgiram. Na medida do que se julgou interessante para este trabalho esses caminhos foram devidamente mapeados.

2. No trecho 2 da trilha, através de visitas ao campo, constatou-se que o Salto dos Pretos se localiza a 3 (três) quilômetros, aproximadamente, à leste, do local que é indicado na folha topográfica - procedeu-se à correção. $O$ mesmo se deu em relação à Pedra do Carmo que pela folha topográfica estaria no trecho 2, mas na realidade está a $9 \mathrm{~km}$, aproximadamente, a leste, aparecendo assim no trecho 3 . Outra correção foi efetuada no trecho 8 , pois constatou-se que a cachoeira dos Diamantes está 1 quilômetro rio acima, do que o observado na folha topográfica.

$3 \mathrm{Na}$ definição do traçado da Trilha da Mantiqueira, tomou-se por tarefa a união das regiões mais significativas: Morro do Lopo; Serra dos Poncianos (Pedra do Selado); Pedra do Baú; Parque Estadual de Campos do Jordão; Pico dos Marins e Itaguaré; Serra Fina e Parque Nacional de Itatiaia. Para tanto, adotou-se a estratégia de uni-los por estrada vicinal de terra, já existente, ao invés de se propor abertura de trilha, próxima à cumeada da grande serra, por três motivos: a) as estradas já existem e sua paisagem de entorno é relativamente pitoresca; b) novas trilhas cortariam, certamente, áreas particulares, 0 que poderia, pelo menos a princípio, ser um fator de complicação; c) por não haver ainda uma cultura de conservação de trilhas, nem capacitação para tanto, seria temerário abrir-se novos caminhos, principalmente em uma região, que por suas características biofisiográficas, os riscos de impactos negativos são enormes.

$4 \mathrm{Na}$ Trilha da Mantiqueira não se incluiu a Pedra Bela, belíssima montanha no município de mesmo nome, porque a região entre ela e a Pedra do Lopo - início da grande Trilha apresenta alteração antrópica bastante grande, sem trechos 
significativos de áreas silvestres, como ocorre nos $300 \mathrm{Km}$ considerados.

5 O Pico dos Marins, com $2421 \mathrm{~m}$, é considerado o mais alto do Estado de São Paulo. Porém, a Pedra da Mina, na Serra Fina, apresenta $2770 \mathrm{~m}$ de altura, sem confirmação, ao contrário da altitude do Pico dos Marins. Mas, sem dúvida, a Pedra da Mina poderá ser adotada, embora na Divisa com Minas Gerais, como o ponto culminante do Estado de São Paulo.

6. Todas as trilhas e estradas que integram a Trilha da Mantiqueira, incluindo aquelas que atravessam propriedades privadas, são de passagem livre, pois existem há bastante tempo para assim serem consideradas. Porém, tanto nas proximidades da Pedra da Guaraiúva (trecho 1), como na Fazenda Lavrinhas (trecho 8), por problemas causados por intrusos, os proprietários impediram, temporariamente, a passagem de estranhos pelo caminho sobre o qual se assenta a grande Trilha.

7. Para garantir conforto e segurança aos usuários e ao mesmo tempo máxima proteção aos recursos naturais e culturais envolvidos, há que se adequar o traçado em vários locais, pois algumas trilhas surgiram, como podem ser observadas, sem planejamento. Práticas como reorientação da drenagem, combate a erosão, construção de pontes e pinguelas, construção de degraus, contenção de pequenas encostas, recuperação de áreas degradadas, deverão ser implementadas em vários trechos, com rigor e a curto prazo, a bem da integridade física da Trilha.

8. A sinalização é inexistente em quase toda grande Trilha e salvo melhor juízo, deve-se adotar placas de madeira, totens e marcação à tinta, discretamente, em pedras.

9. O programa de treinamento e capacitação de voluntários e técnicos institucionais é de vital importância para que se construa uma filosofia conservacionista e para que alguns valores sejam definidos e consolidados. 
10. As instituições além de apoiarem as atividades voluntárias, devem orientá-las e catalizá-las aportando as bases técnicas e metodológicas.

11. Além de um curso básico, pré-requisito, para cada voluntário ser engajado na implantação da Trilha da Mantiqueira, outros tantos poderão ser formatados e oferecidos pelas instituições coordenadoras.

12. Foi proposto a participação do SENAC, em comissão para coordenar a discussão e implantação da Trilha, não só por seu caráter pedagógico, como também por sua participação em cursos de formação de Guarda-Parques, Pós-Graduação em Turismo Ambiental, e acima de tudo por sua tradição na área de prestação de serviços.

13. A relação das organizações ambientalistas e clubes excursionistas é apenas um ponto de partida para o recrutamento de voluntários. Porém, qualquer pessoa, sem distinção alguma, poderá ser engajada como voluntário, bastando para tanto participar do curso básico. 


\section{CONSIDERAÇÕES FINAIS}

1. É possível se deslocar, caminhando próximo a cumeada da Mantiqueira, do morro do Lopo até o Parque Nacional de Itatiaia, através de $300 \mathrm{~km}$ de estradas e trilhas, porém sem o devido conforto e segurança.

2. O fato da Trilha da Mantiqueira começar no morro do Lopo e terminar no Parque Nacional de Itatiaia é uma questão de convenção. Pode naturalmente ocorrer o contrário.

3. A exemplo da Trilha Cênica dos Apalaches, que se estende por mais de $3200 \mathrm{Km}$, atravessando os estados norteamericanos de Maine, New Hampshire, Massachusets, Vermont, Connecticut, New York, New Jersey, Pennsylvânia, Maryland, West Virginia, Virginia, Tennessee, North Carolina e Georgia (MURFIN, 1989), a Trilha da Mantiqueira e seu entorno poderiam compor uma categoria específica de unidade de conservação, denominada Trilha Cênica, e integrar nosso sistema nacional de unidades de conservação, em apreciação pelo Congresso Nacional.

4. A Trilha da Mantiqueira atravessa áreas de grande significado cênico e ecológico. Nas proximidades da cumeada da serra encontram-se vastas extensões de áreas naturais protegidas, que bem poderiam compor um futuro Parque Natural da Serra da Mantiqueira, de gestão inédita no Brasil: tri-estadual.

5. Caso o plano proposto venha ser implementado, os itens conforto e segurança poderão ser atendidos.

6. Será importante a futura caracterização patrimonial e fundiária das terras atravessadas pela Trilha

7. Num momento em que os compromissos governamentais são de difícil cumprimento, principalmente na área ambiental, a conservação da natureza tem na força voluntária uma grande aliada. 
8. A viabilização de um projeto implantado com a participação de força voluntária poderá acarretar a participação da mesma em outras atividades a favor da conservação da natureza.

9 Com relação a se definir trechos prioritários, para início da implantação do projeto ora proposto, tanto o Parque Nacional do Itatiaia, como o Parque Estadual de Campos do Jordão, seriam estratégicos por contar com infra-estrutura física e humana, servindo como apoio ao trabalho voluntário. O último ainda tem a seu favor o fato de o autor da presente dissertação, ali desempenhar suas funçōes institucionais.

10. Uma vez implantada, a Trilha da Mantiqueira, ora proposta, poderá ser ampliada, agrupando trilhas ramificadas em diversos contrafortes da grande serra, vindo a ser composto um sistema de trilhas da Mantiqueira. Enfim, quem viver, verá. 


\section{REFERÊNCIAS BIBLIOGRÁFICAS}

AGATE, E. Footpaths. A Practical Conservation handbook. Wallingford, 1983. British Trust for Conservation Volunteers. 192p.

ALMEIDA, F.F.M. de. Fundamentos geológicos do relevo paulista. São Paulo. 1974. Série Teses e Monografias, 14:IGEDG/USP, p.

ANDRADE, W.J. \& SILVA, C. A. Inverno nas Montanhas: Roteiro dos Parques Nacionais. Guia de Camping. São Paulo, julho, 1987.

ANDRADE, W.J. de Curso de Manejo de Áreas Silvestres. 1, 1993. São Paulo: Instituto Florestal (Apostilado).

ANDRADE, W.J. de, MARCONDES, M.A.P., MATTOS, I.F. de A., ROSSI, M., SILVA, D.A. da, CARVALHO, J.L. de, VILAR, D.D., ROBIM,M. de J., ZANCHETTA, D. Proposta de Criação e Manejo do Monumento Natural Estadual da Pedra do Baú. In: CONGRESSO NACIONAL SOBRE ESSÊNCIAS NATIVAS, 2., São Paulo. Anais. São Paulo, Instituto Florestal, 1992. p.947955.

ANDRADE, W.J. de, MARCONDES, M.A.P., MATTOS, I.F. de A., ROSSI, M., SILVA D.A. da, CARVALHO, J.L. de, NALON, M.A., VILAR, D.D. Proposta de Criação e Manejo do Parque Estadual da Serra Fina. In "CONGRESSO FLORESTAL BRASILEIRO, 7., Curitiba, 1993. Anais. Curitiba, SBS/sbef, 1993. p.723.

ANDRADE,W.J. de \& ROCHA, L.M. Planejamento, implantação e manutenção de trilhas. In: CONGRESSO FLORESTAL BRASILEIRO, 6., Campos do Jordão, 1990. Anais. São Paulo, SBS/sbef, 1990. vol.3. p 86/93.

ASSOCIACIÓN DE VOLUNTARIOS EN INVESTIGACIÓN Y DESAROLLO AMBIENTAL (VIDA). Home Page - 
http://www.vida.org/volunspa.html. Programa de Voluntariado (PV). 15/04/1998. Costa Rica

AUSTRALIAN TRUST FOR CONSERVATION VOLUNTEERS. Home Page - http://users.netwit.net.au/ atcv/. 16/04/1998. Ültima modificação: 16/07/1997. Web site criado por Scott Snowden. Austrália

BARBOSA, A.. Avifauna do Parque Estadual de Campos do Jordão - São Paulo. São Paulo, 1988. Instituto Florestal. Bol Técn.if, v-42 (único). p.33-56.

BELART, J.L. Trilhas para o Brasil. Boletim Informativo. FBCN, Rio de Janeiro, 1978. 13(1): 49-51.

BECK, S. Caminhos da Aventura. Edição do Autor. São Paulo, 1998. 226p.

BIRKBY, R. Lightly on the Land. the SCA manual of backcountry work skills. Seattle, 1996. The Mountaineers, $267 \mathrm{p}$.

BRASIL. Ministério da Agricultura. Serviço Nacional de Pesquisas Agronômicas. Comissão de Solos. Levantamento de reconhecimentos dos solos do estado de São Paulo. Rio de Janeiro. 1960. 350p. Bol.12.

BRASIL. Ministério das Minas e Energia. Levantamento dos recursos naturais. Folhas SF 23/24. Rio de Janeiro / Vitória. Rio de Janeiro. 1983. 780p. (Projeto Radombrasil, 32).

BRITSH TRUST FOR CONSERVATION VOLUNTEERS. Home Page - http://www.newtownpowis.co.uk/btcv.htm. 16/04/1998. Reino Unido.

CATALDI, N.L. Projeto Atuar. São Paulo, 1993. 185p. (Apostilado). 
CEBALLOS-LASCURÁIN, H. O Ecoturismo como um Fenômeno Mundial. In: ECOTURISMO: um Guia Para Planejamento e Gestão. Kreg Lindberg, Donald E. Hawkins (editores). tradução de Leila Cristina de M. Darin. Ed. SENAC São Paulo. São Paulo, 1995.

CORULLON,M. Home Page - http://www.partners.bsbdc.org I volutrab.htm. O Trabalho Voluntário. Manual elaborado para o Programa de Promoção do Voluntariado do Conselho Comunidade Solidária, 1998.

COSTA, J. P. de O. Aiuruoca, Matutu - Pedra, um Estudo de Conservação Ambiental e Cultural. São Paulo, 1987, v. il. Tese de doutorado - FAU / USP.

FOREST SERVICE - UNITED STATES DEPARTMENT OF AGRICULTURE - USDA. Volunteering with the Forest Service. Washington, 1995. 1v.

FUNDAÇÃO INSTITUTO BRASILEIRO DE GEOGRAFIA E ESTATÍSTICA - IBGE. Geografia do Brasil. Rio de Janeiro, SERGRAC - IBGE, 1977. 667p.

FUNDAÇÃO SOS MATA ATLÂNTICA. Grupo de Ação Voluntária. São Paulo, 1989. Boletim GAV n 01/set. 2p.

GASQUES, M.V. Caminhadas em Agulhas Negras. Editora Brasiliense. São Paulo, 1990. 64p.

Caminhos da Mantiqueira. São Paulo, Editora Brasiliense, 1992. 117p.

GRIFFITH, J.J. \& VALENTE, O.F. Aplicação da técnica de estudos visuais no planejamento da paisagem brasileira. Brasília, 1979. Brasil Florestal, 10 (37): 6 - 14, jan/mar. 
GRIFFITH, J.J. Análise dos recursos visuais do Parque Nacional do Caparaó. Curitiba, 1983. Floresta, 14 (2): 15-21.

GROVE, N. A Tunnel through time. The Appalachian Trail. National Geografic, Washington, D.C., vol. 171, n² 2, 216 - 243, fev.1987.

GUILLAUMON, J.R.\& POLL, E. \& SINGY, J.M. Análise das trilhas de interpretação. São Paulo, 1997. Instituto Florestal, 57p. (Bol. Técn. 25).

HESSELBARTH, W. \& VACHOWSKI, B. Trail Construction and Maintenance Notebook. Missoula, 1996. USDA Forest Service, $141 \mathrm{p}$.

HÖFLING,E. \& CAMARGO,H.F. de A., \& IMPERATRIZFONSECA,V.L. Aves da Mantiqueira. Editora ICl Brasil , São Paulo, 1986. 87p.

HUECK, K. As florestas da América do Sul: Ecologia, Composição e Importância Econômica. Trad. Hans Ruchartalt. São Paulo, 1978. Polígono, USP, 466p. llustr.

INSTITUTO BRASILEIRO DE DESENVOLVIMENTO FLORESTAL IBDF \& FUNDAÇÃO BRASILEIRA PARA A CONSERVAÇÃO DA NATUREZA - FBCN. Plano de Manejo: Parque Nacional da Serra da Canastra. Brasília, 1981. IBDF/FBCN, 96p.

IPT - Instituto de Pesquisas Tecnológicas. Mapa geomorfológico do Estado de São Paulo. IPT, Divisão de Minas e Geologia Aplicada. São Paulo, 1981b. V.1, 126p. V.2. (série monografia). llustr.

JOUTARD P. L`invention du Mont Blanc. Paris, Gallimard, 1986.

KANIAK,V.C. Trabalho de Voluntários na Proteção e Manejo dos Parques Nacionais do Brasil. Curitiba, 1990. 104p. (MestradoUniversidade Federal do Paraná- Setor de Ciências Agrárias). 
KURKDJIAN,M.L.N.O; VALÉRIO FILHO,M; VENEZIANI,P. et al.Macrozoneamento da Região do Vale do Paraíba e Litoral Norte do Estado de São Paulo. São José dos Campos: INPE, 1992. 176p.

LEITE, M. A Região da Mantiqueira. Lisboa, "s.ed"., 1951. 244p.

LEONARD, R.E. \& SPENCER, E.L. \& PLUMLEY, H.J. Backcountry Facilities: Design \& Maintenance. s.l., s.d. 214p.

LIMA SILVA, I.A. de. Pedra do Baú "s.I.", Bianchi Editores, 1988. $107 p$

LINDBERG, K. \& HAWKINS, D. Ecoturismo: um guia para planejamento e gestão. Tradução de Leila Cristina de $M$. Darin.. Editora Senac São Paulo, São Paulo 1995. 292p.

MA - INSTITUTO BRASILEIRO DE DESENVOLVIMENTO FLORESTAL - IBDF \& FUNDAÇÃO BRASILEIRA PARA A CONSERVAÇÃO DA NATUREZA - FBCN.Plano de Manejo do Parque Nacional de Itatiaia. Brasília, 1982. 207p.

MATER NATURA - Instituto de Estudos Ambientais Ecolista Cadastro Nacional de Instituiçōes Ambientalistas. Coord. por Paulo Aparecido Pizzi. 2a. ed. rev. ampl. Curitiba: wwf, 1996. 348p.

MEIRELLES,S. Mantiqueira, a riqueza nativa da Mata Atlântica. Ecologia e Desenvolvimento, Rio de Janeiro, 9: 20-27, nov.1991.

MELLO, Homem de. Atlas do Brazil, Rio de Janeiro, F.Briguiet \& Cia Editores. 1909. 66p.

MENDES JR, L.O., ANTONIAZZI,M.,VIEIRA, M.C.W., SUCEMIHL, P., coord. Relatório Mantiqueira. São Paulo, Frente em Defesa da Mantiqueira, 1991. 54p. 
MONTEIRO, C.A. de F. A dinâmica climática e as chuvas no estado de São Paulo: estudo geográfico sob a forma de atlas. I.G. - USP, São Paulo. 1973.

MORAES FILHO, P. \& CARDOSO, J.P. Limites entre São Paulo e Minas. Rio de Janeiro, 1920. 278p.

MOREIRA,J.E. Caminhos das Comarcas de Curitiba e Paranaguá. Curitiba, Imprensa Oficial, 1975. 3v.

MURFIN, J. The National Parks of America. Gallery Books. New York, 1989. 280p.

NEGREIROS,OC., CARVALHO,C.T. de, CESAR,S.F., DUARTE, F.R., DESHLER, W.O., THELEN, K.R. Plano de Manejo para o Parque Estadual da llha do Cardoso. Boletim Técnico. Instituto Florestal- São Paulo 9:1-56, abr. 1974.

NPS - UNITED STATES DEPARTMENT OF THE INTIRIOR NATIONAL PARK SERVICE. Volunteers in parks guideline. Release $n^{\circ} 3$, U.S. Government Printing Office. 1986. p218 381.

PETRONE, P. Povoamento e caminhos no século XVIII e primeira metade do século XIX. In: A Baixada Santista, aspectos geográficos. São Paulo, 1965. EDUSP. p: 75 - 138, cap. 7 (Povoamento e população, v.2).

PINTO, A. A. A viação na época colonial. In: História da viação pública em São Paulo, Brasil. São Paulo, 1903. Typographia e Papelaria de Vanorden e Cia. p: 7 - 20 (xerox).

PROUDMAN, R.D. AMC Field Guide to Trail Building and Maintenance. New Hampshire. 1977. Appalachian Montain Club. 192p. 
RADAMBRASIL. Ministério das Minas e Energia. Levantamento dos Recursos Naturais. Folhas SF 23 / 24, Rio de Janeiro / Vitória. Rio de Janeiro, 32: 780. 1983.

REDDEN, J.D. \& RYAN,F.A. Filosofia da educação. 2 ed. Rio de Janeiro, Agir, 1961. 533p.

RIZZINI, C.T. Tratado de fitogeografia do Brasil - aspectos sociológicos e florísticos, V.2. HUCITEC. Ed. da Universidade de São Paulo. 1979.

RUSHMANN, Doris van de Meene. Turismo e Planejamento Sustentável: A proteção do meio ambiente. Campinas, SP: Papirus, 1997. (Coleção Turismo)

SAINT-HILAIRE, Auguste de Segunda Viagem do Rio de Janeiro a Minas Gerais e a São Paulo,1822; tradução revista e prefácio de Vivaldi Moreira. Belo Horizonte, Ed. Itatiaia; São Paulo, Ed. da Universidade de São Paulo, 1974. 125p. ilust. (Reconquista do Brasil, v.11).

SANTOS, A. P. C. Proposta para a Educação Ambiental Diretrizes de aplicação: exemplos para o segundo cíclo. São Paulo, 1998. 79p. no prelo. (Trabalho de Graduação Individual, a ser apresentado ao Departamento de Geografia - FFLCH USP).

SÃO PAULO (Estado). Coordenadoria de Planejamento Ambiental. Áreas Proteção Ambiental do Estado de São Paulo- APAs Proposta de Zoneamento Ambiental Secretaria do Meio Ambiente, Coordenadoria de Planejamento Ambiental. São Paulo, 1992.(Série Documentos, ISSN 0103-264X) 76p.

Secretaria do Meio Ambiente. Coordenadoria de Educação Ambiental. Universidade Estadual de Campinas. Núcleo de Estudos e Pesquisas Ambientais.Diretrizes para uma Política Estadual de Ecoturismo: Proposta. 
Coordenação geral José Flavio de Oliveira e Célia M.T. Serrano. São Paulo: SMA, 1997. (Documentos Ambientais).72p.

SAVI, M. Manejo de visitantes para implementação de Parques Estudo de caso: Parque Estadual Marumbi. Curitiba, 1997, 11p. (Apostilado).

SCHEINER, T.C. O uso Educativo da paisagem: Educação Ambiental e interpretação da Natureza. s/l, s/d, datilografado, $8 p$.

SCHELHAS, J. Construção e manutenção de Trilhas. In: CURSO DE TREINAMENTO E CAPACITAÇÃO EM GERENCIAMENTO DE PARQUES E OUTRAS ÁREAS PROTEGIDAS. São Paulo, 1986. Apostila. São Paulo. Instituto Florestal, 1986. 1 v. (não paginado).

SEIBERT, P., NEGREIROS, O.C., BUENO, R.A., EMMERICH, W., MOURA NETTO, B.V., MARCONDES, M.A.P., CESAR, S.F., GUILLAUMON, J.R., MONTAGNA, R.G., BARRETO, R.A.A., NOGUEIRA, J.C.B., GARRIDO, M.A.O., MELLO FILHO, L.E., EMMERICH, M., MATTOS, J.R., OLIVEIRA, M.C. de, GODOI, A. Plano de Manejo do Parque Estadual de Campos do Jordão. São Paulo - Instituto Florestal, 153p.

SEIBERT, P. Seminário Manejo da Paisagem e Mapeamento da Vegetação do Parque Estadual de Campos do Jordão. São Paulo, 1975. Publicação IF n5. 198p.

SERRANO, C. M. T. Uma introdução à discussão sobre turismo, cultura e ambiente. In: VIAGENS À NATUREZA: Turismo, cultura e ambiente. Célia Maria de Toledo Serrano e Heloísa Turini Bruhins (orgs.). Campinas, SP: Papirus, 1997 (Coleção Turismo).

SERRANO, C. M. T. A Invenção do Itatiaia. Campinas, 1993. 181p. (Mestrado - Instituto de Filosofia e Ciências Humanas/UNICAMP). 
SILVA,P.deT.E. da. Plano de interpretação ambiental do uso múltiplo da Floresta Nacional de Passa Quatro, Minas Gerais. Viçosa, 1998, Universidade Federal de Viçosa. 183 p.(Tese de "Magister Scientiae").

SIMAS,E. Montanha e vida natural. Rio de Janeiro . Clube Excursionista Rio de Janeiro. 1983.1p. (Divulgação CERJ,3).

SORRENTINO, M, et al. Educação Ambiental: algumas reflexões teóricas.... In: CADERNO DO III FÓRUM DE EDUCAÇÃO AMBIENTAL. São Paulo, 1995, 245p.

TOLEDO, B.L. DE. Projeto Lorena; os caminhos do mar: revitalização, valorização e uso dos bens culturais. São Bernardo do Campo, 1975. Prefeitura do município, 40p.

U.S. ARMY CORPS OF ENGINEERS.Volunteer for America's Environment. Nashville, 1994 (folder).

VÁRZEA,A. Relevo do Brasil. Revista Brasileira de Geografia, Rio de Janeiro, 04:97-130, jan/mar. 1942.

VASCONCELOS, F. Por dentro do Caminho de Santiago de Compostela. Folha de São Paulo. Suplemento de Turismo, São Paulo, 15 jun. 1998. p. $13-17$

WENDEL, G. Caminhos antigos na Serra de Santos. In: CONGRESSO BRASILEIRO DE GEOGRAFIA, 10. Rio de Janeiro, 1952. Anais. Rio de Janeiro, Conselho Nacional de Geografia, p: 77 - 100 (xerox).

ZIMMERLY,E. Senderos naturales de Suiza. Parques, 3(1) : 17-19, abr./jun., 1978. 
ANEXO 1 - Hotéis, pousadas, pensões e áreas de camping nos municípios atravessados pela trilha

\begin{tabular}{|c|c|c|}
\hline \multicolumn{3}{|c|}{ MINAS GERAIS } \\
\hline CAMANDUCAIA & Hotel Central & $\begin{array}{l}\text { Pça Senador Francisco } \\
\text { Escobar } n^{\circ} 11\end{array}$ \\
\hline DELFIM MOREIRA & Hotel São João & $\begin{array}{l}\text { Pça São João Bosco nº } 4 \\
\text { Fone } 624-1133\end{array}$ \\
\hline & Pousada Alegria & $\begin{array}{l}\text { Fazenda Alegria - Estrada da } \\
\text { Barreira. Fone } 624-12335\end{array}$ \\
\hline EXTREMA & Fazenda Vale Suíço & $\begin{array}{l}\text { Rod. Fernão Dias km } 869 \\
\text { Fone: } 434-1302\end{array}$ \\
\hline & Fazenda Lago Dourado & $\begin{array}{l}\text { Estr. do Barreiro, } 5 \mathrm{Km} \\
\text { Fone: } 435-1394\end{array}$ \\
\hline & Extrema Park & $\begin{array}{l}\text { Estr. } \mathrm{p} / \mathrm{Juncal}, 7 \mathrm{~km} \\
\text { Fone: } \mathrm{SP}(011) 872-6155\end{array}$ \\
\hline ITAMONTE & Casa Alpina & $\begin{array}{l}\text { BR-354, km } 721 \\
\text { Fone: } 363-1231 \text { Fax: } 363- \\
1230\end{array}$ \\
\hline & Thomaz & $\begin{array}{l}\text { R. Joaquim Murtinho, } 527 \\
\text { Fone: } 363-1689\end{array}$ \\
\hline & Alsene & $\begin{array}{l}\text { Estr. p/Abrigo Rebouças, km } \\
12 \\
\text { Fone: Resende (0243)54- } \\
3344\end{array}$ \\
\hline & Fragata & $\begin{array}{l}\text { Estr. p/ Monte Belo,36 km } \\
\text { Fone: (012) 341-3435 }\end{array}$ \\
\hline MARMELÓPOLIS & Pensão da Regina & $\begin{array}{l}\text { R. Dep. Manoel Costa n } 65 \\
\text { Fone } 625-1214\end{array}$ \\
\hline PASSA QUATRO & Recanto das Hortênsias ${ }^{\star \star \star}$ & $\begin{array}{l}\text { R. Cel. Arthur Tibúrcio, } 10 \\
\text { Fone: } 371-1400\end{array}$ \\
\hline & Pousada do Verde ${ }^{*}$ & $\begin{array}{l}\text { Estr. da Selinha, 6Km } \\
\text { Fone: } 371-1180\end{array}$ \\
\hline PIRANGUÇU & Pousada Casa Branca & $\begin{array}{l}\text { Pça Mario Pereira } \\
\text { Mendonça } n^{\circ} 8\end{array}$ \\
\hline SAPUCAÍ - MIRIM & Pousada Florada da Serra & $\begin{array}{l}\text { Rodovia São José - } \\
\text { Paraisópolis, a } 1 \text { km de } \\
\text { Sapucaí Mirim }\end{array}$ \\
\hline
\end{tabular}

RIO DE JANEIRO

\begin{tabular}{lll}
\hline ITATIAIA & Simon & Pq. Nacional, $13 \mathrm{~km}$ \\
& do Ipê & Fone: $52-1122$ \\
& Pq. Nacional, $14 \mathrm{~km}$ \\
& Pousada Esmeralda & Fone: $52-1453$ \\
& Estr. p/ Pq. Nacional, km 4,6 \\
& Fone: $52-1643$ \\
& Pq. Nacional, $11 \mathrm{~km}$ \\
& Fone: $52-1110$ Fax: $52-1509$ \\
& Pabanas de Itatiaia & Facional, $8 \mathrm{~km}$ \\
& acesso Pq. Nacional, $3 \mathrm{~km}$ \\
& Conora & Fone: $52-1282$
\end{tabular}


Monte Parnaso

Aldeia da Serra

Vanbas

Fazenda da Serra

Pousada do Elefante

Chalés Terra Nova

Fazenda Santa Mônica

Camping CCB- RJ-06

RESENDE

\section{Castel Plaza}

Fazenda Cabanas do Lago

Espigão Palace acesso Pq. Nacional, $5 \mathrm{~km}$

Fone: 52-1223

Pq. Nacional, $8 \mathrm{~km}$

Fone: 52-1152

Vila Residencial de Furnas,

3km Fone: 52-1579

acesso pela Rod Pres. Dutra, $\mathrm{km} \mathrm{313;} 9$ km Fone: $52-1611$

$\mathrm{Pq}$. Nacional, $12 \mathrm{~km}$ acesso Pq. Nacional, $7 \mathrm{~km}$ Fone: Resende (0243) 54-

\section{2}

acesso pela Rod Pres. Dutra, km

313; $10 \mathrm{~km}$ Fone:54-4807

Penedo

Av. Mal.Castelo Branco, 301

Fone: 54-1091 Fax: 54-4025

Estr. Resende-Vargem

Grande, $\mathrm{km} \mathrm{8,} 10 \mathrm{~km}$ Fone:

54-3279 Fax: 54-2049

R. Sebastião José Rodrigues, 255 Fone: 54-1855 Fax:542160

\section{São Paulo}

CAMPOS DO JORDÃO Mont Blanc

Estr. p/Pico do Itapeva, $8 \mathrm{~km}$ Fone: 263-2721 Fax: 2641173

Orotour Garden

R. 3, 3 km (Jaguaribe)

Fone/Fax: 262-2833 
Mont Blanc Othon ****

Toriba ***

Terrazza ***

Matsubara***

Leão da Montanha**

Château**

Plaza Inn Suitotel ${ }^{* *}$

Nevada*

Vila Regina*

Veredas*

Pousada Vale Verde*

GUARATINGUETÁ

JOANÓPOLIS

LAVRINHAS

PIQUETE

QUELUZ
Clube dos $500^{\star *}$

Fazenda Sete Lagos ${ }^{* *}$

O Paturi**

Ponto de Luz

Hotel Mantiqueira**

Pousada Santa Rita

Pousada Monte Leone

Pousada Blue Mountain

Pousada Recanto dos

Pampas

Pousada Requinte

Cisne Branco
R. Adolfo Torresin, 500

Fone: 263-2011

Av. Ernesto Diederichsen, 2962

Fone: 262-1566

Av. Senador Roberto

Simonsen, 1071

Fone: 263-1255

Rua Prof. José Paulo, 80

Fone: 262-3177

Rua Dr. Raul Mesquita,443

Fone: 263-1811

Av. Macedo Soares, 713

Fone: 263-2634

Estr. da Usina do Fojo, $10 \mathrm{Km}$

Fone: 263-2000

Pça. Maria de Lourdes

Gonçalves, 27

Fone: 263-1611

Av. Dr. Emílio Lange Jr., 323

Fone: 263-1036

Acesso pelo morro do

Elefante, $\mathrm{Km} 6$

Fone: 263-2626

Av. Pedro Paulo, 901

Fone: 263-2091

Rod. Pres. Dutra, km 60

Norte. $7 \mathrm{~km}$

Fone: 532-3555

Estr. das Pedrinhas $\mathrm{Km} 8$, $12 \mathrm{Km}$

Fone: 532-5133

Rod. Pres. Dutro, Km 59

Norte, $8 \mathrm{Km}$

Fone: $532-1000$

Estr. p/ Cancan, $19 \mathrm{Km}$

Fone: 7869-9382

R. Antonio L. da Silveira $n^{\circ}$

63 Centro

Estrada dos Pires km 4,5

Fone 7869-9191

Estrada dos Bandeirantes, km 9 Fone 7844-0485

Estrada dos Bandeirantes

km 9 Fone 9941-9223

R. Virgílio Dávila $n^{\circ} 870$

Centro

Rodovia Lorena-Itajubá

km 64

Rod. Pres. Dutra p/S.

Paulo,Km14,6Km

Fone: 547-1163 
SÃo BENTO dO SAPUCAí Estância*

SÃO JOSÉ DOS CAMPOS Novotel

Eldorado**

Urupema**

Modena*

Novo Mundo*

Plaza*

San Marco
Saída para Paiol Grande, $\mathrm{Km} 1,1 \mathrm{Km}$

Fone: 3711396

Estrada do Paiol km 3,5

Av. Dr. Nélson D'Ávila, 2200

Fone: 321-1011

Av. Dr. Nélson D'Ávila, 233

Fone: $341-8588$

Av. Nove de Julho, 1037

Fone: 321-1599

Av. Dr. Nélson D'Ávila, 1234

Fone: $321-3777$

R. Vilaça, 875

Fone: 341-8622

R. Pres. Bernardes, 33

Fone: 322-5987

Av. Adhemar de Barros, 457

Fone: 322-5244 
ANEXO 2 - Listagem de organizações ambientalistas encontradas nos municípios e capitais envolvidas no estudo, com possibilidades de participarem do trabalho voluntário proposto

\section{MINAS GERAIS}

ASSOCIAÇÃO BRASILEIRA DE ENGENHARIA SANITÁRIA E AMBIENTAL ABES/MG

AV. DO CONTORNO, 842 - SALA 702 30110-060 - BELO HORIZONTE - MG

TEL. (031) 224-8248

FAX (031) 238-1728

ASSOCIAÇÃO CULTURAL ECOLÓGICA LAGOA DO NADO

AV. GENERAL OLÍMPIO MOURÃO FILHO, 400 - PLANALTO

31720-200 - BELO HORIZONTE - MG

TEL. (031) 443-2344

ASSOCIAÇÃO UM ÁRVORE UMA VIDA RUA AFONSO BARBOSA MELO, 259 - SÃO BENTO

30360-090 - BELO HORIZONTE - MG

TEL. (031) 344-1004

CENTRO ECOLÓGICO OMKINKAY

AV. ANTÔNIO ABRAÃO KARAN, 622 -

PAMPULHA

31275-000 - BELO HORIZONTE - MG

TEL. (031) 441-9834

CLUBE DE OBSERVADORES DE AVES COAMG

RUA AIMORÉS, 656 - FUNCIONÁRIOS

30140-070 - BELO HORIZONTE - MG

TEL. (031) 222-6367
ASSOCIAÇÃO COMUNITÁRIA E DE DEFESA

DO MEIO AMBIENTE DO BAIRRO

PALMARES

RUA FERNÃO DIAS, 48 - PALMARES

31050-080 - BELO HORIZONTE - MG

TEL. (031) 444-9207

ASSOCIAÇÃO DE DEFESA DO MEIO AMBIENTE - AMDA

RUA VIÇOSA, 542 - A - SÃO PEDRO 30330-160 - BELO HORIZONTE - MG

TEL. (031) 344-7798

TELEX (031) 3184 ASDA BR

BRIGADAS VERDES - GRUPO DE APOIO ECOLÓGICO CULTURAL

RUA APORÉ, 227 - SÃO FRANCISCO

31235-060 - BELO HORIZONTE - MG

TEL. (031) 226-3700

CENTRO PARA A CONSERVAÇÃO DA NATUREZA EM MINAS GERAIS - CCN - MG RUA MARIA VAZ DE MELO, 71

31260-110 - BELO HORIZONTE - MG

TEL. (031) 443-2119

FAX (031) 441-7037

CLUBE DE OBSERVADORES DE AVES COANACIONAL

RUA SÃO DOMINGOS DO PRATA, 631

30330-110 - BELO HORIZONTE - MG

TEL. (031) 342-2991 OU 337-4679 
COMISSÃO NACIONAL DE ECOLOGIA E SANEAMENTO - CONESAN

AV. AMAZONAS, 5.253 - NOVA SUICÇA 30480-000 - BELO HORIZONTE - MG

TEL. (031) 332-8400 R 137

FAX (031) 334-5042 A/C CEFET

GRUPO ECOLÓGICO ILHAS VERDES GEIV

RUA DESEMBARGADOR CUSTÓDIO LUSTOSA, 317 - ITAPOÃ

31710-630 - BELO HORIZONTE - MG

INSTITUTO BRASILEIRO DE PROTEÇÃO ECOLÓGICA - IBRAPE

RUA CAMPOS GERAIS 247 - C. PRATES

30710-380 - BELO HORIZONTE - MG

LIGA DE PRESERVAÇÃo À CRUELDADE CONTRA O ANIMAL - LPCA

RUA ESPIRITO SANTO, 935 - APTO 803 30160-031 - - BELO HORIZONTE - MG

TEL. (0310 224-4735

MOVIMENTO ECOLÓGICO PACIFISTA

RUA K 142 - DOM JOAQUIM

31910 - BELO HORIZONTE - MG

TEL. (031) 486-1694
FORUM DAS ENTIDADES

AMBIENTALISTAS MINEIRAS - FAM

RUA VIÇOSA, 542 - A - BLOCO A

30330-160 - BELO HORIZONTE - MG

TEL. (031) 344-7798

TELEX (031) 3184

GRUPO ECOLÓGICO VERDE NOSSO RUA 132, 90 - SERRA VERDE

31620-350 - BELO HORIZONTE - MG

\section{INSTITUTO DE PRESERVAÇÃO}

AMBIENTAL CONSERVATION

INTERNACIONAL DO BRASIL

RUA BUENO BRANDÃO 393 - SANTA

TEREZA

31010-060 - BELO HORIZONTE - MG

TEL. (031) 226-5145

FAX (031) 222-8429

LINHA DE AÇÃO ECOLÓGICA

RUA QUIMBERLITA, 442 - APTO 411-B -

SANTA TEREZA

31060-260 - BELO HORIZONTE - MG

TEL. (031) 463-4436

FAX (031) 273-5737

SOCIEDADE MINEIRA DE PESQUISA DO MANEJO E REPRODUÇÃO DA FAUNA

SILVESTRE - SOMMA

RUA F, 55 - DOM JOAQUIM

31920-010 - BELO HORIZONTE - MG

TEL. (031) 486-1723 
SOCIEDADE MINEIRA PROTETORA DOS ANIMAIS

RUA JAGUARIBA, 66 - GUARANI

31840-200 - BELO HORIZONTE - MG

TEL. (031) 222-3463

FUNDAÇÃo CLOÉ - MISAEL CARDOSO PINTO FILHO DE PROTEÇÃO À FAUNA E À FLORA

RUA ANTÔNIO ONISTO - CASA DO

TELHADO VERDE

37640-000 - EXTREMA - MG

TEL. (037) 435-1470 OU 435-1571

DEFESA DO AMBIENTE NATURAL

RUA PADRE HENRY MOTHON 52

37701-009 - POÇOS DE CALDAS - MG

RIO DE JANEIRO

\author{
ASSOCIAÇÃO PRÓ - NATUREZA DO \\ PENEDO \\ RUA TOIVO SUNI, S/N - PENEDO \\ CX. POSTAL 82.583 \\ 27530-970 - ITATIAIA - RJ \\ TEL. (0243) 51-1275
}

PROJETO DE ECODESENVOLVIMENTO INTEGRADO DO MACIÇO DO ITATIAIA

AV. FINLÂNDIA, 259 - PENEDO

CX. POSTAL 82.529

27580-000 - ITATIAIA - RJ

TEL. (0243) 54-3222 R 127

ASSOCIAÇÃO DOS PROTETORES DA NATUREZA DOS VALES DE BOCAÍNA APROBO

FAZENDA BOA VISTA (MG) - A/C LINO

MATHEUS DE SÁ PEREIRA

CX. POSTAL 82.056

27501-970 - RESENDE - RJ
SOCIEDADE ORNITOLÓGICA MINEIRA SOM

RUA DA BAHIA 1.148 - SALA 631

CX. POSTAL 611

30160-011 - BELO HORIZONTE - MG

TEL. (031) 226-6302

ESPELEO GRUPO DOS ALUNOS, PROFESSORES E FUNCIONÁRIOS DA ESCOLA FEDERAL DE ENGENHARIA DE ITAJUBÁ - EGEFEI

AV. B.P.S. 1.303 O PINHEIRINHO

CX. POSTAL 50

37500-010 - ITAJUBÁ - MG

TEL. (035) 622-1966 R 161

TELEX (035) 4274

FAX (035) 622-3596

GRUPO AMBIENTALISTA DA MANTIQUEIRA

- GRAMA

CX. POSTAL 484

37701-970 - POÇOS DE CALDAS - MG

TEL. (035) 721-3477

ASSOCIAÇÃO PRÓ - PARQUE NACIONAL DO ITATIAIA - APROPANI

RODOVIA PRESIDENTE DUTRA, KM 315 -

SALA 09

27580-000 - ITATIAIA - RJ

TEL. (0243) 52-1606

ASSOCIAÇÃO DE MEIO AMBIENTE DA REGIÃO DE VISCONDE DE MAUÁ - AMA CX. POSTAL 81.644

27501-970 - RESENDE - RJ

MOVIMENTO ECOLÓGICO DE RESENDE MOVER

VILA ADELAIDE, 458 - JARDIM BRASÍLIA

27501-970 - RESENDE - RJ

TEL. (0243) 54-5503 OU 54-2822 
ALIANÇA EM DEFESA DOS DIREITOS ANIMAIS - ADDA

RUA IPIRANGA 91 - APTO 703 -

LARANJEIRAS

22231-120 - RIO DE JANEIRO - RJ

ÁREA AMBIENTAL DO INSTITUTO DE RELAÇÕES INTERNACIONAIS DA PUC/RJ RUA MARQUES DE SÃO VICENTE, 225 CASA 19 - GAVEA

22453 - RIO DE JANEIRO - RJ

TEL. (021) 274-1296 OU 529-9494

FAX (021) 274-1296

ASSOCIAÇÃO BRASILEIRA DE DEFESA ECOLÓGICA - ABRADE

RUA MÉXICO, 70 - SALA 410 - CENTRO

20031-000 - - RIO DE JANEIRO - RJ

ASSOCIAÇÃO BRASILEIRA DE

ENGENHARIA SANITÁRIA E AMBIENTAL ABES

AV. BEIRA MAR, $216-13^{\circ}$ ANDAR -

CASTELO

CX. POSTAL 15029

20021-060 - RIO DE JANEIRO - RJ

TEL. (021) 210-3221

TELEX (021) 31902 ABST BR

FAX (021) 262-6838

ASSOCIAÇÃO DE MEIO AMBIENTE DE

BANGU - AMAR - BANGU

RUA RAIMUNDO SISNANDO, 51 - PADRE MIGUEL

21720-480 - RIO DE JANEIRO - RJ

TEL. (021) 332-2871 OU 332-5435

\section{AMARVERDE}

RUA CARVALHO DE MENDONÇA, 24 - SALA 401 COPACABANA

20020-050 - RIO DE JANEIRO - RJ

ASOCIACION INTERAMERICANA DE INGENIERIA SANITARIA Y AMBIENTAL AIDIS

AV. BEIRA MAR $216-13^{\circ}$ ANDAR 20021-060 - RIO DE JANEIRO - RJ

TEL. (021) 210-3221

ASSOCIAÇÃO BRASILEIRA DE ECOLOGIA ABE

AV. NILO PEÇANHA, $128^{\circ}$ ANDAR - SALA

801 - CENTRO

20020-100 - RIO DE JANEIRO - RJ

TEL. (021) 242-4374

ASSOCIAÇÃO BRASILEIRA DE

ORGANIZAÇÕES NÃO - GOVERNAMENTAIS - ABONG

RUA BENTO LISBOA, 58 - CATETE - A/C

FASE

22221-011 - RIO DE JANEIRO - RJ

TEL. (021) 285-2998

FAX (021) 205-3099

ASSOCIAÇÃO DE MEIO AMBIENTE DE DUQUE DE CAXIAS - AMADUQUE

RUA ASSIS BRASIL, 143 - BLOCO 01 - SALA 704 - COPACABANA

22030-010 - RIO DE JANEIRO - RJ 
ASSOCIAÇÃO ECOLÓGICA LAGOA DE MARAPENDI

AV. SERNAMBETIBA, 6.350 - CONDOMÍNIO ALFA BARRA - BARRA DA TIJUCA 22620-012 - RIO DE JANEIRO - RJ TEL (021) 433-1609

ASSOCIAÇÃO HARMONIA AMBIENTAL COONATURA

RUA HANS STADEN, 24 - BOTAFOGO

22281-060 - RIO DE JANEIRO - RJ

TEL (021) 246-3017

ASSOCIAÇÃO INTERNACIONAL PARA AVALIAÇẤO DE IMPACTOS AMBIENTAIS RUA GENERAL CRISTÓVÃO BARCELOS 211-APTO 203

22245-110 - RIO DE JANEIRO - RJ

ASSOCIAÇÃO SOS VERDE

RUA FRANCISCO MURATORI, 45 - LAPA

20230-080 - RIO DE JANEIRO - RJ

TEL (021) 242-8643

FAX (021) 242-6823

BANCO DE INFORMAÇÕES AMBIENTAIS BIA

A/C ECO-DIGITAL E INFORMÁTICA

RUA URUGUAIANA, 39 - SALA 1.201

20050-000 - RIO DE JANEIRO - RJ

TEL (021) 221-2013

\section{CENTRO DE ESTUDOS AMBIENTAIS - CEAM}

RUA BARATA RIBEIRO, 264 - COBERTURA 01

22040-000 - RIO DE JANEIRO - RJ

TEL (021) 256-7898

COMITÊ DE APOIO AOS POVOS DA

FLORESTA

RUA PEREIRA DA SILVA, 231 - APTO 404-B - LARANJEIRAS

22221-140 - RIO DE JANEIRO - RJ
ASSOCIAÇÃO GUARATIBANA DE ECOLOGIA E CULTURA - AGEC RUA BARROS DE ALARCÃO 341 23027-340 - RIO DE JANEIRO - RJ

ASSOCIAÇÃO INTERNACIONAL DE PESQUISA DA PAZ - IPRA

GRUPO DE ESTUDOS DE SEGURANÇA

ECOLÓGICA \& PAZ

RUA IPU 26 - BLOCO 2 - APTO 5 -

BOTAFOGO

22281-040 - RIO DE JANEIRO - RJ

TEL (021) 246-5488

FAX (021) 266-7079

ASSOCIAÇÃO SOCIUS PARA DESENVOLVIMENTO CULTURAL COMUNITÁRIO E PESQUISAS AMBIENTAIS RUA MARECHAL MASCARENHAS DE MORAIS, 156 - COPACABANA 22030-040 - RIO DE JANEIRO - RJ TEL (021) 235-5412 OU 255-9227

BANCO DE DADOS EM MEIO AMBIENTE TRILHA

PRAIA DE BOTAFOGO, 430 - APTO, 804

22250-040 - RIO DE JANEIRO - RJ

TEL (021) 246-3084

CAMPANHA POPULAR EM DEFESA DA NATUREZA - CPDN

RUA SAMBAÍBA, 400 - APTO 301 - LEBLON 22450-140 - RIO DE JANEIRO - RJ

TEL (021) 274-0460

CLUBE DE OBSERVADORES DE AVES COARJ

RUA PINHEIRO MACHADO, 76 - APTO 302 LARANJEIRAS

22231-090 - RIO DE JANEIRO - RJ

TEL (021) 553-1437

DEFENSORES DA TERRA

RUA PAULO CÉSAR DE ANDRADE, 222 -

SALA 802

22221-090 - RIO DE JANEIRO - RJ

TEL (021) 265-7517 
ECO COMUNITÁRIA

RUA DA MATRIZ, 63

23045 - RIO DE JANEIRO - RJ

ESPIRAL ECOLOGIA E DESENVOLVIMENTO

AV. HENRIQUE DUMONT, 122 - $8^{\circ}$ ANDAR 22410-060 - RIO DE JANEIRO - RJ

TEL (021) 245-5118

FEDERAÇÃO DOS ÓRGÃOS PARA ASSISTÊNCIA SOCIAL E EDUCAÇÃO FASE

RUA BENTO LISBOA, 58 - CATETE

22221-11 - RIO DE JANEIRO - RJ

TEL (021) 285-2998

FAX (021) 205-3099

FRENTE PRÓ CIDADANIA AMBIENTAL

CX POSTAL 15.578

20132-970 - RIO DE JANEIRO - RJ

TEL (021) 295-0043

FUNDAÇÃO BOTÂNICA MARGARET MEE AV. RIO BRANCO, 181 - SALA 2.007 20040-007 - RIO DE JANEIRO - RJ TEL FAX (021) 533-1486
EQUIPE DE CONSERVACIONISTAS CRUZ ECOSC

RUA URÁ, 47 - SANTA CRUZ

23515-130 - RIO DE JANEIRO - RJ

TEL (021) 395-2864

FEDERAÇÃO DAS BANDEIRANTES DO BRASIL

AV. MARECHAL CÂMARA, 186 - $2^{\circ}$ ANDAR CENTRO

20020-080 - RIO DE JANEIRO - RJ

TEL (021) 240-9220

FORUM BRASILEIRO DE ONGS E MOVIMENTOS SOCIAIS PARA O MEIO AMBIENTE E DESENVOLVIMENTO

RUA DO CATETE, 153 - ANEXO1 - MUSEU DA REPÚBLICA

22220-000 - RIO DE JANEIRO - RJ

TEL (021) 205-9480

FAX (021) 205-7537

FUNDAÇÃO ASHOKA

RUA DO RUSSEL, 450 - SALA 401 - GLÓRIA 22210-010 - RIO DE JANEIRO - RJ

TEL (021) 285-7553

FAX (021) 2055087

FUNDAÇÃO BRASILEIRA PARA A CONSERVAÇÃO DA NATUREZA - FBCN

RUA MIRANDA VALVERDE, 103 -

BOTAFOGO

22281-000 - RIO DE JANEIRO - RJ

TEL (021) 266-5008 OU 226-2654

TELEX (021) 37984

FAX (021) 226-1345

FUNDAÇÃO PRÓ VITA

AV. NILO PEÇANHA, 50 - SALA 1.101 CENTRO

20020-100 - RIO DE JANEIRO - RJ

TEL (021) 220-3510 OU 220-4885

FAX (021) 220-3465 
ASSOCIAÇÃO CIVIL GREEPEACE

RUA MÉXICO, 21 - SALA 1.301 A/B -

CENTRO

CX POSTAL 1.996

20031-140 - RIO DE JANEIRO - RJ

TEL (021) 262-7318

FAX $(0210240-1690$

GRUPO DE AÇÕES ECOLÓGICAS EM

COMUNIDADES - GAECO

ESTRADA DA GÁVEA, 407 - CONJUNTO 1

22451-261 - RIO DE JANEIRO - RJ

TEL (021) 351-3704

GRUPO DE ESTUDOS AMBIENTAIS -GEA

RUA BARÃO DE PETRÓPOLIS, 181-CASA 6APTO 201

20251-061 - RIO DE JANEIRO - RJ

TEL (021) 273-5764

GRUPO ECOLÓGICO CICLO VITAL

RUA CADETE POLÔNIA, 679 - APTO 304 -

SAMPAIO

20961-050 - RIO DE JANEIRO - RJ

GRUPO ECOLÓGICO FRENTE VERDE

AV. 13 DE MAIO, 13 - SALA 1.410

20003-000 - RIO DE JANEIRO - RJ

TEL (021) 240-7687

GRUPO MULHER EDUCAÇẢO INDÍGENA GRUMIN

RUA DA QUITANDA, 185 - SALA 503

20011-030 - RIO DE JANEIRO - RJ

TEL (021) 293-1745

INSTITUTO APOIO JURIDICO POPULAR AJUP

AV. BEIRA MAR, 216 - SALAS 401 E 701

20021-060 - RIO DE JANEIRO - RJ

TEL (021) 262-3406

FAX (021) 262-3536

INSTITUTO DE ECOLOGIA E CIÊNCIA DA TERRA - IECO

AV. GENERAL JUSTO, 171 - $2^{\circ}$ ANDAR -

CENTRO

20021-020 - RIO DE JANEIRO - RJ
GRUPO AÇÃO ECOLÓGICA - GAE

ESTRADA DO CAPENHA, 275 - APTO 801 -

BLOCO 2 - JACAREPAGUÁ

22743-041 - RIO DE JANEIRO - RJ

TEL (021) 327-5475

GRUPO DE DEFESA ECOLÓGICA - GRUDE ESTRADA DOS TRÊS RIOS, 1.416 - BLOCO

1 - APTO 401 - JACAREPAGUÁ

CX POSTAL 70.528

22745-003 - RIO DE JANEIRO - RJ

TEL (021) 392-6309

GRUPO DE ESTUDOS UNIVERSITÁRIOS DO

MEIO AMBIENTE DO RIO DE JANEIRO -

GEUMARJ

RUA MARQUÊS, 41 - APTO 202 - HUMAITÁ

22260-240 - RIO DE JANEIRO - RJ

TEL (021) 226-7488

GRUPO ECOLÓGICO DE VILA KENNEDY GEVIK

RUA ZÂMBIA, 49 - VILA KENNEDY

21850-510 - RIO DE JANEIRO - RJ

GRUPO ECOLÓGICO ZONA OESTE

RUA DOS ESTAMPADORES, 386 - BANGU

21820-100 - RIO DE JANEIRO - RJ

HARMONIA AMBIENTAL

RUA GENERAL ROCA, 916 - SALA 103 -

TIJUCA

CX POSTAL 41.021

20521-070 - RIO DE JANEIRO - RJ

INSTITUTO BRASILEIRO DE PESQUISAS E ESTUDOS AMBIENTAIS - PRÓ-NATURA

RUA MONTE ALEGRE, 374 - SANTA TERESA

20240-190 - RIO DE JANEIRO - RJ

TEL (021) 224-3994 OU 252-1191

FAX (021) 222-6742

INSTITUTO DE ECOLOGIA E

DESENVOLVIMENTO - IED

RUA DIAS DE BARROS, 51 APTO 302 -

SANTA TEREZA

20241-020 - RIO DE JANEIRO - RJ

TEL (021) 242-6940 OU 242-4951 
INSTITUTO DE ECOLOGIA TROPICAL ECOTROPIC

RUA ALMIRANTE ALEXANDRINO 2.161 -

SANTA TEREZA

20241-261 - RIO DE JANEIRO - RJ

TEL (021) 232-3956 OU 222-1672

FAX (021) 242-8939

INSTITUTO DE POLÍTICAS ALTERNATIVAS PARA O CONE SUL - IPACS

RUA JOAQUIM SILVA, 11 - SALA 95 CENTRO

20241-110 - RIO DE JANEIRO - RJ

TEL (021) 252-0366

INSTITUTO NASCE DE ECOLOGIAE TECNOLOGIA APROPRIADA - NASCEE

RUA TIMOTEO DA COSTA, 297/203 -

LEBLON

22450-130 - RIO DE JANEIRO - RJ

TEL (021) 294-1164

INSTITUTO TERRA DE ECOLOGIA E EDUCAÇÀO AMBIENTAL

AV. PAULO DE FRONTIN, 581 -

COBERTURA 8 - A/C FREDERICO

FULLGRAF

20260-011 - RIO DE JANEIRO - RJ

TEL (021) 551-5908

MOBILIZAÇÃO ECOLÓGICA DO BRASIL MEB

RUA ALVARO ALVIM, 37 - APTO 1.716 -

CENTRO

20031-010 - RIO DE JANEIRO - RJ

MOVIMENTO BRASILEIRO DE DEFESA DO MEIO AMBIENTE

CX POSTAL 64.079

22012-970 - RIO DE JANEIRO - RJ

MOVIMENTO ECOLÓGICO SOCIALISTA

ALTERNATIVO - MESA

RUA EFIGÊNIO SALES, 189 - SALA 102 -

COSME VELHO

22241 - RIO DE JANEIRO - RJ

TEL (021) 205-3066

FAX (021) 265-0882
INSTITUTO DE EDUCAÇÃO AMBIENTAL PRESERVAÇÃO À CRUELDADE AOS

ANIMAIS E PLANTAS - PCAP

RUA VISCONDE DE CARAVELAS, 70 - APTO 402 - BOTAFOGO

22271-030 - RIO DE JANEIRO - RJ

TEL (021) 227-7063

INSTITUTO IGUAÇU DE PESQUISA E PRESERVAÇÃO AMBIENTAL

RUA MÉXICO, 119 - SALA 601 - CENTRO

20017-900 - RIO DE JANEIRO - RJ

TEL (021) 220-2125

FAX (021) 240-1910

INSTITUTO REDE BRASILEIRA

AGROFLORESTAL - REBRAF

RUA VISCONDE DE PIRAJÁ, 111 - SALA 713

- IPANEMA

CX POSTAL 70.060

22422-970 - RIO DE JANEIRO - RJ

TEL (021) 521-7896

FAX (021) 521-1593

LIGA DE DEFESA DOS ANIMAIS

RUA GAGO COUTINHO, 44 - APTO 601 -

LARANJEIRAS

22221-070 - RIO DE JANEIRO - RJ

TEL (021) 265-7867

MOVIMENTO BRASILEIRO EM DEFESA DA

VIDA - MBDV

RUA CARVALHO DE MENDONÇA, 36 - APTO

802 - COPACABANA

22020-050 - RIO DE JANEIRO - RJ

TEL (021) 542-1386

MOVIMENTO ECOLÓGICO AMIGOS DA

NATUREZA - MEAN

RUA ARAÇUAÍ, 50 - JACAREPAGUÁ

21341-300 - RIO DE JANEIRO - RJ

TEL (021) 359-6192

NATURALISTAS ASSOCIADOS - NA

RUA DR. LACERDA, 57 - PAQUETÁ

20397-000 - RIO DE JANEIRO - RJ

TEL 90210 397-0095 OU 591-6592 
NÚCLEO CENTRAL DE DEFESA DO MEIO AMBIENTE

CX POSTAL 46.501

20562-970 - RIO DE JANEIRO - RJ

PROJETO ECOLÓGICO VIDA

ALTERNATIVA

RUA INTENDENTE MENEZES, 46 - APTO

204 - MÉIER

20720-060 - RIO DE JANEIRO - RJ

SERVIÇO PAZ E JUSTIÇA - SERPAJ

RUA DAS LARANANJEIRAS, 01 - APTO 603 20001-970 - RIO DE JANEIRO - RJ

TEL (021) 232-8535

SOCIEDADE BRASILEIRA DE PROTEÇÃO AMBIENTAL - SOBRAPA

AV. COMANDANTE VERGUEIRO DA CRUZ, 480 - OLARIA

20021-020 - RIO DE JANEIRO - RJ

TEL (021) 260-2633 OU 590-7493

FAX (021) 240-4189

SOCIEDADE DAS FLORESTAL DO BRASIL RUA PACHECO LEÃO, 2.040 - SOLAR DA IMPERATRIZ

22460-030 - RIO DE JANEIRO - RJ

TEL (021) 294-7208

SOCIEDADE ECOLÓGICA PARA

RECUPERAÇÃO DA NATUREZA - SERENA

RUA CORREAA DUTRA, 119 - APTO 310 -

CATETE

CX POSTAL 16.259

22210-050 - RIO DE JANEIRO - RJ

TEL FAX (021) 285-2836

TERRA AZUL

RUA DA MATRIZ, 30 - BOTAFOGO

22260-100 - RIO DE JANEIRO - RJ
OS VERDES - MOVIMENTO DE ECOLOGIA

SOCIAL

CXPOSTAL 4.449

20001-970 - RIO DE JANEIRO - RJ

TEL (021) 252-0920

RESISTÊNCIA ECOLÓGICA

CXPOSTAL 12.263

22022-970 - RIO DE JANEIRO - RJ

FAX (021) 257-4498

SOCIEDADE BADEN-POWELL DE CONSERVAÇÀO DA NATUREZA - SBPCN RUA CABO MOISES DE OLIVEIRA, 71 - SALA 101 - CAMPO GRANDE

CX POSTAL 10.136

23080-250 - RIO DE JANEIRO - RJ

FAX (021) 316-1807 A/C IDÉIA LEVE LTDA

SOCIEDADE BRASLEIRA PARA A

VALORIZAÇÃO DO MEIO AMBIENTE -

BIOSFERA

CX POSTAL 3.591

20001-970 - RIO DE JANEIRO - RJ

TEL (021) 542-2272 OU 295-0032 R 243

FAX (021) 542-2272

SOCIEDADE DE PESQUISA EM VIDA

SELVAGEM

RUA BARONESA DE POCONÉ, 18 - APTO

203 - LAGOA

22471-270 - RIO DE JANEIRO - RJ

SOL E TERRA - AGROVILA ECOLÓGICA

CXPOSTAL 70.541

22741-970 - RIO DE JANEIRO - RJ

UNIVERSIDADE PARA LA PAZ

RUA ALMIRANTE TAMANDARÉ, 32 - APTO

402 FLAMENGO

22210-060 - RIO DE JANEIRO - RJ

TEL (021) 265-7866 


\section{SÃO PAULO}

AMATERRA - AMIGOS DA TERRA

RUA LEOPOLDO SOARES AMARAL, 550

12940-000 - ATIBAIA - SP

TEL.: (011) 484-8159

GRUPO ECOLÓGICO DE BRAGANÇA

PAULISTA - DEFENSORES DA NATUREZA

CX. POSTAL 266

12900-000 - BRAGANÇA PAULISTA

TEL.: (011) 433-6520 OU 433-1356

FUNDAÇÃO NACIONAL DO TROPEIRISMO CX. POSTAL 50

122800-000 CAÇAPAVA - SP

TEL.: (012) 252-1733

ORGANIZAÇÃo NATURALISTICA E DE CONTROLE AMBIENTAL - ONCA

CX. POSTAL 105

122800-000 - CAÇAPAVA - SP

TEL. (012) 252-4695

GRUPO ECOLÓGICO RESERVA DOS

ESQUILOS - GERE

AV. JANUÁRIO MIRAGLIA, 1.750

12460-000 - CAMPOS DO JORDÃO - SP

INSTITUTO DE ESTUDOS

VALEPARAIBANOS

PRAÇA CONSELHEIRO RODRIGUES

ALVES, 48

$2^{\circ}$ ANDAR - CENTRO

CX. POSTAL 88

12500-000 - GUARATINGUETÁ - SP

TEL.: (012) 522-3674
PEDRA GRANDE INTERAÇÃo ECOLÓGICA

RUA JOSÉ IGNÁCIIO, 322

CX. POSTAL 374

12940-000 - ATIBAIA - SP

CONSELHO DE DEFESA AMBIENTAL DE

CAÇAPAVA - CODAM

CX. POSTAL 50

122800-000 CAÇAPAVA - SP

INSTITUTO DE ESTUDOS

VALEPARAIBANOS

CX. POSTAL 105

12280-000 - CAÇAPAVA - SP

TEL.: (012) 252-1733

GRUPO DE ESTUDOS ECOLÓGICOS E CONTROLE AMBIENTAL - GECA HOLOS RUA ENGENHEIRO DIOGO DE CARVALHO, 229

12460-000 - CAMPOS DO JORDÃO - SP

TEL.: (012) 263-1741

GRUPO ECOLÓGICO DE GUARATINGUETÁ VERDE GAIA

RUA FEIJÓ, 91 CENTRO

12500-000 - GUARATINGUETÁ - SP

TEL. : (012) 532-4659

FAX: (012) 5469-2264

GRUPO ECOLÓGICO DO COLÉGIO AGRÍCOLA DE JACAREI

AV. 09 DE JULHO, 05

CX. POSTAL 18

12300-000 - JACAREÍ - SP

TEL.: (012) 351-5230 
NÚCLEO DE DEFESA ECOLÓGICA

AV. JAPÃO, 377 - APTO 14

12300-000 - JACAREÍ - SP

COMUNIDADE ALTERNATIVAS DE

PINDAMONHANGABA

FAZENDA NOVA GOKULA

CX. POSTAL 164

12400-000 - PINDAMONHANGABA - SP

GRUPO ECOLÓGICO A.N.T.A. - AMIGOS DA NATUREZA PELO TRABALHO AMBIENTAL

AV. ANTONIO COZZI, 760 - A/C Dr. LESSA 12400-000 - PINDAMONHANGABA - SP

TEL. (012) 242-1934

GRUPO DE ESTUDOS DOS ECOLÓGICOS E CONTROLE AMBIENTAL DE SANTO ANTÔNIO DO PINHAL - GECA PRAÇA MONSENHOR JOÃO J. AZEVEDO, 33

12450-000 - SANTO ANTÔNIO DO PINHAL $\mathrm{SP}$

CENTRO DE AMIGOS DA NATUREZA CAMIN

AV. BRASIL, 535 - MONTE CASTELO 12243-630 - SÃO JOSÉ DOS CAMPOS - SP

\section{GRUPO CONSCIÊNCIA ECOLÓGICA}

CX. POSTAL 585

12201-970 - SÃO JOSÉ DOS CAMPOS - SP

TEL.: (012) 331-8644 OU 331-8362 (A/C

DATANAVE)
GRUPO CONSCIÊNCIA ECOLÓGICA

AV. SETE DE SETEMBRO, 2 - VILA

CELESTE

07600-000 LORENA - SP

GRUPO DE ESTUDOS ECOLÓGICOS E CONTROLE AMBIENTAL DE

PINDAMONHANGABA - GECA

RUA MONSENHOR ANTÔNIO OLINTO DE

PAIVA DUTRA, 141

12400-000 - PINDAMONHANGABA - SP

FUNDAÇÃO JOSÉ LUIZ PASIN

FAZENDA BOA VISTA - ROSEIRA VELHA 12580-000 - ROSEIRA - SP

TEL.: (012) 246-1360

GRUPO ALPINO EXCURSIONISTA - GAE CX. POSTAL 676

13560-000 - SÃO CARLOS - SP

CENTRO ESPELEOLÓGICO DE PESQUISAS HISTÓRICAS

RUA SANTA CLARA, 333 APTO 51 I VILA

ANDINA

12243-630 - SÃO JOSÉ DOS CAMPOS - SP

GRUPO ECOLÓGICO DE SÃO JOSÉ DOS CAMPOS

RUA AGUAPEÍ, 456

12231-440 - SÃO JOSÉ DOS CAMPOS - SP 
SOCIEDADE AMIGOS DA CIDADE VISTA VERDE - SAVIVER

RUA SANTA FÉ, 270

12223-340 - SÃO JOSÉ DOS CAMPOS - SP

TEL. (012) 329-5518

AÇÃo ECOLÓGICA ALQUIMIA

RUA ANTÓNIO CASTILHO ALONSO, 48

04546-010 - SÃO PAULO - SP

TEL. (011) 533-2277

ASSEMBLÉIA PERMANENTE DE

ENTIDADE EM DEFESA DO MEIO

AMBIENTE DO ESTADO DE SÃO PAULO -

APEDEMA/SP

RUA JOAQUIM GALVÃO, 466 - A/C

CLÁUDIO BECCACCIA

05627 - SÃO PAULO - SP

TEL. (011) 842-2818

FAX (011) 542-8821

ASSOCIAÇÃO BRASILEIRA DE COMUNIDADE ECOLÓGICAS - ABRACE

RUA ABÍLIO SOARES, 272 - PARAÍSO

04005-000 - SÃO PAULO - SP

TEL. (011) 283-1456 OU 284-9991

\section{ASSOCIAÇÃO BRASILEIRA DE}

ENGENHARIA SANITÁRIA E AMBIENTAL ABES/SP

RUA COSTA CARVALHO, 234 - PINHEIROS

05429-000 - SÃO PAULO - SP

TEL. (011) 814-1872 OU 814-1901

TELEX (011) 81453

ASSOCIAÇÃO BRASILEIRA DE RECURSOS HÍDRICOS - ABRH

AV. PROFESSOR LÚCIO MARTINS

RODRIGUES, 120 - MORUMBI

05621-030 - SÃO PAULO -SP

TEL. (011) 814-6303 OU 211-1933 R237

TELEX (011) 81304

FAX 813-5217
ACADEMIA DE CIÊNCIAS DO ESTADO DE SÃO PAULO - ACIESP

TRAVESSA "J", 374 - SALA 426 - CIDADE

UNIVERSITÁRIA

CX. POSTAL 22.297

013017-970 - SÃO PAULO - SP

TEL. (011) 211-5106

ASSOCIAION INTERAMERICANA DE

INGENIERÍA SANITARIA Y AMBIENTAL -

AIDIS

RUA NICOLAU GAGLIARDI, 354

05429 - SÃO PAULO - SP

TEL. (011) 212-4080

TELEX (011) 81453

FAX(011) 814-2441

ASSOCIAÇÃO BRASILEIRA DE ARTES E APOIO ECOLÓGICO - AECO

RUA NILO, 202 - ACLIMATAÇÃO

01533-010 - SÃO PAULO - SP

TEL. (011) 288-8517

FAX (011) 288-4272

ASSOCIAÇÃO BRASILEIRA DE PREVENÇÃO À POLUIÇÃO DO AR ABEPPOLAR/SEDE NACIONAL

AV. DOS TRÊS PODERES, 303 - BUTANTÃ 05514-000 - SÃO PAULO - SP

TEL. (011) 259-8253 OU 212-5544

FAX (011) 65-0930

ASSOCIAÇÃO BRASILEIRA DE

OCEANOGRAFIA

RUA 13 DE MAIO, 1.100 - CONJUNTO 32 -

BOA VISTA

01327-000 - SÃO PAULO - SP

ASSOCIAÇÃo BRASILEIRA DE

TECNOLOGIA ALTERNATIVA NA

PROMOÇÃO DA SAÚDE - TAPS

CX. POSTAL 20.396

04034-970 - SÃO PAULO -SP

TEL. (011) 572-0466 
ASSOCIAÇÃO CANOAR -ASCAN

RUA DOS CAETÉS, 410 - PERDIZES

05016-081 - SÃO PAULO -SP

TEL. (011) 871-2282

ASSOCIAÇÃo CULTURAL PRÓ PARQUE MODERNISTA

RUA SANTA CRUZ, 325 - VILA MARIANA 04121-000 - SÃO PAULO -SP
ASSOCIAÇÃO CIVIL GREENPEACE

AV. BRIGADEIRO FARIA LIMA, 1.390 -

CONJUNTO 11

01452-001 - SÃO PAULO -SP

TEL. (011) 814-6167

FAX (011) 210-0154
ASSOCIAÇÃO DE AMPARO AOS ANIMAIS AAA

RUA ÁLVARO RODRIGUES, 573

04582-001 - SÃO PAULO -SP

TEL. (011) 543-9492 P/RECADOS

ASSOCIAÇÃO DE DEFESA DO MEIO

AMBIENTE - ADEMA

RUA PEDROSO ALVARENGA, 1.245 - $5^{\circ}$

ANDAR

04351-012 - SÃO PAULO -SP

TEL. (011) 280-7244

TELEX (011) 36115

FAX (011) 852-2662

ASSOCIAÇÃO DE ESTUDOS AMBIENTAIS AEA

RUA CONDE D'EU, 168 - SANTO AMARO

04738-010 - SÃO PAULO -SP

ASSOCIAÇÃO DE PRESERVAÇÃO DA VIDA SELVAGEM - APVS

PRAÇA UIRAPURU, 20 - CIDADE JARDIM

05675-030 - SÃO APULO - SP
ASSOCIAÇÃO DE AGRICULTURA ORGÂNICA - AAO

AV. FRANCISCO MATARAZZO, 455 -

PRÉDIO DO FAZENDEIRO - SALA 20

05001-300 - SÃO PAULO -SP

TEL. (011) 263-8013

FAX (011) 262-5995

ASSOCIAÇÃO DE DEFESA DA SERRA DA CANTAREIRA

AV. NOVA CANTAREIRA, 4.211 - SALA 11 -

TUCURUVI

02341-002 - SÃO PAULO -SP

ASSOCIAÇÃO DE DEFESA DO PARQUE DA ACLIMAÇẪO - ADEPA

RUA XIMBÓ, 297 - ACLIMAÇÃO

04108-040 - SÃO PAULO -SP

TEL. (011) 570-6055
ASSOCIAÇÃO DE MORADORES E AMIGOS DE MAMANGUÁ - AMAM

PRAÇA BENEDITO CALIXTO, 86 - APTO, 71 -

PINHEIROS

05406-040 - SÃO PAULO -SP

TEL. (011) 64-1861

ASSOCIAÇÃo DE USUÁRIOS E AMIGOS DO

PARQUE IBIRAPUERA - ASSUAPI

PARQUE IBIRAPUERA - GRANDE

MARQUISE

04094-000 - SÃO PAULO - SP

TEL. (011) 575-5511 R 17 OU 575-7131 (À NOITE) 
ASSOCIAÇÃO DOS AMIGOS DAS PRAÇAS, PARQUES E AFINS - AAPP RUA EDUARDO DE SÁ, 195 - CIDADE ADHEMAR

04385-050 - SÃO PAULO - SP

TEL. (011) 562-8728

ASSOCIAÇÃO ECOLOGISTA TIAIA RUA NAGIBIZAR, 314 TATUAPÉ 03337-070 - SÃO PAULO - SP

TEL. (011) 294-4449

ASSOCIAÇÃO EM DEFESA DO RIO PARANÁ, AFLUENTES E MATA CILIAR APOENA

RUA CAPOTE VALENTE, 1.307 -

PINHEIROS

05409-003 - SÃO PAULO -SP

\section{ASSOCIAÇÃO MOCOQUENSE DE} ECOLOGIA

RUA FREI CANECA, 443 - APTO 72

01307-001 - SÃO PAULO - SP

ASSOCIAÇÃO PROTETORA DE ANIMAIS "SÃO FRANCISCO DE ASSIS"- APASFA

RUA SANTO ELISEU, 272

02121 - SÃO PAULO - SP

TEL. (011) 292-9308

CENTRAL GERAL DOS TRABALHADORES - CGT/NACIONAL

DEPARTAMENTO DE MEIO AMBIENTE

RUA DA GLÓRIA, $1525^{\circ}$ ANDAR - SALA 52 LIBERDADE

01510-000 - SÃO PAULO -SP

TEL. (011) 35-8827

FAX (011) 34-1059
ASSOCIAÇÃO ECOLÓGICA FISCAIS DA NATUREZA

RUA CANUTO DO VALE, 160 - VILA

BUARQUE

01224-040 - SÃO PAULO - SP

ASSOCIAÇÃO EM DEFESA DA JURÉIA PRÓ - JURÉIA

RUA CARDOSO ALMEIDA, 1.497 - CASA 2 -

PERDIZES

05013-001 - SÃO PAULO - SP

TEL. FAX (011) 864-2787

ASSOCIAÇÃO MATA CILIAR

RUA DOS MIOSÓTIS, 179

04047-030 - SÃO APULO - SP

TEL. (011) 577-5595

ASSOCIAÇÃO PAULISTA DE CANOAGEM APACA

RUA MIGUEL ISASA, 67 - PINHEIROS

05426-090 - SÃO PAULO - SP

ASSOCIAÇÃO - TERRA INTEIRA

RU CUXIPONES, 71

05030-020 - SÃO PAULO - SP

CENTRAL ÚNICA DOS TRABALHADORES CUT/NACIONAL

COMISSÃO NACIONAL DO MEIO AMBIENTE RUA SÄO BENTO, 405 - $7^{\circ}$ ANDAR CENTRO 01011-100 - SÃO PAULO - SP

TEL. (011) 255-7500

TELEX (011) 21524 CUTB

FAX (011) 239-5274 
CENTRO BRASILEIRO DE ESTUDOS

AMBIENTAIS - CEA

RUA ORIGINAL, 165

TEL. (011) 210-9720

FAX (011) 813-3782

CENTRO DE ESTUDOS E ATIVIDADES DE CONSERVAÇÃO DA NATUREZA - CEACON RUA CARDOSO DE ALMEIDA, 1.479 - CASA 2 - PACAEMBU

CX. POSTAL 20.684

01317-970 - SÃO PAULO - ȘP

TEL. FAX (011) 864-2787

CENTRO DE ESTUDOS ORNITOLÓGICOS CEO

RUA DR. ALFREDO DI VERNIERI, 294 -

BUTANTÃ

CX. POSTAL 64.532

05497-970 - SÃO PAULO - SP

TEL. (011) 212-2074

\section{CENTRO DE PESQUISAS DE ÁGUAS}

SUBTERRÂNEAS - CEPAS

RUA DO LAGO, 562 - BUTANTÃ

CX. POSTAL 20.899

01498-970 - SÃO PAULO - SP

TEL. (011) 813-8777

FAX (011) 210-4958

\section{CENTRO ECUMÊNICO DE}

DOCUMENTAÇÃO E INFORMAÇÃO - CEDI

AV. HIGIENÓPOLIS, 983 - HIGIENÓPOLIS

01238-001 - SÃO PAULO - SP

TEL. (011) 825-5544

FAX (011) 825-7861
CENTRO DE APOIO A VIDA - CAV

AV. ADOLFO PINHEIRO, 805 - SANTO

AMARO

04733-100 - SÃO PAULO - SP

TEL. (011) 522-4860

014400-000 - SÃO PAULO - SP

TEL. (011) 852-2817

CENTRO DE ESTUDOS E PRESERVAÇÃO

DA NATUREZA NOVA

TERRA/HIPPOKAMPUS

CENTRO ACADÉMICO DE BIOLOGIA DA

USP

CX. POSTAL 11.461

05422-970 - SÃO PAULO - SP

CENTRO DE ESTUDOS RURAIS E

URBANOS - CERU

AV. PROFESSOR LUCIANO GUALBERTO,

315 - CIDADE UNIVERSITÁRIA

CX. POSTAL 8.105

TEL. (011) 210-2122 R 488

FAX (011) 211-6281

CENTRO DE TRABALHO INDIGENISTA - CTI RUA FIDALGA, 548 - SALA 13 - PINHEIROS 05432-000 - SÃO PAULO - SP

TEL. (011) 813-3450

FAX (011) 825-7861

CENTRO EXCURSIONISTA UNIVERSITÁRIO - CEU

AV. PROFESSOR MELLO MONTES, 65 -

CIDADE UNIVERSITÁRIA

A/C CENTRO ACADÊMICO DE EDUCAÇÃO

FÍSICA DA USP

CX. POSTAL 1.124

01059-970 - SÃO PAULO - SP 
CENTRO MARI DE EDUCAÇÃO INDÍGENA DEPARTAMENTO DE ANTROPOLOGIA DA USP

CX. POSTAL 8.105

01065-970 - SÃO PAULO - SP

TEL. (011) 211-2552

CLUBE DOS AMIGOS DA NATUREZA E DA ECOLOGIA - CANECO VERDE

CX. POSTAL 4.145

01061-970 - SÃO PAULO - SP

TEL. (011) 579-8285 OU 577-6711

COMANDO ESPELEOLÓGICO V-30

RUA PROFESSORA SEBASTIANA DA SILVA MINHOTO, 51

03316-030 - SÃO PAULO - SP
CLUBE ALPINO PAULISTA - CAP

AV. VIEIRA DE MORAES, 1.584 - CAMPOS BELO

04617-005 - SÃO PAULO - SP

CLUBE DOS OBSERVADORES DE AVES COASP

RUA ANDRÉ DREIFFUS - 109 - APTO 113 BLOCO 2

$01252-010$ - SÃO PAULO - SP

COMISSÃO DE DEFESA DA FAUNA DA

APEDEMA/SP

CX. POSTAL 55.237

04799-970 - SÃO PAULO - SP

TEL. (011) 246-9111 OU 246-7390

TELEX ( 011) 56799

FAX (011) 246-9354

COMISSÃO INTERINSTITUCIONAL SOBRE MEIO AMBIENTE E EDUCAÇÃO UNIVERSITÁRIA - UNIAMBIENTE AV. PROFESSOR FREDERICO HERMAN JÚNIOR, 345

05459-010 SÃO PAULO - SP

TEL. (011) 210-1100 R 566

COMISSÃO PELA CRIAÇÃO DO PARQUE YANOMAMI -CCPYISP

RUA MANOEL DA NÓBREGA, $1113^{\circ}$ ANDAR - CONJUNTO 32

04001-080 - SÃO PAULO - SP

TEL. (011) 2891200

FAX (011) 284-6997

COMISSÃO PRÓ - ÍNDIO DE SÃO PAULO CPI/SP

COMITÉ DE APOIO AOS POVOS DA FLORESTA

AV. DR. ARNALDO, 128 - PACAEMBU 01246-000 - SÃO PAULO - SP

TEL. (011) 256-0521

TEL. (011) 864-1180

TELEX (011) 82153 MST

FAX (011) 871-4612 
COMITÊ LATINO AMERICANO DE

MICROBIOLOGIA AMBIENTAL - CLAMA AV. PROFESSOR FREDERICO HERMAN JÚNIOR, 345 - ALTO DE PINHEIROS 05459-010 - SÃO PAULO - SP

TEL. (011) 210-1100

TELEX (011) 83053

FAX (011) 575-2170

\section{CONSELHO DE PROTEÇÃO E DEFESA} DOS ANIMAIS - CDPA

RUA SANTA EULÁLIA, 86 - SANTANA 02031-020 - SÃO PAULO - SP

TEL. (011) 290-9755

FAX (011) 299-9823

CONSELHO NACIONAL DE AUTOREGULAMENTAÇÃO PUBLICITÁRIA CONAR

RUA BAHIA, 1.140 - HIGIENÓPOLIS 01244-000 - SÃO PAULO - SP

TEL. (011) 258-7611

FAX (011) 231-4508

TELEX (011) 22544
CONSELHO DE ENTIDADES

PRESERVACIONISTAS DO ESTADO DE SÃO PAULO - CEPESP

RUA SANTA CRUZ, 325

04121-000 - SÃO PAULO - SP

TEL. (011) 575-2170

CONSELHO INTERNACIONAL DE

EDUCAÇÃO DE ADULTO

PROGRAMA DE EDUCAÇÃO POPULAR

AMBIENTAL - 1.991/1.993

CX. POSTAL 4.651

01061-970 - SÃO PAULO - SP

TEL. (011) 62-7050

FAX (011) 871-3457

DEPARTAMENTO DE MEIO AMBIENTE E USO DO SOLO DA FEDERAÇÃO DAS INDÚSTRIAS DO ESTADO DE SÃO PAULO DMAVFIESP

AV. PAULISTA, $1.313-13^{\circ}$ ANDAR - SALA 1.333

01311-200 - SÃO PAULO - SP

TEL. (011) 251-3522 R 267

TELEX (011) 22130

FAX (011) 284-3971

ECO - ASSOCIAÇÃO PARA ESTUDOS DO AMBIENTE

RUA GOMES FREIRE, 125

05075-010 - SÃO PAULO - SP

TEL. (011) 815-7512 OU 814-5254

\section{ECO PRESS}

RUA ITAPÓLIS, 1.893 - PACAEMBU

01245-000 - SÃO PAULO - SP

TEL. (011) 258-6150 OU 258-6793

FAX (011) 257-6195 
FRENTE DE PROTEÇÃO À NATUREZA FREPNA

RUA DONA ANTONIA DE QUEIROS, 469 APTO 701

01307-010 - SÃO PAULO - SP

FRENTE VERDE

RUA CÓNEGO MANOEL VAZ, 585 -

SANTANA

02019-050 - SÃO PAULO - SP

FUNDAÇÃO NACIONAL DE AÇÃO

ECOLÓGICA - FNAE

AV. BRIGADEIRO LUIZ ANTONIO, 4.442 JARDIM PAULISTA

01402-002 - SÃO PAULO - SP

TEL. (011) 885-3424

FAX

FUNDAÇÃO PARA A PESQUISA

AMBIENTAL - FUPAM

RUA DO LAGO, 876 EDIFÍCO FAUUSP -

CIDADE UNIVERSITÁRIA

05508-900 - SÃO PAULO - SP

TEL. (011) 814-0829

FAX (011) 815-1271

FUNDAÇÃO SOS MATA ATLÂNTICA

RUA MANOEL DA NÓBREGA, 456

04001-001 - SÃO PAULO - SP

TEL. (011) 887-1195
FRENTE DE DEFESA DA APA DA

MANTIQUEIRA -FEDAPAM

AV. BRIGADEIRO LUZ ANTONIO, 2.756 -

JARDIM PAULISTA

01402-000 - SÃO PAULO - SP

TEL. (011) 288-7153

FUNDAÇÃO AMAZONAS FOREVER GREEEN

AV. GIOVANI GRONCHI, 6.186 - MORUMBI

05724-002 - SÃO PAULO - SP

TEL. (011) 521-3963 OU 523-2993

FAX (011) 246-8092

FUNDAÇÃO PANTANAL ALERTA BRASIL RUA BELA CINTRA, 1.618 - SALA 5

01415-001 - SÃO PAULO - SP

TEL.

FAX

FUNDAÇÃO PRÓ - NATUREZA -

FUNATURAVSP

RUA JOAQUIM ANTUNES, 819+ - APTO 151

05415-012 - SÃO PAULO - SP

TEL. (011) 852-5559 OU 257-3291

GAIA FUNDATION

RUA ATLÂNTICA, 771 - JARDIM AMÉRICA 01440-000 SÃO PAULO - SP 
GRUPO DA GEO DE ESPELEOLOGIA INSTITUTO DE GEOCIÊNCIAS DA USP RUA DO LAGO, 552

CX. POSTAL 20.899

01317-970 - SÃO PAULO - SP

TEL. (011) 813-8777 R 225

TELEX (011) 82564

FAX (011) 8154272

GRUPO DE ESTUDOS E PESQUISAS EM ANIMAIS SILVESTRES - GEPAS

DEPTO DE PATOLOGIA DA FACULDADE DE MEDICINA VETERINÁRIA DA USP

AV. CORIFEU DE AZEVEDO MARQUES,

2.720 - VILA LAJEADO

05340-000 - SÃO PAULO - SP

TEL. (011) 813-6944 R 2709

FAX (011) 210-2224

GRUPO ECOLÓGICO IRINEU MARIN NETO CX. POSTAL 14.557

03698-970 - SÃO PAULO - SP

TEL. (011) 293-4566

GRUPO ECOLÓGICO "SAMPA VERDE SAMPA"

AV. GUILHERME GIORGI, 555

03422-000 - SÃO PAULO - SP

GRUPO ECOLÓGICO SOBREVIVÊNCIA

RUA DOMINGOS FERNANDES, 705 - APTO 16

04509-011 - SÃO PAULO - SP

GRUPO ESPELEOLÓGICO “OS OPILIÕES”

RUA ANTONIETA LEITÃO, 171 - APTO 51

02925-160 - SÃO PAULO - SP

TEL. (011) 965-6012
GRUPO DE AÇÃo ECOLÓGICA ARCO-ÍRIS

RUA ALFREDO SASSI, 439

03966-040 - SÃO PAULO - SP
GRUPO DE ESTUDOS E PRESERVAÇÃO DA ECOLOGIA NACIONAL - GREPEN

PRAÇA CORONEL FERNANDO PRESTES, 74

01124-060 - SÃO PAULO - SP

GRUPO ECOLÓGICO RESISTÊNCIA VERDE -REVER

RUA MOZELOS, 193

02073-100 - SÃO PAULO - SP

GRUPO ECOLÓGICO BRASIL MENINO

RUA PROFESSOR JOSÉ SANTANA DO

CARMO, 15 - MANDAQUI

02419-000 - SÃO PAULO - SP

TEL. (011) 267-3484

GRUPO ECOLÓGICO VIDA

RUA DR. CÉSAR SALGADO, 83

CX. POSTAL 18.647

05750-180 - SÃO PAULO - SP

GRUPO PIERRE MARTIN DE ESPELEOLOGIA - GPME

RUA DO AÇAL, 03 -ÁGUA RASA

03347-100 - SÃO PAULO - SP

TEL. (011) 965-6012 
GRUPO SEIVA DA ECOLOGIA

CX. POSTAL 55190

04799-970 - SÃO PAULO - SP
INSTITUTO BRASILEIRO DE ECO -

DESENVOLVIMENTO - IBED

RUA DOS PINHEIROS, 812 - PINHEIROS

05422-001 - SÃO PAULO - SP

TEL. (011) 282-8089

FAX (011) 282-3651

INSTITUTO BRASILEIRO DE TECNOLOGIA

ALTERNATIVA - IBTA

RUA CALIFÓRNIA, 73 - BROOKLIN

PAULISTA

CX. POSTAL 19.319

04566-060 - SÃO PAULO - SP

TEL. (011) 240-2059

INSTITUTO ANTROPOLOGIA E MEIO

AMBIENTE

050443-050 - SÃO PAULO - SP

TEL. (011) 210-1301

FAX (011) 210-1338

MAINÁ ECOLOGIA EXPERIMENTAL

RUA COTOXÓ, 1.001 - APTO, 11

CX. POSTAL 05021-001 - SÃO PAULO - SP

CX. POSTAL 11.453

05422-970 - SÃO PAULO - SP

TEL. (011) 491-0833

MATA ADENTRO ECOLOGIA - MAE

RUA SETE DE ABRIL, 235 - SALA 103

01043-000 - SÃO PAULO - SP

TEL. (011) 256-4766

\author{
MOVIMENTO ARTE E PENSAMENTO \\ ECOLÓGICO - MAPE \\ CX. POSTAL 6.984 \\ 01064-970 - SÃO PAULO - SP \\ TEL. (011) 223-3533
}

MOVIMENTO ECO - SOCIALISTA URBANO

- MESU

CX. POSTAL 8.418

01065-970 - SÃO PAULO - SP

TEL. (011) 231-5222

MOVIMENTO ECOLÓGICO INFANO JUVENIL PERDIZ

RUA DR. SAMPAIO VIANA, 228

04004-000 - SÄO PAULO - SP

TEL. (011) 885-1030 OU 885-1633

MOVIMENTO AMBIENTALISTA DA TERRA MATER

RUA MINISTRO GODOY, 1134 - APTO, 2

05015-001 - SÃO PAULO - SP

TEL. (011) 256-4766

MOVIMENTO BRASILEIRO PELO

DESARMAMENTO E A PAZ

AV. DR. ARNALDO, 2.333 - SUMARÉ

01255-000 - SÃO PAULO - SP

TEL. (011) 62-8169

MOVIMENTO ECOLÓGICO DA TRILOGIA

ANALITICA - META

AV. REBOUÇAS, 3.819

05401-450 - SÃO PAULO - SP

TEL. (011) 815-9708 OU 210-3616

MOVIMENTO ECOLÓGICO LESTE - MEL RUA SENADOR PAULO EGÍDIO, 34 - SALA 43

01006-010 - SÃO PAULO - SP 
MOVIMENTO ECOLÓGICO VERDE É VIDA RUA DANIEL MONGOLO, 303 - APTO 13-B 08250-060 - SÃO PAULO - SP

MOVIMENTO EM DEFESA DA AMAZÔNIA RUA PIRATINGUI, 75 - LIBERDADE 01508-020 - SÃO PAULO - SP

MOVIMENTO EM DEFESA DO VALE DO ARICANDUVA - MDVA

RUA JOÃO KEPLER, 108

03971-030 - SÃO PAULO - SP

TEL. (011) 919-9862 OU 919-014

\author{
MOVIMENTO ECOLÓGICO FUTURO \\ VERDE \\ RUA TIMBURIBÁ, 127 - SALA 1 - VILA \\ MARIANA \\ 04119-000 - SÃO PAULO - SP \\ TEL. FAX (011) 573-6344
}

MOVIMENTO NACIONAL DE ATINGIDOS POR BARRAGENS - MAB

RUA SANTA CRUZ, 281 - VILA MARIANA

04121-000 - SÃO PAULO - SP

TEL. (011) 573-5926

FAX (011) 572-7537

MOVIMENTO SOCIAL PRÓ VERDE

CX. POSTAL 2.241

01060-970 - SÃO PAULO - SP

TEL. (011) 37-3231

MUSEU ABERTO/COOPERATIVA DE EDUCAÇÃO AMBIENTAL

RUA GEÓRGIA, 949 - BROOKLIN PAULISTA 04559-012 - SÃO PAULO - SP
MOVIMENTO ECOLÓGICO ZONA SUL

RUA HILÁRIO RIBEIRO, 168

04319-060 - SÃO PAULO - SP

MOVIMENTO EM DEFESA DA VIDA - MDV

RUA TRAJANO REIS, 186 - APTO, 91 -

EDIFÍCIO PINHEIRO

05541-030 - SÃO PAULO - SP

TEL. (011) 842-5880

FAX (011) 871-3457

MOVIMENTO FEMININO ANTINUCLEAR

RUA NUN ALVARES, 60 - JARDIM LUZITÂNIA

04032-110 - SÃO PAULO - SP

MOVIMENTO ECOLÓGICO PAULISTANO

RUA CORONEL XAVIER DE TOLEDO, 266 -

$4^{\circ}$ ANDAR

01048-000 - SÃO PAULO - SP

TEL. (011) 258-3185

MOVIMENTO PRÓ - TIETÊ - PARQUE ECOLÓGICO DO TIETÉ

AV. BRIGADEIRO ANTONIO, $277-8^{\circ}$ ANDAR 01318-000 - SÃO PAULO - SP

MOVIMENTO SOS MATA DO CARMO

RUA XAVIER PALMERIM, 218

08275-340 - SÃO PAULO - SP

TEL. (011) 919-9862 OU 205-5937

NÚCLEO DE CULTURA INDÍGENA - NCI/UNI PRAÇA DR. ENNIO BARBATO, S/N -

CAXINGUI

05571-040 - SÃO PAULO - SP

TEL. (011) 211-9996 OU 813-1754

FAX (011) 211-9996 
NÚCLEO DE PROTEÇÃO DA VIDA - NPV AV. JUREMA, 888 - SALA 71 INDIANÁPOLIS

04079-002 - SÃO PAULO - SP

TEL. (011) 211-0324 OU 543-2945

OFICINA DE CONSULTORIA AMBIENTAL OCA

RUA SIMÃO ALVARES, 773 - SALA 4

05417-030 - SÃO PAULO - SP

OS AMIGOS DA TERRA

RUA BOTUCATU, 30

04023-060 - SÃO PAULO - SP

PROTER - PROGRAMA DA TERRA

RUA LACERDA DE ALMEIDA, 59

05015-050 - SÃO PAULO - SP

TEL. (011) 263-1840

FAX (011) 864-3980

PROJETO JUSTIÇA, PAZ E

ECOLOGIA/IFAN

RUA THIERS, 310 - CANINDÉ

03031-000 - SÃO PAULO - SP

TEL. (011) 227-0255

SERVIÇO DE INFORMAÇÃO AMBIENTAL SIA

CX. POSTAL 7.709

01064-970 - SÄO PAULO - SP

TEL. (011) 223-6144 OU 223-3533

SERVIÇO INTERFRANCISCANO DE JUSTIÇA, PAZ E ECOLOGIA DO ESTADO DE SÄO PAULO

CX. POSTAL 5.650

01061-970 - SÃO PAULO - SP

TEL. (011) 36-0081

SOCIEDADE AMIGOS DA CIDADE DE SÃO PAULO

RUA BENJAMIM CONSTANT, 77 - $6^{\circ}$ ANDAR

- SALA 610

01005-000 - SÃO PAULO - SP

TEL. (011) 34-8591
NÚCLEO UNIÃO PRÓ - TIETÊ

RUA MANOEL DA NÓBREGA, 456 -

PARAÍSO

04001-001 - SÃO PAULO - SP

TEL. (011) 887-1195

FAX (011) 885-1680

ORDEM DOS ADVOGADOS DO BRASIL OAB/SP

SUBCOMISSÃO DE MEIO AMBIENTE

AV. MIGUEL STÉFANO, 3.900

04301-002 - SÃO PAULO - SP

TEL. (011) 577-4042

PRÓ - JOJOBA - MOVIMENTO ECOLÓGICO

AV. REBOUÇAS, 1.735

05401-250 - SÃO PAULO - SP

PROJETO FUNDAÇÃO PLANETA AZUL

RUA CAMARGO, 26 - BUTANTÃ

05510-050 - SÃO PAULO - SP

TEL. (011) 212-4473 OU 815-8547

PROJETO SALVA MAR

AV. DOM PEDRO, 1.328 - CAMBUCI

01552-000 - SÃO PAULO - SP

TEL (011) 273-0504 OU 275-6971

SERVIÇO DE PAZ E JUSTIÇA DE SÃO

PAULO - SERPA/SP

LARGO SETE DE SETEMBRO, 52 - SALA 707

- LIBERDADE

01501-050 - SÃO PAULO - SP

TEL. (011) 34-0891

SOCIEDADE ALTERNATIVA AÇÃO

ECOLÓGICA

AV. NHANDU, 319

04059-000 - SÃO PAULO - SP

TEL. FAX (011) 581-9070

SOCIEDADE BENEFICIENTE DE

PROTEÇÃO AOS ANIMAIS "QUINTAL DE

SÃO FRANCISCO"

RUA DR. CESÁRIO MOTA JÚNIOR, 476 - $7^{\circ}$

ANDAR - SALA 702-A

01221-020 - SÃO PAULO - SP

TEL. (011) 257-0867 
SOCIEDADE BRASILEIRA DE ECOLOGIA HUMANA

ALAMEDA SANTOS, 2.359 - APTO 61

01419-002 - SÃO PAULO - SP

SOCIEDADE BRASILEIRA DE

SILVICULTURA

AV. PAULISTA, $2.006-11^{\circ}$ ANDAR - SALA

1.113

01310-200 - SÃO PAULO - SP

TEL. (011) 289-2313 OU 283-1850

SOCIEDADE BRASILEIRA PARA O

PROGRESSO DA CIÊNCIA - SBPC

COMISSÃO DE MEIO AMBIENTE

RUA COSTA CARVALHO, 222 - PINHEIROS

05429-000 - SÃO PAULO - SP

TEL. (011) 211-5008 OU 211-0933

FAX (011) 212-1376

\section{SOCIEDADE ORNITOLÓGICA}

\section{BANDEIRANTES}

RUA DOMINGOS DE MORAIS, 2.829 - SALA 3

04035-001 - SÃO PAULO - SP

SOCIEDADE ZOÓFILA EDUCATIVA SOZED

AV. REBOUÇAS, 1.735

CX. POSTAL 20.714

05401-250 - SÃO PAULO - SP

UNIÃO ECOLÓGICA

RUA JOAQUIM GALVÃO, 466

05627-010 - SÃO PAULO - SP

TEL. (011) 842-2818
SOCIEDADE BRASILEIRA DE PAISAGISMO

CX. POSTAL 19.178

04599-970 - SÃO PAULO - SP

TEL. (011) 280-4279

FAX (011) 280-4462

SOCIEDADE BRASILEIRA PARA A DEFESA

DA FLORA E DA FAUNA - SBDFF

RUA DR. MÁRIO PINTO SERVA, 90 - CASA

VERDE ALTA

02555-090 - SÃO PAULO - SP

TEL. (011) 858-5700

FAX (011) 265-3598

SOCIEDADE MUNDIAL PARA A PROTEÇÃO AOS ANIMAIS - WSPA/BRASIL ( WORLD SOCIETY FOR PROTECION OF ANIMALS WSPA)

AV. MANOEL NÓBREGA, 471 - APTO 02

TEL. (011) 884-8787

FAX (011) 884-2663

SOCIEDADE PROTETORA DO MEIO

AMBIENTE

RUA CARLOS SAMPAIO, 154 - CASA 1

01333-020 - SÃO PAULO - SP

UNIÃO DAS NAÇÕES INDÍGENAS - UNI

PRAÇA DR. ÉNNIO BARBATO, S/N -

CAXINGUI

05517-040 - SÃO PAULO - SP

TEL. (011) 813-1754

FAX (011) 211-9996

UNIÃO EM DEFESA DA NATUREZA - DNA

RUA GRANJA JULIETA, 345

04721-060 - SÃO PAULO - SP

TEL. (011) 246-9111 OU 246-7390

TELEX (011) 56799 
UNIÃO INTERNACIONAL PARA A

CONSERVAÇÃO DA NATUREZA -

IUCN/BRASIL ( THE WORLD

CONSERVACION UNION)

AV. NOVE DE JULHO, 4.877 - $8^{\circ}$ ANDAR -

BLOCO D

01407-200 - SÃO PAULO - SP

TEL. (011) 853-5905

FAX (011) 822-5468

VEÍCULO INTERCÂMBIO E DIVULGAÇÃO AMBIENTAL - VIDA

CX. POSTAL 6.984

01064-970 - SÃO PAULO - SP

VOLUNTÁRIOS DEFENSORES DA

NATUREZA

CX. POSTAL 3.438

01060-970 - SÃO PAULO - SP

FRENTE VERDE VALA DO PARAÍBA

RUA MARQUÊS DOHERVAL, 165

12080-250 - TAUBATÉ - SP

TEL. (012) 222-5947

GRUPO ECOLÓGICO SOS NATUREZA

AV. DOM PEDRO 1, 1.753 - BOSQUE DA

SAÚDE

12081-000 - TAUBATÉ - SP

UNIÃO VALEPARAIBANA DE

AMBIENTALISTAS - UVA

RUA BENEDITO CURSINO DOS SANTOS,

168 - BOM CONSELHO

TEL. (012) 233-4779 OU 233-5317

FAX (012) 233-4779
UNIÃO INTERNACIONAL PROTETORA DOS

ANIMAIS - UIPA

RUA ÁLVARO DE CARVALHO, 238 -

CENTRO

01050-070 - SÃO PAULO - SP

TEL. (011) 259-0448

FAX (011) 228-0178

VITAE CIVILE - INSTITUTO PARA O DESENVOLVIMENTO DO MEIO AMBIENTE EA PAZ

RUA CUXIPONÉS, 71 - SUMARÉZINHO

CX. POSTAL 20.635

05030-020 - SÃO PAULO - SP

TEL. (011) 815-4202 P/ RECADOS

GRUPO ECOLÓGICO NATUREZA ATIVA GENA

VIA RAPOSO TAVARES, KM 55,8

CX. POSTAL 274

18130-000 - SÃO ROQUE- SP

TEL. (011) 425-4838

GRUPO DE ESTUDO ECOLÓGICO E CONTROLE AMBIENTAL - GECA

RUA BENEDITO CURSINO DOS SANTOS,

168 - BOM CONSELHO

CX. POSTAL 200

12010-970 - TAUBATÉ - SP/TEL. FAX (012) 233-4779

SOCIEDADE AMIGOS DA MATA CILIAR

AV. CHARLES SCHENEIDER, 128

12040-000 - TAUBATÉ - SP

TEL. (012) 232-3900

GRUPO DE ESTUDOS ECOLÓGICO E CONTROLE AMBIENTAL - GECA PATURI

AV. DA SAUDADE, 310 FUNDOS

CX. POSTAL 42

12120-000 - TREMEMBÉ - SP

TEL.(012) 72-1505 P/RECADOS 